

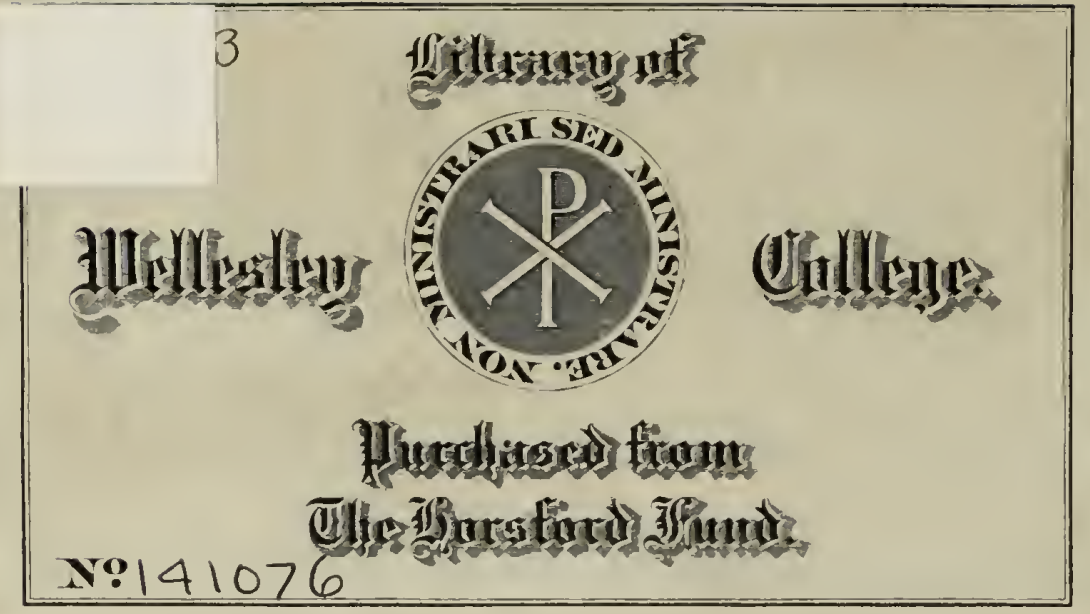


- 
. 



\section{University of Toronto \$tubieg}

JBiological Eerieg

THE NORTH AMERICAN DRAGONFLIES OF THE GENUS AESHNA 
Digitized by the Internet Archive in 2016 with funding from

Boston Library Consortium Member Libraries 


\section{THE NORTH AMERICAN DRAGONFLIES}

OF THE

GENUS AESHNA

BY

E. M. WALKER, B.A., M.B.

LECTURER IN ZOOLOGY IN THE UNIVERSITY OF TORONTO

UNIVERSITY OF TORONTO LIBRARY

MCMXII

33 



\section{BIOLOGICAL SERIES No. 11.}

\section{ERRATA.}

Page 72, line 2, for "septeatrionnlis" read "septentrionalis."

Page 99, insert the following paragraphs after the one on Measurements :

Material determined-8 o7 12 . Nova Scotia : Pictou, Sept. 2, 1889 (Sheraton, Acad. N.S. Phil., I $९$ ). Quebec: Anticosti Island, 1902 (Dr. Joseph Schmidt, Coll. Div. Ent., Ottawa, I ?). Ontario : DeGrassi Point, Lake Simcoe, Sept. 2, 1906 (Walker, I $\%$ ); Temagami Forest Reserve, near Lake Obabika, Sept. 11, 1908 (Walker, $\left.10^{7}\right)$; Nipigon, Aug. 28, 30, 1907, Aug. 6, 1910 (Walker, 4 o 6 \%). Michigan: Isle Royale, Aug. 8-16, 1995 (B. F. Savery and C. C. Adams, Coll. Univ, Mich. and Williamson, $3 \sigma^{7} 2 \%$ ). Manitoba : Winnipeg, Sept. 9, 1910 (J. B. Wallis, 1 \%).

Nymphs-Nipigon, Ont., Aug. 5-8, 1910, I o $^{7}$ (St. F) ; 1 q exuvia.

Page 205, omit fifth reference : 1909. The Insects of New JerseyOdonata. 



\section{PREFATORY NOTE.}

It gives me great pleasure to state as preface to the present $m$ nograph of the North American Dragonflies of the Genus At ina, that the cost of the admirable plates illustrating it, which might have proved a difficulty in the way of its being issued by the Committee on University Studies, has been generously met by Sir Edmund Walker, Chairman of the Board of Governors of the University.

R. RAMSAY WRIGHT. 



\section{TABLE OF CONTENTS}

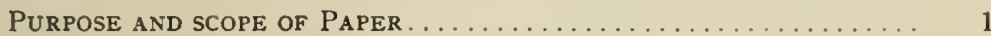

Sources of MAterial ANd ACknowledgments . . . . . . . . . . 1

Field Observations . . . . . . . . . . . . . . 3

THE NAME AESHNA. . . . . . . . . . . . . . . .

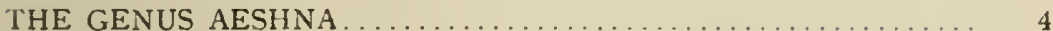

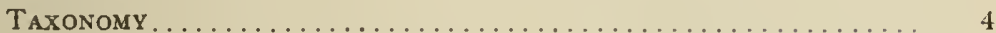

Generic Characters of the Adult.................. 5

Generic Characters of the Nymph................. 6

Secondary Sexual Characters. ................... 6

Characters of Specific Value and Terminology............ 7

Imago .............................. 7

Colour-pattern...................... 8

Genitalia........................... 10

(a) Accessory Genitalia of Male.............. 10

(b) Genitalia of Female................. 12

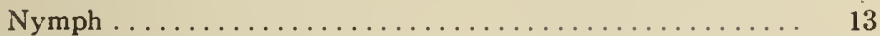

Measurements and Abtreviations.................. 14

Genetic Relationships of the Genus Aeshna............... 15

The Subfamily Aeshninæ..................... 15

The Aeshna Group. ...................... 21

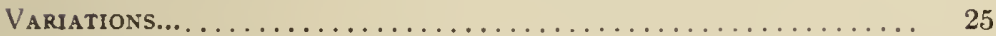

Climatic Variations.......................... 25

Colour Variation of Females..................... 29

Geographical Races.............................. 29

General Life History. . . . . . . . . . . . . . . . . . 30

Season of Imaginal Life. . . . . . . . . . . . . . . . 30

Length of Imaginal Life....................... 31

Habitat................................. 31

Infuence of Weather Conditions.................. 33

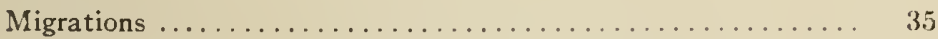

Seasonal Variation in Number of Individuals . . . . . . . . . 35

Food..................................... 35

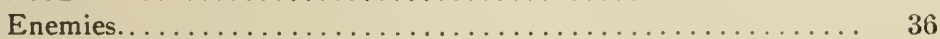

Mating Habits................................ 38

Copulatory Position. ........................ 39

Comparison of Copulatory Position with that of Other Odonata.. 41 
Oviposition. PAGE

The Egg. . . . . . . . . . . . . . . . . . . . . . . 46

Probable Number of Nymphal Stages................. 46

Changes at the Various Ecdyses................... 47

Length of Nymphal Life. . . . . . . . . . . . . . . . . . . . 49

Habitat of Nymph........................ 50

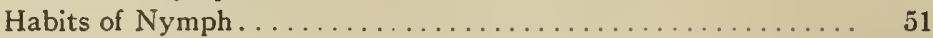

Symbiosis of Nymph and Green Alga ................ 53

Emergence of the Imago . . . . . . . . . . . . . . . . 54

THE NORTH AMERICAN SPECIES OF AESHNA . . . . . . . . 56

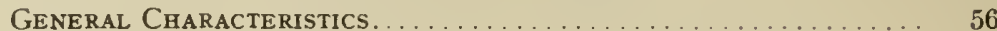

Key to the North American Species of Aeshna-Adults:

I-Males.............................. 57

II-Females. . . . . . . . . . . . . . . . . . . 62

Key to the Nymphs of North American Species of Aeshna . . . . . 66

The Caerulea Group. . . . . . . . . . . . . . . . . . . . . . 69

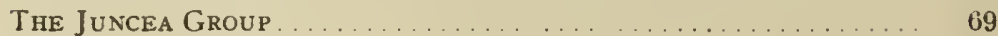

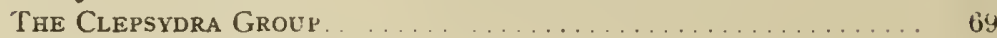

The Cyanea Group......................... 70

The Californica Group . . . . . . . . . . . . . . . . 71

The Multicolor Group. . . . . . . . . . . . . . . . . . 71

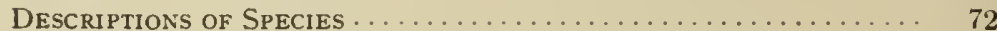

Aeshna caerulea septentrionalis .................. 72

Aeshna sitchensis.......................... 77

Aeshna juncea . . . . . . . . . . . . . . . . . . . . . . . 83

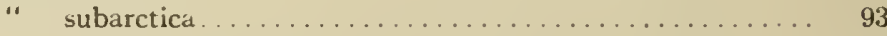

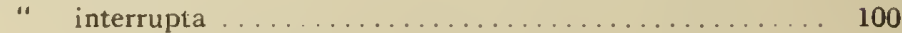

" " interrupta................... 103

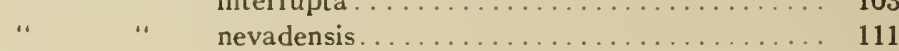

" $"$ lineata . . . . . . . . . . . . . . . . . . 112

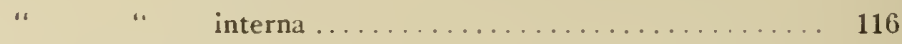

$"$ eremita............................. 119

" clepsydra............................ 129

" canadensis........................... 135

" verticalis............................. 145

" tuberculifera. ....................... 152

“ palmata .......................... 157

“ umbrosa . . . . . . . . . . . . . . . . . . . . . . 165

" "

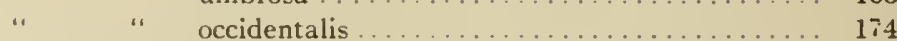

" constricta...................... 176

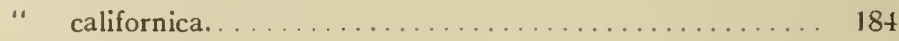

" multicolor ........................... 190

" $\operatorname{mutata} \ldots \ldots \ldots \ldots \ldots \ldots \ldots \ldots \ldots . \ldots \ldots \ldots$

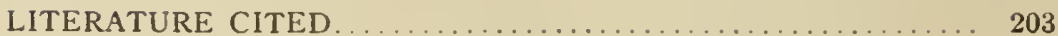




\title{
THE NORTH AMERICAN DRAGONFLIES OF THE GENUS AESHNA.
}

\author{
INTRODUCTION.
}

Purpose and scope of paper-During the summer of I 906 while spending the latter part of the season at De Grassi Point, Lake Simcoe, Ontario, I became interested in the large dragonflies of the genus Aeshna Fab. by reason of their great abundance that year. Rough observations in the field seemed to point to the existence of more species than were recognized in any of the writings on the Odonata of eastern North America and the published descriptions of our species of this genus impressed me in nearly every case as being more or less vague or superficial. Correspondence with the eminent Odonatist, Mr. E. B. Williamson, elicited the fact that his observations on Aeshna in Indiana and northern Ontario corresponded closely with my own, and it seemed evident that the genus was in need of thorough revision. Accordingly, on Mr. Williamson's suggestion, I undertook to make a careful study of this neglected group with the aim of placing our systematic knowledge of the North American species upon a sound basis and obtaining as much information as possible relating to their life histories, ecology, seasonal and geographical distribution. Only the species which have been found north of Mexico are considered here, as the Mexican and Central American forms have already been ably dealt with by Calvert (Od. B.C.A., I905).

Sources of material and acknowledgements-During the four years in which I have been engaged in this study I have examined most of the larger collections in North America, as well as a considerable number of specimens received from collectors not specially interested in the Odonata, and I take pleasure in expressing publicly my deep gratitude to all those who have thus assisted me in what would otherwise have been a very incomplete piece of work. Especial thanks are due to Mr. E. B. Williamson and Professor P. P. Calvert, 
who have been ever ready with helpful suggestions and encouragement and most generous in the loan of material. The entire collection of North American Aeshnae belonging to the former, probably the largest in existence, has been in my hands since the work was commenced. Other large collections which were in my possession for a considerable period of time are those of the United States National Museum, for which I have to thank Dr. L. O. Howard and Mr. R. P. Currie, and that of Miss Mattie Wadsworth, to whom I am also much indebted. The total number of specimens examined was about 1720 .

The following is a list of the sources of the material studied, in addition to that in my own collection, together with the names of those to whose kindness I owe the privilege of examining it:

The United States National Museum, Washington, D.C. (Dr. L. O. Howard and Mr. R. P. Currie.)

The Museum of Comparative Zoology, Cambridge, Mass. (Mr. Samuel Henshaw.)

The British Museum, London. (Mr. G. M. Waldo.)

The Academy of Natural Sciences of Philadelphia. (Prof. P. P. Calvert.)

The Boston Society of Natural History. (Mr. C. W. Johnston.)

The Public Museum of Milwaukee. (Mr. R. A. Muttkowski.)

The University of Michigan. (Dr. C. C. Adams.)

The Provincial Museum of Ontario. (The late Dr. $\mathrm{W} \mathrm{m}$. Brodie.)

Also the private collections of Mr. E. B. Williamson, Bhliffton, Indiana; Prof. P. P. Calvert, Philadelphia; and Miss Mattie Wadsworth, Hallowell, Mé.; and numerous specimens from Messrs. C. H. Kennedy, Sunnyside, Wash. (to whom I am also indebted for valuable field-notes, and colour sketches); J. B. Wallis, Winnipeg; Norman Criddle, Aweme, Man.; T. N. Willing, Regina; A. G. Huntsman, Toronto; R. C. Osburn, New York; Prof. J. G. Needham, Ithaca, N. Y.; E. V. Cowdry, Waterford, Ont.; the late Dr. James Fletcher of Ottawa; Mr. K. J. Morton, Edinburgh, from whom I 
received a fine series of British specimens of Aeshna juncea; and Dr. F. Ris, Rheinau, Switzerland, who furnished me with nymphs and exuviae of the same species.

Field observations - In addition to the knowledge gained from the study of this material I have been able to observe in the field most of the eastern species herein described and in such cases descriptive notes on the colour-pattern and, wherever possible, coloured drawings have been made from the fresh material. Of nearly all the species that I have not seen in life I have examined recently captured specimens preserved in strong alcohol, in which the colours are retained practically unaltered for a considerable length of time.

In regard to the earlier stages I have not been very successful in my efforts to obtain and rear the mature nymphs, and it was only by persistent effort and the help of others that a considerable series of nymphs and exuviae representing eleven species has been accumulated. Although it is impossible to prove that those nymphs which have not been reared belong to the species to which they have been referred, I am confident that there is very little possibility of error in any of my determinations.

Much kind assistance has also been rendered to me in the work of collecting the imagines by Mr. Paul Hahn and in collecting and rearing the nymphs by Mr. A. R. Cooper.

\section{THE NAME AESHNA.}

The name Aeshna, formerly coextensive with the modern family Aeshnidae, was given to these insects by Fabricius in 1775 (Syst. Ent., p. 424), but was afterwards changed to Aeschna by the editors of "Illiger's Magazin für Insektenkunde" (Bd. I, S. I26, I 822). In this form it was universally quoted until Calvert, in 1905, restored the original spelling, in which he has been generally followed by American but not by European writers. Various attempts have been made to interpret this word. The first suggestion is found in "Illiger's Magazin" (loc. cit.) as follows:

"Aeschna, ae (nicht Aeshna) f. Schmaljungfer viel-

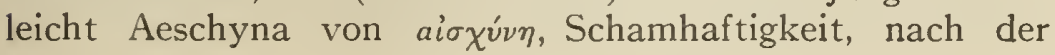


Aehnlichkeit mit Jungfer? In Charleton, Exercitatt. de differentiis et nominib. animal., Oxon. I677, kommt aoxva als Name eines Insekts vor."

Williamson (Drag. Ind., p. 303, I 899) regarded the word as probably derived from ai $\chi$ pós, "ugly," but recently the same writer has communicated to me a suggestion made by Mr. R. J. Tillyard that the original spelling was a printer's error for Aechma (ai $\chi \mu \eta$, "a spear," in allusion to the long slender form of the body). As, however, it is impossible to decide the question of the meaning of this word with any approach to certainty it is unfortunately necessary to fall back upon the original spelling, for although "Aeshna" is impossible as a Greek word, "Aeschna," in spite of its better appearance, is also meaningless and impossible to derive from any Greek word without making allowance for errors. This is the more unfortunate as the composites of Aeshna must all retain the emended form in which they originally appeared (Basiaeschna, etc.).

\section{THE GENUS AESHNA.}

\section{Taxonomy.}

The genus Aeshna is here considered in its narrowest sense and the species separated from it by Williamson ('O3) under the name Coryphaeschna have not been included, although this group of forms has not been generally recognized as having generic rank. It is true that the characters, taken singly, which separate Coryphaeschna from Aeshna, sensu stricto, are seemingly slight and that some species, now referred to the latter genus, are in some respects intermediate between these two types; nevertheless the points of difference between such forms as Coryphaeschna ingens and Aeshna juncea are numerous, and, taken together, fully deserving of generic rank, according to the usual conception of a genus as held by modern entomologists. A number of apparently slight differences, difficult of definition, may be of greater phylogenetic significance than a few easily definable ones. Thus any typical species of Aeshna may be readily 
separated from Oplonaeschna by the unforked radial sector, while the distinctions between the former and Coryphaeschna are much less easily defined (vide Williamson, loc. cit.). Yet apart from this one character, which is really a very slight one, Oplonaeschna is a typical Aeshna, while Coryphaeschna differs from the latter in many points, small individually but together giving the group a distinct habitus of its own.

It must be admitted, however, that the separation of Coryphaeschna as a genus may necessitate further subdivision of the genus Aeshna asdefined at present, but it is not improbable that this would be an advantage, as the numerous species which the latter now embraces are not all obviously nearly related forms and possibly represent several distinct lines of descent.

The genus Aeshna as understood here may be characterized as follows :

Generic characters of the adult--Eyes contiguous for a distance not greater than the dorsal length of the frons and frontal vesicle combined; frons not unusually produced in advance of the eyes, the face more or less convex in profile view; wings moderately broad, the base of the hind wing and the anal loop well developed; males with an anal triangle and the postero-anal margin of the hind wing angulate; membranule of hind wing extending along the anal margin for a distance equal to or greater than the distance along which it extends on the postcosta; upper piece of arculus equal to or longer than the lower piece; median space free; subcosta not prolonged beyond the nodus, pterostigma distinctly braced; ${ }^{1}$ triangles typically with two basal cells, inner side of triangle of hind wing at least half as long as the outer side; radial sector forking more or less unsymmetrically a short distance before the pterostigma or at the level of its proximal end, the posterior branch generally continuing the direction of the main stem more nearly than the anterior branch, two to four rows of cells (generally three in North American species) between the forks at the level of the distal end of the pterostigma, increasing at the margin; radial sup-

${ }^{1}$ Those of one pair of wings are sometimes without the brace in Ae. caerulea and sitchensis. 
plement more or less sinuate, diverging from the radial sector and converging again distally, the intervening space with at least three rows of cells in its widest part; Mra arising from just before to just behind the stigma; $M_{4}$ unbroken though more or less sinuate distally; abdominal segments without accessory lateral carinae; ${ }^{1}$ segment 2 in the male with a pair of auricles, segment 3 longer than segment 4 , more or less constricted before the middle, especially in the males; ventral surface of segment 10 in the female spinulose or denticulate towards the posterior margin.

Generic characters of the nymph-Eyes prominent, the antero-posterior diameter not longer, generally distinctly shorter, than the posterior margin; hind angles of head rounded or rarely bluntly angulate; posterior margin of head straight or slightly excavate. Mentum of labium reaching back to the bases of the middle legs, the lateral lobes, generally, but not always, squarely truncate, their hind margins minutely and feebly crenulate, the terminal hook minute or occasionally absent. Wing-cases in full-grown nymphs usually reaching back to the base or apex of segment 4 , sometimes over a part of segment 5 , showing the curve of Rs toward the anterior margin and its unsymmetrical apical fork, and the radial and median supplements curving toward the posterior margin; abdomen broadest at segment 6 or 7 , without dorsal hooks, lateral spines typically present on segments 6 to 9 , but sometimes those on segment 6 are almost obsolete, while in others they are distinctly developed on segments 5 to 9 . Superior appendage a little shorter than the inferior appendages, deeply excavated at apex.

Secondary sexual characters-Beside the differences in the genitalia, abdominal appendages, and angle of the hind wing and length of the pterostigma, the sexes in Aeshna, as in most Odonata, differ considerably in the general form of the body and in the relative proportions of its parts, and to a greater or less extent in colour-pattern. The thorax is slightly smaller in the female owing probably to the lesser development of the muscles of fight than in the male, which is the

${ }^{1}$ Rudinentary accessory lateral carinae are sometimes present, e.g., in Ae. californica. 
more active sex. The abdomen is a little shorter, being generally more nearly equal in length to the hind wings, but is considerably deeper, though nearly the same in breadth. The greater depth is most marked at segment 3, which is considerably shorter and less constricted than in the male, and at segments 8 and 9 . The ground colour is generally paler in the female, the abdomen being brown, darkened at the sutures and elevated parts and around the pale areas. Of these the dorsal thoracic bands and posterior abdominal spots (PD) are smaller, the lateral abdominal spots larger, than in the male. The lateral thoracic bands tend to be slightly broader in the female. The colour of the pale areas may be the same (homœochromatic females) or more or less widely different (heterochromatic females) from that of the male (vide p. 29).

Characters of specific value and terminology--The abdominal appendages are generally regarded as offering the most important specific characters in the adults, but the accessory genitalia are at least as valuable and perhaps more so as group characters. Other important specific characters are found in the female genitalia, the dark markings of the face, the thoracic colour-pattern and to a less extent that of the abdomen. In particular cases other characters are useful, such as the relative lengths of the occiput and line of contact of the eyes, the colour of the membranula and certain venational features, especially the form and position of the fork of the radial sector and the origin of Mia.

In the nymphs the best systematic characters are found in the form of the labium, especially of its lateral lobes, the supracoxal processes of the prothorax, the length of the lateral spines of the abdomen, the size of the female genitalia, the relative lengths of the abdominal appendages, and the colour-pattern.

In the descriptions of both imagoes and nymphs I have found it convenient to introduce a few new terms.

A. Imago-The preocular band is the black ocular margin of the frons and nasus, which is broadest above where it crosses the head just in front of the frontal vesicle, narrowing as it passes ventrad along the sides of the frons 
and usually the nasus. It is confluent above with the " $\mathrm{T}$ spot" in all North American species. The lateral lobes of the nasus are the two rounded or subangulate ventro-lateral processes of that structure. The remaining new terms all refer to the colour-pattern of the abdomen and the genitalia.

I. Colour-pattern-The colour-pattern in the genus Aeshna is on the whole very uniform, remarkably so in the North American species, and in the ordinary cabinet specimens the appearance of uniformity is exaggerated by the disappearance of the natural colours and the frequent obscurity of the markings. Hence Odonatists generally have relied almost exclusively upon structural features in characteriżing the species of this genus, particularly upon the abdominal appendages of the male, with the result that the species of Aeshna have been "lumped" to an unusual degree and the belief has become prevalent that the coloration, though relatively uniform for the genus, is very variable within the limits of a given species.

The study of these insects in large series demonstrates conclusively that this is not the case and that each species has its characteristic colour-pattern, which usually varies but very slightly, if exception be made of the wide variation in colour alone of the females of most species, in which a tendency to dimorphism may be observed (vide p. 29). I have therefore described at considerable leng th the colour-patterns of all the species and subspecies, and, as the same type of pattern is present in all the forms, it has been found convenient to give special names to the more characteristic spots and bands of the thorax and abdominal segments.

(a). Thorax-The dorsal thoracic bands are the pale longitudinal stripes on the mesepisternum, frequently described as "antehumeral stripes." The term lateral thoracic band is used in describing two oblique lateral bands or pale areas on each side of the thorax, even when these areas cannot be well described as "bands." When other pale areas occur on the side of the thorax they are not included in the term.

(b). Abdomen-Except the first abdominal segment, on which there is nearly always a dorsal and generally a lateral spot, the serial homologies of the pale areas of the various 
segments in any species of Aeshna are quite obvious; and as in all the species the pale areas of corresponding segments are homologous the same terms are applicable to these areas in every case.

The most typical arrangement of these spots is generally seen on segments 4 to 7 and may be understood by reference to text figure $\mathrm{I}$, which gives dorsal and lateral views of segments I to 4 in the male of Aeshna juncea. It will be observed that the spots can be divided into a dorsal and a lateral series, and each of the series into anterior, middle and posterior spots. These will be referred to hereafter by the abbreviations used in text figure $I(A D, M D, P D, A L$,

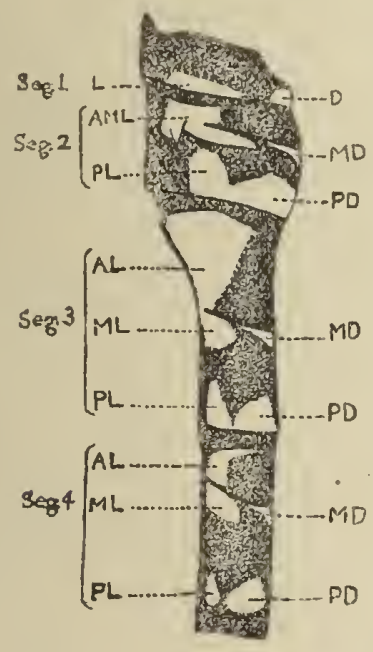

1

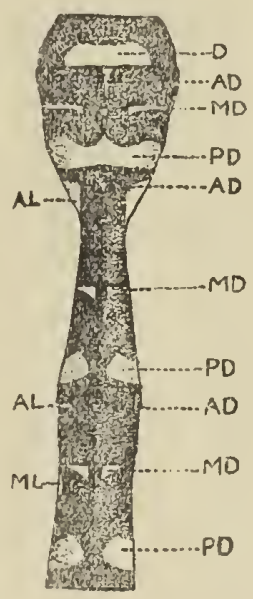

2

PrG. I-Aeshna juncea $\mathrm{L}$, abdominal segments $\mathrm{t}-4$, showing the characteristic spots ; $\mathrm{I}$ laterai view; a dorsal view. D dorsal spot (of segment r); L lateral spot (of segnent r); AL anterolateral spot ; ML medio-lateral spot; PL postero-lateral spot; AD antero-dorsal spot ; $M D$ medio-dorsal spot; PD postero-dorsal spot. AML (on segment 2) is a combination of Al,

$M L, P L) . A D$ is always small and of ten absent in North American species, and except for the sake of uniformity in the terminology need not have received a special term. MD 
and PD are paired, the former generally small and yellowish or greenish and represented on segments 2 to 7 or 8 , the latter large and typically blue, and nearly always present on all the segments. PD or PD+PL is the "apical spot" of Hagen. Of the lateral spots, all of which are typically blue, $\mathrm{AL}$ and ML are partly or wholly separated by the transverse carina and together form the "lateral divided basal spot" of Hagen. They are generally represented on segments 2 to 8 , AL gradually decreasing in size caudad to a mere dot on 8 , while ML increases to 6 or 7 , becoming smaller again on 8 . On segment $2, \mathrm{AL}$ and $\mathrm{ML}$ are almost always united, forming a single spot AML. PL, which is generally small and frequently a mere ventral offshoot of $\mathrm{PD}$, is the most variable in development of all the spots. It always decreases in size caudad and is of ten represented on only a few of the anterior segments. In females, PL and ML are usually confluent on segment 2 , and occasionally, in both sexes, also on segment 3 .

2. The genitalia. (a). The accessory genitalia of the male-These are lodged in a deep median groove or pocket, the genital fossa, on the ventral side of segment 2 , bounded laterally by the tergal margins, which are more or less approximated behind but divergent cephalad in the region occupied by the anterior hamuli and anterior lamina. The vesicle of the penis is a sac with chitinous walls lying at the posterior end of the genital fossa and attached by its broad posterior end to the front of the sternum of segment 3 . Arising from the dorsal surface of the vesicle, at its distal end, is the penis, a three-jointed chitinous tube whose lumen is continuous with that of the vesicle. The first joint is the longest and is bent upon itself, the proximal limb being directed dorsad, the distal limb ventrad. The second joint is clirected ventrad and caudad and has a longitudinal slitlike aperture on its convex surface, communicating with the lumen of the penis. The third joint consists of a small strongly chitinized piece, and two large fleshy distal lateral lobes, which are complexly folded and lie in a marked depression in the wall of the vesicle at its anterior end. When not in use the bent penis is protected by the sheath of the penis. 
a concave chitinous process arising from the floor of the genital fossa; and on each side of the sheath, generally concealed by the overlapping tergal margins, is one of the posterior hamuli, two simple chitinous processes of the walls of the genital fossa bearing upon their apices a number of long hairs.

In front of the posterior hamuli, and in some species (none North American) partly concealed by the hairs of the latter, are the much larger and more complicated anterior hamuli. Each anterior hamulus consists of a broad, somewhat triangular thickening of the wall of the genital fossa and a folded, strongly chitinized mesially concave process, arising from its sloping mesial surface. The two concave processes of opposite hamuli form a pair of claspers for the ovipositor during copulation and their efficiency as such is increased by the presence, in each concavity, of a small elevation thickly covered with spinules, (fig. 2, $t$ ). For descriptive purposes each clasper may be divided into two parts, the hamular process and the hamular fold. The hamular process (fig. $2, h p$ ) is a freely projecting structure, the most anteriorly and ventrally situated part of the clasper. The two processes together form the floor of the passage for the ovipositor. The hamular folds (fig. 2, hf), so called from their folded form, are the more posterior and dorsal part of the clasper and close the passage above and behind. Generally the hamular process and fold are not sharply marked off from one another, the free margin of the one passing insensibly into that of the other; but in some cases the

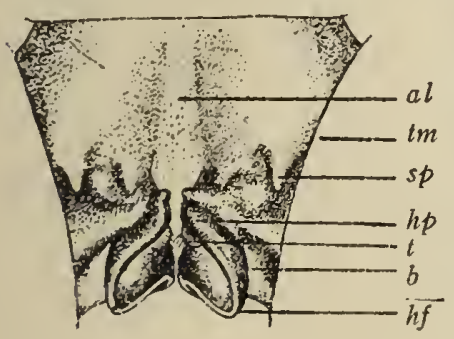

A

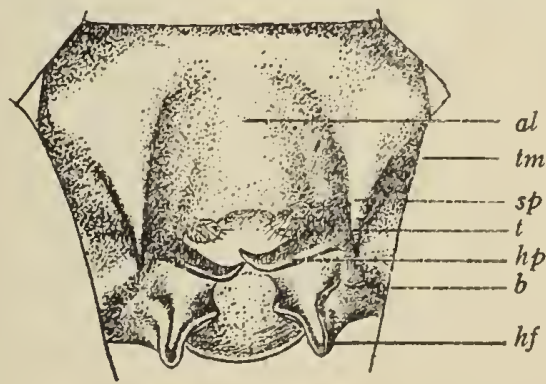

B

FIG. -Anterior lamina and anterior hamuli of (A) Aeshna interrupta Walk.. (B) Ae juncea L: $a l$ anterior lamina ; $t m$, tergal margin of segment $z ; s p$ spine of anterior lamina; hp hamula process ; $t$ spinulose tubercle : $b$ basal part of hamulus ; $h f$ hamulas fold. 
hamular processes assume highly specialized forms and bècome partly or entirely separate from the folds, which are in such cases more or less reduced (fig. 2, B). Both of these structures differ greatly in form in different species and are of great systematic importance.

Immediately in front of the anterior hamuli is the anterior lamina (al), a large plate, deeply but broadly cleft in the middle line, the cleft forming the anterior termination of the genital fossa. The anterior lamina bears on each side at or near the margin a more or less acute process, the spine of the anterior lamina $(s p)$, which is directed more or less caudad and either ventrad or dorsad according to the species. In form and size it exhibits great variation within the limits of the genus, but offers excellent group and sometimes specific characters.

(b). The genitalia of the female-These are situated on the ventral side of segment 9. Under this term are included the ovipositor, genital valves, styli and lateral genital plates

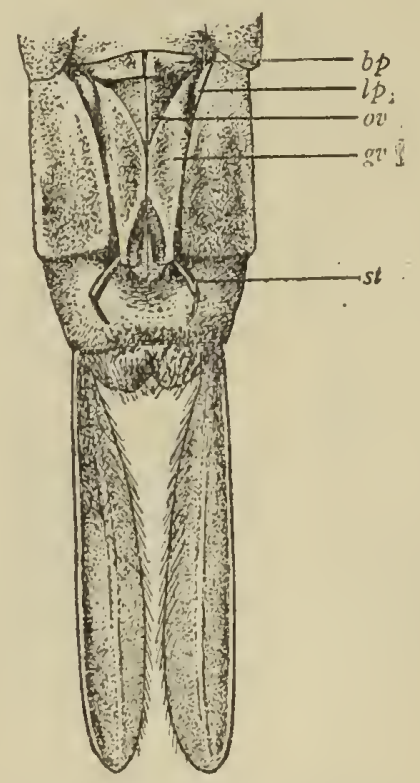

Frg. 3-Aeshra rlepsudra Say, female genitalia and appendases, ventral view: bp. basal plate : is lateral plate : or ovipositor: genital valve; st stylus. 
(fig. 3). The ovipositor (ov) is attached to the apex of segment 8 and consists of a pair of somewhat falciform processes, concave internally and fitting together to form a laterally compressed tube. Each process consists of an upper and a lower piece fitting closely together along their adjacent margins and sharply pointed at their distal extremities. The outer surface of the upper piece, at the apex, is marked by a series of fine transverse ridges like a file, while the lower piece is quite smooth. At the base of the lower piece is a short broad transverse plate, the basal plate of the ovipositor $(b p)$. When not in use the ovipositor is largely concealed by the genitalvalves (gv), a pair of broad thin chitinous plates, attached to the whole length of segment 9 under cover of the tergal margins. At the base, the genital valves are widely separated; leaving part of the ovipositor exposed, but beyond a point somewhat before the middle they are attingent and form a complete protective sheath for the apical part of the ovipositor. Each valve generally exhibits distinct lateral and ventral surfaces separated by a lateral carina which terminates at the apex of the valve. Dorsal to the apices the valves are produced caudad and dorsad in to a beak-like process, which fits into a depression on the sternum of segment Io and serves as a sheath for the apex of the ovipositor. Articulating with the lateral surface of each genital valve, a littledorsad of the apices, are the styli (st), or valvular processes, a pair of short one-jointed cylindrical processes, each bearing an apical pencil of hairs. The lateral genital plates $(l p)$ are a pair of small folds not present in all species, occupying the proximal part of the space between the tergal margins and the genital valves. They perhaps give additional support to the latter.

B. Nymph-The only terms that require special mention are those used in describing certain scar-like inlpressions and spots which are present in all Aeshna nymphs. The lateral scars are a series of pairs of smooth areas on each side of the abdomen, parallel to the lateral margin. The ventral scars are two series of similar areas on the ventral surface. The dorsal punctae consist of a number of groups of impressed dots and transverse streaks arranged in a median 
dorsal series, there being two pairs on nearly every segment. The lateral punctae are a series of dark spots or dots, one on each side of every segment near the base and just mesad of the lateral scars. The dorso-lateral punctae are smaller dots mesad and distad of the lateral punctae. They are absent from segment 9.

Measurements and abbreviations-All measurements are given in millimetres. The terms length and breadth, when their meaning is not otherwise obvious, refer to the anteroposterior and transverse dimensions, respectively, of the measured part.

The relative lengths of the occiput and line of contact of the eyes are not accurately definable, but they are occasionally of some taxonomic value. The somewhat arbitrary point selected as the apex of the occipital triangle is the meeting-point of two tangents drawn to the curves of the ocular margins a little in front of the middle of the sides of the triangle (fig. 4).

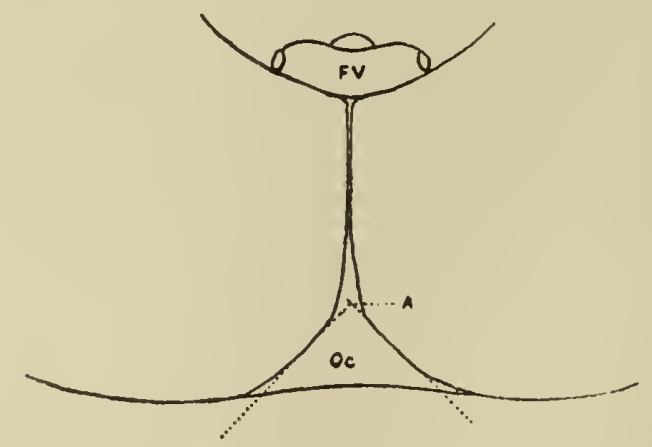

Yik. 4-Method of mensuring the relative lengths of the occiput (oc) and line of contact of the eyes The latter is measured from the apex of the occipital triangle $(A)$ to the hind margin of the front vesicle (FV).

The measurements of the T-spot when not otherwise indicated are those of the transverse dimension of the crossbar.

The lengths of the thorax, abdomen and its segments are measured on the side along the dotted line in fig. 5 .

The width of the hind wing is measured at the nodus.

The pterostigma is measured along the posterior margin. 


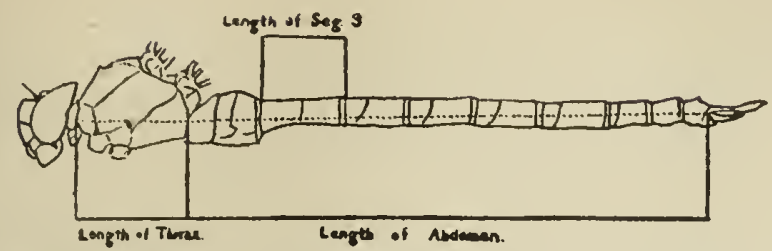

FIG. 5-Method of measuring the lengths of the thorax, abdomen and abdominal segments.

The abbreviations used in describing the abdominal colour-pattern have already been given (p. 9). The only others besides those used in reference to wing-venation (vide fig. 6 ) are the following: apps. =appendages; h.f. = hind femur; h.w. $=$ hind wing; pter. = pterostigma ; gen. $\mathrm{v} .=$ genital valve; gen. $q=$ genitalia of female.

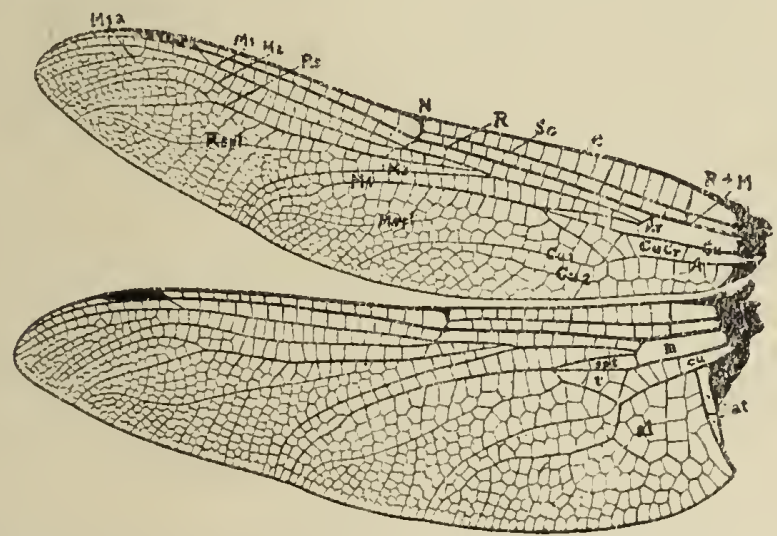

Fic. 6--Wings of Aeshna eremita Scudd. C costa; Sc subcosta ; $R$ radius; Rs radial sector Kspl radial supplement; $M$ media; $M_{r}, M_{r}, M_{2}, M_{3}, M_{4}$ branches of media ; Mspl mediar supplement; $\mathrm{Cu}$ cubitus. Cur, $\mathrm{Cu} z$ branches of cubitus; A anal vein; at anal triangle ; al anal loop; m median space; cu cubital space; $\mathrm{CuCr}$ cubito-anal cross-veins; $t$ triangle; spt supratriangle; $A r$ arculus ; $N$ nodus.

Genetic relationships of the genus Aeshna. (a). The sub. familyAeshninae-The natural classification of the Aeshninae, like that of most groups of organisms, is complicated by the occurrence of many cases of parallel evolution which seem to have arisen through certain orthogenetic tendencies, more or less characteristic of the entire group. As Needham ('O3) has pointed out, there are five dominant tendencies in the development of the venation in the Aeshnidae: "(I) The similar elongation of 
the triangle in both wings; (2) the development of strong supplements; (3) the hypertrophy of two antenodal cross-veins; (4) the development of a brace to the stigma; (5) the angulation of the hind angle of hind wing in the males." These characters are generally least developed in the most generalized members of each subfamily and best developed in the most highly specialized forms, so that we find resemblances between specialized members of different subfamilies or smaller subdivisions which are not due to genetic relationships but to parallel development. The brace of the pterostigma in the Gomphinae and Aeshninae or the elongation of the triangles and the forking of the radial sector in such distantly related Aeshnine genera as Nasiaeschna and Staurophlebia are examples of such parallelisms.

It is therefore almost an impossible task to represent in detail with any approach to certainty the genetic relationships of the genera of such a large group as the Aeshninae. Some approximation to the truth is all that we can expect to arrive at.

The earliest classification of the Aeshninae that can be regarded as an approach towards a representation of the natural affinities of the genera in this group is the system proposed by Karsch ('9I). On venational grounds alone he divided the subfamily into five groups; Anax, Aeschna, Hoplonaeschna (Oplon-), Allopetalia and Brachytron, the two dominant groups being those of Aeshna and Brachytron. Needham (loc. cit.) has also shown that the two main lines of venational specialization in this subfamily are indicated by the members of these two groups respectively, though he excludes from the Aeshna group the genera Staurophlebia and Neuraeschna. Karsch's groups of Oplonaeschna and Allopetalia are the most generalized forms according to Needham, while the Anax group and the genera Staurophlebia and Neuraeschna represent independent side lines of descent.

My attempt to group these genera in a natural way is based upon the two admirable works cited above, and I have been able, to considerable extent, to substantiate by the study of other characters the phylogenetic interpretations which Professor Needham has placed upon the venational 
characters alone. In the placing of those genera which I have not seen I have relied chiefly upon the numerous illustrations in Martin's recent work on the Aeshninae of the Selys collection (Martin, '08).

The only important points in which my conclusions differ from those of Needham are in the positions of $A$ nax and Hemianax and of Neuraeschna and Staurophlebia. Although I should place the first two genera in a different group from Aeshna, I regard them, as well as the other two genera, not as belonging to independent side-lines of descent from primitive ancestors, but as specialized offshoots from the Aeshna line. My reasons for this belief will be given later.

The genera which represent the Aeshna line of descent, including the four just mentioned, have the following characteristics in common: (a). The radial sector is curved forward under the stigma and is forked, the fork being more or less unsymmetrical as a result of the curve. (b) The radial supplement is bent toward the posterior margin of the wing so that the space between it and the radial sector is widened, being occupied at its widest part by three or more rows of cells. (c) The median supplement is similarly curved and the space between it and $\mathrm{M}_{4}$ similarly widened. (d) $\mathrm{M}_{4}$ is bent away from $\mathrm{M}_{3}$, at a point about opposite the proximal end of the radial supplement and is apparently more or less distinctly forked at the point of deflection. In most of the genera the trigonal supplement joins the median supplement. To this group belong the genera Aeshna, Coryphaeschna, Anaciaeschna, Amphiaeschna, Heliaeschna, Gynacantha, Triacanthagyna, Tetracanthagyna, Platacantha, Cornacantha, Subaeschna, Neuraeschna, Staurophlebia, Hemianax and Anax.

To the Brachytron group belong a number of genera which agree with those of the Aeshna group in the forked radial sector, but differ in the absence of the other characters given. In these the radial sector is not curved forward but is straight and the fork is symmetrical, or nearly so, and is generally deeper than in the Aeshna group. The radial.and median supplements are also straight, and there are only one or two rows of cells between these supplements and the longi- 
tudinal veins in front of them ( $\mathrm{Rs}$ or $\mathrm{M}_{4}$, as the case may be). $M_{3}$ and $M_{4}$ tend to be parallel throughout their course and the trigonal supplement does not join the median but is separate from it by a row of cells. To this group belong the genera Brachytron, Austroaeschna, Nasiaeschna, Epiaeschna, Caliaeschna, Aeschnophlebia, Telephlebia and Periaeschna.

Of the remaining genera which agree in the unforked radial sector, Basiaeschna and Oplonaeschna approach the Aeshna group, in that the radial and median supplements are similarly curved toward the posterior margin of the wing. Rs is slightly bent forward and $M_{4}$ is more or less deflected from $M_{3}$. These features are present in but a slight degree in Basiaeschna, in which, also, the base of the hind wing is not much enlarged, but in Oplonaeschna the only character which separates it from Aeshna, is the simple radial sector, the anterior branch of which is represented, as in Basiaeschna, by a line of cross-veins which is tending to straighten out. In some species of Aeshna, such as Ae.caerulea, this anterior branch is but little better developed than in Basiaeschna and Oplonaeschna, and in many individuals of this species the radial sector cannot be described as forked at all. The two genera Basiaeschna and Oplonaeschna also resemble Aeshna in all other characters and may therefore be regarded as very nearly related to the immediate ancestors of the Aeshna group.

The corresponding prototype of the Brachytron group is Boyeria, in which the venation is very like that of Basiaesch$n a$, but differs mainly in that Rs is still straighter, the supplements straight, and $M_{3}$ and $M_{4}$ nearly parallel. As in Basiaeschna the position of the trigonal supplement in relation to the median supplement is undecided and the anterior branch of Rs is represented by a line of cross-veins tending to form a longitudinal vein. The median space is reticulated.

The evidence of the relationships supplied by these venational characters is supported by the characters offered by the auricles and accessory genitalia of the males. These structures, as found in Basiaeschna (or Oplonaeschna) and 
Boyeria, are typical of the Aeshna and the Brachytron groups respectively (pl. 12 , figs. 2,3 ). In the great majority of the former group the auricles bear but few well separated teeth, the hamular processes are short, not lying close to the floor of the genital fossa, and are continuous with the well-developed hamular folds, with which they form a pair of concave chitinous plates. The spines of the anterior lamina are typically well developed. In Boyeria and the Brachytron group the auricles bear a large number of small teeth, more or less closely crowded together, and the anterior hamuli are strikingly different from the Aeshna type. The bases tend to increase in size and extend caudad, the hamular folds are greatly reduced or scarcely distinguishable at all (pl. 12, fig. 3) and are sharply marked off from the hamular processes, which are large and peculiarly shaped, being broad and elevated behind, mesially attingent and prolonged cephalad with an acute apex which lies close to the floor of the genital fossa. The spine of the anterior lamina is usually less developed than in the Aeshna group.

This type of auricle, hamuli and anterior lamina, modified in detail in various ways, is present in Boyeria, Caliaeschna, Brachytron, Austroaeschna, Nasiaeschna and Epiaesch$n a$, and presumably in other genera of the Brachytron group. Hamuli simulating this type more or less closely are present in Aeshna caerulea and Ae. sitchensis and in Gynacantha and Staurophlebia and probably also in other genera related to the latter two. The resemblance in these two genera is very remarkable, and in Gynacantha is sometimes shared to a certain extent by the auricles, which have a larger number of teeth than are usually present in the members of the Aeshna group. Hamuli of an intermediate character are present in Amphiaeschna ampla, and as there is no similarity in venation between these forms and the Brachytron groups the resemblance in the hamuli is probably to be interpreted as a case of parallelism not of relationship.

Of the primitive genera other than the three mentioned Allopetalia resembles Boyeria in the straightness of the radial and median supplements, the nearly parallel course of $\mathrm{M}_{3}$ and $\mathrm{M}_{4}$ and many venational details, but differs in the short- 
ness of the triangles and of the stigma, in the free median space and in the much less curved course of $\mathrm{Cu}$ and $\mathrm{Cu}$. In these latter characters it resembles Oplonaeschna closely, and seems in venation to be nearly intermediate between these two genera. As I have seen no maies of this genus I have no knowledge of the accessory genitalia. The resemblance between Martin's figures of the male appendages of A. reticulosa and Boyeria irene is perhaps worthy of note.

The three remaining genera of Aeshninae with. a simple radial sector, excluding the Petalia group, which is probably worthy of subfamily rank (vide Williamson, Proc. U.S.N.M., 33, p. 27I, 1907), are Linaeschna, Jagoria and Gomphaeschna. These are evidently nearly related genera and differ but little from one another in venation, except that, in the order given, the triangles are successively shorter and the venation, in general, less complex. Linaeschna most nearly resembles Boyeria and Basiaeschna in the comparatively complex venation and the elongated triangles, but possesses only two cubito-anal crossveins and has the base of the hind wings less dilated, with a smaller anal loop and no supplementary anal loop, which is present in the other two genera, though imperfectly developed. In Jagoria, and still more so in Gomphaeschna, the number of cells in the wings is reduced, the triangles are less elongated and the supplements less strongly developed than in the other genera noticed. The bifid form of the inferior appendage of the males present in all three of these genera and very marked in Gomphaeschna is probably another primitive feature. It is also present in a slight degree in Allopetalia. Gomphaeschna is the only genus of this group in which I have examined the auricles and accessory genitalia of the male. These are quite typical of the Brachytron group and much resemble those of Boyeria. It should not be concluded, however, that the hamuli of this group are of a more primitive type than those of the Aeshna group, because of their presence in the primitive genus Gomphaeschna. On the contrary it seems more probable that the Aeshna type, as found for instance in Basiaeschna, is the nore primitive. It is a simple folded chitinous plate borne 
upon a stout bàsis and; apart from its shortness, bears a considerable resemblance to the anterior hamuli of Cordulegaster (pl. 12, fig. I)." It seems highly probable, too, that in Gynacantha and allied genera the hamuli, which closely resemble those of the Brachytron group, have been derived from those of the Aeshna type, so that here at least they are secondary to this type. A knowledge of these structures in the archaic Petalia group, the nearest living relatives of the Aeshninae, is very desirable.

(b). The Aeshna group - Of the genera belonging to this group Aeshria appears to be the most generalized, and is probably the parental form of many of the other genera. It is the only genus in the group in which the forking of Rs is sometimes imperfect and we find a series of stages in the development of this character within the genus. In $A e$. caerulea Rs is but little curved forward under the stigma and the anterior branch is slenderer than the posterior and its connection with the latter is not always distinct. There is a long line of cross-veins between Rś and M2 proximal to the fork and continued also a short distance beyond the latter in front of its anterior branch. In Ae. sitchensis this line of cross-reins is also present, though somewhat shorter, and the fork is generally distinct, but the anterior branch comes off somewhat abruptly, the posterior branch continuing the course of the main vein. In Ae. juncea the fork is similar, but the line of cross-veins is reduced and of ten absent, especially in the male. With the further development of the fork and the strengthening of the anterior branch the line of cross-veins is no longer needed and is lost; Rs as a whole tends to bend farther forward and the anterior branch to come off at a smaller angle so that the fork becomes more nearly symmetrical. In Ae. californica, for instance, the fork is but slightly unsymmetrical at base and the posterior branch no longer continues the course of the main steni. Further in Coryphaeschna, Heliaeschna, Anax, etc.; the forward curvature of Rs is so marked that the anterior branch continues the direction of the main sten, while the posterior arises at a more or less distinct angle. This is most marked in $A$ nax and Hemianax, in which the posterior branch becomes 
only the most distal of a series of subparallel branches arising from the posterior side of Rs. With these progressive changes in the radial sector are associated corresponding alterations in other longitudinal veins. M2 becomes more strongly curved forward, the radial supplement tends to diverge more and more from Rs and then become convergent again; the median supplement bears a similar relation to $\mathrm{M}_{4}$, which tends to become more deflected from $\mathrm{M}_{3}$.

Considering now the relationships of the various genera we must again return to Aeshna. In this large cosmopolitan genus great variety exists in the characters of venation, appendages and accessory genitalia. The latter differ so much in different subdivisions of the genus as to suggest a polyphyletic origin from several parent genera resembling Basiaeschna and Oplonaeschna which, themselves, differ considerably from one another in these structures.

Some species of Aeshna, such as californica and multicolor, and to a less extent those of the grandis and clepsydra groups, closely resemble Basiaeschna in the structure of the anterior hamuli, particularly in the form and large size of the hamular folds, while in others such as Ae. affinis, isoceles, cyanea, constricta, etc., there is a closer resemblance to Oplonaeschna, in which the folds are but little developed, than to Basiaeschna. In other species again they are of other types and their affinities difficult to determine.

Of the other genera Coryphaeschna is a lateral offshoot from Aeshna, in which the specialization in wing characters has been carried a little farther than in the latter genus. Amphiaeschna is also very near Aeshna but the median space is reticulated. The hamuli of $A$. ampla are very like those of certain species of Aeshna but approach those of Gynacantha and allied genera in the somewhat reduced hamular folds and the knob-like elevation of the posteroventral part of the processes.

Of the remaining genera (Heliaeschna, Gynacantha, Neuraeschna, Staurophlebia,Tetracanthagyna, Triacanthagyna,Platacantha, Cornacantha and Subaeschna) I have seen examplesonly of the first four, but with the possible exception of Subaeschna, only the male of which is known, they appear to form a 
natural group, having much in common in their venational plan in spite of certain apparently important differences, and in which the membranule is much reduced and the tenth abdominal segment in the female is not spinulose as in most genera, but is armed with a few long spines or with a long bifid process.

Needham's objections to associating the genera Neur. aeschna and Staurophlebia with the Aeshna group are that the tip of the subcosta in these genera extends beyond the nodus, the stigma lacks a brace, and in Neuraeschna (and also Heliaeschna and Amphiaeschna) the median space is reticulated. These appear to be primitive characters but in view of the otherwise close resemblance in venation and other characters between these genera and others of the Aeshna group, especially Gynacantha, I feel satisfied that they belong to this group and have acquired these characters secondarily. The presence of cross-veins in the median space in such genera as Neuraeschna may well be due to the same influences which have brought about the general multiplication of cross-veins in this genus. It is also very doubtful whether the apparent continuation of the subcostal vein beyond the nodus really belongs to that vein, or is a short series of cross-veins in line with it, as its irregular course suggests. The point can only be settled by a study of the early stages. Furthermore I see no reason why the brace of the stigma should not be lost by reversion to an earlier condition in which it was not needed. In some species of Aeshna, as Ae. sitchensis and Ae. caerulea septentrionalis, the stigma of one pair of wings may be sometimes well braced, that of the other pair not at all (cf. fig. of Heliaeschna uninervulata in Coll. Zool. Selys, XX, p. 163, fig. 164).

For similar reasons it seems to me more natural to regard Anax and Hemianax as representing a highly specialized offshoot from the Aeshna group than as constituting an independent line of descent. The position of the media at the arculus and the rounded anal margin of the hind wing of the male are considered by Needham to be primitive characters, but in none of the otherwise primitive genera of Aeshnidae are these characters found, and in all other respects 
Anax and Hemianax are very highly specialized. Moreover in the genus Anaciaeschna, which is unmistakably very close to certain species of Aeshna (cf. figures of the wings of Aeshna martini and Anaciaeschna triangulifera, Coll. Zool. Selys, XVIII, p. 30, fig. 24 and p.72, fig. 7o), some of the peculiarities of Anax are present in a rudimentary condition; the upper part of the arculus is shorter than the lower, vein M2 is strongly curved forward behind the stigma in a manner resembling that of Anax, the auricles are very small (absent in $A n a x$ ) and there are vestiges of the supplementary lateral carinae, which are well developed in that genus. The hamuli and anterior lamina of Anaciaeschna jaspidea and of Aeshna affinis and Ae. isoceles, which belong to that section of the genus which is most nearly allied to Anaciaeschna, are very much alike and bear a decided resemblance to these structures in Anax.

My views on the relationships of the genera of Aeshninae are expressed in the accompanying phylogenetic tree. (Fig. 7.)

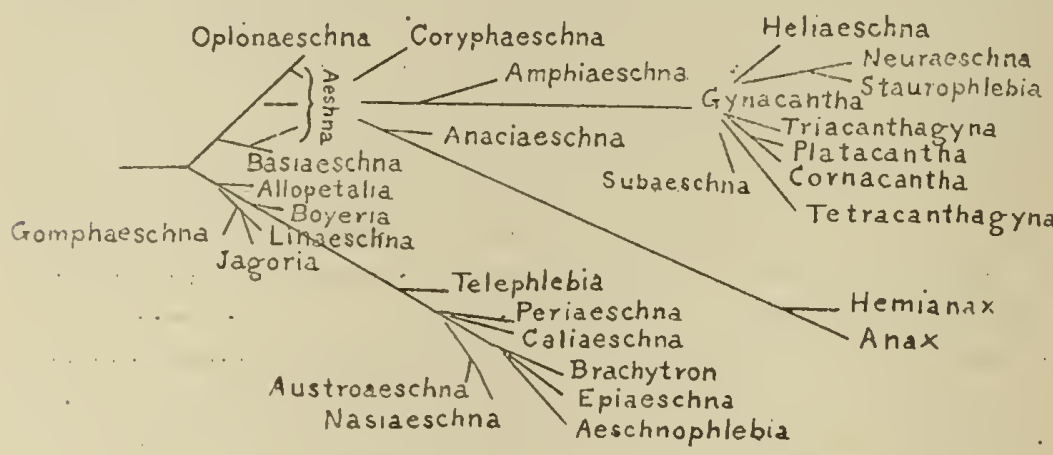

FIG. -Diagram showing the relationships of the genera of Aeshnunae.

It is impossible to arrange these genera satisfactorily in a. linear series. The arrangement that appears to me most consistent with the phylogenetic tree is that which is given below. It has the necessary defect that the most primitive

'I have omitted Förster's genera Limnelron, Protoacschna and Rhionacschna, as I have seen neither specimens nor figures of any of them. Limnctron evidentiy belongs to the Brachytron series while the other two are apparently members of the Acshna series. 
genera of the two great groups of Aeshna and Brachytron are widely separated from one another, e. g., Basiaeschna and Oplonaeschna from Boyeria, Allopetalia, etc., but similar difficulties are encountered in any other attempt to arrange the genera naturally. The only alternative would be to divide the genera into three main groups, the first comprising the primitive genera (those in which $\mathrm{Rs}$ is not forked, etc.), the other two containing the specialized members of the Brachytron and Aeshna groups respectively. This method is perhaps the simpler of the two, but is less exact than that which I have adopted.

\section{BRACHYTRON GROUT.}

Boyeria $\left\{\begin{array}{l}\text { Allopetalia } \\ \text { Gomphaeschna } \\ \text { Sagoria } \\ \text { Linaeschna } \\ \text { Boyeria }\end{array}\right.$

Brachy- $\quad$ tron $\left\{\begin{array}{l}\text { Telephlebia } \\ \text { Caliaeschna } \\ \text { Periaeschna } \\ \text { Austroaeschna } \\ \text { Nasiaeschna } \\ \text { Epiaeschna } \\ \text { Brachytron } \\ \text { Aeschnophlebia }\end{array}\right.$

\begin{tabular}{|c|c|}
\hline \multicolumn{2}{|c|}{ AEshina Group. } \\
\hline $\begin{array}{l}\text { Aeshna } \\
\text { Series }\end{array}$ & $\left\{\begin{array}{l}\text { Basiaeschna } \\
\text { Oplonaeschna } \\
\text { Aeshna } \\
\text { Coryphaeschna } \\
\text { Anaciaeschna } \\
\text { Amphiaeschna }\end{array}\right.$ \\
\hline $\begin{array}{l}\text { Gynacan- } \\
\text { tha Series }\end{array}$ & $\left\{\begin{array}{l}\text { Gynacantha } \\
\text { Triacanthagyna } \\
\text { Platacantha } \\
\text { Cornacantha } \\
\text { Tetracanthagyna } \\
\text { Heliaeschna } \\
\text { Staurophlebia } \\
\text { Neuraeschna } \\
\text { Subaeschna }\end{array}\right.$ \\
\hline $\begin{array}{l}\text { Anax } \\
\text { Series }\end{array}$ & $\left\{\begin{array}{l}\text { Hemianax } \\
\text { Anax }\end{array}\right.$ \\
\hline
\end{tabular}

Varfations.

(1). Climatic variations-On a whole the variations among the individuals of a given species of Aeshna in a given locality are not great. The only striking ones are found in the colour of the females, in which there is a tendency towards dimorphism. This subject will be considered later. The abdominal appendages of the female, which are appar- 
ently functionless structures, and the third segment of the abdomen, are also subject to considerable variation, the former in length and the latter in depth. The range of variation in these parts in widely distributed species is found, however, to be much greater over the whole area of distribution than in any one locality. A correlation is also noticeable in the variations of these structures. Thus in the females shortening of the abdominal segments, especially segment 3 , is accompanied by deepening of the same segments and a shortening of the appendages. In the males the latter variation does not appear, as the appendages are functional structures and must be of a more or less definite length.

It may also be shown that these variations are dependent in a great measure upon locality. Thus if we compare specimens of Ae. eremita from the following three localities, Bay of Islands (Newfoundland), Heyden (northern Ontario), and Toronto (southern Ontario), we find that the abdomen of the Newfoundland females is distinctly shorter and deeper than in the Toronto specimens, and the appendages are much shorter, while the Heyden females are about intermediate between those from the two other localities.

Similar variations occur in the case of Ae. interrupta, canadensis, juncea, palmata and umbrosa, and it may be further shown that the various species from a given locality resemble one another more or less closely as regards these variable features. Thus in Newfoundland and the Magdalen Islands, Aeshna juncea, canadensis, eremita, and interrupta all have relatively short and deep bodies and the females have short appendages as compared with the same species in Ontario; while the same differences in less degree are observable in the specimens of these species from northern Ontario or northern Michigan and southern Ontario respectively (except in Ae. juncea which does not occur in southern Ontario). In the case of the widespread and common Ae. umbrosa, specimens from Anticosti, Vancouver Island and New Bridge, Oregon, are very similar in the comparatively short abdomen, which is relatively stout at seg. 3 , while in those from Toronto, Bluffton (Ind.), and various localities 
in New York, Pennsylvania and Ohio the abdomen is long and slender, particularly at seg. 3. Specimens from northern Ontario and Manitoba come nearer the latter than the former, though varying somewhat towards those of the first category, especially in the females. ${ }^{1}$ Again in the circumpolar Ae. juncea, specimens from the Magdalen Islands (Que.), Alaska and Great Britain are nearly alike in form and are stouter than specimens from Nipigon (Lake Superior), the Bighorn Mountains (Wyoming) and other parts of the interior of North America.

The obvious correlation of these variations with locality suggests climatic influence as a factor in their causation, and as the form of the body does not change during adult life we must look for the factor in the environment of the nymph.

In an aquatic life like that of the nymph the most important climatic influence is probably that of temperature, although light may also be of some importance. During the winter the nymphs are obviously not influenced much by temperature as they cannot withstand freezing and therefore must live in water at $0^{\circ} \mathrm{C}$. wherever the ponds or streams in which they breed are frozen over throughout the winter; and this is the case throughout nearly all of the territory under consideration. Moreover there is probably no growth of the nymph during the winter as they apparently take no food at this time, at least in the later stages. That the winter temperature has nothing to do with the phenomena in question is also obvious when we compare the mean temperature of winter or of January, the coldest month, in the various localities where the individuals of a given species of Aeshna are similar in form. Thus of Ae. umbrosa specimens from Treesbank, Man., and Toronto, Ont., are nearly identical but differ considerably from Anticosti examples, although the mean January temperature of Anticosti is nearly midway between those of the other two localities: thus, Anticosti (eastern point), I I. $9^{\circ} \mathrm{F}$; ; Toronto, $22.9^{\circ} \mathrm{F}$; Treesbank (Winnipeg), $2.6^{\circ} \mathrm{F}^{2}{ }^{2}$

${ }^{1}$ No females of umbrosa from Manitoba have been seen.

${ }^{2}$ These and the following temperatures were kindly furnished by Mr. R. F. Stupart, Director of the Meteorological Observatory, Toronto. 
But if we compare the mean July temperatures, or better, those of the season of growth from May to September inclusive, we find a decided correlation between the variations in temperature and those exhibited by the insects, This may be illustrated by the following tables' ( 1 . = length, $d .=$ depth). (See also plate I.)

(I). Aeshna eremita.

\begin{tabular}{|c|c|c|c|c|c|c|}
\hline Locality. & $\begin{array}{c}\text { Mean } \\
\text { Temp. } \\
\text { May-Sep. }\end{array}$ & $\begin{array}{l}\text { No. of } \\
\text { Speci- } \\
\text { mens. }\end{array}$ & $\begin{array}{l}\text { 1. abd. } \\
\text { (mean) }\end{array}$ & $\begin{array}{c}\text { l. seg. } \\
3 \\
\text { (mean) }\end{array}$ & $\begin{array}{c}\text { d. seg. } \\
3 \\
\text { (mean) }\end{array}$ & $\begin{array}{c}1 . \\
\text { apps. } \\
\text { (meau) }\end{array}$ \\
\hline $\begin{array}{l}\text { Bay of Islands, Newfoundland } \\
\text { (Temp.St.George's Bay, Nfld.) }\end{array}$ & 54.3 & 2 & 7.3 & 7.3 & 4.35 & $\left(\begin{array}{l}(1) \\
\text { spec. })\end{array}\right.$ \\
\hline $\begin{array}{c}\text { Heyden, Algoma, Ont. } \\
\text { (Temp. Sault Ste. Marie, Ont.) }\end{array}$ & 56.4 & 3 & 8.31 & 8.31 & 3.19 & 6.51 \\
\hline Toronto, Ont. & 63.3 & 2 & 8.7 & 8.7 & 2.4 & 7.7 .5 \\
\hline
\end{tabular}

(2). Aeshna canadensis.

\begin{tabular}{c|c|c|c|c|c|c}
\hline Locality. & $\begin{array}{c}\text { Mean } \\
\text { Temp. } \\
\text { May-Sep. }\end{array}$ & $\begin{array}{c}\text { No. of } \\
\text { Speci- } \\
\text { mens. }\end{array}$ & $\begin{array}{c}\text { 1. abd. } \\
\text { (mean) }\end{array}$ & $\begin{array}{c}\text { 1. seg. } \\
3 \\
\text { (mean) }\end{array}$ & $\begin{array}{c}\text { d. seg. } \\
3 \\
\text { (mean) }\end{array}$ & $\begin{array}{c}\text { L. apps } \\
\text { (mean) }\end{array}$ \\
\hline $\begin{array}{c}\text { Grand Entry, Magdalen Is. } \\
\text { (Temp. Grindstone, Magd. Is.) }\end{array}$ & 53.8 & 2 & 45.5 & 6.92 & 4.5 & 4.2 \\
\hline $\begin{array}{c}\text { Nipigon, Ont. } \\
\text { (Temp. Port Arthur, Ont.) }\end{array}$ & 55.4 & 2 & 47.0 & 7.15 & 4.0 & 4.7 \\
\hline Ottawa, Ont. & 62.4 & 2 & 46.75 & 8.00 & 2.75 & 5.6 \\
\hline
\end{tabular}

(3). Aeshna umbrosa.

\begin{tabular}{|c|c|c|c|c|c|}
\hline Locality. & $\begin{array}{c}\text { Mean } \\
\text { Temp. } \\
\text { May-Sep. }\end{array}$ & $\begin{array}{l}\text { No. of } \\
\text { Speci- } \\
\text { mens. }\end{array}$ & 1. abd. & 1. seg. 3 & d. $\operatorname{seg} .3$ \\
\hline $\begin{array}{l}\text { Ellis Bay, Anticosti Id., } \\
\text { (Temp. East Point, Anticosti.) }\end{array}$ & 49.2 & 3 & $\left.\begin{array}{l}48.0 \\
48.5 \\
47.5\end{array}\right\} \begin{array}{l}\text { Av. } \\
48.0\end{array}$ & $\left.\begin{array}{l}7.33 \\
8.33 \\
8.25\end{array}\right\} \begin{array}{ll}\mathrm{Av} \\
7.97\end{array}$ & $\left.\begin{array}{l}2.0 \\
1.9 \\
2.9\end{array}\right\} \begin{array}{ll}\text { Av } \\
1.97\end{array}$ \\
\hline $\begin{array}{l}\text { Nipigon, Ont. } \\
\text { (Temp. Port Arthur, Ont.) }\end{array}$ & 55.4 & 3 & $\left.\begin{array}{l}50.0 \\
50.25 \\
51.0\end{array}\right\} \begin{array}{cc}50.75 \\
\end{array}$ & $\left.\begin{array}{l}9.2 \\
3.8 \\
8.9\end{array}\right\} 8.96$ & $\left.\begin{array}{ll}2.0 \\
1.8 \\
1.9\end{array}\right) \begin{array}{l}A v .9 \\
\end{array}$ \\
\hline $\begin{array}{l}\text { IVinnipeg Beach, Man. } \\
\text { (Temp. Winnipeg, Man.) }\end{array}$ & 59.2 & 2 & $\left.\begin{array}{l}51 . \\
50 .\end{array}\right\}_{50.75}^{A x}$ & $\begin{array}{l}9.0 \\
9.25\end{array}$ & $\left.\begin{array}{l}1.7 \\
1.9\end{array}\right\} \begin{array}{l}\text { Av. } \\
1.5\end{array}$ \\
\hline Toronto, Ont. & 63.3 & 3 & $\begin{array}{l}52.0 \\
51.0 \\
50.0\end{array}$ & $\begin{array}{l}9.7 \\
9.3 \\
9.0\end{array}$ Av. 9.33 & $\left.\begin{array}{l}1.75 \\
1.80 \\
1.75\end{array}\right\} \begin{array}{ll}A 1.7 \\
1.7\end{array}$ \\
\hline
\end{tabular}

${ }^{1}$ The tables are merely illustrative, my conclusions having been based upon the examination of a much larger series of specimens. 
Thus with an increase of the mean summer temperature there is an increase in the length and a decrease in the depth of segment 3 , and an increase in the length of the female appendages. Similar but slightervariations in some of the other abdominal segments posterior to segment 3 are demonstrable in some cases, but segments I and 2 seem to take little or no part in these modifications.

I am as yet unable to offer any suggestions as to the operation of this factor of temperature in the production of these variations.

(2). Colour variation of females-The females of all or nearly all the North American species of Aeshna are very variable in colour but the variations are all in one direction. A certain number of females of each species are coloured like the males in which, with very few exceptions, the abdomen is nearly black, spotted with blue. In a number of other females all the pale markings are yellow or yellowish green and the wings often flavescent. These two types may be known respectively as the homœochromatic and the heterochromatic types-terms employed by Calvert ('05) to designate similar colour phases in the females of Ischnura and other Coenagrionine genera. These two colour phases are, however, not sharply marked off from one another, but are connected by intermediate forms. Homœochromatic females are generally less common than the heterochromatic and intermediate forms, but the proportion varies in different species. In some species, e.g., Ae.canadensis, heterochromatic females are never pure yellow but always greenish; while in others, such as $A e$. constricta and californica, the extreme heterochromatic examples are yellow-spotted without a trace of green. This tendency to dimorphism is doubtless of the same kind as that which occurs in a more perfect form in Ischnura, Anomalagrion, etc. The so-called third form of female, met with in some species of these genera, is probably merely an intermediate between the other two forms.

(3). Geographical races-While some species of Aeshna of wide distribution are very uniform over their entire range 
of territory, others are more or less distinctly divisible into geographical races or subspecies. The characters which separate these races are altogether different from those whose variability depends on climate and hence also on geographical distribution, but are similar in kind to the specific characters of the genus. The species in which such races are best defined is Ae. interrupta, which ranges from Newfoundland and the northern New England States to Great Slave Lake, and the northwestern coast of British Columbia, and thence southwards to Nevada and New Mexico. It includes three dominant races, interrupta, which inhabit the wooded regions east of the Great Plains; lineata, the characteristic Aeshna of the Canadian prairies, found from the Dakotas to Great Slave Lake; and interna, a mountain form, ranging from the southern boundary of Alberta and British Columbia into New Mexico.

Lineata and interna intergrade in the southeastern Canadian Rockies; a form appears in northwestern British Columbia extremely like the eastern interrupta but approaching also the other two races; in Nevada another occurs (nevadensis), also approaching all three of the other forms, while in the Magdalen Islands, in the extreme east, the species takes on certain features of colour-pattern resembling those of the western races interna and nevadensis.

Ae. umbrosa is likewise divisible into an eastern race umbrosa and a western one, occidentalis, the latter approaching $A$ e. palmata, the characteristic western species of the same group, more closely than does the race umbrosa, while the latter in the Canadian Zone (in northern Ontario) approaches the race occidentalis. Ae. palmata itself varies considerably throughout its range and it would thus appear that the varied topography of the western half of the continent has reacted on the species of Aeshna as on many others groups of organisms with the production of many local races.

\section{General Life Mistory.}

Season of imaginal life-In Canada and the northern United States, the metropolis of the North American species of Aeshna, the imagoes of most species are abroad during 
the latter part of summer and in early autumn. July, August and September are the months when they are most abundant. Most of the species first appear in July, but $A e$. canadensis is generally on the wing before the end of June in the Transition Zone in Ontario, while Ae. californica, multicolor and mutata reach maturity still earlier, the two first named species appearing early in April. Most of the species have nearly disappeared by the beginning of October but Ae. umbrosa, and probably others such as Ae. constricta and Ae.verticalis, may linger on until the middle of the month, disappearing only after severe frost.

Length of imaginal life-As the majority of individuals of a given species in a given locality emerge within a period of about two weeks, the length of the imaginal life would appear to be at least a month, probably considerably longer in most cases. Reared specimens kept in captivity and unfed live only a few days and do not acquire their mature coloration.

Habitat-The imagoes are found, as a rule, most abundantly about their breeding grounds, but may of ten be seen foraging in large numbers more than half a mile away from any possible breeding-place. The majority of species breed in still shallow waters, thickly grown up with the smaller species of reeds, sedges, Sparganium, Acorus calamus L., Equisetum fuviatile L., and other plants of similar habit. Open marshes bordering rivers or at the mouths of sluggish streams, shallow reedy lakes, ponds or bays, are favourable localities for most of the species, and during the season of flight the imagoes may be seen foraging over these marshes, generally at a height of two to five feet above the vegetation and following as a rule, no regular course; though they may also be frequently seen flying low and following the water's edge, darting in and out of the washouts or little recesses between the clumps of reeds and rushes, on the lookout for their prey. Ae. umbrosa is an exception to all the other eastern species that I have observed in the field, in that it frequents small woodland streams and ditches, or small pools on the edges of woods, never being found associated with the other species in open marshes. The imagoes 
fly up and down such streams or pools keeping, as a rule, near the water, and when the streams are large, close to the margins.

Field notes made at Tenagami, Ontario, Sept. 14, 1908, on the species of Aeshna observed about a small lake between Lakes Wakimaka and Obabika, Temagami Forest Reserve :

This lake is an expansion of the Obabika Creek which connects the two lakes named above, and is broadly margined by an open marsh, behind which is a dense spruce forest. Just below the lake the creek is broad and passes for a short distance through the same kind of open marsh, thence entering the deep woods. On the west side is an area of several acres of marsh in the midst of which is a pond of some 300 square feet in area. It was about this pond and between the pond and the creek that the Aeshne were most abundant. The soil is a soft dark mud into which one would frequently sink to the knees, but, as a rule, owing to the abundant cover of horse-tails and sedge, one could obtain a fairly good footing. Muose-tracks were numerous about the margins of the creek and along the edge of the woods. The vegetation of the marsh consisted largely of Equisetum fluviatile L. with a few sedges and coarse grasses, and in a few places where the ground was a little higher, Myrica gale L. grew in abundance with tufts of Spiraea salicifolia L., Triadenum virginicum L. and a few grasses.

Four species of Aeshna, Ae. eremita, interrupta, canadensis and subarctica, were taken here, and the following additional species of Odonata: Lestes congener, L. disjunctus, Enallagma hageni, Somatochlora williamsoni, Sympetrum scoticum, costiferum, semicinctum and obtrusum. The Aeshno were very abundant but extremely difficult to capture. Ae. interrupta was the most abundant, Ae. canadensis coming next. Of Ae. eremita quite a number were seen but only two captured, while of Ae. subarctica only one was taken. They were flying back and forth following no definite course, though many would skirt the margin of the creek for some distance and then fly inwards over the marsh or across to the other side. They seemed to be similar in habits and character of flight. The males, which appeared to be in the great majority, were foraging and seemed to prey entirely upon a species of caddis-fly (Limnephilus indivisa Walk.)' which was very abundant among the horse-tails and sedge of the marsh. The male Aeshnce were flying rather low, 3-5 feet from the ground, and were constantly descending within a few inches of the water, making their way for some distance among the horse-tails on the lookout for caddis-flies. Their rustling could be heard at a distance of 6 or 7 yards. When two males came near one another they would dash off together up into the air but generally soon separated and continued their foraging.

Shortly after reaching maturity the imagoes may often be found in large numbers at some distance from their breeding-grounds, flying about the borders of woods or in openings in them, along wood-roads, etc. Some species, particularly Ae. canadensis, are especially attracted by open coniferous woods and are fond of settling on the trunks in the sunshine or hanging from twigs. Ae. umbrosa shows a marked preference for more or less shady haunts, while its near ally, Ae. constricta, is most of ten seen ranging over open fields or bushy pastures. Late in the season they return to their breeding-grounds.

'Determined by Mr. Nathan Banks. 
Influence of weather conditions - Although generally most active in bright sunny weather the species of Aeshna are influenced to a less degree than most Odonata by conditions of light. Most if not all of our species fly readily in dull warm weather and sometimes even during very light rains, while Aeshna umbrosa habitually flies till well after dusk. This habit, which is common among the Aeshninae, has also been observed by Mr. Williamson in the case of Ae. interrupta, eremita and canadensis.

According to Mr. C. H. Kennedy, the activity of certain species of Aeshna is decreased in intensely hot weather. In a letter to the writer he says of Ae. californica and multicolor, at Sunnyside, Washington: "Both californica and multicolor hang in the shade from the underside of leaves of trees on very hot days (when the thermometer rises to $100^{\circ}$ or $105^{\circ} \mathrm{F}$.). I have not noticed them resting on days when the temperature was less than $100 .^{\circ}$ These rests last for a few minutes only but occur at short intervals. It is only at such times that they are easily taken away from the water. One very hot afternoon for a few minutes I caught them, while hanging up, as fast as I could empty my net, and two only fifteen feet from the back door."

In Ontario, where the weather is very rarely as hot as described above, this habit must be attributed to some other cause. Indeed, it is on the warmest days that the Aeshnae are least likely to be seen resting, while in cool bright weather although they fly readily enough, they take very frequent and of ten prolonged rests, sometimes in the shade, sometimes in sheltered sunny places, the difference here being also probably a question of temperature. On the other hand on hot still days, when the thermometer is at $80^{\circ}$ or $90^{\circ} \mathrm{F}$. they are often very restless and almost ceaselessly on the wing. On July 22, I 910 , between 4 and 4.30 p.m. the writer observed Aeshnae flying in considerable numbers at De Grassi Point, Lake Simcoe, among the young bushy trees near the edge of a dense low wood bordering a large area of pasture land. The weather was very hot and still and the sun partly obscured by the smoke from forest fires. It was observed that Aeshnae kept in the small open places, a few square yards in 
area, which were well shaded by the surrounding trees. Generally speaking each of these small spaces was occupied by not more than a single Aeshna which flew around the space in a more or less regular course at a few feet from the ground, and was not readily frightened by my attempts to capture it, being driven away only when actually touched by the net. A number of specimens were captured, all except a single female Ae. constricta proving to be Ae. canadensis.

Similar flights of Aeshnae have on several other occasions come to my notice, as shown by the following extract from my note-book: "On August 28, 1909 (at De Grassi Point, Lake Simcoe), Aeshnae were observed in considerable numbers flying over the tennis lawn and garden, a few rods from the lake shore. The weather was cloudy but very hot and still and the Aeshnae were for the most part flying within a few feet from the ground, each confining its movements to a more or less definitely limited area or beat. There were apparently about fifteen or sixteen individuals flying about the tennis lawn alone and about half that number fiying over a small vegetable-garden about 20 square yards in area. The land surrounding the lawn and garden is covered with long grass, tall herbs, numerous bushes and young trees and the Aeshnae were flying here too, but it was noticeable that they preferred the more open places. They were hawking among the multitudes of Chironomidae that were abroad and were often observed to capture them. At 6.30 p.m. they were still numerous, but at 7.00 p.m. only one was seen, flying rather high. The following were captured: Ae. constricta, $3 \sigma^{\pi} ;$ Ae. canadensis, $2 \sigma^{\pi}, 3 \%$; Ae. umbrosa, I $9 . "$

A similar but smaller flight was observed about ten days before this one, about the same time of day, the weather being likewise still and rather warm, although the sky was clearer. As I was without a net only one was captured, a female constricta, but others were recognized as belonging to this species. The first flight of this kind that I remember was on a warm still afternoon in August i 906 . The insects were observed at the same locality, about 5 p.m. or a little later and it was estimated that about twenty-five Aeshnae 
were flying over the tennis-lawn at one time. A number were captured and all proved to be Ae. constricta.

Migrations-Brown ('9I) records a migratory swarm of dragonflies in Wisconsin, one of which was captured and determined as Aeshna eremita Scudd. This appears to be the only case on record of a North American species of this genus exhibiting the migratory trait, though Campbell ('85) described a similar swarm of the European Ae. mixta, which he observed flying along the banks of the Gironde in France. They were first noticed about five o'clock in the afternoon, and the swarm lasted from one and a half to one and threequarters hours. "The weather was fine and warm but the sky was clouded and rain had fallen during the day. There was little or no wind."

Seasonal variation in number of individuals-The number of individuals of some species of Aeshna varies greatly from year to year. The season of 1906 in the vicinity of Lake Simcoe was remarkable for the extraordinary abundance of Ae. constricta and Ae. canadensis, while in 1907 both of these species were comparatively scarce. Since then they have both been common enough, but not remarkably so, until the season of I9II, when very few individuals of either species were observed. Ae. verticalis is also inconstant in numbers, occasionally occurring in abundance. Ae. umbrosa, on the other hand, seems to be more or less common every year, but apparently never occurs in excessive numbers as in the case of the other species mentioned.

The relative scarcity of individuals during some seasons is not dependent upon the drying up of the waters in which they breed. Ae. umbrosa is the only species that would be at all likely to suffer from this cause, since its nymph often breeds in small pools and ditches, but it is the most constant in point of numbers of all the species whose habits are familiar to me. Possibly the irregularity of appearance is dependent upon parasites.

Food-The food of Aeshna consists of flying insects, generally of small size, especially Chironomidae and other Diptera, caddis-flies, small moths, etc. On Aug. 4, 1910, I observed a male $A$ e eremita at Nipigon, Ontario, flying about over a small clearing on the river shore with a grasshopper 
in its jaws. It was watched for three or four minutes, while it flew about the edge of the woods. The grasshopper was of about the size of Camnula pellucida and was probably this species, which positively swarmed on the clearing, to the exclusion of almost all other Orthoptera. I have also observed the nearly allied Basiaeschna janata feeding upon a somewhat teneral specimen of Gomphus spicatus, and in the U.S. National Museum collection there is a female specimen of Nasiaeschna pentacantha which was taken with a worn specimen of Papilio asterias in its clutches. The European Aeshnine Brachytron hafniense has been observed to feed upon Libelluline dragonflies.

A microscopic examination of the stomach contents of a female Ae. canadensis taken while foraging revealed only minute chitinous fragments of small Diptera and possibly of other insects.

Enemies-In the adult state Aeshna seems very well able to take care of itself and has but few enemies. The most critical periods of its life are doubtless the time of emergence from the nymph and while still teneral; and in the case of females, while they are engaged in oviposition.

Tenerals are doubtless of ten caught in spiders' webs, but no instance of the kind has come under my notice. On one occasion, however, I found a fully mature female of Aeshna tubcrculifera in the web of a spider (Argiope trifasciata Forsk.).1 This was on the banks of the Etobicoke Creek, near Toronto, on Sept. 30, r908. The web was in the grass on the steep slope of the bank about two feet from the water's edge, and the dragonfly whose thorax was partly eaten had evidently been recently killed as the colours were still fresh.

Doubtless tenerals also frequently fall victims to some of the larger insectivorous birds. Mir. R. P. Currie sent me a specimen of Coryphaeschna ingens and the male abdominal appendages of Epiaeschna heros, both from stomachs of the chuck-will's-widow. The latter species has also been recorded as having been captured by the king-bird (Tyrannus tyrannus) (Moore, 'oo).

Possibly the most serious enemy of the adult Aeshna

${ }^{1}$ Determined by Mr. Nathan Banks. 
is the frog, which no doubt destroys many ovipositing females. Mr. C. H. Kennedy suggests that the scarcity of females of some species of Aeshna, notably Ae. umbrosa and Ae. palmata, is due to this cause. In support of this belief he has sent me the following interesting observations on these species, made in the Blue Mountains, Oregon:

"Of Ae. umbrosa and Ae. palmata the females were a rarity, males were much more abundant. This was inexplicable to me until one day 1 saw a female umbrosa while ovipositing knocked into the water by a frog. Thestreams and ponds, particularly of the Blue Mountains, are almost swarming with a medium-sized frog. I examined the stomachs of several but found only grasshoppers and water-bugs. However, I felt certain that the abundance of frogs explained the paucity of female Aeshnas, because in both umbrosa and palmata, while the males are high wide fliers, the females nearly always fly less than a foot above the water and even lower when ovipositing.

"The above observations were made in Eagle Valley, all of which lies in the upper Sonoran and Transition Zones. Later when I collected in Pine Valley, which is a higher valley, I had my case against the frogs strengthened.

"The lower end of Pine Valley lies in the Transition Zone but the upper end is in the Canadian Zone. These frogs are not found in the Canadian Zone. They are peculiar to the sage-brush regions, ceasing abruptly at the lower edge of the timber. Only males of umbrosa were seen in the lower end of Pine Valley, where the frogs were abundant, while females were as abundant as the males up at Carson in the Canadian or timber zone, where there were no frogs."

I may add that in Ontario, also, the females of umbrosa are apparently much rarer than the males, though my experience in rearing the nymphs and collecting the exuviae shows that the two sexes enter the adult stage in about equal numbers.

In this connection $\mathrm{Mr}$. Kennedy also observes that the males and females of Ae. californica and multicolor in the Yakima Valley, Wash., occur in about equal numbers, and he attributes this fact to the entire absence of frogs in the 
ponds of this valley: "There are here a small ground-inhabiting tree frog and a small toad, neither of which resort to the water except for a short time in the spring to breed."

Mating habits-Pairing may take place at any time during the season of maturity. Mr. Kennedy has observed Ae. californica in coitu as early as May 8, and I have seen Ae. clepsydra paired at Go Home Bay, Georgian Bay, Ontario, before the end of July, and took a female Ae. canadensis ovipositing at the same locality on July I7, I907. August and early September are, however, the months in which pairing may be most frequently observed.

The pairing habits differ somewhat in the different species of Aeshna. Of the common species that I have observed, $A e$. constricta isconspicuous for its habit of pairing in open bushy places often some distance from water, for its wild nuptial flight and the tenacious grasp in which the male holds the female. When abundant it is very often seen in copula, while I do not recall a single occasion on which I have identified with certainty a pair of the still more abundant Ae. canadensis. Ae. verticalis I have also on several occasions taken paired a long way from its breeding haunts, but its habits appear to be more retiring than those of constricta and unlike the latter species the pairing individuals separate immediately when taken into the hand.

Mr. Kennedy writes: "While in copulation pairs of californica cling to bushes, not indulging as much in wild nuptial flights as multicolor, which species in copulation is not often seen hanging to bushes." It is probable that the highly differentiated male abdominal appendages of constricta and multicolor, and the unusually large genitalia of both sexes in constricta, are an adaptation to their active copulating habits, in which a firmer union between the two sexes is necessary than in such retiring species as Ae. verticalis and californica, the males of which have comparatively simple abdominal appendages.

In most species the males seize the females while ranging over the reeds and rushes which grow in their breeding places. Very frequently the females are picked up while ovipositing. If copulation ensues, the pair usually fly off 
to the nearest trees, of ten after circling about in the air a few times.

As might be expected from the close resemblance of the various species to one another, the uniformity of colourpattern and unspotted wings, together with the marked differences in the external genitalia and male abdominal appendages, there is no contest between the males for the females, nor are they apparently able to distinguish the females of their own species from those of other species of the genus. Pairing between different species is probably prevented by the mutual inadaptibility of the genitalia of the two sexes.

In the Temagami Forest Reserve, Ontario, the following notes were made on the pairing habits of the species of Aeshna observed there (the locality and date are the same as those quoted on p. 32):

"Now and then a buzzing of wings was heard in the reeds and a pair would emerge, flying off swiftly, sometimes making a bee-line for the neighbouring woods, sometimes circling about at first but always flying eventually to some sheltering bush or tree.

"Several times pairs were observed which were not in coitu, the male simply grasping the head of the female by the abdominal appendages. Some of these pairs were flying with the bodies of both sexes extended after the manner of the damsel-flies (Coenagrionidae), no attempt at copulation being made. In others the abdomen of the female was seen to curve upward frequently toward the male accessory genitalia but without establishing a connection.

"While some or all of these partial unions may have taken place between different species, two positive cases of this kind were observed. A male of $A e$. subarctica was taken with a female of Ae. canadepsis and a male of Ae. interrupta also with a female of canadensis. In the former case no union had been effected when the pair was captured though taken in the net at the same time. It was believed, however, that the male had taken hold of the female by the appendages. In the latter case a connection was apparently established for a few seconds between the genitalia of the female and the accessory genitalia of the male but the pair dropped to the ground and a scuffle ensued, during which they were captured.

"The only pair in coitu that was observed at close enough range to permit of recognition of the species was one of Ae. interrupta, which was followed some distance to the bushes at the edge of the wood and then approached very closely, though not captured."

In the first week of August, 1910, the writer observed a number of copulating pairs of Aeshna on the Nipigon River, where six species of the gerus are more or less common. Several pairs of evemita and interrupta were recognized but nothing of special interest observed except a series of three individuals connected in line and consisting apparently of two males and a female, the first male holding the head of the second, which in turn was grasping the head of th: female. I also saw two males making frantic efforts to secure a single female, but apparently not attempting to drive each other away. They were flying at a ccnsiderable height and the species was not recognized.

Copulatory position-In the paper by Williamson and Calvert, on "Copulation of Odonata" (Ent. News, XIII, I906, pp. I43-150) the former writer states that in copulating 
the male Aeshna grasps the female by the head, the inferior appendage resting on the top of the head, the superior appendages on the rear of the head. The plate accompanying this paper (pl. VII) is from a photograph of a pair of $A e$. umbrosa (referred to constricta) in coitu, and shows the general position of the two sexes in copulation, but the appendages of the male are no longer in contact with the head of the female, nor is the connection between the genitalia of the female and the accessory genitalia of the male exactly as it is in life. I have been fortunate in obtaining two pairs of Ae. constricta and one of Ae. clepsydra in all of which the natural position of the male appendages has been retained, and in one pair of constricta the connection between the genitalia of the two sexes has also been preserved. Both pairs of constricta which were taken at De Grassi Point, Lake Simcoe, Aug. 20 and Sept. 2, 1909, were carried in the hand over a quarter of a mile before the benzine necessary for killing them suddenly could be obtained. The pair photographed (pl. 2, fig. I) in which the natural position has been preserved in every detail was dried in an envelope over a coal oil lamp after being killed with benzine. The pair of Ae. clepsydra was taken at Go Home Bay, Georgian Bay, by Mr. W. J. Fraser, who immediately severed the abdomen of the male at the sixth segment, thus leaving the distal portion and the appendages adhering to the female.

An examination of the two pairs of constricta shows that Williamson's statement is correct as far as it goes, but that in addition to the head of the female being grasped by the superior and inferior appendages, of the male, the prothorax is held between the two superior appendages, the superointernal surfaces of the latter being applied to the lateral surfaces of the pronotum (pl. 2, figs. 3 and 4). The preapical spine of the superior appendages fits into the groove or space between the rear of the head and the cardo or basal joint of the maxilla, and the preapical tubercle, on the inner surface rests in a depression just under the lateral margin of the anterior lobe of the prothorax.

In $A$ e. clepsydra, (figs. 5 and 6) the position issimilar but the prothorax of the female is apparently less firmly grasped by 
the superior appendages of the male, which are much narrower and simpler in structure than in constricta. The pointed apices occupy the same position as the preapical spine of constricta, with which it is homologous. Probably the slightly elevated and denticulate apical portion of the superior carina corresponds in position to the tubercle in constricta, but this cannot be determined from the specimen.

The relative positions occupied by the accessory genitalia of the male and the genitalia of the female in $A e$. constricta are shown in plate 2, fig. 2. The ovipositor $(\mathrm{Ov})$ is unsheathed from the genital valves (GV) and lies for the most part in the genital fossa of the male (ventral side of seg. 2). In its basal half it is grasped by the posterior hamuli $(\mathrm{PH})$ and from its position and relation to the anterior hamuli $(\mathrm{AH})$ it must pass through the channel formed by the concavities of the hamular processes and folds, the two anterior hamuli thus forming a pair of claspers. The two parts of the anterior lamina are closely applied to the ventral surfaces of the genital valves and are turned somewhat inwards, the tips of the two spines ( $\mathrm{Sp}$ ) lying close to the concave margin of the ovipositor and possibly braced against the sides in life. The appendages of the female and the styli apparently take no part in copulation.

Comparison of copulatory position with that of other Odonata-Aeshna is the only genus of Anisoptera, so far as known, the male of which grasps the prothorax of the female during copulation, although many, if not all, of the other Aeshnine genera doubtless resemble Aeshna in this respect. In many of the Zygoptera, as Williamson has shown, the anterior surface of the hind lobe of the prothorax is grasped by the inferior appendages, but there is nothing comparable in the mechanism to that which obtains in Aeshna. Of the other subfamilies of Anisoptera, the head alone of the female is grasped by the male appendages in the Gomphinae and Libellulinae.

I have a pair of Gomphus spicatus taken at Go Home Bay, Georgian Bay, in July, I907, which well illustrates the method in the former group. This pair which was resting on the ground was captured by carefully placing the mouth 
of a large net over it. The position was observed and the pair was partially anaesthetized with chloroform and then placed in a cyanide bottle. Unfortunately in carrying them they came apart but the appendages of the male were easily replaced, for the large ventral tooth on each superior appendage had made a deep depression on the rear of the head of the female. It will be seen from the figure of this specimen (pl.2, fig. 7) that the superior appendages have no connection with the pronotum. The occiput of the female is held between the two pairs of appendages at their bases, while the curved apices on the forked inferior appendage are applied to the head between the frons and the frontal vesicle.

It will be noticed that in the Gomphinae and Libellulinae the upper surface of the superior appendages is smooth and rounded while the under surface is commonly provided with toothlike projections or denticles, while in the Aeshninae it is the upper (supero-internal) surface which shows the greater amount of structural differentiation. In the Cordulegasterinae, the general form of the male appendages resembles that of the Gomphinae and the superior pair probably also rests upon the rear of the head of the female during copulation.

The nearest approach to the Aeshnine method of clasping thus far known is that of Petalura gigantea which has been described by Tillyard ('o9). In this species the superointernal surface of the superior appendages of the male were applied to the shoulders of the female, while the inferior appendage is pressed down upon the occiput.

Oviposition-Females begin to oviposit soon after becoming fully mature and apparently continue to do so from time to time throughout the rest of their life. I have found Ae. canadensis, a species which does not of ten appear before the last week of June, ovipositing at Go Home Bay, Georgian Bay on July I 7, I907, and I have found the same species ovipositing at the end of August. Ovipositing females are most frequently seen in August and early September.

I have watched the process of oviposition at close range in the case of two species of Aeshna, Ae. eremita and Ae. constricta. The former was observed in a small reedy bay on the Nipigon River on Aug. 5, I910. The insect when first 
seen was clinging to the blade of a bur-reed (Sparganium) close to the surface of the water with about half the abdomen immersed (pl.3, fig. I). She was watched for about five minutes at the end of which she suddenly flew away. During this time the end of the abdomen was thrust against the stem every two or three seconds and was gradually lowered until wholly under water. Soon after this depth was reached she flew away.

I then examined the reed and found the punctures made by the ovipositor arranged as shown on pl.3, fig. 2. They were confined to the two narrow surfaces of the three-cornered reed and the great majority were on one surface. The uppermost were found about $1.5 \mathrm{~cm}$. above the surface of the water, the lowermost about $4^{\circ} \mathrm{cm}$. beneath the surface. It will be seen that they are not arranged in a double row as described by Needham ('or) for Basiaeschna janata, but tend to be grouped in oblique rows, although the arrangement is by no means regular. A few eggs lying near the edge of the reed were exposed by carefully picking away the tissues on one side of them. They were found to lie a little beneath the surface and very obliquely placed, occupying more nearly a vertical than a horizontal position (fig.3). The pointed anterior ends were in all cases outermost.

On the following day another ovipositing female of the same species was observed at still closer range, in fact I was almost directly above the insect while watching her. She was supported on a collection of dead floating reeds among a thick growth of living ones and was thrusting the ovipositor, seemingly at random, into any piece of reed within reach. She did not remain more than a minute or so, but the lever-like thrusts of the ovipositor could be seen distinctly when the abdomen was turned sideways. In making these thrusts the terminal abdominal segment served as the fulcrum (fig. I).

Many other individuals were seen ovipositing in the same way in both living and dead floating reeds and it appeared that in the latter case the thrusts of the insect were always irregular, as though the insect were not satisfied with the site for her operations. 
In the case of Aeshna constricta, which I observed ovipositing only once, though at close quarters, the female was seen to alight upon a sweet-flag (Acorus calamus L.) growing at the edge of a broad sluggish creek near De Grassi Point, Lake Simcoe, Although about two and one-half feet above the water she at once began to oviposit, curving her abdomen and using her large ovipositor apparently in the same way as Ae. eremita but spending a longer time, four or five seconds, over the deposition of each egg. Instead of lowering the abdomen during the operation, she gradually climbed upwards and seemed little disturbed by the very strong breeze that was blowing. When she had climbed about six inches and was not far from the end of the flag she flew away.

On first examining the seat of her operations I could find nothing to show that she had been there, but on a closer inspection longitudinal slits in the epidermis were found along the whole path of the operations. These were each a few millimetres long, the length varying considerably, and arranged somewhat irregularly in two rows (pl. 3, fig.5). An egg was placed longitudinally under each incision, the anterior end upward. They lay rather loosely in the slit in the parenchyma. The flag was taken home and the lower end placed in a jar of water but it gradually withered and the eggs did not hatch that season and were finally destroyed by an accident.

Although the slits did not open with the drying of the flag it is probable that they do so under natural conditions and thus allow the eggs to drop in to the water before hatching. The unusually large size of the ovipositor in Ae. constricta seems to be related to the practice of making elongate incisions instead of mere punctures in the tissues of the plants. This method of ovipositing high above the surface of the water is unique as far as I know among the Anisoptera but has been described by Needham ('oo) in the case of the Zygopterous species, Lestes unguiculatus, and L. uncatus.

A number of other species of Aeshna were also séen ovipositing, viz., Ae. juncea, subarctica, interrupta, canadensis and umbrosa, and the process was in general the same as that 
of Ae. eremita, as nearly as could be judged, but although reeds or reed-like plants are usually chosen by the female for this purpose it is no invariable rule. Thus Ae. canadensis usually oviposits in the ordinary way in aquatic plants but I have seen it at Grenadier Pond, Toronto, performing this function on the side of an alga-covered log, just below the water-line. The eggs were apparently distributed quite irregularly. I have also observed the same species apparently utilizing for this purpose the fine wet sand on the shore of Obabika Lake, near the mouth of Obabika Creek, Temagami District, Ontario. There is a stretch of open marsh here covered largely with Equisetum and coarse sedges, which, earlier in the season had evidently been under water for some distance back from the shore and the sand, especially within a few yards of the water's edge, was beaten hard by the waves. It was this fine wet sand some yards back from the water-line into which the dragonfly was thrusting her abdomen, as though in the act of ovipositing.

A similar act was also observed in the case of $A e . u m$ brosa, a female of which was observed ovipositing in the mud of a partly dried up bed of a short creek connecting Lakes Temagami and Obabika. Although pools of water were near at hand the insect chose the wet mud of the streambed, clinging to the base of a sedge-stalk and thrusting the end of the abdomen into the mud in the direction of the stem and moving it irregularly to right and left but apparently not touching the stem with the ovipositor. While the female was thus engaged, a male swooped down upon her and the pair were thus captured.

Miss Wadsworth sent me a female of this species which she observed ovipositing on the nearly dead trunk of an alder shrub in the middle of a stream. She observed the insect light on the trunk and "press the eggs into the wet bark of the alder. Some were placed about half an inch from the water line and from there down to the water line, and a very few just below. A male soon came to her and as they flew I got the net over both but the male escaped."

Sometimes a female Aeshna may be seen tapping the apices of the genital valves against a rock or other hard 
substance, apparently adjusting their position in relation to the ovipositor. I have observed this performance in the case of two species, Ae. umbrosa and Ae. eremita.

While ovipositing the female Aeshna is never accompanied by the male as sometimes occurs in the case of Anax junius.

The egg-The eggs of Aeshna (pl.3, figs. 4 and 6) are elongate, smooth, cylindrical, rounded at the posterior and pointed at the anterior end. They are pale yellow when first deposited but may darken considerably before the nymph is hatched (Ae. eremita). The size and exact form of the mature egg varies according to the species, e.g., in Ae. eremita they are $1.7-1.8 \mathrm{~mm}$. long and about five times as long as broad; in Ae. constricta they are about the same size and general form but are somewhat less acute at the anterior end; in Ae. canadensis they are about 1.6-1.66 mm. long, and slightly more acute than in eremita; while in Ae. sitchensis the length is only about I.I mm., the breadth proportionately somewhat greater than in the other species, and the anterior ends but little pointed.

The ovaries of a female Ae. umbrosa, taken at Lake Simcoe on Aug. 29, 1909, were found to contain 839 eggs, nearly all of which were full-grown.

Probable number of nymphal stages-With a sufficiency of material it is not a difficult matter to determine the number of stages in the nymphal life after the wing-buds have begun to appear, as with each ecdysis there is a very definite increase in the relative size of these organs. Of the stages preceding the first appearance of the wing-buds I have no knowledge.

The material I have obtained by collecting nymphs of Aeshna canadensis and Ae. umbrosa is sufficient for the determination of the number of ecdyses that the nymph goes through after attaining a length of about $I \mathrm{~cm}$. The results thus obtained were partially confirmed by rearing nymphs of various sizes through several ecdyses and comparing the exuviae with the collected material. Nymphs of various sizes of Ae. eremita, interrupta, juncea, californica and mul- 
ticolor, as well as the two species previously mentioned can in all cases be referred to a particular stage.

The earliest stage represented in the material at hand is a nýmph of Ae.canadensis, measuring $10.5 \mathrm{~mm}$. in length. The wing-cases are barely indicated by a pair of minute buds and the antennæ are five-jointed. Beginning with this stage the nymph apparently moults eight times before emerging as the adult insect, there being eight instars including the fullgrown nymph. Judging by the size of the egg and the relative sizes of the known instars it appears probable that there are three or four ecdyses in addition to those observed, making a probable total of twelve or thirteen stages. This would make the number about the same as in the Agrionidae, according to Balfour-Browne ('09), who found I0-I 4 stages in various British species, the number varying considerably among individuals of the same species. It is possible that the number varies also in Aeshna but I am inclined to believe that the number of stages in a given species is constant.

Changes at the various ecdyses-As I have not been able to determine the number of stages with certainty I have designated the various known ones as $A, B, C, \ldots H$, stage $H$ being the mature nymph. Owing to lack of material in the earlier stages I shall not describe in detail the changes which appear in the nymph at each ecdysis. I shall do little more than indicate some of the external characters by which each instar may be recognized. The younger instars among those represented in the material at hand differ from the mature nymph chiefly in the somewhat greater relative size of the eyes, which are less prolonged mesad, the smoother surface of the interocular region, the relative lengths of the antennal segments, the shorter and somewhat narrower thorax, and, of course, the smaller genitalia and shorter wing-cases, when these are present. The colour changes also with the growth, the younger instars being darker than the older ones. Instars $\mathrm{A}$ and $\mathrm{B}$ of Ae. canadensis and umbrosa, C, D and sometimes $\mathrm{E}$ of $A e$. constricta are nearly black, except for a short time after each month, but in the succeeding stages the colours of the full-grown nymph are rapidly assumed.

Stage A. Antennæ 5-jointed, terminal joint very long, 
wing-cases very minute buds, probably appearing for the first time at this stage.

Stage B. Antennæ 6-jointed, terminal joint long, wing-cases still small and tubercle-like (pl. 4, fig. I).

Stage C. Antennæ 7-jointed, the terminal joint of preceding stage having divided into two. Wing-cases in the form of small triangular flaps, the posterior pair reaching back about as far as the posterior margin of the metathorax (fig. 2).

Stage D. Antennæ 7-jointed, wing-cases still widely separated mesially, the hind pair extending to about the middle of seg. I of the abdomen, their front margins meeting the hind margins of the front pair but not overlapping the latter (fig. 3).

Stage E. Front wing-cases though still separated mesially are much more closely approximated and their hind margins are overlapped by the hind pair, which reaches about as far back as the apical margin of seg. I (fig. 4).

Stage $F$. Front wing-cases attingent and about half covered by the hind pair, which reaches nearly to the apical margin of seg. 2 , or to the middle of seg. 3 , and a little beyond the middle of the hind femora (fig. 5).

Stage G. Hind wing-cases reaching the base or apical margin of seg. 3 and nearly to the ends of the hind femora (fig. 6).

Stage $H$ (full-grown). Hind wing-cases generally reach as far back as the middle or apical margin of seg. 4 and extend a little beyond the ends of the hind femora (pls. 5 and 6).

The above characters are based chiefly on the nymphs of $A e$. umbrosa and Ae. canadensis but they apply equally well to those of all the other species seen except Ae. constricta. Two nymphs of this species apparently belonging to stage $D$, but with slightly longer wing-cases than is characteristic of that stage in other species were found in a creek near De Grassi Point, Lake Simcoe, in early July, 1910. After the next moult which occurred about a week later the nymphs were intermediate in wing-length between stages 9 and 10 , and after another moult, in August, they had all the appear- 
ance of full-grown nymphs, except that they were a little below normal size for full-grown nymphs of this species. One of them died just after the moult, but the other lived until Dec. 24, when it died apparently from a too rapid change of temperature in the aquarium. The genitalia in this specimen, which is a female, are fully developed, extending beyond the apical margin of segment 10 , and the wing-cases reach a considerable distance beyond the apices of the hind femora. I am unable to say at present whether these peculiarities are characteristic of this species or were the result of abnormal conditions under which the nymphs were reared.

Length of nymphal life-Our knowledge of the nymphal life of Aeshna is not sufficient to warrant a positive statement as to its length, which indeed is not necessarily the same in all species, nor in every locality. It is, however, exceedingly probable that in southern Canada and the northern United States three years is the normal length of life of Ae. canadensis and Ae. umbrosa, if not of all the species found there.

It seems to be a general rule that stage $F$ is entered upon about a year before the imago emerges. Of thirtyseven nymphs of Ae. multicolor collected by Mr. C. H. Kennedy at Sunnyside, Wash., in May, about the time when the imagoes were emerging, eleven were mature, twenty-four belonged to stage $\mathrm{F}$ and two to stage $\mathrm{E}$. As the imagoes all emerge within a period of a few weeks the nymphs belonging to the latter two stages certainly remain over until the following year. Stage $\mathrm{F}$ of $A e$. canadensis is the oldest stage that I have found in late summer after the time of emergence of this species and I have never found it in the early half of the season. I succeeded in rearing one individual taken during this stage. It moulted in the fall and became mature in the spring (the dates were lost), emerging on June 25. Six nymphs of this species taken at Go Home Bay, Ontario, on Aug. 14, 1908, all belong to this stage, while of six others taken on July 29, at nearly the same locality, four belonged to stage $\mathrm{D}$ and two to stage $\mathrm{E}$. Six nymphs of Ae. canadensis taken at De Grassi Point on Sept. 6, I9 Io, belong to stage $C$. Two of these soon moulted but all entered 
the winter either as stage $C$ or D. Finally I have taken stages A and B on July 27,1910 , and one example of stage C on July $3 \mathbf{I}$.

These facts seem to show that stages $E$ and $F$ and of ten $D$ are passed through during the season before that in which the imago emerges, and that $\mathrm{A}, \mathrm{B}$ and $\mathrm{C}$ belong to a still earlier season. The remaining early stages doubtless belong to the early part of the same season, as I have never been able to find any trace of them in the summer and autumn, in which practically all my nymph-collecting has been done. Thus it seems very probable that in Ae. canadensis the imago appears in the third season after the egg is deposited. This conclusion is, of course, open to doubt, and is offered merely as a basis for future work. And even if true in the case of canadensis it is not necessarily so for other species, as the following observations seem to indicate. On Aug. 8, I9Io, I took ten nymphs of Ae. eremita from a marsh on the Nipigon River, Ontario. At this time the imagoes were flying in numbers, the great majority fully mature and some worn, though a few tenerals were still to be seen. Of these nymphs two were mature, three belonged to stage $F$, two to stage $E$. and three to stage $\mathrm{B}$. The mature nymphs were taken home alive and I expected them to emerge within a fortnight at the latest, but they did not do so that season and are still alive at the time of writing, Jan. 25, I9II. Thus it is possible that an additional year is required by this species to complete its life-history, at least in the northern locality where these nymphs were found.

Habitat of nymph-Although fresh water is probably the normal habitat of the nymphs of all the North American species of Aeshna, Ae. californica has been found in brackish water at Victoria, B.C. (Osburn '06), and Mr. C. H. Kennedy has taken the adults of Ae. interrupta interna and Ae. palmata at an alkaline slough near Baker City, Oregon, where it is possible they were bred.

Nymphs of Aeshna are unable to withstand freezing even for a short time and are killed by rapid changes in the temperature of the water. On July 29, I908, I found a number of young nymphs of Ae. canadensis (stages D and $\mathrm{E}$ ) in a 
very shallow pond with a sandy bottom. The water over many square yards was not more than about three inches deep and had been heated by the sun to such a degree that it was almost uncomfortable to step into it with bare feet. The temperature must have been at least $38^{\circ} \mathrm{C}$. Nymphs of Ischnura verticalis Say and Nehallennia irene Hagen were also common here and all were quite as active as usual. I brought a number of the Aeshna nymphs to the laboratory and left them overnight in a jar of water, but all were dead the next morning.

The nymphs of Aeshna and the Aeshninae in general are climbers, living among reeds and rushes in still waters usually a few inches to one-and-one-half feet deep. Still weedy waters with a soft muddy bottom grown up with reeds, bur-reeds (Sparganium), sweet-flag (Acorus), horsetails (Equisetum), coarses edges, etc., with an abundance of true aquatic plants, such as water-milfoil and pondweed, and of aquatic life in general, offer the best conditions for their existence. Reed beds growing in water that is subject to any considerable wave-action may be searched in vain for any species of this genus, nor have any North American species been found in rapid streams where the allied genus Boyeria sometimes occurs. Only one species of Aeshna, Ae. umorosa, has been found in shady woodland streams free from all reeds or reed-like plants, although this species seems to prefer a certain quantity of such growth. It never occurs in the open reed-like beds frequented by the majority of the species of this genus.

Habits of nymph - The nymphs cling to the reeds, lying in wait for their prey. In captivity they are usually almost motionless, except when attracted by some moving object. Some nymphs of Aeshna which I kept in glass jars placed upon a window sill overlooking a lawn were often attracted by white clothes hanging from a clothes-line, when moved by the wind. They usually rest with the head downwards and in insufficiently aerated aquaria the tip of the abdomen is kept at the surface with the valves open. The opposite position is, however, of ten assumed, particularly when the time for emergence is near at hand. Nymphs 
of Ae. cyanea, which I found in abundance in small pools at Tübingen, Württembury, and Wiesen, Bohemia, were more frequently seen resting upon the bottom with the abdomen tilted slightly upwards than clinging to the reeds, though this is also a common habit. They were quite often observed to swim short distances with their characteristic straight jerky movements. While swimming all three pairs of legs are directed backwards, close to the body.

The food of the nymph of Aeshna is similar to that of other large Odonate nymphs. Tadpoles, nymphs of smaller dragonflies, such as Leucorrhinia, Sympetrum, Lestes, or the smaller nymphs of their own species, nymphs of mayflies, Notonecta, larvae of aquatic beetles, crustaceans such as Gammarus and Asellus, leeches, etc. According to Needham ('o3a) the nymphs of Ae. constricta (=Ae. umbrosa) will eat young brook-trout as long as themselves. This was demonstrated by confining them together in a breeding-cage. The trout disappeared one by one until all had been eaten.

In aquaria I have found small earthworms convenient for feeding the older nymphs. The larger earthworms are avoided by Aeshna. Leeches are still better, where they are easily obtained, as they remain alive a long time in the aquarium. A leech, however, will of ten succeed in slipping away from the nymph after the latter has apparently succeeded in obtaining a firm hold of his prey. I have also fed Aeshna nymphs on flies, water-snails removed from their shells and suspended upon a thread in front of the insects, and on the larvae of the larch saw-fly (Nematus erichsonii), which has at times proved very convenient on account of its abundance. I tried also the larvae of Leconte's saw-fly (Lophyrus lecontei) which occurred in large numbers on young white pines at De Grassi Point, but although seized by the nymph they were at once rejected. Probably the strong odour of turpentine which they give forth when crushed was disagreeable.

In the words of Professor Needham, "the Aeshna nymph approaches its prey with the slowness and poise and stealth of a cat till within striking distance." Those who have watched these insects in captivity will at once recognize the aptness of this comparison. 
Considerable difference may be observed between different species of Aeshna in the boldness and voracity of their nymphs. Those of the cyanea group are distinctly less shy than those of the clepsydra group that I have observed. None of our species as far as I know is as voracious as $A e$. cyanea which I reared in Germany, though Ae. umbrosa is very like it both in appearance and habits. Ae. cyanea would seize almost any object thrust into the water in the breeding-jar, such as a twig or even one's finger and would attack earthworms of a size that would certainly be shunned by Ae. umbrosa. According to Stefanelli ('82) this European species sometimes comes out of the water at night and devours the newly emerged imagoes of its own species. Williamson has observed a nymph of Ae. constricta (umbrosa?) kill and partly consume within an hour seven toad tadpoles measuring about $13 \mathrm{~mm}$. in length. I have seen one feeding upon an earthworm for over half an hour. The younger nymphs are eaten readily by the older nymphs of the same or other species of Aeshna or by other large Aeshnine nymphs, such as Anax junius. According to Needham (loc.cit.) nymphs of $A$ e. umbrosa are eaten by brook-trout.

Symbiosis of nymph and green alga-Kammerer ('07) has described an interesting case of symbiosis between the nymph of Aeshna cyanea and the green alga Oedogonium undulatum (Alex. Braun). The nymphs were all found in a small pool near St. Margaretenbad, Bohemia, which had been used for a number of years by the washerwomen of the neighbourhood. All the nymphs of Ae. cyanea in the pool supported a growth of the alga, while none of those found in neighbouring pools not disturbed by the washerwomen were thus affected. A series of experiments showed conclusively that the association was a true case of symbiosis and that the alga-covered nymphs unlike those not associated with the plant were able to live in water strongly contaminated with various impurities, such as soap, their own excreta, etc., by reason of the more abundant supply of oxygen provided by the algae. They were also more resistant towards certain ectoparasites, such as Saprolegnia, which cannot live in an 
atmosphere rich in oxygen. Thirdly, the growth of algae serves to hide the nymph from its enemies.

On the other hand the alga has the benefit of free transport from place to place, which favours the processes of assimilation, and is able to obtain a richer food-supply from the fecal matter of the nymph and the mud, in which it frequently burrows. The author also suggests that the spines and sharp corners of the chitinous sclerites of the nymph offer favourable points of attachment for the alga and that the latter is protected from many animals which ordinarily feed upon its filaments.

It was also shown by experiments that the association between these two species could be brought about artificially, using individuals originally free-living and independent of one another, but that, with the exception of a temporary attachment to the cyanea nymph of the alga Oedogonium capillare no similar connections could be established between other aquatic larvae and algae. Anax and Libellula nymphs, for example, were refused as hosts by Oedogonium undulatum.

No similar associations have been recorded from among North American Odonata and it is somewhat improbable that they will be found under such circumstances as those attending the case described by Kammerer.

Emergence of the imago-For a week or more prior to the time of emergence the nymph is sluggish and takes no food, and a few days before this event takes place certain changes in its appearance are noticeable. The eyes of the developing imago can be distinctly seen through the integument of the head, nearly meeting at the middle line and extending farther back than those of the nymph. As the time for transformation approaches, the eyes become mesially attingent and the hind margins move backwards until they nearly reach the hind margin of the head. While these changes are taking place the labium is acquiring the form which it assumes in the imago and becomes entirely withdrawn from the larval cuticle, which appears quite empty shortly before the imago begins to emerge. During the last few days before emergence the nymph rests at the surface of the water with the head partly exposed. 
Judging from the very few occasions on which I have observed the emergence of Aeshna or the freshly transformed imagoes, it would seem that this process usually takes place late in the afternoon or in the evening. On August I5, 1908, I witnessed the entire process in the case of Ae. canadensis, a nymph of which I had been keeping in a breeding-jar in my room at De Grassi Point. At Io p.m. I found that the nymph had crawled up a reed which had been placed for the purpose in the jar. It was clinging to the reed with the body in a vertical position (pl. 5, fig. I). It remained almost motionless for nearly ten minutes and then began to execute slight jerky movements of the abdomen and lifting movements of the wing-pads. These were accompanied by a bulging of the thorax and head, the integument of which almost immediately split in the usual way, i.e., in an arc across the eyes, along the mid-dorsal line of the back part of the head and thorax to the bases of the wing-cases, and along the upper edges of the thoracic pleura. In five minutes from the time when the abdominal movements commenced the head was free, and immediately afterwards the first pair of legs, followed rapidly by the second pair, these movements being accompanied by a backward curving of the body. The extraction of the wings and then the third pair of legs followed in less than a minute and at I0.I6 p.m. the imago was hanging back in the position shown in fig. 5 , the accessory genitalia plainly exposed and projecting, and only the last four abdominal segments not yet free. In this position the insect rested almost motionless for eleven minutes, the only noticeable change during this time being the very slight elongation of the wings. Then the legs began to move irregularly and at intervals but the position remained the same for seven minutes longer. At I0.34 p.m. there was a sudden convulsive movement of the whole abdomen and slight movements of the legs, and ten minutes later the insect suddenly bent forward, grasped the anterior part of the exuvia with the legs and quickly withdrew the rest of the abdomen (figs. 6 and 7). The abdomen now measured $32 \mathrm{~mm}$. and the wings $10 \mathrm{~mm}$. The colour was pale greenish grey, the lateral thoracic bands faintly distinguishable. In the next twelve minutes the 
wings became fully expanded but the abdomen remained very little longer than before (fig. 8). Bobbing movements of the abdomen ensued, followed by a gradual clearing of the wings. Rhythmical up-and-down movements of the whole body and irregular telescopic movements of the abdomen were next observed. At II.30 the abdomen had not quite reached its full length and was still stout. The colour was practically unchanged.

Exuviae of Aeshna nymphs are, as a rule, difficult to find. As most of our species transform on reeds or other plants growing closely together in shallow waters they are not at all conspicuous and are very easily overlooked. They should be sought during the period of emergence, or soon afterwards, for they are soon blown into the water by the wind. They are generally found clinging to reeds a few inches above the water. Exuviae of Ae. umbrosa are sometimes found on stumps or logs at the water's edge.

\section{The North American Species of Aeshna.}

\section{General Characteristics.}

Although the number of described North American species of Aeshna is somewhat greater than that of the Palæarctic species, the latter are more diversified in size, structure and colour-pattern and represent a larger number of groups. All of the North American groups except those of californica and multicolor occur also in the Palæarctic region, where in addition to these the groups of grandis, ${ }^{1}$ mixta, ${ }^{2}$ isoceles $^{3}$ and melanictera ${ }^{4}$ are represented. The North American species are remarkably uniform in size, form and coloration, the males of nearly all the species having the abdomen brownish black, spotted with blue, no such variety of colour-pattern occurring as in the Palæarctic species grandis, viridis, isoceles, melanictera and cyanea.

In both regions the greater number of species inhabit the cooler parts of the temperate zone and among these are

I Including Ae. grandis L. and Ae. viridis Eversm.

Including Ae. mixta Latr. and Ae. affinis van der Linden.

Including Ae. isoceles Müller and Ae. martini Selys, and possibly others.

- Including this species alone (?) 
some of the most characteristic dragonflies of the subarctic and arctic regions. A number of the North American species, including two groups, are entirely restricted to the boreal region, where they are a dominant group, both in species and individuals.

\section{Key to the North American Species of Aeshna.}

I. Males.

A. Anal triangle 2-celled; spines of anterior lamina directed ventrad.

B. Line of contact of the eyes little or no longer than the occiput; lateral thoracic bands less than $1 \mathrm{~mm}$. broad, the first band sigmoid or bent twice at alternate angles; hamular processes large, broad and elevated behind, acute in front, their inner margins straight and attingent or approximated; hamular folds small, more or less concealed by the hamular processes with which they are connected by a low ridge..... (caerulea group). C. Preocular band not produced forward on each side behind the T-spot; distance from hind margin of occiput to frontal vesicle less than $2 \mathrm{~mm}$.; spines of anterior lamina not longer than the hamular process, stout, straight, bluntly pointed; MD large, irregular or subquadrate. .................. ....................erulea septentrionalis Burm. CC. Preocular band produced forward on each side of the stem of the T-spot; distance from hind margin of occiput to frontal vesicle about $2.5 \mathrm{~mm}$.; spines of anterior lamina longer than the hamular process, curved ventrad and tapering to a slender point; $\mathrm{MD}$ of ordinary size, triangular... sitchensis $\mathrm{Hag}$. BB. Line of contact of eyes distinctly longer than the occiput; lateral thoracic band generally more than $\mathrm{I} \mathbf{m m}$. broad, when narrower never sigmoid; hamular processes never with straight closely approximated inner margins; hamular folds (except in Ae. subarctica) not at all concealed by the hamular processes.

D. Hamular processes long and slender, separated from the hamular folds, which are more or less reduced; spines of anterior lamina very long, tapering to a fine 
point; superior appendages more or less acute at apices, the superior carina not denticulated; a black band on the fronto-nasal suture............. (juncea group).

E. Lateral thoracic bands broad, the margins straight; spines of anterior lamina curved ventrad; apices of hamular processes acute and somewhat hooked; hamular folds plainly visible in a perpendicular view...................juncea $\mathrm{L}$. EE. Lateral thoracic bands broadly excavated in front, the first one narrowed and slightly bent a little above the middle; spines of anterior lamina straight, very slender; hamular processes rounded at apices, almost concealing the small hamular folds in a perpendicular view......... subarctica Walk. DD. Hamular processes short, continuous with the hamular folds, which are well developed; spines of anterior lamina short and straight... (clepsydra group).

F. Superior appendages without a prominent basal inferior tubercle; seg. 10 with a pair of pale dorsal spots (PD) which are sometimes confluent.

G. Dorsal thoracic bands reduced to a pair of small isolated spots (often absent in dried specimens); lateral thoracic bands reduced, either narrow and nearly straight or divided into an upper and lower spot. M ra arising normally beyond middle of pterostigma; spines of anterior lamina very short and blunt; superior carina of superior appendages generally with a few small denticles; a black line on the fronto-nasal suture...... interrupta Walk. GG. Dorsal thoracic bands complete, expanded at their upper ends; lateral thoracic bands broad, more or less excavated or sinuate in front; Mra arising normally before the middle of the pterostigma.

H. Superior appendages with a low sub-basal inferior prominence, expanding almost symmetrically from the base, the inner margins in dorsal view not sinuate; apices rounded, normally without a terminal spine and not at 
all decurved; superior carina rather strongly elevated apically, where it bears 6 or 8 wellmarked denticles; a black line on the frontonasal suture (sometimes absent in arctic specimens); first lateral thoracic band strongly constricted about the middle by the deep excavation of the front margin............. ....................... eremita Scudd.

HH. Superior appendages expanding unsymmetrically from the base, their inner margins sinuate in dorsal view; apices acute with a terminal spine; superior carina moderately or but little elevated apically.

I. A black line on the fronto-nasal suture; a large pale triangular spot immediately in front of the humeral suture below ; lateral thoracic bands very broad, the upper end of the first band narrowed and bent cephalad; pale spots between the bands very large, occupying the greater part of the space between them; outer margin of the superior appendages in lateral view very slightly elevated apically, with 3-5 small denticles............ clepsydra Say. II. No black line on the fronto-nasal suture; no triangular spot in front of humeral suture below ; first lateral thoracic band bent caudad at the upper end ; spots between the lateral bands, when present, small; outer margin of superior appendages in lateral view more or less upcurved, apices decurved; superior carina moderately elevated apically.

J. Lateral thoracic bands blue or green, the first generally green below, blue above, its anterior margin almost rectangularly sinuate; superior carina of superior appendages with a few denticles, apices rather abruptly decurved; ham- 
ular processes rather long, directed cephalad, subparallel, the apices convergent; PL typically represented on abd. segs. 2-6.............canadensis Walk. JJ. Lateral thoracic bands yellowish green, the anterior margin of the first band obtusangularly sinuate; superior carina of the superior appendages not denticulated; apices usually gently decurved; hamular processes directed mesad and ventrad, each consisting of a stout proximal and a slender distal part; PL typically represented on abd. segs. 2-4. ................ verticalis Hag.

FF. Superior appendages with a prominent inferior basal tubercle; superior carina moderately elevated apically, not denticulated; apices rounded with a small projecting spine, not decurved ; lateral thoracic bands broad, not excavated in front; abd. seg. Io wholly black...............tuberculifera Walk.

AA. Anal triangle 3 -celled; spines of anterior lamina curved dorsad.

K. Abd. seg. I without a distinct ventral tubercle; dorsum of seg. Io smooth; superior appendages without a well-developed superior carina but with an anteapical internal hairy tubercle and an anteapical inferior spine; apices broadly rounded............. (cyanea group).

L. A black line (rarely a fine brown line) on the frontonasal suture; dorsal thoracic bands I $\mathrm{mm}$. or less broad, tapering somewhat towards each end or sometimes suddenly expanded at the posterior end; lateral thoracic bands nearly straight and equal; a distinct greenish yellow lateral spot on seg. I ; lateral carinae of seg. 7 in ventral view, slightly or not at all sinuate; venter of abdomen and rear of head wholly black; generally one cell between $\mathrm{A}_{2}$ and $\mathrm{A}_{3}$ at their origin. palmata Hag. LL. Without a black line on the fronto-nasal suture; 
dorsal thoracic bands rapidly widened caudad so as to be triangular in form with the base just in front of the antealar sinus; generally two cells between A2 and $\mathrm{A}_{3}$ at their origin.

M. Rear of head in part fuscous; lateral thoracic bands rather narrow (I $\mathrm{mm}$.) ; straight, not widening above the middle, surrounded by a dark margin; a pair of large pale basal spots on the ventral surfaces of segs. 4, 5 and 6; lateral carina of seg. 7 , viewed ventrad, strongly sinuate in its anterior two-fifths. ..........................umbrosa Walk.

MM. Rear of head wholly black; lateral thoracic bands broader, not surrounded by a dark margin, widening above the middle, margins of first band, especially the anterior, sinuate; venter of abdomen without pale spots; lateral carinae of seg. 7 , viewed ventrad, at most feebly sinuate..... constricta Say.

KK. Abd. seg. I with a distinct spinulose ventral tubercle; dorsum of seg. Io with median and submedian tooth-like elevations; superior appendages with a welldeveloped superior carina.

N. A black line on the fronto-nasal suture; superior appendages without an anteapical inferior spine, the apices obtusangulate or rounded, superior carina not angulate or denticulate; inferior appendage somewhat less than half as long as the superior pair. ......................... californica Calv. NN. No black line on the fronto-nasal suture; superior appendages with an anteapical inferior spine, the apices acute and decurved, superior carina angulate; inferior appendages slightly more than half as long as the superior pair.............. (multicolor group).

O. Abdomen (excl. appendages) less than four times as long as the thorax; a prominent ventral tubercle on abd. seg. I; inferior sub-basal tubercle of the superior appendages at one-fourth to onefifth the length of the appendages; height of superior carina above outer margin, in profile, not less than the depth of the appendage directly below it; 
distance from summit of superior carina to apex of appendage greater than one-third of the length of the appendage; outer side of anal loop in hind wing longer than inner side of the triangle........ ..................... multicolor Hag. OO. Abdomen (excl. appendages) not less, generally a little more, than four times as long as the thorax; ventral tubercle on abd. seg. I but little elevated; inferior sub-basal tubercle of the superior appendages at one-sixth to one-seventh the length of the appendage; height of superior carina above outer margin, in profile, generally much less than the depth of the appendage directly below it; distance from summit of superior carina to apex of appendage about one-third of the length of the appendage; outer side of anal loop in hind wing about as long as the inner side of the triangle. mutata Hag.

\section{Females.}

A. Abd. seg. I without a distinct ventral tubercle; fork of $\mathrm{Rs}$ decidedly asymmetrical at base.

B. Line of contact of eyes little or no longer than occiput; lateral thoracic bands less than I $\mathrm{mm}$. broad, the first band sigmoid or bent twice at alternate angles. Genital valves in ventral view tapering evenly to the narrow attingent apices, lateral carinae prominent.

C. Distance from hind margin of occiput to frontal vesicle less than $2 \mathrm{~mm}$.; preocular band not produced forward on each side above; appendages about as long as segs. $9+10$, more slender proximally than distally, the apices rounded or broadly and obscurely pointed............caerulea septentrionalis Burm. CC. Distance from hind margin of occiput to frontal vesicle about $2 \mathrm{~mm}$.; preocular band produced forward on each side of the stem of the T-spot; appendages slightly longer than the dorsa of seg.9+10, tapering equally at base and apex, the latter distinctly though bluntly pointed ............... sitchensis Hag. 
BB. Line of contact of eyes distinctly longer than occiput; lateral thoracic bands generally more than I $\mathrm{mm}$. broad, when narrower never sigmoid.

D. Basal plate of ovipositor distinctly bilobate, lateral genital plates absent; PL large but separate from PD (sometimes narrowly connected on 2).

E. Lateral thoracic bands broad, not excavated in front, first band gradually tapering to the upper end, without a distinct posterior offshoot; genital valves with a distinct ventral surface; appendages shorter than abd. segs. $8+9$ ( $5 \mathrm{~mm}$. or less). juncea $\mathrm{L}$.

EE. Lateral thoracic bands narrower, broadly excavated in front, first band gently widening above the middle to the upper end from which a narrow posterior offshoot is given off; genital valves without a distinct ventral surface, appendages about as long as abd. segs. $3+9$ (6-6.8 mm.) . .

subarctica Walk.

DD. Basal plate of ovipositor not bilobate, its hind margin straight or slightly arcuate; lateral genital plates present; PL generally confluent with PD (often separate in $A e$. umbrosa).

F. Styli much shorter than the dorsum of abd. seg. Io; appendages less than $1.5 \mathrm{~mm}$. broad, decidedly slenderer in the basal than in the apical third; broadest beyond the middle; apices generally rounded.

G. A black line on the fronto-nasal suture.

$\mathrm{H}$. Genital valves $2-2.5 \mathrm{~mm}$. long; apices not elevated, bearing a very minute pencil of hairs.

I. Dorsal thoracic bands absent or represented each by a minute and usually illdefined spot; lateral thoracic bands reduced, I $\mathrm{mm}$. or less in width, each band often divided into an upper and lower spot; Mra normally arising beyond the middle of the pterostigma.......... interrupta Walk. II. Dorsal thoracic bands distinct in wellpreserved specimens, complete, or the upper 
end separated as a distinct spot; lateral thoracic bands more than I $\mathrm{mm}$. broad, never divided but the first band deeply excavated in front; Mia normally arising in front of the middle of the pterostigma.

$\mathrm{J}$. Without a pale triangular spot in front of the humeral suture; first lateral thoracic band not bent forward at the upper end; spots between lateral bands not unusually large. ............... eremita Scudd. JJ. A large pale triangular spot in front of the humeral suture below; first lateral thoracic band bent forward at upper end; spots between lateral bands very large, often confluent with the bands. ..................... clepsydra Say.

HH. Genital valves 3-3.5 mm. long, apices elevated, without a terminal pencil of hairs; lateral thoracic bands about I $\mathrm{mm}$. broad, straight, not excavated in front............. palmata Hag. GG. Without a black line on the fronto-nasal suture.

K. Lateral thoracic bands green or yellowish green (rarely blue) not margined with black, the anterior margin of the first band distinctly sinuate, the second band elongate-triangular; genital valves $2-2.6 \mathrm{~mm}$. long, apices not elevated, bearing a minute pencil of hairs.

L. First lateral thoracic band with the anterior margin almost rectangularly sinuate, much narrowed about the middle, its upper end giving off caudad a very narrow offshoot; posterior (postero-inferior) margin of second band generally curued ventrad at the upper end; sulcation of ventral surfaces of genital valves not distinctly delimited posteriorly, appendages usually $4-6 \mathrm{~mm}$. long........... 
LL. First lateral thoracic band with the anterior margin obtusangularly sinua te, not much narrowed about the middle, its upper end giving off caudad a broad offshoot; posterior margin of second lateral band straight; sulcation of ventral surfaces of genital valves terminating more or less abruptly some distance before the apices; appendages $5.75-7 \mathrm{~mm}$. long.

verticalis Hag.

KK. Lateral thoracic bands yellow, margined with black or dark brown, about I mm. broad, straight, the first band expanded a little below, but not at all sinuate, the second band with the margins subparallel; genital valves $2.7-3 \mathrm{~mm}$. long, apices slightly elevated, without a terminal pencil of hairs. ................... umbrosa Walk.

FF. Styli as long as the dorsum of abd. seg. Io (1.5-2 mm.); appendages $2 \mathrm{~mm}$. broad or nearly so; basal third fully as broad as the apical, expanding rapidly with convex margins so that the greatest breadth is attained before the middle; apex generally acute, never broadly rounded; no black line on the fronto-nasal suture.

M. First lateral band with the anterior margin straight or nearly so, gradually tapering dorsad and not giving off a distinct posterior offshoot; second lateral band not widened at the upper end; genital valves $3.1-3.5 \mathrm{~mm}$. long, apices broad in profile, each bearing a minute pencil of hairs; styli $1.5 \mathrm{~mm}$., spinules on ventral surface of abd. seg. I comparatively few and coarse............. tuberculifera Walk. MM. First lateral band with the anterior margin distinctly sinuate, the upper end giving off a small posterior offshoot; second lateral band rapidly widened at the upper end; genital valves 4-4.5 mm. long, apices slender in profile, without a pencil of hairs; styli nearly I $\mathrm{mm}$. long; spinules on ventral surface of abd. seg. Io numerous, minute and close-set.................. constricta Say. 
AA. Abd. seg. I with a distinct ventral tubercle; fork of Rs nearly symmetrical at base; genital valves without distinct lateral carinae.

N. A black line on the fronto-nasal suture; supratriangle of fore wings clear or with a single cross-vein. .................................

NN. Without a black line on the fronto-nasal suture; supratriangle of fore wings with 2-4 cross-veins.

O. Abdomen scarcely more than four times as long as the thorax; a prominent ventral tubercle on abd. seg. I; appendages somewhat shorter than segs. $8+9$ $(5-6 \mathrm{~mm}$.$) , both margins arcuate, the curve of the inner$ margin not much stronger than that of the outer; outer side of anal loop of hind wings longer than inner side of triangle................multicolor Hag. OO. Abdomen four and one half times as long as thorax; ventral tubercle on abd. seg. I but little elevated; appendages a little longer than segs. $8+9$ (6.5-7.5 mm.); outer margin straight, inner margin arcuate; outer side of anal loop of hind wings about as long as inner side of triangle........ mutata $\mathrm{Hag}$.

Key to the known Nymphs of North American Species of Aeshna.

A. Mentum of labium distinctly more than half as broad at base as at apex; genitalia of female usually not reaching the posterior margin of 9 and never extending beyond it.

B. Lateral spines present on abd. segs. 5-9; lateral lobes of labium squarely truncate.

C. Postero-lateral angles of head bluntly angulate or but little rounded.................eremita. CC. Postero-lateral angles of head broadly rounded. interrupta lineata?

BB. Lateral spines present on abd. segs. 6-9; posterolateral corners of head well rounded.

D. Femora dark with three pale annuli; abdomen marked with irregular pale blotches on a darker ground colour; lateral lobes of labium squarely truncate, the outer apical angle scarcely rounded. 
DD. Femora uniform; abdomen without irregular blotches, more or less distinctly longitudinally striped; lateral lobes of labium, when truncate, with the outer apical angle distinctly rounded off.

E. Lateral lobes of labium truncate; abdomen not conspicuously striped; lateral spines on 6 rudimentary, distant from the posterior margin of the segment by at least four times their own length.

F. Punctae conspicuously marked with dark brown, those of the lateral series distinctly larger than the dorso-lateral; lateral spines on 9 not quite reaching as far caudad as the middle of the dorsum of I0; lateral appendages of female half as long as the inferior pair............juncea. FF. Punctae very inconspicuously marked, the dorsal series being scarcely darker than the ground colour, those of the lateral and dorsolateral series about equal in size; lateral spines on 9 reaching as far caudad as the middle of the dorsum of IO; lateral appendages of female threefifths as long as the inferior pair...... subarctica. EE. Lateral lobes of labium not truncate, but exteriorly curving to a prominent internal terminal hook; abdomen with conspicuous well-defined dorsal longitudinal bands; lateral spines on 6 welldeveloped, distant from the posterior margin by about their own length.

G. Lateral margins of mentum of labium in the basal half not in the least degree arcuate, lateral lobes terminating in a broadly curved hook; dark median band on abdomen not deepened about the dorsal punctae...................clepsydra. GG. Lateral margins of mentum of labium in the basal half very feebly arcuate, lateral lobes terminating in a very abruptly curved and almost truncate hook; dark median band on abdomen deepened about the dorsal punctae. canadensis. 
AA. Mentum of labium not, or scarcely more than half, as broad at base as at apex.

$\mathrm{H}$. Lateral lobes of labium tapering to a slender slightly hooked point; legs uniformly coloured; genitalia of female reaching caudad nearly or quite to the apical margin of ro...............................

HH. Lateral lobes of labiun squarely truncate; femora, and generally the tibiae also, with alternate pale and dark annuli; genitalia of female never reaching caudad to the middle of $\mathrm{I} 0$.

I. Eyes very prominent, postocular part of head comparatively long with straight lateral margins, and prominent, though rounded, postero-lateral angles; mentum of labium strongly narrowed in the proximal foursevenths, distal part with the lateral margins strongly arcuate; genitalia of female reaching to or beyond the posterior margin of 9 .

J. Apical breadth of mentum of labium equal to about four-fifths of its length, lateral lobes without an internal apical tooth; supracoxal processes equal; genitalia of female extending over the basal third of ro....................... palmata. $\mathrm{JJ}$. Apical breadth of labium equal to about threefourths of its length, lateral lobes with a small internal apical tooth; supracoxal processes unequal, the posterior somewhat the larger; genitalia of female extending barely to the posterior margin of $9 . \ldots \ldots \ldots \ldots \ldots \ldots \ldots \ldots$............... . . . .

II. Eyes but little prominent, postocular part of head short with scarcely any development of the lateral margin as distinct from the curve of the posterolateral angles; mentum of labium expanding almost evenly, distal part with the lateral margins moderately arcuate; genitalia of female not reaching the posterior margin of 9 .

K. Posterior supracoxal process distinctly longer than the anterior; lateral spines on abd. seg. 6 distant from the posterior margin by $\mathrm{I}-2$ times their own length; anterior wing-cases with II-I5 ante- 
cubital veins; basal part of superior appendages of male about as long as the basal breadth; tibiae without, or with indistinct, annuli......californica. KK. Supracoxal processes subequal; lateral spines on 6 rudimentary, distant from the posterior margin by at least four times their own length; anterior wing-cases with 16 -I9 (rarely 15) antecubital veins; basal part of superior appendages of male distinctly longer than the basal breadth; tibiae with distinct annuli......................... multicolor.

The caerulea group-A well circumscribed group of boreal distribution, consisting of the circumpolar Ae. caerulea with its two races, caerulea and septentrionalis, and the North American Ae. sitchensis. Their origin and affinities are obscure, their nearest allies being apparently the juncea group, with which they share the long downwardly directed spines of the anterior laminae and the reduced hamular folds. In the feeble and undecided development of the anterior branch of the fork of the radial sector, especially in caerulea, and the long line of cross-veins between Rs and M 2 the group appears to be a primitive one, approaching the genera Oplonaeschna and Basiaeschna.

The juncea group-This is also a sharply defined group of two boreal species, of which juncea is circumpolar, subarctica North American. Their nearest affinities are with the clepsydra group, to certain members of which they bear a remarkably close resemblance, both in the adult and nymphal state. The wide differences in the genitalia, however, show that there is no very close relationship between the two groups.

The clepsydra group-Another circumboreal group of eight species, ${ }^{1}$ six of which occur in North America, two in Asia and one in Europe. Their nearest allies are the Palæarctic species grandis and viridis, which differ chiefly in the simpler and more generalized form of the male abdominal appendages and the more specialized type of coloration. The genitalia of both sexes are of precisely the same type and

1e. nigroflava Martin, from Japan, is probably also a member of this group bui as I have not seen it I prefer to leave it out. 
the venational characters are also very similar in the two groups.

The North American species of the clepsydra group are for the most part remarkably alike and it seems probable that they have diverged from a common ancestor at a comparatively recent period. Species are apparently still in the process of evolution, as exemplified in the case of the geographical races of Ae. interrupta. The most generalized member of the group, however, is the Siberian Ae. crenata, in which the lateral thoracic bands are broad and straight as in juncea and grandis. This species closely resembles interrupta and eremita in the accessory genitalia of the male, and the appendages of this sex combine the characters of several of the American forms such as eremita, interrupta and clepsydra. It would thus seem very probable that the clepsydra group had a common origin with the grandis group in the Palæarctic region.

The cyanea group-This is a very well-marked group of four species, remarkable for the form of the male appendages. In the Palæarctic Ae. cyanea thespecialization in these structures has not been carried quite so far as in the other forms and the downwardly directed apical spine is clearly homologous with the pointed apices in the ordinary type of appendage, while the hairy anteapical tubercle is less developed than in the other species and appears to represent part of the superior carina. Of the other three species palmata is in most respects intermediate between umbrosa and constricta and may be regarded as nearly representing the parental form from which they have descended. This being so, it is an interesting fact that palmata occurs in northeastern Asia as well as western North America.

Thus it is probable that the cyanea group is also of Palæarctic origin, Ae. cyanea being the most primitive species in the form of the male appendages, though most specialized in coloration, while Ae. palmata is the most generalized of the other three. In this connection it may be noted that $A e$. umbrosa has diverged from palmata more widely in the east than in the west, the abdominal coloration being more similar to that of palmata in British Columbia and the Western 
States, where both species occur together, than in eastern North America where only umbrosa is found.

The californica group-The nearest allies of Ae. californica are found in a group of species from South and Central America and Mexico. This group as pointed out by Calvert ('o5b) consists of such species as Ae. diffinis, marchali, cornigera, galapagoensis, bonariensis and confusa. Ae. haarupi probably also belongs here. Not having studied many of these forms closely, I am uncertain as to the limits of the group, or whether it is sharply marked off from the following group, to which it is certainly very closely allied. The nymphs of californica and multicolor are remarkably similar.

The multicolor group-The peculiar form of the abdominal appendages of the male seems to be the only character by which this group differs from the preceding, of which it is probably an offshoot. It is best developed in southern Mexico, where Ae. dugesii, multicolor and jalapensis occur. The only other species, Ae. mutata, is a northeastern offshoot, occurring in the eastern half of the United States.

Besides the species of Aeshna described here, one other, the Palæarctic Ae. grandis $\mathrm{L}$, has been once recorded from North America by Hagen ('6I), who observed a single individual at Bergen Hill, N.J. This specimen was believed to have been introduced by a vessel. There is also a specimen of grandis in the collection of the Ontario Agricultural College, Guelph, labelled "London, Ont., J. M. Denton." Nothing, however is known of the history of this specimen and in the absence of such information I prefer to exclude this species from the present account.

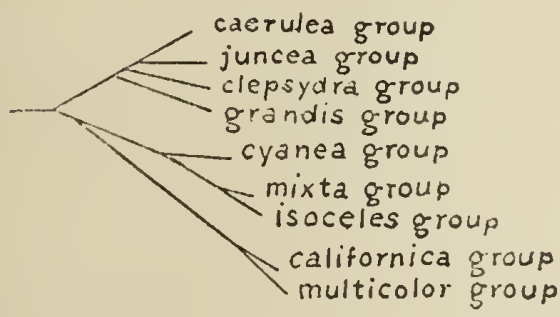

Fre. 8-1nterrelationships of the various groups of Aeshua represented in North Amorica and Europe. 


\section{Descriptions of Species.}

Aeshna caerulea septeatrionnlis Burmeister.

(Pl. 12, fig. 4; pl. I5, figs. I, Ia; pl. I8, figs. I, Ia; pl. 22, figs. $1,2,3$.)

Aeschna sepientrionalis, Burmeister, Handb. der Ent., II, 839 (I 839); Hagen, Syn. Neur. N.A., p. 120 (I86I); Pr. Bost. Soc. Nat. Hist., XVIII, p. 33 (1875); Kirby, Syn. Cat. Neur. Od., p. 87 (I 890); Hagen, Psyche, V, p. 354-355 (I 89o); Banks, Trans. Am. Ent. Soc., XIX, p. 353 (1892): Calvert, Trans, Am. Ent. Soc. XXV, p. 54 (I 898); Fyles, Ann. Rep. Ent. Soc. Ont., XXXI, p. 54 (I90I); Williamson, Ent. News, XVII, p. I35 (1906); Martin, Coll. Zool. Selys., XVIII, pp. 37-4I, 79, figs. 35, 36 (I908); Gen. Ins., CXV, p. II, pl. 3 , figs. I, Ia. Ib (I911).

Aeshna septentrionalis, Calvert, Occas. Pap. Bost. Soc. Nat. Hist., VII, 6, p. 23 (I905) ; Williamson, Ohio Nat., VII, p. I50 (I907); Walker, Can. Ent., XL. pp. 386, 390, 45I (I908); Muttkowski, Cat. Od. N.A., p. I I3 (I9Io).

A rather small, moderately stout species.

Male-Occiput pale yellowish, broader than long, as long as, or somewhat longer than, the line of contact of the eyes, which measures less than I mm. in length; frontal vesicle very large, about twice as broad as long, the front margin straight or slightly emarginate, black with a median yellow spot not reaching the lateral ocelli; eyes much narrowed above and smaller than in other North American species; T-spot with cross-bar very heavy, $2-2.5 \mathrm{~mm}$., the stem very short, about $.5 \mathrm{~mm}$. broad; preocular band not curved forward on each side of the $T$-spot, but continued ventrad as a marginal line to the bases of the lateral lobes of the nasus, expanding considerably to the fronto-nasal suture, but narrow on the nasus; a heavy black line on the fronto-nasal suture, widened only at the outer ends; face dull yellowish or brownish olivaceous with a pale submarginal band, short, the frons being about four times, and the nasus three times, as broad as long (vertical dimension); two transversely impressed areas near the lower margin of the nasus not marked with black, lateral lobes rotundo-rectangulate, feebly flaring; rhinarium reddish brown; labrum greenish yellow with a black upper, and generally a brownish lower, margin; labium dull yellow stained with reddish brown peripherally; rear of head black.

Thorax somewhat more robust than in Ae. sitchensis, dull olivaceous brown, darkened along the sutures and about the lateral bands. Dorsal bands reduced to a pair of minute, 
though distinct, elongate pale spots $1-1.75 \mathrm{~mm}$. long. A pale streak usually present along the lower half or more of the humeral suture in front. Lateral thoracic bands narrow and irregular, pale yellow (bluish above?). First band very strongly sinuate, being twice bent, at alternate angles; broadest in the middle and lower parts, but nowhere more than I $\mathrm{mm}$. and sometimes (in Labrador specimen) very narrow and broken; a narrow posterior offshoot is given off at the upper end. Second band nearly straight, narrowed and sometimes divided at the middle, upper ends expanding along the posterior margin of the thorax above and below. Two small spots generally present between the lateral bands, one at the metastigma, the other above it.

Legs rather pale reddish brown, darkened on the tarsi, distal ends of the tibiae and under surface of the femora.

Abdomen about four times as long as thorax and barely longer than the hind wing, considerably stouter than in sitchensis, strongly constricted at 3 , then rapidly expanding and attaining nearly its full width at the apex of that segment; base of ro considerably narrower than the apical margin of 9 . Seg. I without a ventral tubercle; auricles with 4-6 teeth; tergal margins of 2 approximated but not angular.

Spines of the anterior lamina rather stout, shorter than in $A e$. sitchensis, reaching caudad nearly to the posterior margin of the hamular processes, and projecting a little below the tergal margins, nearly straight, rather bluntly pointed, directed ventrad, caudad and slightly mesad. Hamular processes very large, their posterior margins broad, rounded and strongly elevated, the apices bluntly acute, the inner margins rather narrowly separated at base but approximated apically. Outer surfaces strongly concave and almost vertical apically; hamular folds very small and almost concealed in a direct ventral view by the hamular processes with which they are connected by a low ridge; closely approximated mesially.

Lateral carinae on 7 and 8 nearly straight; on 9 present, as a rule, only on the apical half. Dorsum of io with a prominent median basal tooth and a smaller one on each side of it.

Superior appendages a little shorter than $9+10$, modera te- 
ly slender and slightly divergent in their basal fifth, where they are separated by a space 2.5 times their width, thence expanding on the inner margins to the middle, where the breadth is 1.5 to 1.4 times the length, tapering slightly in the distal half to the well-rounded apices, which are without a terminal tooth; outer margins moderately convex, inner margins sinuate in the basal half. Superior carina obsolete or feeble in the basal third, considerably elevated in the apical fourth and strongly arcuate at apex, nearly smooth or with a few minute elevated points. In profile the outer margin appears gently upcurved or nearly straight but the appendage appears considerably upcurved apically on account of the elevated superior carina and arcuate inferior carina, which is formed by the deflected inner margins. Basal part thickened, with a low sub-basal inferior prominence. Inferior appendage triangular, slightly less than one-half as long as the superiors, basal breadth three-fifths to two-thirds of the length, sides barely convex, apex very bluntly rounded, surmounted by a pair of small recurved teeth. Upper margin in profile view very gently curved, lower margin strongly curved, the sides very broad near the base, tapering rapidly.

Abdomen brownish black, all the pale markings probably blue, varying considerably in size but always large.

Seg. 1. Dorsal spot apparently large, lateral spot variable, sometimes $1.5 \mathrm{~mm}$. in the transverse dimension, sometimes obsolete (?Labrador specimen).

Seg. 2. AML very large, covering most or all of the lateral surface back to the transverse carina, connected with or narrowly separated from MD. PL and PD confluent, covering about two-thirds of the posterior half of the segment, deeply notched in front, broadly confluent above with its fellow and with a median dorsal band, more than $1 \mathrm{~mm}$. broad, which runs cephalad nearly to the anterior margin.

Segs. 3-10. AL on 3-8, upper margins straight, no basal offshoots; on 3 covering almost the whole lateral surface in front of the transverse carina. ML large, rounded posteriorly. MD very large, irregularly semi-elliptical or subquadrate, and generally broadly confluent with ML except on 8 , where it is reduced to a mere dot; generally confluent 
also with PD on some or all of the segments, the variation in this regard being considerable. In the Labrador specimen these spots are more widely separated than in the others. PD on $3-10$, varying in length from $1.5 \mathrm{~mm}$. on 3 to $2 \mathrm{~mm}$. on 8 , always well separated from its fellow, except sometimes on Io where there may be a narrow connection next the posterior margin; inner margins nearly straight on last 2 or 3 segments, elsewhere convex or somewhat indented and irregular. PL usually on $3-8$, on 3 and 4 only in the Labrador specimen, connected with PD, straight and elongate where well-developed and separated from PD throughout, or narrowly connected on 3 and sometimes 4 ; of ten also with ML on 3 and 4 .

Wings of average size and usual form, the hind wing about as long as the abdomen, hyaline; costal margin moderately dark brown; pterostigma long, brown; membranule uniform grey, extending caudad to cross-vein of the anal triangle, which is 2-celled; one cell between $\mathrm{A}_{2}$ and $\mathrm{A}_{3}$ at their origin. Upper branch of Rs following a somewhat irregular course, not always distinct at its origin and, when distinct here, coming off at a rather marked angle, at a point opposite the first to the third postnodal cell before the pterostigma ; 3 (rarely 2) rows of cells between the forks at the level of the distal end of the stigma, and 3-4 rows of cells between the forks at the margin. Rspl nearly straight, separated from Rs at the point of greatest divergence by 4 (rarely 5) rows of cells. Two rows of cells between $R s$ and $M_{2}$ for a considerable distance before and beyond the fork of the Rs, sometimes indications of a third row. Mra arising under the stigma at a point opposite or somewhat before the middle.

Antenodals $\frac{\mathrm{I} 3-\mathrm{I} 6}{9-\mathrm{II}}$, postnodals $\frac{\mathrm{II}-\mathrm{I} 2}{\mathrm{I}-\mathrm{I} 4}, \mathrm{Cu} \mathrm{Cr} \frac{4-6}{5}, \mathrm{Spt} \frac{2-3}{\mathrm{I}-2}$.

Female-Abdomen about as long as hind wing, deeper than in the male, especially at seg. 3 , the dorsal and ventral surfaces of which appear in profile nearly straight. Seg. 3 almost as long as $I+2$, barely longer than 4 .

Genital valves a little longer than the dorsum of 9, ventral margin in profile slightly convex, especially at apex; lateral carinae percurrent, sharp and very prominent; space between them in ventral view, suddenly widened a little be- 
yond the base, thence tapering evenly to the narrow pointed apices, the greatest width being about two-fifths of the length. Ventral surface of valves moderately declivent. Styli somewhat less than one-half as long as the dorsum of 10 . Basal plate of ovipositor of moderate size, the posterior margin nearly straight. Ventral surface of io deeply cleft by the posterior margin. Appendages slightly shorter than $9+$ Io, somewhat incurved at base, lanceolate, greatest width beyond the middle, somewhat less than one-fourth of the length; curve of inner margin slightly stronger than that of the outer; apices rotundo-angulate without a projecting tooth.

The colour-pattern differs but little from that of the male. Dorsal abdominal spots somewhat smaller, lateral spots slightly larger than in the male. MD sometimes comparatively small, triangular and isolated, sometimes large, subquadrate and confluent with ML and PD on some of the segments. PL on 2-7 separate from PD, but confluent with ML on some or all of the segments.

Measurements-Thor. ơ 9-10, क 9-9.5; abd. o 37.5-42, क 35-40; seg. 3 o 5.8-6.7, क 5-5.8; depth seg. 2 व 4-4.5, क 4-4.8 ; depth seg. 3 o 2-2.6, \& 3.3-3.6 ; apps. o 4-4.I, 3.5 ; gen. v. 2.4-2.6; h.w. $\sigma^{7} 36-40$, $\$ 34-38.5$; width h.w. ơ I I-I 2.5, क I I-I 2.8; pter. of 3.5-3.8, क 4 .

Type-o, Museum Comp. Zoology-Labrador.

Nymph-Unknown.

Material determined-5 $\sigma^{7} 5$ \%. LABrador (M.C.Z. I $\sigma^{\prime \prime}$ I $\&$, Brit. Mus. I $\sigma^{\circ}$ ). Newroundland: Grand Lake, July 21, 1910 (D.A. Atkinson, coll.Williamson, I 8). New Hampshire: White Mountains (Scudder, M.C.Z.., I $\sigma^{7}$ ). Northwest TERRITORY : Fort Resolution, Great Slave Lake, 1861 (Kennicott, M.C.Z., 20 " 3 \%).

Identity-I can find no good characters for the separation of this form from the Palæarctic caerulea Ström (borealis Zett.). The only distinctive structural character is the shorter and relatively broader form of the appendages of the female in septentrionalis, but as I have shown elsewhere these structures vary greatly in length in most species of Aeshna and, as a rule, long appendages are relatively narrower than short ones. It must also be borne in mind that very few female specimens of septentrionalis exist in collections, and still fewer with unbroken appendages. In fact I have seen but two such specimens. 
The upper branch of Rs is generally somewhat less definite in typical caerulea than in septentrionalis, the venation in general slightly more complex and the size slightly larger, but none of these characters are constant enough to be of any value in separating the two forms.

The colour-pattern is also almost identical in the two forms but here there is one point of difference in the form of the first lateral thoracic bands. These are somewhat wider opposite the lowest bend in caerulea, the hind margin not being angularly bent as in septentrionalis but only slightly curved. This feature, however, seems too trivial to be made the basis of a specific distinction, and may prove to be inconstant when the species is better known.

The distinctive characters for these forms given by Martin ('o8) are incorrect. The line of contact of the eyes is quite as short in this form as in typical caerulea. Martin's figure of the wings of septentrionalis belongs to some other species, one of the clepsydra group and probably interrupta. It may be noted that the maximum number of antenodal veins in the fore wings as given by Martin is 18 , and the number in his figure is I9. The figures of the appendages are also apparently from one of the races of interrupta, though the profile view is as much like septentrionalis as any other species.

Distribution-This is a circumboreal species, the race septentrionalis inhabiting the Hudsonian and northern part of the Canadian Zone from the Atlantic at least as far west as Great Slave Lake.

\section{Aeshna sitchensis Hagen.}

$$
\begin{aligned}
& \text { (Pl. 12, fig. } 5 \text {; pl. 15, figs. 2, 2a ; pl. 22, fig. } 4 \text {; } \\
& \text { pl. 23, figs. 1, 2.) }
\end{aligned}
$$

Aeschne silchensis, Hagen, Syn. Neur. N.A., p. II9 (I86I); Pr. Bost. Soc. Nat. Hist., XVIII, p. 33 (1875); Kirby, Syn. Cat. Neur. Od., p. 87 (I890); Hagen, Psyche, V, p. 353-355 (I 890); Banks, Trans. Am. Ent. Soc., XIX, p. 353 (I892); Currie, Pr. Wash. Acad. Sci., III, pp. 217, 222 (IgoI); Skinner, Ent. News, XV, p. 288 (I904); Osburn, Ent. News, XVI, p. I 86 (I905); Williamson, Ent. News, XVII, p. I35 (1906); Fletcher and Gibson, 38 th Ann. Rep. Ent. Soc. Ont., p. I32 (I908); Martin, Cat Coll. Zool. Selys, XVIII, pp. 4I, 79, fig. 37 (I908); Gen. Ins., CXV, p. II (IgII).

Aeshna silchensis, Williamson, Ohio Nat., VII, p. I 50 (I907); Walker, Can. Ent.,XL, pp. 386, 390, 451 (1908); Fletcher and Gibson, 39th Ann. Rep. Ent. Soc . 
Ont., p. I14 (1909); Muttkowski, Cat. Od. N.A., p. II4 (Ig10); Hebard, Ent. News, XXI, p. 134 (1910). Gibson, 40th Ann. Rep. Ent. Soc. Ont., p. 126 (1910).

A rather small, moderately slender species.

Male-Occiput, pale greenish yellow, broader than long, two-thirds to fully as long as the line of contact of the eyes. Frontal vesicle large, usually somewhat more than twice as broad as long, pale yellow with a black border of variable extent, usually confined to the ocular margin but sometimes surrounding the vesicle and always including the lateral ocelli. Eyes shorter than in the other North American Aeshnae except Ae. caerulea septentrionalis, their colour in the living insect unknown, in dried specimens dark olivaceous brown. T-spot heavy, the cross-bar thick, 2-2.5 mm., stem very short, .5-.75. $\mathrm{mm}$. broad; preocular band extending laterally a little beyond the limits of the $T$-spot, curving a little cephalad and terminating abruptly a little beyond the base of the antenna, its breadth near the end being about $.5 \mathrm{~mm}$. From this band a narrow black line passes ventrad along the ocular margin of the frons and nasus to the tips of the lateral lobes of the latter. A black line on the fronto-nasal suture, not very heavy in the middle but expanding to form a broad black triangular area where it joins the marginal line. Face pale, dull greenish or olivaceous, sometimes dark brownish in dried specimens, paler next the ocular margin. Nasus short, the vertical dimension being about equal to one-third of the transverse, the two depressed areas near the lower margin not marked by black dots; lateral lobes not flaring, bluntly angulate, the outer margin straight. Rhinarium dark reddish brown. Labrum pale yellowish green, margined narrowly above, broadly below, with black. Labium pale yellow, the lateral lobes and the apical part of the median lobe reddish brown. Rear of head black.

Thorax moderately dark brown with a bronzy lustre, rather thinly covered with greyish hairs, venter more or less covered with a greyish bloom. Dorsal thoracic bands reduced to a pair of small narrow pale spots about $1 \mathrm{~mm}$. long, often ill-defined and sometimes indistinguishable in dried specimens. Antealar sinus without pale markings. 
Ventro-lateral angles of meso-episternum with a pale spot. Lateral bands narrow and irregular, pale yellow or whitish, generally shading above, especially the second band, into pale bluish or blue. First band very strongly sinuate, being twice bent, at alternate angles, broadest at about the lower bend $\left(.5^{-} .75 \mathrm{~mm}\right.$.), narrowest above the second bend $(.2-.5 \mathrm{~mm}$.), more or less expanded toward the upper end. The lowest part of the band is oblique, bounding the humeral suture, the middle part nearly horizontal, the upper part sub-vertical. Second band nearly straight behind, constricted and sometimes nearly divided by the deep excavation of the front margin, the breadth below the constriction $.4 \cdot .75 \mathrm{~mm}$.; expanding at the upper end to about 2 or $2.5 \mathrm{~mm}$. Behind the upper bend in the first band is a narrow sinuate pale streak. Spots at bases of wings above pale yellowish.

Legs dark reddish brown, under side of femora nearly black, no pale streak on fore femora.

Abdomen 4.5 times as long as thorax and slightly longer than hind wing, rather slender, considerably constricted before the middle of 3 , thence expanding on this segment to nearly its full width, which is attained at the apex of 4 ; sides of 9 not at all divergent caudad, continuous with those of 10.

Seg. I without a ventral tubercle, auricles on 2 with 3 teeth (rarely 2), tergal margins of 2 subangulate, widely separate at base, but closely approximated a little beyond the middle. Spines of the anterior lamina long, reaching caudad a little beyond the hamular processes, stout at base, and proximally directed caudad, thence tapering and curving ventrad to the finely pointed apices, which project distinctly below the level of the tergal margins. Hamular processes very large, triangular; bases rounded, apices acute, directed cephalad; inner margins straight and attingent along their entire length, considerably elevated. Hamular folds small, close together, nearly or quite covered in a direct ventral view by the hamular processes, with which they are connected by a rather low ridge. Lateral carinae on 7 and 8 straight. Dorsum of 10 with a fairly prominent median sub-basal tooth and one or two minute ones on each side of it. 
Superior appendages more or less granulate, about as long as the last two segments, their bases slender and about one-third as broad as the space between them, expanding gradually on the inner margin to the middle or a little beyond, when the breadth is about one-fifth of the length, thence narrowing slightly to the rotundo-angulate apices, which terminate in a small abruptly decurved spine; outer margin moderately convex, inner margin (vertical view) gently concave at the proximal half, straight, or nearly so, in the distal half. Superior carina arising in a basal dorsal tooth, partly concealed by the tergum of 10 , percurrent, though often indistinct in the basal third, gradually and moderately elevated beyond, bearing 8 or 10 minute denticles on the apical third. In profile the outer margin appears nearly or quite straight, the part of the appendage internal to the superior carina forms a fairly prominent subangulate ventral carina, the deepest part of which is opposite the apical fifth or sixth of the appendage. Inferior appendage triangular, barely more than one-half to three-fifths as long as the superior pair, breadth at base equal to three-fifths of the length, sides straight, apex rounded; in lateral view very gently curved, the curve of the lower margins considerably stronger than that of the upper, tapering considerably in the distal two-thirds.

Seg. I brown, dorsal spot blue, lateral spot pale greenish, 2.5-3 $\mathrm{mm}$. in transverse dimension, acute above, widening below to $\mathrm{I} \mathrm{mm}$. or a little more.

Seg. 2 brown. AL and ML pale greenish or bluish, separated except for a very short distance above the auricle by a black streak. AL oblong, about $1.5 \mathrm{~mm}$. broad (transverse), covering more or less of the upper surface of the auricle, but not extending below the latter in front. ML a narrow streak generally extending somewhat farther dorsad than $\mathrm{AL}$ and nearly meeting $\mathrm{MD}$. PL blue, about as long as broad, front margin roundish and almost touching the transverse carina. PD blue, nearly as long as PL, with which it is narrowly connected, connate with its fellow of the opposite side, concavely emarginate on each side of the median line, along which it is continued forward as a narrow streak 
joining $\mathrm{AD}$ (a small yellowish triangle) at the front margin.

Segs. 3-Io brownish black, the pale areas except MD blue and somewhat larger than usual. $\mathrm{AL}$ on 3-8, large, quadrate, giving off narrow basal transverse offshoots which do not form complete rings; upper margins straight, inclined more or less dorso-caudad (except on 3). ML present on 3-8, large, subrhomboidal, somewhat rounded behind, not indented in front. MD on 3-8, greenish or yellowish, quadrate and broadly confluent with $\mathrm{ML}$ on 3 , triangular on 4-7 and connected with ML on 3 and sometimes narrowly on 4, small and transversely elongate on 8. PD increasing in length from I-I.25 mm. on 3 to $I .75-2 \mathrm{~mm}$. on 9 and IO. It covers about half the dorsum of 8 , four-fifths or more of 9 and Io and may be more or less connate with its fellow of the opposite side on all of these segments, though generally separate throughout. The front margins are rounded on the more anterior segments, somewhat irregular and indented on the last four or five, the inner margins posteriorly subparallel. PL on 3-7, rather large, connected behind on all the segments with PD, of which it forms a broad, somewhat curved offshoot, pointed at the anterior ends.

Wings of average size and usual form, the hind wing very slightly shorter than abdomen, hyaline, costal margin moderately dark brown; pterostigma long, dark brown, yellowish beneath; membranule uniform smoky brown, extending caudad fully as far as the cross-vein of the anal triangle, which is 2-celled. ${ }^{1}$ One or 2 cells between A2 and $\mathrm{A}_{3}$ at their origin. Rs forking under the proximal end of the stigma or the first postnodal cell before it, in the hind wing occasionally opposite the distal half of the second cell before it; the fork distinct but the upper branch is slenderer and comes off at a much greater angle than the lower branch; 2-3 rows of cells between the forks at the level of the distal end of the stigma and 2-4 cells between them at the margin, towards which the forks are often slightly convergent. Two rows of cells between $\mathrm{Rs}$ and $\mathrm{M}_{2}$ for a

${ }^{1}$ I have a specimen from the Isle d'Orleans, Quebec, in which a minutethird cell is present on each side, including the outer basal angle. 
considerable distance before and after the point of forking. Rspl gently sinuate, 4-5 rows of cells between it and Rs where most widely separated. Mra arising under the stigma at a point about opposite the middle.

$$
\text { Antenodals } \frac{16-18}{10-1 \mathrm{I}} \text {, postnodals } \frac{\mathrm{IO}-\mathrm{I} 3}{\mathrm{II}-\mathrm{I} 5}, \mathrm{CuCr} \frac{5-6}{5-6}, \mathrm{Spt} \frac{2-3}{\mathrm{I}-2} \text {. }
$$

Female-Abdomen about as long as the hind wing, deeper than in the male, especially at 3 , the dorsal and ventral surfaces of which appear straight in profile. Seg. 3 about as long as $I+2$ or 4 .

Genital valves barely longer than the dorsum of 9 , ventral margin in profile nearly straight, apices scarcely elevated. Lateral carinae percurrent, very prominent and of nearly equal height throughout; the space enclosed by them, in ventral view, widening a little from the base to about three-tenths of the length, where the breadth is equal to about two-fifths of the length, thence tapering evenly to the narrow pointed apices. Ventral surface of valves strongly declivent, distinctly grooved inside the lateral carinae; styli about half as long as dorsum of $10(.6 \mathrm{~mm}$.); basal plate of ovipositor of moderate size, the posterior margin straight or indistinctly bilobed.

Appendages about as long as dorsa of $9+10$, lanceolate, broadest about the middle, where the breadth is about onefourth of the length. Apices tapering but little more abruptly than the bases, rotundo-angulate with a small terminal tooth; both margins evenly convex, the curve of the inner somewhat stronger than that of the outer.

The colour-pattern differs from that of the male in the usual way. Dorsal thoracic bands represented by a pair of minute ill-defined spots, or absent; lateral bands in the Newfoundland specimen broader than in any of the males seen. Abdominal spots PD considerably smaller than in the male and more widely separated, especially on 8 and 9 , the intervening space being somewhat more than $1 \mathrm{~mm}$. broad on 8 ; lateral spots considerably larger than in the male. PL large, quadrate, connected narrowly with $P D$, and confluent on 2 with ML. 
The colour of the face and thoracic bands seems to have been about the same in the Newfoundland female as in the male. The lateral bands in the Isle Royale specimen are wholly greenish yellow. Of the abdominal spots, PD appears to have been a yellowish green, MD yellow and the lateral spots green on seg. I, bluish green on the others. The wings are hyaline in the Newfoundland and Burrough's Bay specimens, somewhat smoky in the one from Isle Royale. No doubt considerable variation occurs in the females of this as in other species of Aeshna.

Measurements-Thor. o7 9-10, o 9 ; abd. क⿱ $\sigma^{7}$ 40-44.5, 9 38.5-40; seg. 3 का 6.75-8, क 5.7-6; depth seg. 2 o7 4-4.4, 9 4.5-4.75; depth seg. 3 o $1.5-2, \% 3.25$; apps. $\sigma^{7} 4-4.7$, \& $3.5-3.75$; gen. v. 2.2-2.25; h.w. on $38-40.5$, \& 36.5-40; width h.w. $\sigma^{7} 11-12.3$, क $12-12.5$; pter. $\sigma^{7} 3.75-4$, क $4.5-5$. Type- - $\sigma^{7}$, Mus. Comp. Zoology-Sitka, Alaska.

Material delermined - $15 \sigma^{7} 6 \%$. NewFoundland: (R. Thaxter, M.C.Z. $20^{7}$ I 9 ) : Bay of Islands, July 7, 1901 (D.A. Atkinson, coll. Williamson, I ot I १). Quebec: Ellis Bay, Anticosti Is., Sept. 12, 1910 (E. V. Cowdry, coll. Walker, I $0^{7}$ ); Levis (T. W. Fyles, coll. Walker, I $0^{7}$ ) ; Isle d'Orleans, Aug. 26, 1904 (Walker, I ơ). Ontario: De Grassi Pt., Lake Simcoe, July I, I 905 (A. L. Walker, I $\left.\sigma^{7}\right)$; Sault Ste. Marie, Sept. I4, I907 (Donaldson, coll. Williamson, I ${ }^{7}$ ). MicHIgan: Isle Royale, Aug. 21,1905 (C. C. Adams, Univ. Mich., I ơ'). Mrnnesota: Duluth, Sept. 2 (O. Sacken, M.C.Z., I $\sigma^{7}$ ). ManitoBA: Winnipeg Beach, L. Winnipeg, Sept. 6, 1909 (J. B. Wallis, I $0^{7}$ ) ; Westbourne, Aug. 19, 1908 (J. B. Wallis, coll. Walker, I $0^{7}$ ). SaSkatchewaN (Scudder, Kennicott, M.C.Z., 2 or 1 9). NORTHWEST TERRITORY: Fort Resolution, Great Slave Lake, July I 862 (Kennicott, M.C.Z., I \%). "British AMERICA" (Scudder, M.C.Z., I \%). AlasKa: Sitka, (M.C.Z. I ơ, type); Burrough's Bay, Aug. 5, I894 (J.A. Cadenhead, coll. Walker, I \&).

Distribution-Canadian and Hudsonian Zones.

Most of the records of this insect are from the southern part of its area of distribution, where it is rare and local. The single specimen from Lake Simcoe must be regarded as a straggler from the north, as it is certainly not native there. This specimen is the largest that I have seen.

\section{Aeshna Juncea Linné.}

(Pl. 12, fig. 6; pl. 15, figs. 3, 3a ; pl. 18, figs. 3, 3a ; pl. 23, figs. 3-4.)

Libellula juncea, Linné, Syst. Nat. I, p. 544 (1758.)

A shna juncea, Stephens, IIl. Brit. Ent.,6, p. 84 (I835); Evans, Brit. Lib., p. 21, pl. II, fig. 2 (I 845); Calvert, Occ. Pap. Bost. Soc. N.H., VII, 6, p. 23 (I905); Williamson, Ohio Nat.,VII, p. I50 (1907); Walker, Can. Ent., XL, pp. 385, 390, 45 I, pl. IO, figs. I, 2, 5 (1908); Muttkowski, Cat. Od. N.A., p. I I I (I9I0). 
A eschna juncea, Selys, Mon. Lib. Eur., p. 106 (1840); Hagen, Stett. Ent. Zeit., XVII, p. 369 (1856); Hagen, Syn. Neur. N.A., p. I20 (I 86I); Pr. Bost. Soc. Nat. Hist., XVIII, p. 35 (1875); Ris, Faun. Helv., p. 25 (1885); Kirby, Syn. Cat. Neur. Od., p. 87 (I890); Banks, Trans. Am. Ent. Soc., XIX, p. 353 (I892) ; Calvert, Trans. Am. Ent. Soc., XX, p. 199, 207 (1893); Wallengren, Ent. Tidsk., XV, p. 256 (I 894); Calvert, Trans. Am. Ent. Soc., XXV, p. 54 (I898); Lucas, Brit. Drag.. p. 190, pl. I6, o7 9 (1900); Currie, Pr. Wash. Acad. Sci., III, p. 219 (I90I); Williamson, Ent. News, XIII, p. I46 (I902) ; Williamson, Ent. News, XIV, p. 7. pl. 2, fig. I (1903); Osburn, Ent. News, XVI, p.I 90 (I905); Williamson, Ent. News, XVII, p. I34, I 35 (I906); Martin, Cat. Coll. Zool. Selys., XVIII, pp. 34, 82, fig. 29 (Ig08); Cockerell, Ent. News, XIX, pp. 455. 457-459 (I908); Martin, Gen. Ins., CXV, p. II, pl. I, figs. I-8b (I II I).

Libellula ocellata, Mueller, Nova Acta Leop. Carol. Acad., III, p. I25 (1867).

Aeschna ocellata, Hagen, Syn. Lib. Eur., p. 54 (1840).

Aeschna rustica, Zetterstedt, Ins. Lapp., p. I040 (1840).

Aeschna picta, Charpentier, Lib. Eur., p. I 12 , pl. 20, ơ \& (1840).

Aeschna picta var. caucasica, Kolenati, Mel. Ent., V., p. I I4 (I846).

Aeschna caucasica, Selys, Rev. Odon., p. 300 (I850). part 1 .

Aeschna propingua, Scudder, Pr. Bost. Soc. Nat. Hist., X, p. 215 (I866) [in

A rather stoutly-built species, of medium or somewhat less than medium size, though attaining a large size in Europe.

Male-Occiput light yellow, sometimes darkened at apex, distinctly broader than long, of ten twice as broad, and from one-fifth to two-thirds as long as the line of contact of the eyes. Frontal vesicle more than twice as broad as long, generally wholly yellow above, except a small area around the lateral ocelli and a narrow hind margin, but sometimes the yellow area is confined to the anterior half or two-fifths. Eyes emerald green above, fading below to pale yellowish green and pale blue behind, the hind margin above greenish yellow. Preocular band about 2.5-3 times as broad, at base of antennæ, as one of the lateral ocelli, narrowed to a thread line on the sides of the frons and nasus. T-spot heavy, but with a rather slender stem, the sides of which are slightly divergent or subparallel, cross-bar $2.5-3 \mathrm{~mm}$., stem .5-.6 mm. broad in front, $.7-.8 \mathrm{~mm}$. broad behind. Frons and nasus yellow or greenish yellow, more or less infuscated just below the T-spot; a heavy dark brown line on the fronto-nasal suture, narrowing laterally, and two impressed dark brown dots near the lower margin of the nasus. Lateral lobes of the nasus rotundo-angulate, somewhat flaring. Rhinarium dark reddish brown, with a yellowish upper margin. Labrum yellow or greenish yellow, with upper and lower black marginal lines. (In one male from the Bighorn Mts., Wyo., it is com- 
pletely surrounded by a heavy black margin.) Labium light yellow, more or less infuscated towards the margins. Rear of head black.

Thorax rather heavily built, dark reddish brown. Dorsal bands pea-green, $4 \mathrm{~mm}$. long $\cdot 4-.75 \mathrm{~mm}$.broad at the middle, straight or slightly curved, sides nearly parallel, lower ends pointed, separated by 4-4.5 mm., upper ends generally somewhat expanded, .75-I.3 mm. broad, separated by $1.3-2.3 \mathrm{~mm}$. A green spot in the antealar sinus and sometimes an ill-defined humeral streak. Lateral bands broad, straight, greenish yellow, pale blue at the upper ends, surrounded by an ill$\mathrm{d}$ fined dark margin; first band rounded at lower end, near which it is $1.25-1.5 \mathrm{~mm}$. broad, gradually tapering to about half that breadth at the upper end, from which no offshoot is given off; margins nearly straight. Second band rounded at the lower end, which is generally slightly narrower than the upper end, sides straight. Between the two bands are two elongated yellowish spots, sometimes united into an undulate streak. Spots at bases of wings above light yellow, those on the tergum between the wings, pale greenish blue.

Legs black, the posterior surfaces of the fore coxae and bases of fore femora pale yellowish.

Abdomen nearly or quite 4.5 times as long as the thorax, strongly constricted before the middle of 3 , widening to about the apex of 4 and narrowing again slightly on the posterior 4 or 5 segments, though generally expanding slightly on 7 . Seg. I without a ventral tubercle; spinulose area on ventral surface of 2 generally restricted to the apical fourth; auricles with 3-5 teeth; tergal margins angularly approximated opposite the sheath of the penis. Spines of the anterior lamina long, projecting below the tergal margins, curved ventrad and inclined caudad and slightly laterad, stout at the base but tapering to a fine point. Hamular processes long, slender, spine-like, slightly hooked at the tips, inclined ventrad and mesad, the tips often overlapping a little. Hamular folds separate from the hamular processes, and somewhat widely separated from one another, rather small and contracted, the outer and posterior margins meeting at a rotundo-acute angle. Seg. 3 one-fifth to one-third longer than $I+2$ or 4 , the 
relation depending upon climate (vide postea). Lateral carinae on 8 not angulate, obsolete on the basal half of 9 , generally distinct on the apical half. Dorsum of Io with a prominent median tooth between two pairs of much smaller teeth.

Superior appendages as long as, or slightly shorter than, $9+10$, their basal breadth about one-third of the space which separates them, gradually expanding to the middle or a little beyond (dorsal view), where the breadth is about onefifth of the length; thence narrowing again somewhat to the rounded or somewhat angulate apices which bear, near the outer margin, a terminal decurved spine of variable size, generally small but sometimes well developed. Outer margin in dorsal view moderately curved, inner margin feebly or scarcely at all sinuate. In profile view the outer margin is moderately to strongly curved upwards in the distal half, the lower margin minutely denticulate, slightly convex in the basal fifth, somewhat concave before the middle, produced in the distal three-fifths or two-thirds into a rather prominent angulate or arcuate inferior carina. Superior carina distinct except at base, somewhat elevated and arcuate in the apical fourth, smooth. Inferior appendage triangular, about three-fifths as long as the superior pair, the breadth at base equal to three-fifths or two-thirds of the length, sides straight or barely convex, apex rather blunt and rounded, lateral margins terminating above in a pair of minute recurved teeth; in profile gently curved, tapering evenly to the apices.

Seg. I brown, dorsal spot blue, lateral spot greenish yellow, generally about $3 \mathrm{~mm}$. long and $.75-1 \mathrm{~mm}$. broad but much narrower in the Alaskan specimen and generally in European specimens.

Seg. 2 brown, AML greenish yellow in front, blue behind, subrhomboidal, I.75-2 mm. broad at the middle, covering sides of auricle, partly divided by the transverse carina, behind which it is produced dorsad as a narrow offshoot not quite reaching MD. PL yellow in front, shading into blue, about four-fifths as long as the posterior division of the segment, fairly broadly connected with $\mathrm{PD}$, which is confluent with its fellow of the opposite side, forming a broad blue band, 
whose front margin is convexly curved on each side of the middorsal line, and from which a pale greenish median streak extends forward to the front margin, where it is somewhat expanded (AD).

Segs. 3-10 brownish black, AD and MD pale green, PD blue, lateral spots bluish green, on 3 of ten blue. AL on $3-8$, of moderate to small size; on 3, subtriangular, nearly as broad at base as long, upper margin straight, very oblique; on 4-5 or 6 giving off a small basal transverse offshoot which does not form a complete ring. ML on 3-8, of moderate size, enlarging to 6 , angular with the upper margin very oblique on the more anterior segments, more rounded on the posterior segments, front margin not indented. AD represented on 3-8 by a minute spot; MD on 3-8, not connected with ML, a transverse streak on 8 , transversely elongate-triangular on the other segments, the postero-lateral margins more or less concave. PD on 3-IO, I-I.25 mm. long on 3, increasing to I. $5 \mathrm{~mm}$. on 8 , rounded in front; the space separating them gradually increasing from about . $4 \mathrm{~mm}$. on 3 to I or $1.25 \mathrm{~mm}$. on 8 , then decreasing again slightly; inner margins straight on 8 and 9 , nearly parallel on 8 , slightly divergent on 9 , rounded on the other segments. PL on $3-5,-6$ or -7 , separate throughout from PD or narrowly connected on 3 only, triangular on the anterior segments, becoming an elongate streak farther caudad, and finally a mere dot. Ventral surface of abdomen without pale markings.

Wings hyaline to rather strongly flavescent, costal veins brown, ochre-yellow along the free margins, pterostigma long, reddish brown; membranule of hind wing smoky brown, with the basal fourth to more than one-half whitish, not reaching thecross-vein of the anal triangle, which is 2-celled. One or 2 cells between $\mathrm{A}_{2}$ and $\mathrm{A}_{3}$ at their origin. Rsforking at the level of I-2 (fore wing) or I-3 (hind wing) postnodal cells before the stigma, ${ }^{1}$ the upper branch strongly curved proximally; 3 rows of cells between the forks at the level of the distal end of the stigma, and $3-6$ cells between them at the margin. Three or 4 rows of cells between Rs and Rspl at the level of widest separation. Sometimes one or two cross-veins between Rs and $M_{2}$

${ }^{1}$ In European specimens the fork is of ten before the proximal end of the stigma. 
near the point of forking. Mia arising beyond and sometimes opposite the middle of the stigma.

$$
\text { Antenodals } \frac{\text { I6-20 }}{\text { I I-I4 }} \text {, postnodals } \frac{9-\mathrm{I} 3}{\mathrm{II}-\mathrm{I} 5}, \mathrm{CuCr} \frac{5-6}{4-5}, \mathrm{Spt} \frac{3}{2(3)} \text {. }
$$

Female-Abdomen slightly shorter and considerably deeper than in the male, slightly longer than the hind wing. Dorsal and ventral surfaces of 3 nearly straight in profile.

Apices of genital valves not at all elevated, compressed and rather broadly rounded as seen in profile, inner surface obliquely concave. Lateral carinae obscure and rounded at base, prominent in distal half, in profile sinuate, being more or less concave before the middle, convex beyond; in ventral view, sinuate, usually strongly so, being convex in the proximal three-fifths or two-thirds, slightly concave or straight distally. Space enclosed by lateral carinae broadest just before the middle, where the bread th is about three-sevenths of the length, narrowing to about half this breadth before the apices. Ventral surfaces of valves feebly sulcate. Basal plate of ovipositor large, consisting of two rounded lobes, one on each side; lateral plates absent. Styli scarcely more than half as long as the dorsum of Io $(.6 \mathrm{~mm}$.). Appendages about as long as 9+Io, expanding from the moderately slender bases by the curve of the inner margin to about three-fifths of the length, where the bread th is aboutone-fifth of the length, tapering rather abruptly to the rounded or rotundo-angulate apices, which usually terminate in a minute, barely projecting tooth. This tooth is occasionally well developed or may sometimes beabsent. Outer margin nearly straight, inner margin more strongly curved.

The dorsal thoracic bands are usually narrower than in the male and, as a rule, divided in to an anterior longitudinal streak, and a posterior shorter transverse spot at the antealar sinus. The lateral thoracic bands and the lateral abdominal spots tend to be a little broader than in the male, particularly PL, which is represented on $2-7$, and tends to be quadrate in form, and is separated from PD except sometimes on 2 , where they may be narrowly confluent. On the same segment PL is broadly connected with AML and is sometimes 
narrowly joined with ML on 3. AL on 2, quadrate, connected below with ML. PD smaller than in the male, generally connate on 2, but separate in specimens from Alaska and in one from the Magdalen Islands.

The ground colour is like that of the male except that the abdomen is reddish brown, darkened about the margins, sutures and pale areas. Considerable variation exists in the colour of the latter. I have taken both blue and yellow females at Nipigon, Ont., the colour of the former differing but little from that of the male except in the paler shade of blue. In the heterochromatic type all the pale markings are green or yellow. Both types are also represented in a series of British specimens received from Mr. K. J. Morton of Edinburgh. In this series PD varies from blue to greenish yellow and the lateral spots from pea-green to pale yellowish green.

The wings are sometimes hyaline, sometimes more or less flavescent and may be quite deeply suffused with brown. The pterostigma is considerably longer than in the male.

The following colour notes were made on the day of capture from a female taken at Nipigon, Ont.:

Occiput and frons greenish yellow, shading into light yellow slightly tinged with green on the lower part of the nasus and labium; eyes grey-green with a greenish yellow hind margin. Thorax olive-brown, paler beneath; lateral thoracic bands yellowish green, the lower part of the first band yellow. Abdomen brown, lateral spots on I and 2 yellowish green, on the remaining segments pea-green. PD yellowish green, becoming pale green on 9 and ro.

Measurements of North American specimens-Thor. $\sigma^{7}$

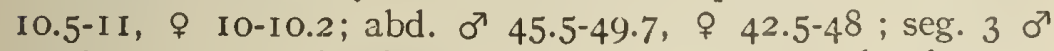
7.4-8.6, क 6-7.1; depth seg. $2 \sigma^{7} 5-5.75$, क क 5-6 ; deptin seg. 3 o 3.75-4.33; apps. $0^{7} 4.8-5.5$, क 4-4.75; gen. v. 2-2.33; h.w. $\sigma^{7} 42-46$, क 39.5-46.5; width h.w. or $12-13$, \& $12.5-13.3$; pter. o' 3.6-4.25, \& 3.7-4.9.

Measurements of British specimens-Thor. $\sigma^{7}$ I0.5-I I.5, o 10.5-12; abd. ơ 47-54.5, क 46-53.5; seg. 3 o 7.5-9, क 6.5-8.33; depth seg. 2 o $5-6.5$, क 6-6.5; depth seg. 3 क 4.25 +.8; apps. $\sigma^{7} 4 \cdot 6-5 \cdot 5$, क 4.33-5.5; gen. v. 2.3-2.5; h.w. of 43.5- 
47. \& 43-47; width h. w. क7 I3-14, क 13.5-15; pter. of $4-4.75$, o $4.33-5.4$.

Nymph (pl.6,fig, I ; pl.8,fig. I ; pl. Io,fig I)-Eyesmoderately prominent, the posterior margin about equal in length to the antero-posterior diameter; lateral margins of head somewhat more oblique than in clepsydra, canadensis, etc., the straight part but little longer than the width of the interocular space; postero-lateral corners of head broadly rounded, posterior region barely emarginate. Mentum of labium seven-elevenths as broad at base as at apex, the apical breadth a little more than two-thirds of the length; proximal three-fifths barely widening distad, the sides feebly arcuate, distal twofifths with the sides rather strongly arcuate; middle lobe somewhat narrow, obtusangulate; lateral lobes narrowing slightly distad, truncate but with the outer apical angle much rounded, the inner with a minute tooth.

Supracoxal processes well developed, equal in length, acute, the posterior a little stouter than the anterior, the intervening space rectangular or slightly narrower than a right angle.

Abdomen of average form, broadest at seg. 6; lateral spines present on segs. 6 to 9, those on 6 rudimentary, on 7 reaching half-way to the posterior margin, on 8 two-thirds of the way to the margin, on 9 not quite to the middle of ro. Lateral appendages rather slender, half as long as the inferior pair ( 9 ), or slightly more $\left(\sigma^{7}\right)$; basal part of superior appendage in the male about four-fifths as long as the lateral pair, its basal breadth a little less than its length, sides feebly emarginate, apex bluntly pointed. Genital valves nearly onehalf as broad as long, not very deeply declivent, nearly or quite reaching the apical margin, the ovipositor slightly shorter.

Head and thorax almost uniform brownish, sides of head and lateral margins above sometimes paler ; legs concolorous. Abdomen brownish; dorsal surface with two longitudinal pale bands, fairly well defined on the anterior four or five segments, but fading caudad and becoming very faint or disappearing altogether at seg. 9.; median dark area between the bands but little or no darker than the general ground colour, but exhibiting a more or less distinct pale 
median line in the anterior half or more of the abdomen; dorsal punctae dark but discrete; sides of abdomen brown, slightly paler outside the lateral scars, which form a pale interrupted wavy band, with a dark inner edge; lateral and dorsolateral punctae dark brown, well marked; no pale mottlings between the lateral scars and the pale dorsal bands.

Measurements-Length of body 39.5-42.8; mentum of labium 6.2-6.9; h.w. 8.4-9.8; h.f. 6.2-7.3; inf. apps. 4.2-4.8; gen. v. I.9-2.4; width of head $7 \cdot 75-8.5$, of abdomen $7-8$.

Material determined - I7 o $19{ }^{\circ}$ (excl. Palæarctic). Quebec: Grand Entry, Magdalen Is., June 30, I901 (D. A. Atkinson, coll. Williamson, 2 ơ I \&). NEw Hampshire: White Mts., Aug. 22, 1862 (Scudder, M.C.Z., I ơ). ONTARIo: Nipigon, July 10, 1907, Aug. 28, 30, 1907, Aug. 4-8, 1910 (Fletcher, Walker, 6 o 4 \%). AlBerTA : Banf, July 17, I902 (Osburn, N.B. Sanson, 2 \%). Britise Columbia: Inverness, Aug. I 890 (Brit. Mus. I \&). NorTHWEST TERRITORY: Ft. Resolution, July, I 862 (Kennicott, M.C.Z., 2 ơ I \&). AlAska: Bethel, Kuskoquin River (Acad. N.S. Phil., I o'); Kodiak, July 20, I 899 (T. Kincaid, Harriman Exped. U.S.N.M., I $\sigma^{\top}$ ); Unga Is., Shumagins, July I 7 , I 899 (W. E. Ritter, Harriman Exped. U.S.N. M., I \&). Wyoming: Shell Creek, Bighorn Mts., July I5, I896 (Currie, U.S.N.M. I o"). Colorado : "Southeastern part," I0,000-I I,000 ft. (Thos. S. Gillin, Acad. N.S. Phil., 2 o 2 \%). Corfi, Colorado Plains, I872 (M.C.Z., 2 \&). Yellowstone : I 872 (Hayden, M.C.Z., 3 \%). ARCTIC AMERICA: (Brit. Mus., I \%). Also I ơ I \&, without data. British specimens: Io o $\sigma^{7} 8$ \%. Merionethshire, England; Capel Cureg, Wales; Glasgow, and Glen Lochay, Scotland; and Emydale, Ireland.

Nymphs-Cierfs, Switzerland, I 900 metres, July 27, I909, 2 \&, one transforming, the other about to transform; exuviae, $4 \sigma^{7} 5 \%$, one of the latter with teneral imago (Dr. F. Ris).

Distribution-Circumboreal; in North America apparently most abundant in the Hudsonian Zone and not known from the Transition Zone. In Europe it ranges into warmer latitudes than in North America.

Geographical variations-Specimens from Alaska and the Magdalen Islands are somewhat smaller than those from Nipigon, the Bighorn Mts. and southwestern Colorado. The wings in the former specimens are slightly broader and the abdomen perceptibly shorter, particularly seg. 3, which is also relatively deeper. This variation in seg. 3 is most marked in the females and is correlated with variation in the length of the appendages, both being dependent upon climatic conditions (vide p. 26).

The northern specimens are indistinguishable in form from British examples, but are, on the whole, decidedly smaller. The largest American specimens I have seen are from Ontario, Wyoming (Bighorn Mts.) and Colorado and 
are about the size of average European individuals. Specimens from Kamtchatka and other parts of northeastern Asia are also smaller than those from Europe and are quite similar to Alaska specimens.

No constant differences can be found between European and North American specimens of this species, but what is typical of the former is not always typical of the latter. The venation of the European specimens is more complex, as is indicated by the following analysis:

1. Rs tends to fork a little farther distad in European specimens, often uncier the proximal end of the stigma.

2. The number of rows of cells between the forks of Rs at the level of the distal end of the pterostigma is typically 3 in American, 4 in European specimens. In a female from Alaska, however, there are 4 regular rows in each wing and in several British specimens there are only 3 rows. When this is the case, however, there are usually indications of a fourth row:

3. In American specimens, there are 3 or 4 rows of cells between $\mathrm{Rs}$ and $\mathrm{Rspl}$ at the level of widest separation, there being 3 rows in about 65 per cent. of cases. In European specimens there are typically 5 rows, often 6 and only occasionally 4 rows.

4. In American specimens there are 3 rows of cells between $M_{4}$ and $M_{s p l}$ where these veins are most widely separated, in European specinens typically 4, though sometimes 3 or 5 rows.

In colour-pattern the differences are but slight. In the European specimens the yellow of the costal veins is more extensive and brighter in colour, the thoracic bands are generally somewhat narrower, the curved spot between the bands and the lateral spot of abdominal seg. I smaller. The front margin of the first lateral band is frequently slightly excavated above the middle, a feature not seen in American specimens.

Habits-On the Nipigon River, where this species is fairly common, it flies over the open marshes and shallow reed-grown waters which border the river below the rapids. Specimens taken July to were teneral: on Aug. $4^{-8}$ they 
were in good condition, while on Aug. 28-30, on which dates three females were captured, one was still fresh the other two somewhat the worse for wear. These were taken while ovipositing among the reeds. The weather was dull, and one was taken in flight during a very light rain.

Ris ('85) has given an interesting account of the habits of this insect in Switzerland, where they are apparently quite similar to their habits in Canada.

Aeshna subarctica Walker.

(Pl. 12, fig. 7 ; pl. I5, figs. $4,4 \mathrm{a}$; pl. I 8 , figs. 4, 4a; pl. 23, figs. 5,6 .)

Aeschna juncea, Fletcher, 35th. Ann. Rep. Ent. Soc. Ont., p. 104 (1906).

Aeshna subarctica, Walker, Can. Ent., XI, pp. 385, 390, 45 I (Igo8); Muttbowski, Cat. Od. N.A., p. II 4 (19I0).

Aesima subarctica, Martin, Gen. Ins., CXV, p. II (IgII).

Male-Occiput lemon-yellow, I.5-2 times as broad as long and I-3.5 times aslong as the line of contact of the eyes. Frontal vesicle more than twice as broad as long, lemonyellow, with a black posterior border. Eyes sea-green or grey-green to light brownish olivaceous with bluish grey reflections; a small dark transverse streak above, the posterior border yellowish green above, whitish or very pale green laterally. Preocular band 2.5-3 times as broad, at the base of the antennæ, as one of the lateral ocelli, narrowing on the sides to little more than half its dorsal width, except at the fronto-nasal suture, where it is generally expanded. T-spot heavy, $2.8-3 \mathrm{~mm}$., stem $.3-.7 \mathrm{~mm}$. broad in front, I mm. broad behind, the sides divergent. Frons and nasus bright yellow, often with an olivaceous tinge, paler along the ocular margin and on upper surface of frons. A heavy black line on the fronto-nasal suture, broadest in the middle. Two black impressed dots above the lower margin of the nasus. Lateral lobes of nasus somewhat flaring, rotundo-obtusangulate. Rhinarium dull dark brown or plumbeous. Labrum light yellow, margined narrowly above, more broadly below, with black. Labium pale dull yellow or greenish, the middle lobe with an ill-defined median blackish spot next the margin. Rear of head black.

Thorax fairly robust, dark brown with an olivaceous tinge deepening to nearly black around the lower parts of 
the lateral bands. Dorsal bands yellowish green, complete, somewhat curved, strongly divergent below, about $4 \mathrm{~mm}$. long and $.7-.8 \mathrm{~mm}$. broad at the middle, tapering towards each end, the lower ends acute and separated by $4.5 \mathrm{~mm}$., the upper ends suddenly expanded, I-I.5 mm. broad, and separated by about $1.5 \mathrm{~mm}$. An ill-defined elongate greenish spot generally present just in front of the humeral suture. Lateral bands of moderate width, light blue above, greenish yellow below; first band rounded at the lower end, where the breadth is $1.3-1.5 \mathrm{~mm}$. thence narrowing to less than $.5 \mathrm{~mm}$. a little above the middle, where it is bent upwards at a slight angle, thence widening to about I $\mathrm{mm}$. at the upper end from which a narrow posterior offshoot arises. Front margin obtusangularly excavated, hind margin nearly straight. Second band rounded or subangulate at the lower end, a little above which the breadth is I.I-I.35 mm., narrowing to the middle or upper third by a broad rounded excavation of the front margin and widening again to the upper end to a breadth of about $1 \mathrm{~mm}$., or slightly more; hind margin straight. Between the two lateral bands are two yellow spots, one larger one partly enclosing the metastigma, and a smaller one above it. Metasternum with two pale yellowish antero-lateral spots. Interalar spots pale blue, spots at bases of costal veins of the wings yellow.

Legs reddish brown, tibiae and tarsi and underside of femora darker; a pale streak upon the outer surface of the fore trochanters and bases of the fore tibiae.

Abdomen a little more than 4.5 times as long as thorax, of average build, considerably inflated at base, strongly constricted before the middle of 3 , thence expanding to the apical margin of 4 ; sides of 9 feebly divergent caudad. Segs. I +2 about as long as 4 ; seg. 3 rather more than one-third longer. Sternum of I without a tubercle. Auricles with 3-5 teeth. Tergal margins approximated on each side of the penis. Spine of the anterior lamina long, slender and sharppointed, directed ventrad and curved slightly caudad, the apices reaching well below the level of the tergal margins. Hamular processes having the form of elongate, flattened and slightly curved plates, rounded at the apices, rather 
longer than the spines and directed ventrad, mesad and slightly caudad. Hamular folds separate from the processes, difficult to see, except in a strong light, as they are sunk deep in the genital fossa and are partly concealed by the hamular processes in a direct ventral view. The anterior part of the fold is very small, but the posterior portion is large and prolonged caudad, forming with its fellow of the opposite side, with which it is closely united, a somewhat rounded prominence (pl. 12, fig. 7). Lateral carinae of 8 nearly straight, those of 9 more or less obsolete in the basal half. Dorsum of 10 with a prominent but not large median tooth, and one or two minute ones on each side of it.

Superior appendages slightly longer than $9+10$, moderately slender at base, the breadth here being one-third to fourninths that of the intervening space; expanding to about the middle or a little beyond; the slender proximal portion, which is about one-fourth to one-third of the total length, passing almost insensibly into the broader distal part, which is one-sixth to one-fifth of the total length; apices rounded or angulate, terminating in an abruptly decurved tooth of variable size, being sometimes minute, sometimes fairly well developed; outer margin gently and regularly convex, inner margin gently sinuate, being proximally concave, distally convex; a prominent dorsal tooth at the extreme base under cover of the tergal margin of 10 ; superior carina distinct, except on the slender basal part, the apical fourth or third somewhat elevated and gently arcuate, without any indications of denticles. In profile view the appendage is more or less distinctly undulate in the basal half (in one specimen from Nipigon the undulation is scarcely noticeable), curved gently upwards distally; internal part in thedistal three-fif ths to two-thirds bent downwards forming an arcuate inferior carina. Inferior appendage triangular, barely more than half to three-fifths as long as the superiors, basal breadth three-fifths of the length, sides straight, the dorso-lateral margins terminating in a pair of minute preapical teeth, apex rounded; in profile curved as in juncea, tapering considerably from the middle to the apex.

Colour-pattern of abdomen-Seg. I brown, dorsal spot 
narrow, light blue, lateral spot pale greenish yellow to bluish green, elongate triangular, $2.5-3 \mathrm{~mm}$. long, .7-.8 mm. broad.

Seg. 2 brown, AML greenish yellow to pale blue, or yellow in front of the transverse carina, blue behind, covering upper surface of auricles, partly divided by the transverse carina, in front of which it is I-I.5 $\mathrm{mm}$. broad, and extending dorsad behind the suture as a band $2.5-3 \mathrm{~mm}$. long, which is not confluent with MD. MD of the usual form, yellow. PL greenish yellow to pale blue, I.3-I.5 mm. long, rounded in front, narrowly connected with PD, or barely separated from it. PD light blue, somewhat shorter than PL, its front margin rather deeply concavo-emarginate on each side of the middle, along which a narrow greenish streak passes to the front margin.

Segs. 3-Io dark brown, the pale markings variable in colour. AL on $3-8$, greenish blue to pale blue, rather small; on 3 triangular, about $2.5 \mathrm{~mm}$. broad at base, apex reaching the transverse carina; on the succeeding segments semielliptical, not connected with a basal ring but giving off a short basal offshoot. ML on 3-8, greenish blue to pale blue, fairly large, increasing in size to 6 or 7 , subrhombic on the anterior segments, becoming rounded caudad, slightly emarginate in front. AD represented by a small yellow dot on 3-8. MD on 3-8 or -9 , bright yellow, separate from ML, somewhat L-shaped on most of the segments but reduced to a pair of short transverse spots on 8 and of minute dots when present on 9. PD on $\hat{\jmath}$-Io, pale green to pale blue, I $\mathrm{mm}$. long on 3 , increasing to $1.25^{-1.75}$ on 8 , sub-semicircular on $3-7$, the rounded inner margins separated by about $.6 \mathrm{~mm}$.; triangular or subtriangular on 8 and separated posteriorly by about I mm., subovate and about the same distance apart on Io. PL on $3-8$, unconnected with PD, except sometimes narrowly on 3 , straight and elongate on the more anterior segments, dwindling caudad to a dot.

Wings hyaline, costal veins edged with ochre-yellow; pterostigma rather long, dark brown; membranule of hind wing dark smoky brown, the basal fourth or less pale yellowish, not quite reaching the cross-vein of the anal triangle, 
which is 2-celled. One cell between $\mathrm{A}_{2}$ and $\mathrm{A}_{3}$ at their origin. Rs forking at the level of I-3 postnodal cells before the stigma, the upper branch proximally rather strongly curved; 3 (rarely 2) rows of cells between the forks at the level of the distal end of the stigma and 3-6 cells between them at the margin. Three or 4 (rarely 5) rows of cells between Rs and Rspl where most widely separated. MIa arising behind the middle or distal half of the stigma.

$$
\text { Antenodals } \frac{\mathrm{I} 7-2 \mathrm{I}}{\mathrm{I} 2-\mathrm{I} 5} \text {, postnodals } \frac{\mathrm{II}-\mathrm{I} 4}{\mathrm{I} 3-\mathrm{I} 6}, \mathrm{CuCr} \frac{6-7}{5-5}, \mathrm{Spt} \frac{3-4}{2-3}
$$

Female-Abdomen about 4.5 times as long as the thorax and about as long as the hind wing. Seg. 3 rather deep, moderately constricted, about equal in length to I and 2 and about I mm. longer than 4 .

Genital valves short, not longer than the dorsum of 9, strongly compressed on the distal half, lateral carinae distinct only in the distal three-fifths, in profile arcuate, especially distally, in ventral view parallel in the distal half, divergent and indistinct proximally. The ventral surface of the valves is not developed in the distal half and proximally slopes outward, passing almost insensibly into the lateral surfaces. Apices strongly compressed and blade-like, in profile broad and rounded, with a very minute tuft of hair. Styli $.5-6 \mathrm{~mm}$. long. Basal plate of ovipositor unusually large, consisting of a pair of rounded lobes, one on each side. Appendages about as long as $8+9$, lanceolate, considerably slenderer at base than at apex, greatest width at three-fifths to two-thirds the length, equal to onefifth or three-tenths of the length; curve of outer margin very slight, that of the inner margin much stronger; apices rounded, with or without a small terminal tooth.

The pterostigma is somewhat longer than in the male. Rs forks at the level of I-2 postnodal cells before the stigma or beneath its anterior end. Two cells are present between $A_{2}$ and $A_{3}$ at their origin.

The dorsal thoracic bands are narrower than in the male and are sometimes complete but generally divided into an upper shorter and lower more elongate spot, or the latter only 
may be present. Lateral bands of similar form to those of the male but slightly broader, the intermediate spots of ten confluent. PD somewhat smaller than in the male, all the other spots larger, AL and AD often connected by complete basal rings. $\mathrm{AL}$ on 3 trapezoidal, confluent with ML. PL large, subquadrate, separate throughout from PD, but generally confluent with ML on 2 and sometimes also on 3. PD irregularly quadrate on 8 and 9 .

Dichromatism occurs in this species and the colour variations are very similar to those of $A e$. juncea. In several specimens seen in life the coloration was almost like that of the male, the lateral abdominal spots being pale blue or blu $\mathrm{i}_{\mathrm{i}} \mathrm{h}$ white and $\mathrm{PD}$ varying from very pale blue to greenish. In others all the pale markings are yellow or greenish yellow. The eyes vary from grey-green to Indian yellow and the wings from hyaline(generally in homœochromatic individuals) to deeply flavescent(generally in heterochromatic individuals).

Measurements - o IO-II, क 9.5-10.5 ; abd. के 47-5I.5, क 43.5-49; seg. 3 o 8.7-9.5, ㅇ 7-7.6; width seg. 2 का 5-5.5, क 5.25-5.7; width seg. 3 ơ 3-3.75; apps. का 5.3-6, क 5.33-6; gen. v. I. $8-2$; h.w. of 42-46, of 39.5-44.5; width h.w. $\sigma^{7}$ I2-12.5, o 12-I 4 ; pter. of 3.6-4.2, क 4.2-4.7.

Types- $\sigma^{7}$ and $\%$, coll. Walker-Nipigon, Ont.

Nymph-Among the nymphs and exuviae which I collected at Nipigon, Ont., in August, I9I0, there are two species of Aeshna which I had not met with before. As the nymphs of only two of the six species of this genus that occur at Nipigon are unknown, viz., Ae. subarctica and Ae. interrupta, it is reasonable to refer the two unknown nymphs to these two species.

The form referred to Ae. subarctica is placed under this species for the following reasons:

I. It resembles the nymph of juncea, the only near ally of subarctica, very closely in both structure and colour-pattern, and particularly in the details of the labium. One of the most marked differences is the distinctly longer lateral appendages of the female. As these organs are the rudiments of the appendages of the adult this is what we should expect 
in view of the similar difference in the length of the appendages of the adult females of these two species.

2. Of the two nymphs only one exuvia of the form referred to subarctica was found, against five of the form referred to interrupta, and of the adults of these two species interrupta is by far the more abundant.

3. The form referred to interrupta most closely resembles that of eremita, the nearest relative of this species.

Head similar to that of juncea, except that the posterolateral angles are more prominent, though well rounded off, being nearly as in interrupta. Labium indistinguishable from that of juncea.

Supracoxal processes well-developed, subequal, the anterior considerably slenderer than the posterior.

Abdomen a little slenderer than in juncea, broadest at segs. 6 and 7. Lateral spines present on segs. 6-9, those on 6 mere rudiments, those on 7 distant from the posterior margin by about their own length and on 8 by about one-fifth their length, on 9 reaching to the middle of $\mathrm{I} 0$. Lateral appendages three-fifths as long as the inferior pair. Genitalia of female barely reaching the posterior margin of seg. 9, the genital valves more steeply declivent and somewhat narrower than in juncea.

Colour-pattern similar to that of juncea, differing only in the more faintly marked punctae, which are but little darker than the ground colour, and in the somewhat larger size of the dorso-lateral punctae.

In the young nymphs there is a very dark brown band on the sides of the head and prothorax (also distinguishable in the exuvia on the prothorax and anterior part of the mesothorax) and a very distinct medio-dorsal pair of narrow dark brown longitudinal streaks. These may also be seen in the nymph of juncea.

Measurements-Length of body 40 ; mentum of labium 6 ; h.w. 9 ; h.f. 7 ; inf. apps. 4.5 ; gen. v. 2.2 ; width of head 7.5 ; width of abdomen 7 .

Distribution, etc.- This species inhabits the Canadian Zone, from the Atlantic coast to Manitoba. The single female from Lake Simcoe was probably a wanderer from the north, as 
I have collected there for many seasons and have never seen another specimen.

Ae. subarctica is closely related to Ae. juncea, the most important differences being found in the accessory genitalia of the male. Apart from these, however, the two species may be readily separated by the differences in the form of the lateral thoracic bands, and by the length of the appendages, particuiarly in the female.

These two species fly together at Nipigon, Ont., and I was unable to distinguish them in flight, nor could I detect any differences in habits.

\section{Aeshna interrupta Walker.}

With the typical form of this species I have united $A e$. lineata, interna and nevadensis, as the study of a large series of specimens seems to indicate that these forms are but gengraphical races of one and the same species.

The chief specific characters are as follows: frontal vesicle rather large, a black or dark brown line on the fronto-nasal suture, dorsal thoracic bands reduced to small isolated spots, or absent, lateral bancis onemillimetre, or less, in breadth, either straight and soinetimes reduced to a mere ine or livided each into an upper and lower spot. Sternum of aldominal segment I without a tubercle but with numerous spines near the posterior margin. Abdominal spots well developed or but little reduced, blue, except, as a rule, MD, which is generally greenish or yellowish. Lateral spot on I very small or absent. Venter wholly black. Rs forking at the level of I-2 postnodal cells before the pterostigma, MIa arising opposite or beyond the distal end of the stigma.

Male-Anal triangle 2-celled, auricles with 3-5 teeth, tergal margins bounding the genital fossa not approximated opposite the sheatin of the penis, considerably elevated behind. Spines of the anterior lamina very short and blunt, directed ventrad and caudad, their apices sunk below the level of the tergal margins and often concealed by them. Hamular processes directed ventrad and mesad, short and very broad, their internal margins rounded and terminating in a minute but well-rounded tubercle. Hamular folds continuous with 
the hamular processes, well developed, ear-like, closely approximated mesially, their lateral margins regularly curved and passing insensibly into those of the hamular processes, apices rounded.

Superior appendages expanding unsymmetrically from the base, the inner margins more or less sinuate. the superior carinae gradually and moderately elevated, usually with a few minute denticles near the apices, which are typically rounded and not at all decurved. Terminal tooth small or absent. Inferior appendage triangular, three-fifths to two-thirds as long as the superior appendages.

Female-Genital valves extending caudad about as far as the apical dorsal margin of 9 , apices not at all elevated; lateral carinae percurrent, very prominent, in lateral view irregularly arcuate concealing the ventral surface except near the base, highest a little beyond the middle, straight or slightly depressed before the apices; in ventral view divergent in the proximal third, thence converging to the small squarely cut apices; breadth of enclosed space about one-third of the length. Ventral surfaces of valves sulcate throughout, most deeply towards the apices. Styli rather more than half as long as the dorsum of $10(.66 \mathrm{~mm}$.). Basal plate of ovipositor of moderate size, posterior margin straight, lateral plates distinct. Appendages slightly shorter to slightly longer than $8+9$, gradually expanding from the slender base to three-fifths or twoihirds the length, where the breadth is about one-fifth of the length, thence narrowing somewhat to the rounded apices, which only rarely have a minute terminal tooth. Inner margin more strongly curved than the outer margin.

This species may be separated into four geographical races by the following table:

A. Lateral thoracic bands each divided into a superior and inferior spot (in the female sometimes only strongly constricted); superior appendages of the male without any indication of a ventro-internal basal tubercle; their apices generally without a terminal tooth; appendages of the female typically as long as, or longer than, $8+9$, their apices broadly rounded.......................... interrupto. AA. Lateral thoracic bands not divided. 
B. Superior appendages of the male without a ventrointernal basal tubercle.

C. Lateral thoracic bands about I mm. broad near the lower end, somewhat narrowed at the middle; inner margin of superior appendages of the male in profile slightly concave before the middle, in dorsal view strongly sinuate, the breadth of the appendage increasing rapidly from the basal fourth, so that at the middle it is fully twice as broad as at base, thence scarcely narrowing to the well-rounded apices, which bear, near the outer margin, a prominent tooth; inferior appendage slightly more than half as long as the superior appendages. Female unknown..........nevadensis. CC. Lateral thoracic bands linear, their breadth rarely more than $.75 \mathrm{~mm}$.; inner margin of superior appendages of male in dorsal view very gently sinuate, in profile straight or slightly convex before the middle, the inferior carina rather low, its angle rounded or obsolete; breadth of appendage at middle scarcely twice that at the extreme base, thence narrowing gradually to the rounded or bluntly angulate apices, which are normally without a terminal tooth; superior carina but little elevated, finely denticulated or smooth, inferior appendage three-fifths to two-thirds as long as the superior appendages. Appendages of the female usually somewhat shorter than $8+9$, their apices less broadly rounded than in interrupta....... lineata. BB. Superior appendages of the male with a low basal tubercle on the ventro-internal surface ; inner margin in dorsal view gently sinuate, in profile slightly concave beyond the middle, beyond which it forms a prominent, more or less obtusangulate, inferior carina; breadth at middle about twice that of the extreme base, thence narrowing gradually to the more or less acute apices, which terminate in a small spine; superior carina moderately elevated before the apex, with a few minute denticles; lateral thoracic bands about I $\mathrm{mm}$. broad below, narrower above; appendages of the female as in lineata. interna. 
Aeshna interrupta interrupta Walker.

(Pl. I, figs. I, 5; pl. I3, fig. I ; pl. 15, figs. 5, 5a ; pl. 20, figs. I, Ia; pl. 22, figs. $6-8$; pl. 24 , figs. 3,4 .) part].

Aeschna propinqua, Scudder, Pr. Bost. Soc. Nat. Hist., X, p. 215 (1886) [in

Aeschna clepsydra, Calvert, Ent. News, V, p. II, fig. 5 (1894); Walker, 36th Ann. Rep. Ent. Soc. Ont., p. 69 (Ig06) [in part] ; Williamson, Ent. News, XVII, p. 133-I35 (1906) [in part]; Walker, Can. Ent., XXXVIII, p. 50 (1906) [in part].

Aeschna " $w$ ", Williamson, Ohio Nat., VII, p. ${ }_{4} 6$ (1907); Walker, Ott. Nat., XXII, p. 55 (1908).

Aeshna interrupla, Walker, Can. Ent., XL, pp. 381, 387, 450; pl. Io, fig. 3 (1908); Muttkowski, Cat. Od. N.A., p. II (1910).

Aeschna interrupla, Martin, Gen. Ins., CXV, p. II (IgIr).

Occiput pale dull yellow, somewhat broader than long, two-thirds to one-half as long as the line of contact of the eyes; frontal vesicle greenish yellow, broadly margined with black, the pale area not reaching the lateral ocelli; eyes varying in colour from olivaceous grey with a bronzy lustre to green or bluish grey with green reflections, a dark curved transverse streak above, posterior border yellow or green, preocular band about twice as broad at base of antennæ as one of the lateral ocelli, continued ventrad on the sides to the lower margin of the nasus where it is scarcely half as broad as upon the frons. T-spot heavy, 2.8-3 mm., stem .5- $1 \mathrm{~mm}$. in front, I-I.4 mm. behind, sides straight or a little convex. Face yellowish green to olive, pale yellow on the sides and dorsal surface of frons. A heavy black line on the fronto-nasal suture, narrowing laterally to a fine line. Lateral lobes of nasus obtusangulate, more or less rounded, not flaring. Rhinarium dull greenish yellow (reddish brown in dried specimens). Labrum pale green, margined narrowly above, more broadly below, with black. Labium pale yellowish, obscured with reddish brown; lateral lobes dull bluish or plumbeous. Rear of head black.

Thorax dark olive-brown, becoming more or less transparent in dried specimens, owing to the thinness of the cuticle and the shrinkage of the tissues away from it; the clothing of hair moderately thick, much longer below the apex of the median carina than above it. Dorsal bands reduced to a pair of lanceolate green spots about $2-2.5 \mathrm{~mm}$. long and somewhat less than $\mathrm{I} \mathrm{mm}$. broad, no spots in the antealar sinus and 
no humeral spots. Lateral bands each divided into a superior blue and an inferior yellowish green spot, surrounded by a diffuse dull blackish margin; the inferior spots ovate, about I mnı., or somewhat less, broad, the anterior somewhat broader, the posterior somewhat narrower than the corresponding superior spot. There are also two small yellowish spots between the lateral "bands," one just below the spiracle, the other, a mere dot, farther dorsad.

Femora dark reddish brown, black beneath, the anterior pair often with a pale streak on the basal third or half of the outer surface, tibiae and tarsi black.

Abdomen moderately slender, being, on the-whole, slightly broader than in Ae.canadensis, clepsydra and verticalis, narrower than in $A e$. constricta. Structural features, accessory genitalia, etc., as given under "specific characters."

Superior appendages generally a little shorter than $9+10$, sometimes slightly longer, slender in the proximal fourth, the basal breadth of which is about one-third of the intervening space, thence expanding mesad to about two-fifths of the length, where the breadth is about twice that at base, and narrowing again very slightly to the broadly rounded apices, which are sometimes armed with a minute projecting tooth; outer margin gently and evenly convex, inner margin rather strongly sinuate; superior carina in dorsal view mesad of the middle line, obsolete in the basal fourth, gradually eleyated distally, where it bears 2-6 minute denticles. Outer margin, in profile, curved gently upwards, inner (lower) margin feebly concave before the middle, beyond which it forms a low, somewhat obtusangulate, inferior carina. Inferior appendage about three-fifths as long as the superior appendages and twice as long as the basal breadth, triangular with straight lateral margins and bluntly rounded apex, surmounted by a pair of small dorsal tubercles; in profile moderately and evenly curved, rather broad in the middle but tapering considerably to the apex.

Colour-pattern of abdomen-Seg. I brown; dorsal. spot well developed, blue; lateral spot green, I-2 mm. long (transverse), $.5 \mathrm{~mm}$. or less broad.

Seg. 2, brown; AD a minute yellowish dot, AMIL a bluc 
band about $.7 \mathrm{~mm}$. broad, continuous above with $\mathrm{MD}$, passing ventrad along the transverse carina to the auricle, then bending cephalad to the posterior margin, where its breadth is about $1.5 \mathrm{~mm}$. MD green ; PL confluent with PD, forming a broad blue band covering two-thirds of the posterior division of the segment above the auricle, the anterior margin deeply excavated laterally and indented on each side of the middorsal line, along which a narrow streak runs cephalad nearly to the front margin.

Segs. 3-10 brownish black; MD green, the other spots azure blue (PD on Io sometimes pale greenish). AL on $3-8$; on 3 separated above at base from its fellow by somewhat more than I $\mathrm{mm}$., the upper margin passing obliquely downwards so that the breadth at the transverse carina, where it ends, is only about I mm.; on 8 a mere dot; on the remaining segments less than $.5 \mathrm{~mm}$. broad and connected with, or narrowly separated from, a narrow basal ring; upper margins oblique, lower margins indented. ML on $3-8$, of moderate size, irregularly quadrate, rounded behind on 6-8, front margins angularly indented. MD distinct and comparatively large on 3-7, generally represented by a pair of dots on 8 , on 3 broadly connected with ML, on 4-7 triangular, the postero-lateral margins angularly excavated. $\mathrm{PD}$ about $\mathrm{I} \mathrm{mm}$. long on 3 , increasing to $1.75 \mathrm{~mm}$. on 7 and 8 , slightly smaller on 9 , inner margins on $3-5$ or -6 rounded, on the remaining segments more or less straight, becoming widely separated (I $\mathrm{mm}$.) on 8-10, and somewhat divergent cephalad on 8 and 9. PL on $3-4,-5$ or -6 , small, more or less indistinct posteriorly; on 3 broadly confluent with PD, on 4 narrowly confluent or separate, on the other segments always separate.

Wings hyaline, costal veins pale brownish yellow, pterostigma dark smoky brown above, pale greenish brown beneath, membranule smoky brown with the basal fifth or third white, extending to the cross-vein of the anal triangle. One or 2 cells between $A_{2}$ and $A_{3}$ at their origin. Rs forking at the level of I-2 postnodal cells before the stigma, 3 or 4 rows of cells between the forks at the level of the distal end of the stigma, and 3 to 5 cells between the forks at the wing-margin. Four or 5 rows of cells between Rs and Rspl at the level of widest separation. 
Antenodals $\frac{15-22}{\text { II } 16}$, postnodals $\frac{8-14}{10-15}, \mathrm{CuCr} \frac{5-7}{5-6}$, Spt $\frac{2-4}{2-3}$.

Female-The abdomen, which is slightly shorter than in the male, varies considerably in form, especially in the length, depth and amount of constriction of seg. 3 (vide postea).

Appendages as long as, or slightly longer than, $8+9$ (slightly shorter in specimens from Newfoundland and the Magdalen Islands), outer margin nearly straight, inner margin evenly curved, apices broadly rounded, without a terminal tooth.

Dorsal thoracic bands still more reduced than in the male, being minute indistinct spots, often wholly invisible in dried specimens and perhaps also in living ones. Spots representing the lateral thoracic bands somewhat larger than in the male, those of the first band of ten barely connected. PD smaller than in the male, especially on the anterior segments, not confluent above on 2, and separated on 8 and 9 by I-I.5 mm. PL on 3-6, much larger than in the male, confluent throughout with $\mathrm{PD}$, and on 2 and 3 sometimes also with AL.

The range of colour variation in this species is complete, but the pure homœochromatic female seems to be rare. Most of the individuals I have observed in the field were intermediate forms, but examples of extreme heterochromatism are not at all uncommon.

In the common intermediate form most of the light markings are more or less greenish yellow, the lateral spots of the abdomen often somewhat bluish, as shown in the specimen figured (pl. 24, fig. 4).

In a heterochromatic female from Nipigon, Ont., the coloration noted just after death was as follows: Thorax and abdomen dark olive-brown. Eyes deep yellowish green, with a yellow hind border; face ochre-yellow. Spots of thorax and abdomen bright cadmium-yellow, tinged with green. ML on 5-9 and PD on 8-Io pale dull greenish.

In another specimen from the same locality the spots of the abdomen were all yellowish olive. 
I have not seen a female with deeply flavescent wings such as are sometimes met with in the races lineata and interna but sometimes a yellowish cast is present and it is probable that deeply flavescent wings sometimes occur.

Measurements (exclusive of specimens from Newfoundland and the Magdalen Islands):

Thor. ơ IO-II.5, \& I0.5-II; abd. o 45.3-5I, \& 47-51.5; seg. $3 \sigma^{7}$ 8. I-9.5, ᄋ 7-9; apps. o 5-5.6, क 6.5-7.5; gen. v. 2.25-2.5: h.w. $\sigma^{7} 43-47 \cdot 5$, \& 46-49; width h.w. $\sigma^{x}$ I2.5-13.6, क 13.6-I 4.33; pter. or 3.33-4, o 3.75-4.5.

Measurements of specimens from Newfoundland and the Magdalen Islands- $\left(\mathrm{I} \sigma^{7}, 4 \%\right)$. Thor. $\sigma^{7}$ I I, \& I0-I 0.5; abd. $\sigma^{7} 49$, क 45-48; seg. 3 o 8.6, \& 6.75-7.5; apps. $\sigma^{x} 5$ mm., क 5.25-5.66; gen. v. 2.33-2.66; h.w. $\sigma^{7} 47$, \& 44.5-46.5; width h.w. $\sigma^{7}$ I $4, \&$ I 3.5-14; pter. $\sigma^{7} 3.5$, \& 4.45 .

Types- $\sigma^{7}+$, coll. Walker-Nipigon, Ont.

Nymph (pl. 6 fig. 2 ; pl. 8, fig. 2 ; pl. Io, fig. 2)-As mentioned on p. 98 two unknown Aeshna nymphs were found at Nipigon, Ont., which were referred to Ae. subarctica and Ae. interrupia respectively. The form described below is referred to interrupta (1) by elimination of all other species occuring at $\mathrm{Ni}$ pigon; (2) because it comes next to the nymph of eremita in point of numbers, as is the case with the adults of these species; (3) because of its close resemblance to the nymph of eremita, the nearest relative of interrupta.

Eyes shaped as in juncea but a trifle more prominent; lateral margins of head slightly arcuate, postero-lateral angles broadly rounded, posterior margin feebly concave. Mentum of labium slightly narrower at base than in $A e$. juncea, the basal breadth equal to about three-fifths of the apical, the latter equal to about five-sevenths of the length ; proximal three-fifths slightly but distinctly widening distad, the sides straight or very nearly so, sides of distal two-fifths strongly arcuate; middle lobe somewhat broader but less produced than in $A e$. juncea, broadly obtusangulate; lateral lobes scarcely narrowed distad, squarely truncate, the outer apical angle little or not at all rounded, the inner angle with a 
minute tooth. Supracoxal processes moderately prominent, the anterior slightly longer and more slender than the posterior, the interval a little less than a right angle. Abdomen broadest at seg. 6 , shaped as in juncea, seg. 9 nearly three times as broad as long; lateral spines present on segs. 6-9, not at all divergent on 8 and 9, extending towards the posterior margin of the corresponding segments as follows : on 6 onethird to two-fifths of the distance, on 7 three-fourths of the distance, or quite, to the margin, on 8 a little beyond the mar- gin, and on 9 as far as the proximal three-fifths of I0. Lateral appendages slender, a little more than half as long as the inferior pair, basal part of superior appendage of male somewhat more elongate than in juncea, the basal breadth equal to about three-fourths of the length, sides distinctly concave, apex rounded. Genitalia of female not quite reaching the apical margin of 9, genital valves about three times as long as broad, more steeply declivent than in juncea.

Head behind the eyes with a pair of roundish scars surrounded by a pale margin, a dark submarginal blotch on each side and a broad pale marginal band, extending from the eyes to the postcrior margin of the pronotum. Dorsum with a pale sigmoid streak in front of the bases of the hind wing-pads. Femora brownish, with three pale rings, a basal, a median and a preapical; tibiae and tarsi almost concolorous. Abdomen brown, varying much in depth of shade and in the extent of the pale mottlings, the arrangement of which, when not greatly obscured, is as follows: dorsal surface with a series of pairs of pale spots, largest on the anterior segments and generally running together on the first three or four segments to form two irregular bands, but separate on the posterior segments and confined to the basal part of each segment; another series of subcrescentic pale blotches, just laterad of the dorso-lateral punctae, diminishing in size caudad and disappearing at seg. 7 or 8 ; a series of large submarginal pale blotches enclosing the lateral scars, which appear outlined in brown and touching the lateral punctae; and a series of pale subovate median dorsal spots, very small on the basal segments but increasing in size to seg. 7 and absent beyond. There is also on several of the middle segments, in 
front of the transverse carina and the lateral scars, a pair of whitish patches alternating with darker ones. Punctae dark brown, the dorsal series sometimes obscured by dark brown blotches. Spines pale, with the apices dark.

Measurements-Length of body 39-4I.5; mentum of labium 5.9-6.4; h.w. 9-1o ; h.f. 6.5-7.2; inf. apps. 4.5-4.9; gen. v. 2 ; width of head 8-8.3, of abdomen 7.25-8.

Material determined - 46 o 31 \%. NEwFoundLAND: Grand Lake, July 21. I901 (D. A. Atkinson, coll. Williamson, I $\sigma^{7}$ ); Bay of Islands, July 7, I90 I (D. A. Atkinson, coll. Williamson, 2 \%). Nova Scoria: (M.C.Z., I o', Brit. Mus., I o'). MaINE : Portland, Aug. 9, 1870 (Jones, M.C.Z., I \&). Vermont: Aug., 1907 (Ellis Frost, coll. Williamson, I $0^{\top}$ ). MASSACHUSETTS: (Uhler, M.C.Z., I o'). Quebec: Grand Entry, Magdalen Is., June 30, I90I (D. A. Atkinson, coll. Williamson, 2 \% teneral); Chicoutimi, Aug. 23, I901 (Calvert, I ơ). ONTario: Ottawa, Meach Lake, July 21, 1907 (A. Gibson, I ㅇ ); Oxtongue Lake, Muskoka, Aug. 22, I904 (Walker, I o) ; Álgonquin Park, Aug. 14, 1903 (Walker, 2 ơ I \%); Temagami Forest Reserve, Lake Obabika, Sept. I I, I 2, I908 (Walker, 8 万ั 3 ᄋ); Temagami, Aug. 15, I 906 (P. Hahn, I o o $^{7}$; Sudbury (J. D. Evans, 2 o'); Sault Ste. Marie, Algoma, Sept. 18, 20, I907 (Donaldson, coll. Williamson, $20^{7}$ ); Heyden, July 31-Aug. 4, I906 (Williamson II or 4 \%) ; Searchmont, Aug. 6-9, 1906 (Williamson, I ơ 2 \%); Nipigon, Aug. 28-30, 1907, Aug. 6-8, I9 10 (Walker $7 . \sigma^{7} 7$ ); Fort William, Aug. 2, 1910 (Walker, I o I 9 ). NEW YORK: Catskill Mts., Aug. 28 (Acad. N.S. Phil., I ơ); Lake St. Regis, Franklin Co., Sept. 5-22, I 890 (J. P. Moore, Acad. N.S. Phil., I ơ 2 o ). MICHIGaN : Isle Royale, July 13, 1905 (Gleason, Coll. Univ. Mich., I \&); Minnehaha Falls, Emmet Co., Aug. 23, I907 (Williamson, I $\sigma^{7}$ ); Douglas Lake, Topinabee, Aug. 20, I9I0 (Miss A. O'Brien, I $\sigma^{7}$ ). British Columbia: Inverness, Aug. I 890 (Brit. Mus., $2 \sigma^{\top} 2$ ค).

Nymphs-Nipigon, Ont., Aug. 5-8, 1910, $10^{7}$ (St. F); exuviae, $40^{7}$ I 9.

Identity-Scudder's description of Ae. propinqua was evidently based partly upon specimens belonging to this species, as the lateral thoracic bands are described as sometimes divided each into an upper and lower spot. The types of propinqua now in existence do not, however, include any specimens of interrupta, but belong to juncea and verticalis. I have therefore let the name propinqua remain in the synonymy and have described the present species under the new name interrupta.

Distribution-The race interrupta is a characteristic inhabitant of the Canadian Zone east of the Great Plains. It occurs only occasionally in the Transition Zone, except in its most northern parts, and is apparently absent from the Upper Austral Zone. It is not known north of the limits of the Canadian Zone. The occurrence of this eastern race in the extreme northwestern part of British Columbia needs confirmation. The four specimens in the British Museum from 
this locality are, however, not quite typical in the form of the superior appendages of the male, these structures approaching those of the races lineata and interna. It is thus possible that the distribution of the British Columbia form is not continuous with that of typical interrupta.

Geographical variations-Considerable variation exists among females in the length and depth of the third abdominal segment and in the length of the appendages, and these variations are dependent to a great extent, though not wholly, upon locality. These structures are shortest and the third segment deepest in specimens from Newfoundland and the Magdalen Islands, longest in a female from Ottawa, Ont. (pl. I, fig. Ic).

Females from the two former localities also differ from the typical form in the coalescence of the spots on the sides of the thorax and in the specimens from the Magdalen Islands the lateral bands scarcely differ from those of the western race, interna (vide pl. 22). Of the two females from this locality, both tenerals, the appendages are present in only one and differ from.those of any other specimen of the race interrupta that I have seen in their slenderness and the acuteness of the apices. It may be that this form is a local race. The appendages of both male and females from Newfoundland are typical in form and the spots of the lateral thoracic bands are separate in the male.

From Nova Scotia westward to Fort William, on the north shore of Lake Superior, no geographical variations could be detected, except those which are apparently the effect of temperature. The lateral thoracic bands are constantly divided in the male and the second band also in the female. The British Columbian specimens, as already mentioned, differ only very slightly in the form of the male appendages, which approach those of interna and lineata. In one of the males the terminal tooth of the superior appendage is distinct though very small, in the other it is barely indicated.

Habits-This species flies over shallow waters grown up with reeds, in bushy pastures, etc. I have observed nothing in which its habits differ from those of juncea, canadensis, etc. Mr. Williamson, however, has taken this species flying over 
water after sundown, a habit which I have observed only in Ae. umbrosa.

Ae. interrupta can be distinguished in flight from the other species with which it is associated by the dark sides of the thorax.

Aeshna interrupta nevadensis Walker.

(Pl. I 5, figs. 6, 6a; pl. 22, fig. 9.)

Aeshna nevadensis, Walker, Can. Ent., XL, p. 382, 45I (1908) ; Muttkowski, Cat. Od. N.A., p. 113 (1910).

Male-Similar in form to the race interrupta, differing chiefly in the form of the lateral thoracic bands and the superior abdominal appendages.

Colour and markings of the head similar to those of interrupta but the black line on the fronto-nasal suture is narrower than is usual in interrupta and in one specimen is very narrow.

Hairs covering the thorax somewhat paler than in interrupta, dorsal bands pale yellow, sometimes well defined, about $2 \mathrm{~mm}$. long and $.3 \mathrm{~mm}$. broad. Lateral thoracic bands not divided, nearly straight, pale yellow below, bluish above. First band rounded at the lower end where it is about I mm. broad, narrowing to $.5 \mathrm{~mm}$., or less, at the middle, and remaining about this width or expanding again slightly to the upper end. Second band .66-1 mm. broad below, generally constricted about the middle and expanding again to about I $\mathrm{mm}$. at the upper end.

Colour-pattern of abdomen nearly identical with that of interrupta. MD on segs. 3-5 tends to be larger and to lose the triangular form and on 3 , and sometimes also on 4, may be broadly confluent with ML. AL and ML are also sometimes confluent on 3. AL is narrowed as in interrupta but is not, or less distinctly, indented below. PL present on 3-7, connected throughout with $\mathrm{PD}$, of which it forms a falciform ventral offshoot.

Superior appendages somewhat shorter than 9+10, differing from those of interrupta in the somewhat greater length of the slender basal portion, which is nearly or quite one-third of the length of the appendage, in the more strongly and angularly sinuate inner margin and consequently more 
rapid expansion of the broad distal part of the appendage, which is slightly broader and less tapering distally than in interrupta, the apices being more broadly rounded and terminating in all the specimens examined in a minute tooth. Superior carina with 3-5 minute teeth. In profile view the superior appendages are practically identical with those of interrupta. Inferior appendage about three-fifths as long as the superior appendages, similar to that of interrupta.

Wings similar to those of interrupta except that the membranule is uniform greyish brown. Rs forking at the level of I-2 postnodal cells before the stigma; 3 rows of cells between the forks at the distal end of the stigma, and 3-4 cells between them at the margin. Three or 4 rows of cells between Rs and Rspl where most widely separated. M Ia arising beyond the middle of the stigma, generally under the distal end. Two cells between $\mathrm{A}_{2}$ and $\mathrm{A}_{3}$ at their origin.

Antenodals $\frac{\mathrm{I} 5-\mathrm{I} 7}{\mathrm{I} 2-\mathrm{I} 3}$, postnodals $\frac{9-\mathrm{II}}{\mathrm{II}-\mathrm{I} 3}, \mathrm{CuCr} \frac{5-6}{4-5}$, Spt. $\frac{3}{\mathrm{I}-2}$.

Female unknown.

Type-o $\sigma^{x}$, Mus. Comp. Zoology-Reno, Nevada.

Measurements (male) - Thor. IO-IO.5; abd. 46-48; seg. 3 8-9; apps. 4.8-5; h.w. 45-47; width h.w. I3.6-14; pter. 3-3.5.

Nymph-Unknown.

Material determined-NeVADA: Reno, 1878 (H. K. Morrison, M.C.Z., $80^{*}$ ). Only two of these, kindly lent me by Mr. Samuel Henshaw, were studied in detail, and the venational characters given above are based on these two specimens alone.

Aeshna interrupta lineata Walker.

(Pl. I6, figs. I, Ia; pl. 24, figs. 5, 6.)

Aeshna lineala, Walker, Can. Ent., XL, pp. 382, 388, 450 (1908); Muttkowski, Cat. Od. N.A., p. II2 (1910).

Male-Head as in race interrupta, the frontal vesicle a little shorter, the naso-frontal line and the black lateral margins of the race generally a little narrower.

Thorax slightly heavier than in interrupta, colour similar but appearing paler on account of the longer and paler growth of hair, which gives it a greyish brown appearance. Dorsal bands generally even more reduced or entirely absent. 
Lateral bands linear, nearly straight, greenish yellow below, more or less bluish or blue above, the first band $.5 \mathrm{~mm}$., or less, broad at the lower end, tapering dorsad to a fine streak; second band still narrower below, somewhat more oblique and gently curved backwards, sometimes interrupted below the middle.

Abdomen slightly shorter and stouter than in interrupta; auricles with 3 teeth (occasionally 4 ); accessory genitalia as described under "specific characters."

Superior appendages barely shorter than the dorsa of $9+10$, showing no very constant differences from those of interrupta, but typically darker in colour, expanding more gradually from the base to three-fifths of the length, where the breadth is generally somewhat less than in interrupta;-apices rounded, usually smaller than in interrupta, sometimes with a very minute terminal tooth; curve of outer margin stronger, inner margin less sinuate, denticles of superior carina usually very minute and occasionally absent altogether; appendage in profile more strongly curved upwards. Inferior appendage three-fifths to two-thirds as long as the superior appendages, the apex smaller than in interrupta, otherwise similar in form.

Colour-pattern of abdomen similar to that of interrupta but the blue spots are somewhat larger.

Seg. I as in interrupta.

Seg. 2. AML broader than in interrupta and less distinctly divisible into vertical and horizontal parts, produced ventrad along the front margin to the ventral surface; PL and PD shaped as in interrupta but slightly broader.

Segs. 3-10. AL generally larger throughout than in interrupta, broadly connected on 3 , and sometimes narrowly on 4. PD as in interrupta, or slightly larger on the anterior segments. PL on $3-5,-6$ or -7 , falciform, connected behind on each segment with PD.

Hind wings about as long as the abdomen, the breadth averaging somewhat greater than in interrupta; membranule brownish grey, generally paler than in interrupta, basal fifth or third whitish. One or 2 cells between $A_{2}$ and $A_{3}$ at their origin. Rsforking at the level of I postnodal cell (in hind wing sometimes 
2) before the stigma or behind its proximal half. Three or 4 rows of cells between the forks of Rs at the level of the distal end of the stigma and 2-4 cells (rarely 5) between them at the margin; MIa arising at or beyond the level of the distal end of the stigma (beyond in 80 per cent. of cases).

$$
\text { Antenodals } \frac{\mathrm{I} 4-\mathrm{I} 8}{9-13} \text {, postnodals } \frac{8-\mathrm{II}}{9-12}, \mathrm{CuCr} \frac{5-7}{4-6}, \mathrm{Spt} \frac{\mathrm{I}-4}{2-4} \text {. }
$$

Female - The differences in form exhibited by the females of lineata and interrupta correspond with those of the males. Appendages usually slightly shorter than $8+9$ (a little longer in I of from Regina, Sask.) Apices somewhat less broadly rounded than in interrupta, often with a feebly indicated apical tooth, otherwise as in the latter race.

Dorsal thoracic bands generally absent, sometimes indicated by a minute and usually indistinct spot. Lateral bands as in the male or a little broader. PD somewhat smaller than in male, not confluent on 2. PL much larger than in male, generally confluent with AML on 2 and frequently with $\mathrm{AL}$ on 3 .

Ground colour of abdomen light reddish brown, darker about the margins and pale areas, the latter varying greatly in colour, sometimes closely resembling those of the male, sometimes strongly heterochromatic. In a Winnipeg example of the latter type, the face is rather dark olivaceous, lemon-yellow laterally and on the upper surface of the frons; the dorsal thoracic spots are distinct though minute and are chrome-yellow, as are also the lateral bands and the spots between the wings above. The abdominal spots are somewhat discoloured except those on I and 2, which are yellow. The other abdominal spots were apparently of the same colour. I have another similarly coloured female from the Swan River, Man., and both of these individuals are remarkable for their flavescent wings, a character which I have seen in no other specimens of this race.

Measurements - Thor. $\sigma^{7}$ 10.25-II, 9 I0-I I ; abd. $\sigma^{7} 45-$ 48 , क 44-46; seg. $3 \quad \sigma^{7} 8.5-9 \cdot 3$, क 7-7.5 ; width of seg. $2 \sigma^{7}$ 5 , क 5-5.8; apps. o 4.5-5, o 4.5-6.5 ; gen. v. 2.3-2.6; h.w. $\sigma^{7} 44-46$, \& 44.5-46; pter. $\sigma^{7} 3.5-4.25$, \& 3.75-4.5; width of h.w. $0^{7}$ 13.5-15, \& I4-2-15. 
Types-ơ + , colll. Walker-Regina, Saskachewan.

Nymph (?)-In the Cabot Collection in the Museum of Comparative Zoology, Cambridge, are two Aeshna nymphs that differ somewhat from any other nymphs that I have seen. They are labelled "Mouth of the Red River of the North, Scudder, I860, " and were originally preserved in alcohol, but are now dry and somewhat shrunken and the colour-pattern has practically disappeared. They seen to be nearest interrupta interrupta, though I was unable to compare them directly with specimens of that form. They differ principally in the presence of small lateral spines on segment 5 and in the somewhat larger labium.

As these nymphs come from the territory inhabited by Ae. interrupta lineata, it is probable that they belong to this race. They are in any case a member of the clepsydra group; and the other members of this group, except Ae. eremita and canadensis, whose nymphs are known, are not known from the Red River country and probably do not occur so far north.

Eyes rather prominent, antero-posterior diameter slightly shorter than the posterior margin; lateral margins of head nearly straight, two-fifths as long as the posterior margin, which is considerably emarginate; postero-lateral angles well rounded. Labium large, apparently extending somewhat behind the bases of the middle legs; proximal margin of mentum a little more than half as broad as the distal margin, which is equal to about five-seven ths of the length; sides subparallel in the basal two-thirds, then diverging, the distal third strongly arcuate; medium lobe short, feebly arcuate; lateral lobes broad, squarely truncate, internal apical angle with a somewhat prominent tooth. Abdomen broadest at seg. 6. Lateral spines present on 5-9; on 5 reaching half way to the margin, on 6 two-thirds of the way, on 7 about to the margin, on 8 beyond the margin by two-thirds of their length, on 9 reaching just beyond the posterior margin of Io (probably a little beyond the middle in exuvia). All the spines are curved slightly inwards, the curve continuous with that of the margin. Lateral appendages ( $q$ ) barely more than half as long as the inferior pair. Genitalia not quite reaching the apical margin of 9. 
Colour-pattern indistinct, probably like that of interrupta and eremita. Femora with broader sub-basal and narrower preapical dark dorsal (not seen distinctly in $\%$ ).

Measurements ( 9 ) - Length of body 36 (shrunken); mentum of labium 7 ; h.w. Io; h.f. 8 ; width of head 9 ; of abdomen 8.

Material delermined-30 $\sigma^{7} 30$ \%. North Dakota : Aug. 13 (Coues, M.C.Z., I o7); La Roche Percée, Aug. I 6, I 873 (Dr. Mack, M.C.Z., I o ); Fargo, June, I3, I902 (N.G. Orchard, coll. Williamson, I o ). Manitoba: Winnipeg, July 6-24, Sept. 7, 1908 (J. B. WVallis, 5 o' 5 के); Winnipeg Beach, Lake iVinnipeg, Aug.-Sept. 6, Igo9 (J. B. Wallis, $2 \sigma^{7} 3$ o ) : Westbourne, July 28-Aug. I9, I908 (J. B. Wallis, $50^{x} 6$ \%); Aweme, July 20, 1906, Aug. Io, 1907 , Aug. 16, 1908 (N. Criddle, $20^{7} 2$ \%); Swan River, Sept. 8, I906 (W. J. Alexander, coll. Walker, I \&). SAskatchewan: (Scudder, M.C.Z., I o7 I \&); Regina, July I8, I 905 (T. N. Willing, $\left.4 \sigma^{7} 2 \%\right)$; Carlton, July 28, I900, July 22, 1907 (J. Fletcher, T. N. Willing, 3 o, teneral) ; Duck Lake, July 22, 1907 (J. Fletcher, T. N. Willing, $2 \sigma^{7}$, teneral); Goose Lake, July 2 I, I907 (T. N. IVilling, I $\sigma^{7}$ ); Parkside, July 24, I907 (T. N. Willing, I $\sigma^{7}$, teneral); Meota, July 8, 1907 (T. N. Willing, I o I \%); Moose Jaw, Aug. 24, I903 (A. N. Caudell, U.S.N.M., I \%). Alberta: Banff, Aug. 4, I906, Aug. I6, I908 (R. P. Currie, U.S.N.M., I o, N. B. Sanson, I $\sigma^{7}$ ); Waterton Lake, Aug. 7-Io, I908 (E. V. Cowdry, coll. Walker, $\left.20^{7} 3 \%\right)$. NORTHWEST TERritory: Great Slave Lake, July I 862 (Kennicott, M.C.Z., I q). Also "UPPER Missouri" (Hagen, M.C.Z., I \&); and "BRITISH AMERICA" (Scudder, M.C.Z. I, o" I $\$$ ). (St. F).

Nymphs (?)-" Red River of the North, Scudder, I $860^{\circ}$ (M.C.Z.) I o I

Distribution-This race of Ae. interrupta is probably the most characteristic dragonfly of the Canadian Prairies, ranging over the whole of this region from Manitoba to the foothills of the Rocky Mountains and northward into the wooded country as far as Great Slave Lake. South of Canada its range extends into North Dakota and to the Upper Missouri. It is thus characteristic of the Canadian Zone, in the middle part of the continent, reaching the northernmost limits of that zone; while southward it ranges well into the Transition Zone.

Geographical rariations-No variations of geographical significance have been detected in this race, except where it intergrades with the race interna (vide postea).

\section{Aeshna interrupta interna Walker.}

(Pl. 16, figs. 2, 2a; pl. 22, figs. I0, II).

Aeschna interna, Hagen, Pr. Bost. Soc. Nat. Hist., p. 35 (1875) (no description); Martin, Gen. Ins., CXV, p. II (IgII).

Aeschne clepsydra, Calvert, Trans. Am. Ent. Soc., XXIX, p. 43 (1903).

Aeschna juncea, Currie, Pr. Ent. Soc. Wash., VII, p. I6 (1905); Osburn, Ent. News, XVI, p. Igo (I905). 
Aeshna inlerna, Walker, Can. Ent., XL. Dp. 381, 388, 450 (1908); Muttkowski, Cat. Od. N.A., p. 112 (1910).

Closely related to Ae. interrupta lineata with which it intergrades where the territories inhabited by the two races meet. It differs from lineata in the form of the superior appendages of the male and in the greater development of the pale areas of the thorax and abdomen.

Head indistinguishable from that of lineata except that the paler area of the frontal vesicle is generally larger, occupying nearly the whole of its upper surface, though not reaching to the lateral ocelli.

Dorsal thoracic bands in the male $2-2.5 \mathrm{~mm}$. long and .5-.6 broad; in the female $1.25 \mathrm{~mm}$. long or less, very narrow and sometimes indistinct or even absent; lateral bands blue above, pale green or yellow below, somewhat variable in width, in typical specimens distinctly broader than in lineata; first band .75-I $\mathrm{mm}$. broad below, narrowing to about half that width a little above the middle, then remaining equal or expanding slightly to the upper end. Second band of about the same width below, curved gently caudad, equal, or slightly constricted at the middle and expanding slightly on the upper half.

Abdomen similar in form to that of lineata. Superior appendages of male somewhat contracted at the extreme base, the proximal three-tenths rather slender, equal; thence expanding gently on the inner margin to about three-fifths the length, where the breadth is somewhat less than twice that of the slender basal part. Distal two-fifths narrowing somewhat to the rounded or angulated apices which bear, externally, a distinct spine. Outer margin curved as in lineata, more strongly than in interrupta, inner margin more distinctly sinuate than in the former. In profile the superior carina appears more elevated apically than is usually the case in either of these races, the denticles very minute or absent, outer margin less curved upwards, lower (inner) margin sinuate, being proximaily slightly convex, concave before the middle, thence produced ventrad to form a somewhat prominent obtusangulate inferior carina, which is usually deeper than in interrupta and lineata. A rather low sub-basal ventro-in- 
ternal tubercle appears in an oblique view from above or below.

Appendages of the female as long as the dorsa of $8+9$, or slightly shorter, shaped as in lineata, apices with a small terminal tooth.

Colour-pattern of abdomen similar to that of lineata but all the spots average somewhat larger.

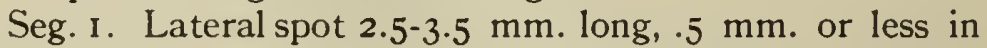
breadth. Seg. 2 as in lineata; PL sometimes confluent with AML in the female, sometimes separate.

Segs. 3-Io. Spots all light blue, almost identical in form with those of lineata; MD considerably larger and the others averaging somewhat larger, though no good differential character can be based upon them. $\mathrm{AL}$ and $\mathrm{ML}$ as in lineata; MD larger, more or less quadrate in the male, at least on $3-5$, triangular in the female, generally broadly confluent with ML on 3 and 4 in the male, separate throughout in the female. PL larger than in lineata, represented on $3-8$, and confluent throughout with $\mathrm{PD}$, becoming recognizable on 8 only as the lower part of the latter. PD as in lineata or barely larger, about $1.25 \mathrm{~mm}$. long on 3 , increasing to nearly or quite $2 \mathrm{~mm}$. on 7 and 8 .

As in races lineata and interrupta, the female exhibits both types of coloration. One female from Utah and one from Oregon are apparently homœochromatic, or at least partially so, with hyaline wings; while onefrom Baker City, Ore., is strongly heterochromatic, all the pale markings being yellow, and the wings, except beyond the pterostigma, strongly flavescent.

Measurements-Thor. ơ I0.2-II, ᄋ I0-I0.5 ; abd. $\sigma^{7} 46$ 48 , क 42.5-46; seg. 3 б 8-9, क 6.8-7; apps. ठ7 4.8-5.25, क 5-5.33; h.w. o7 43-45, क 42.5-44; pter. ơ 3-3.8, \& 3.5-4; width of h.w. $\sigma^{7}$ I 3 -I 3.6, क I 3.4-I 4.

Types- $\sigma^{r} \%$, Acad. Nat. Sc. Philadelphia-Lamb's Cañon, Salt Lake Co., Utah.

Nymph-Unknown.

Material determined-32 072 \% . British Colunsia: (Crotch, M.C.Z., I \&); Kaslo, Aug. 7, 1903 (R. P. Currie, U.S.N.M., I ơ). OREgon: Baker City and vicinity, July 27,30, 1908, Aug. 7, 9, 1909 (C. H. Kennedy, $5 \sigma^{7} 2 \%$ in cop., July 30). Washington: Spokane, July 22, I 882 (S. Henshaw, M.C.Z., 1 \&): Colville, July 23-25, 1882 (S. Henshaw, M. C. Z., $2 \sigma^{7} 4$ \%). Utä: Ogden (Cyrus Thomas, M.C.Z., I $\sigma^{7} 2$ \%); Summit Cavern, Aug, 8. 1875 
(M.C.Z., 2 ơ 8 \&) ; Lamb's Cañon, Wasatch Mts., Salt Lake Co., July 23, I899 (Browning, coll. Calvert, I oै I $q$ ); City Creek Cañon, July 5, I899 (coll. Calvert, I \&). NEw MExico: Beulah, Aug, I5. I90i (coll. Calvert, I ơ).

Also forms intermediate between races inlerna and lineata as follows: ALBERTA: Banff, Sept. 6, 1906, Sept. I, IO, I908 (N. B. Sanson, I $\sigma^{7} 2$ \&). British Columbia: Peachland, Aug. 4-2I, I909 (J. B. Wallis. I8 $\left.0^{7}\right)$.

Distribution-British Columbia to New Mexico, a mountain form.

Geographical variations-All the intermediates between this form and lineata, that I have seen, with the probable exception of a single damaged male from Fort Collins, Col., come from British Columbia. No other geographical variations were noted, specimens from Oregon and Washington being quite like those from Utah and New Mexico.

\section{Aeshna eremita Scudder.}

(Pl. 1, figs. 2, 6; pl. 3, figs. I-4; pl. I3, fig. 2 ; pl. 16, figs. $3,3 \mathrm{a}$; pl. I9, figs. I, Ia; pl. 24, figs. I, 2.)

Aeschna eremita, Scudder, Pr. Bost. Soc. N.H., X, p. 2 I 3 (I 866); Hagen, Pr. Bost. Soc. N.H., XV, p. 376 (1873); Harvey, Ent. News, II, pp. 73, 75 (I 89 I); Brown, Ins. Life, III (189r); Hagen, Rep. U.S. Geol. Surv. Terr., VI, p. 727 (1873); Calvert, Trans. Am. Ent. Soc., XX, p. 206 (I893); Ent. News, V, p. 9 (1894).

Aeshna eremita, Walker, Can. Ent. XL, pp. 383, 388, 45I (I908); Muttkowski, Bull. Wis. N.H. Soc., VIII, p. 56 (I9I0); Cat. Od. N.A., p. I Io (I9I0).

Aeschna eremilica, Hagen, Pr. Bost. Soc. N.H., XVIII, p. 34 (1875); Cabot, Mem. M. C. Z., VIII, p. 23, pl. 2, fig. 2 (nymph) (I 88I).

Aeschne hudsonica, Selys, Ent. M. Mag., p. 242 (1875); Martin, Cat. Coll. Selys, XVIII, p. 35, fig. 30 (I908); Gen. Ins., CXV, p. I I (I 9 I I).

Aeschna crenata, Bergroth. Ent. Nachr., VII, p. 86 (I88I) [in part]; Calvert,

Ent. News, V', p. 9 (1894).

Aeschna clepsydra, Calvert, Trans. Am. Ent. Soc., XX, p. 248 (I893); Ent. News, V., pp. 9-I3, figs. 6 and 7 (1894); l.c., p. 243 (1894); Currie, Pr. Wash. Acad. Sc., III, pp. 217,223 , (I90I); Ruthven, Ec. Surv. N. Mich., p. IOI (I906); Walker, 36th Ann. Rep. Ent. Soc. Ont., p. 69 (I906) [in part]; Walker, Can. Ent., XXXVIII, p. 50 (1906) [in part]; Williamson, Ent. News, XVII, pp 133-135 (I906) [in part].

A eshna " $x$," Williamson, Ohio Nat. VII, pp. I45, I46 (I907).

A species of large size and average or rather stout build. Male-Occiput light yellow, black in front, equilateral or somewhat broader than long, two- to three-fifths as long as the line of contact of the eyes; frontal vesicle rather narrow, emarginate in front, the anterior one- to two-thirds light yellow, this pale area sometimes divided mesially into two spots and not reaching the lateral ocelli. Eyes varying in colour from pale greyish green with bluish reflexions to bright grass-green, hind margin pea-green to yellowish green. Pre- 
ocular band more than twice as wide, at base of antennæ, as one of the lateral ocelli; reduced to a narrow marginal line on the sides of the frons and nasus, reaching the lower border of the latter. T-spot 3-3.3 mm., regularly but not very strongly arcuate in front, stem rather short, $.4-.8 \mathrm{~mm}$. in front, .66I. $66 \mathrm{~mm}$. behind, the sides straight and parallel or somewhat divergent caudad. Frons and nasus light green or yellowish green, pale yellow laterally and on upper surface of frons, nasofrontal line black, very heavy in front but narrowing to a fine line before the lateral margin. Lateral lobes of nasus slightly flaring, rectangular, the apices rounded. Labrum greenish yellow or light green, margined above and usually also below with black, These marginal lines are generally narrow and sometimes the lower one is reduced to a fine brown line, but occasionally the lower one is the broader and in an example from Temagami, Ont., it is very broad and confluent mesially with the upper margin, thus dividing the pale area into two parts. Labium lemon- to dull clay-yellow, lateral lobes bluegreen to "robin's egg" blue. Rear of head black.

Thorax rather robust, dull greyish brown with an olivaceous tinge, greyish below; darker along the sutures and around the lateral bands, dorsal carina and edges of antealar sinus black. Dorsal bands bluish green, 4-5 mm. long, .75 mm. broad at the middle, lower ends separated by about $4 \mathrm{~mm}$., taper-pointed; upper ends separated by about $2 \mathrm{~mm}$., somewhat expanded and truncated, about $1 \mathrm{~mm}$. broad, the expanded portion occasionally separated from the rest of the band as a distinct spot; outer margin straight, inner margin convexly curved. Lateral bands rather broad but irregular in form, first band blue, of ten pea-green in the lower half or margined below with green, rounded at the lower end, 1.75-2 $\mathrm{mm}$. broad in the lower half, greatly constricted just above the middle by the deeprounded excavation of the anterior margin, the breadth here being generally less than $1 \mathrm{~mm}$., thence expanding again to $\mathrm{I}$ or $1.5 \mathrm{~mm}$. at the upper end, from which a short posterior offshoot is given off, or may be separated as a distinct spot; posterior margin gently sinuate. Second band blue, hind margin sometimes green below, expanding from the acutangulate lower end to the upper end, which is $2-3 \mathrm{~mm}$. 
broad; hind margin straight, front margin excavated in the upper two-thirds, but less deeply than in the first band. A small green or blue elongate spot just behind the constricted part of the first band and one or two spots about the metastigma, no pale humeral spot. Spots between the wings azure blue.

Legs very dark reddish brown, the femora paler above; anterior pair generally with a pale greenish streak along the outer surface, extending from the base sometimes to the apex.

Abdomen 4.5 to nearly 5 times as long as the thorax, the length and stoutness, especially of seg. 3, apparently depending to some extent upon locality (vide postea). The constriction at this segment is as usual in this group, the abdomen expanding behind it to the apex of 4 , thence remaining equal as far as 6,7 or 8 , narrowing slightly on the remaining segments.

Ventral surface of I without a distinct tubercle, but bearing numerous minute spines on the posterior half. Auricles with 4 teeth. Tergal margins behind the hamuli somewhat elevated, straight or somewhat divergent. Spines of anterior lamina well developed for the clepsydra group, reaching as far back as the bases of the hamular processes, straight, sharp-pointed, directed ventrad, caudad and laterad. Hamular processes directed ventrad, mesad and cephalad, rather short and thick, ventro-lateral surface somewhat concave, internal margin thick, strongly convex, apices produced into a distinct papilliform process smaller than that of verticalis, but larger than the apical tubercle of interrupta. Hamular folds well developed, closely approximated mesially, their lateral margins continuous with those of the hamular processes, moderately thick, somewhat divergent caudad, forming an acute angle with the well-rounded apices.

Seg. 3 about 2-7 times longer than $I+2$ or 4 . Lateral carinae of 8 rather strongly angulate about the middle. Dorsum of 10 with a prominent median and two smaller lateral teeth.

Superior appendages about one-sixth shorter than $9+10$, basal breadth about one-third or two-sevenths of the intervening space, expanding gradually and almost symmetrically to about the middle, where the breadth is more than twice that 
at base and about one-fifth of the length, and narrowing again very slightly in the distal half to the broadly rounded apices which only very rarely bear a minute terminal tooth;-outer and inner margins in dorsal view very gently and almost equally curved, the latter not being at all sinuate. Superior carina arising in a prominent basal tubercle, percurrent though feeble in the proximal fourth, apical three-fifths rather strongly elevated, arcuate, bearing 6 to 8 well-marked denticles. In profile view the outer margin appears moderately curved, the basal fourth of the appendage thickened by the presence of a rather large but low and rounded sub-basal ventral tubercle, whose surface bears a number of minute denticles. Inner margin produced downward beyond the middle into a fairly prominent rotundo-obtusangulate inferior carina. This carina together with the elevated superior carina just above it gives the appendage the appearance of being rather strongly bent upwards in its apical third. Inferior appendage six-eleven ths to three-fif ths as long as the superior pair and nearly three-fifths as broad at base as long, triangular, apex blunt and rounded; in profile moderately curved, tapering considerably in the distal two-thirds.

Colour-pattern of the abdomen-Seg. I brown, dorsal spot azure blue, lateral spot greenish blue orgreen, 2.5-3.5 mm. long (transverse), .75-1 mm. broad.

Seg. 2 brown ; AML blue, sometimes greenish yellow or green in front, rhomboid, $2.5-3 \mathrm{~mm}$. broad at front margin, which is not produced below the level of the auricles, confluent above with MD; PL and PD united, forming a blue band, which is two-thirds (above), four-fifths (below), as broad as the posterior division of the segment, the anterior margin deeply excavated laterally and confluent above with a fairly large median dorsal blue spot.

Segs. 3-10 brownish black, the spots rather large, azure blue, except $\mathrm{MD}$, which is dull yellow. $\mathrm{AL}$ on $3-8$, average size; on 3 separated by a dark brown dorsal band which is about $\mathrm{I} \mathrm{mm}$. broad in front, $2 \mathrm{~mm}$. broad behind; on 8 minute, on the remaining segments rounded and not indented below, straight above and connected with a basal ring, which becomes very narrow and sometimes obsolete at the middorsal 
line. ML fairly large, being about twice as high on 6 and 7 as $\mathrm{AL}$, quadrate, some" hat rounded behind on the posterior segments, front margin on most of the segments with a small oblique acute indentation. MD on 3-8, fairly large, con. fluent with $\mathrm{ML}$ on 3, transversely elongate-triangular, posterior margins concave. PD about $1.25 \mathrm{~mm}$. long on 3 , increasing to $2 \mathrm{~mm}$. on 8 , front and inner margins more or less rounded on 3 and 4 , nearly straight on the remaining segments, the inner margins narrowly separate except on 8 and 9, parallel except on 9, where they are divergent cephalad. On Io they are connate in about 65 per cent. of individuals, but may be separated by $\mathrm{I} \mathrm{mm}$. PL on $3-9$, straight, narrowly connected behind with PD on all the segments.

Wings distinctly shorter than abdomen, hyaline, costal veins brownish ochraceous, pterostigma smoky brown above, ochre-yellow below, membranule of hind wing dark smoky grey, not reaching the cross-vein of the anal triangle, which is 2 -celled. One or 2 cells ( 2 in 75 per cent.) between $\mathrm{A}_{2}$ and $\mathrm{A}_{3}$ at their origin. Rs in front wing forking at the level of $\mathrm{I}-3$ postnodal cells ( 2 in 65 per cent.) before the stigma, in hind wing at the level of $1-4$ cells ( 3 in 50 per cent.) with 3 (rarely 4 ) rows of cells between the forks at the level of the distal end of the stigma and 2-6 (usually 4 or 5 ) cells between the forks at the margin ; $3-6$ ( 4 or 5 in 92 per cent.) rows of cells between Rs and Rspl where most widely separated; M Ia arising before the middle of the stigma, sometimes before the proximal end.

Antenodals $\frac{\mathrm{I} 5-22}{\mathrm{II}-\mathrm{I} 5}$, postnodals $\frac{\mathrm{II}-\mathrm{I} 6}{\mathrm{I} 3-\mathrm{I} 7}, \mathrm{CuCr} \frac{5-7}{4-6}, \mathrm{Spt} \frac{2-4}{\mathrm{I}-3}$.

Female-Genital valves about as long as 9, lateral carinae broadly rounded and swollen at base but elsewhere sharp and fairly prominent, the apical half almost straight in profile view, in ventral view subparallel or slightly diverging to about two-fifths of the length, then converging and soon becoming subparallel, the greatest width of the enclosed space being equal to about two-fifths of the length; ventral surface of valves feebly sulcate, strongly declivent in the basal half, squarely cut; in profile nearly rectangulate, not elevated, 
bearing a minute pencil of pale hairs. Styli about $.75 \mathrm{~mm}$. long; basal plate of ovipositor of usual size, posterior margin straight; spinulose area on ventral surface of ro rather large, with numerous rather coarse spines. Appendages varying much in length according to locality, sometimes slightly shorter, sometimes a little longer, than $8+9$ (vide postea), much slenderer at base than apex, greatest breadth a little beyond the middle, equal to one-fifth to two-sevenths of the length; curve of inner margin stronger than that of the outer margin; apices broadly rounded, sometimes subangulate but without a projecting tooth.

The dorsal thoracic bands are reduced and divided into an anterior elongate spot, $2-2.5 \mathrm{~mm}$. long and .5 $\mathrm{mm}$., or less, broad, and a posterior, small, more or less transverse spot, corresponding to the expanded upper end in the male. Often the posterior spot is indistinct or absent altogether. Lateral abdominal spots somewhat larger than in the male, PD slightly smaller. The size of the lateral spots depends to a considerable extent on the depth of the abdomen, which is deeper in northern than in southern specimens (vide postea). PL is always connected with PD but is nearly always separate throughout from ML, though rarely narrowly confluent on 2 .

In colour a complete range of variation occurs, from the pure homœochromatic type to a marked degree of heterochromatism. The majority of females that I have seen were of the latter type, the pale markings being usually yellowish green throughout, but in one example from Go Home Bay, Georgian Bay, Ont., the lateral thoracic bands as well as the abdominal spots (except MD) are blue, as in the male. Heterochromatic females of ten have strongly flavescent wings.

Measurements-Thor. ơ II.5-12.5, क I0.5-12; abd. o 51.5-58.5, क 48.3-52; seg. 3 or 9-I I, ㅇ 7-9; depth seg. 3 क 2.4-4.9; apps. $\sigma^{7} 5 \cdot 5-6.3$, $95-7.75$; gen. v. 2.2-2.5; h.w. o $45-52$, क 46-49.5; width h. w. ơ I3-I 4.5, क I3.6-I5; pter. ơ $3.5-4$, क्ष 4-4.6.

Type-or, Mus. Bost. Soc. Nat. Hist.-Hermit Lake, N.H. 
Nymph (pl. 6, fig. 3; pl. 8, fig.3; pl. Io, fig. 3)-Eyes as in canadensis and juncea; lateral margins of head moderately oblique, straight or nearly so, postero-lateral angles obtusangulate, sometimes rounded off a little; posterior margin nearly straight. Mentum of labium about three-fifths as broad at base as at apex, the apical breadth about sevenninths of the length, proximal three-fifths slightly expanding, the sides very feebly arcuate, distal two-fifths much expanded the sides strongly arcuate; middle lobe very little produced, very broadly subarcuate; lateral lobes.broad, equal, squarely truncate, outer angle scarcely rounded, inner angle with a minute tooth. Supracoxal processes somewhat ionger than in interrupta and juncea, about equal in length and similar in form, rather slender, acute and somewhat curved away from one another, the interval nearly rectangular. Abdomen broadest at seg. 6 or 7 , slightly stouter than in juncea; lateral spines present on segs. 5-9, usually more spreading than in other related species but somewhat variable in this respect, reaching back towards the posterior margin of the corresponding segments as follows: on 5 one-fifth or onefourth of the distance, on 6 half way, on 7 three-fourths or quite to the margin, on 8 to the margin or a little beyond, on 9 as far as the proximal three-fifths of Io. Lateral appendages one-half $(q)$, or slightly more than one-half $\left(\sigma^{x}\right)$, as long as the inferior appendages; basal part of superior appendage of male about as broad at the base as long, about four-fifths as long as the lateral appendages, lateral margins feebly concave, apex bluntly pointed. Genitalia of female not quite reaching the posterior margin of 9; genital valves about two-fifths as broad as long, somewhat less steeply declivent than in interrupta and canadensis.

In life the nymph is usually of a very dark greenish colour with paler mottlings, the pattern of which is almost identical with that of interrupta. As seen in the exuviae the pattern is as follows :

Head behind the eyes with an oblique subtriangular brownish patch on each side and a broad pale marginal band extending from the eyes to the posterior edge of the pronotum and sometimes continuing in a sigmoid course to the bases of 
the wing-pads. Femora brownish with three pale rings, a basal, a median and a preapical. Tibiae and tarsi almost concolorous. Abdomen varying much in depth of shade and extent of the pale mottlings, which are almost identical with those of interrupta; dorsal surface with a series of pairs of pale blotches, which run together on the proximal five or six segments, forming two irregular zigzag longitudinal bands, but separate on the posterior segments, where they are confined to the basal part of each segment; another series of pale blotches just laterad of the dorso-lateral punctae, often enclosing them and confluent with the longitudinal pale bands, diminishing caudad and disappearing at 8 ; a series of large irregular submarginal pale blotches enclosing the lateral scars which appear as dark brown rings; and a transverse series of alternately pale and dark basal spots in front of the lateral scars on several of the middle segments; lateral and dorso-lateral punctae comparatively large, dorsal punctae dark brown, discrete; lateral spines whitish, black-tipped.

Measurements-Length of body $4 \mathrm{I}-47.7$; mentum of labium 6.3-8; h.w. 8.4-II ; h.f. 7.5I-8.75; inf. apps. 5-5.9; gen. $\%$ 2.2-2.4; width of head 8-9.5; width of abdomen 8.1-9.5.

This nymph is the same as the one attributed to this species by Cabot. Although I have not yet succeeded in rearing it, there is no possibility of doubt as to its identity. In one specimen which died during emergence the characteristic form of the lateral thoracic bands of eremita (or canadensis) can be made out. Moreover, its size is too large for any other species and it has always been found in localities frequented by adults of eremita. It was by far the commonest nymph at Nipigon in 1910, where the imago was also much more abundant than any other species of Aeshna.

Malerial determined-II8 o $37 \%$. LABRADOR : Hopedale (S. Weiss, M.C.Z., I o' 5 \%). NEwfoundland: (Brit. Mus., I $\%$. Thaxter, M.C.Z., I \&); St. John's (Peary Exped., Ac. N.S. Phil., I ơ); Bay of Islands, July 7, 1901 (D. A. Atkinson, coll. Williamson, 2 or I \&) ; Grand Lake, July 2 I, I 1901 (D. A. Atkinson, coll. Williamson, I $\%$ ). NORTHWEst TERRITORy : Atik River, 45 niles from mouth (Hudson Bay Slope), Aug. 31, 1907 (W. J. Wilson, coll. Walker, I $\sigma^{7}$ ); Fort Resolution. Great Slave Lake, July 1862 (Kennicott, M.C.Z., 13 o" 4 9). "Arctic America" (Brit. Mus., 3 o ). Alaska : (U. S. N. M., 2 o ); Bethel, Kuskoquin River (Acad N.S. Phil., I o ). MAINe: Six Ponds, Piscataquis Co., Sept. 14, 1898 (F. L. Harvey, U.S.N.M., I ơ I $\$$ ). NEW Hampseire: 
Franconia (Mrs. A. T. Slosson, U.S.N.M., $2 \sigma^{7}$ ) ; Hermit Lake, Mt. Washington, Aug. II, 25, I862, Aug. 2, 1890 (Scudder, M.C.Z., and Calvert, Acad. N.S. Phil., Bost. Soc. N.H. and coll. Williamson, 17 o I \&). NEW YORK: Loch Bonnie, near Lake Placid, Adirondack Mts., Sept. Io, 1905 (Calvert, 4 ठ Bone Pond, Saranac Inn, Adirondacks, July 26, 1900 (Needham $20^{7}$ ). QUEBEC, Chicoutimi, Aug. 23, I90I (Calvert, I $\sigma^{7}$ ). ONTARIo: Toronto, Sept. 25, I891, Sept. I5, 1906 (Brodie, Walker, 2 o $0^{7}$ I \&); Go Home Bay, Georgian Bay, Aug. 17, 1907 (Huntsman, I $\sigma^{7}$ I $\%$ ) ; Dwight, northern Muskoka, Aug. 23. I903 (Walker, 2 o 2 9); Temagami Forest Reserve, Kokomo Lake, Aug. 19, 1907 (P. Hahn, I $\sigma^{7}$ ); id., near Lake Obabika and Cross Lake, Sept. 3, II, I908 (Walker, 2 o); Heyden, Algoma, July 30, Aug. 4, I 906 (Williamson, $200^{7} 4$ \%): Searchmont, Algoma, Aug. 7, 1906 (Williamson I o I \&); Nipigon, Aug. 28, 1907 (Walker, I on I 9 ); id., Aug. 4-8, I9Io (Walker, Io ơ 4 \&). Michigan ; Marquette (U.S.N.M., I \&); Oden, July 25, I906 (J. H. Williamson, I $\sigma^{7}$ ); Minnehaha Falls, Emmet Co., Aug. 23, 1907 (Williamson, I $\left.\sigma^{7}\right)$; Isle Royale, July 26-28, I905 (Adams, Gleason, Wood, coll. Univ. Mich., $\left.90^{7}\right)$. Manitoba: Husavick, July 8, IgIo (J. B. Wallis, I $\sigma^{7}$ ). Saskatchewan: I860 (Kennicott, M.C.Z., 6 on 3 \%). ALBERTA: Banff (Sanson, I ơ). British Columbia: Peachland, Aug. 3, Ig09 (Wallis, I $\$$, reared); id., $2500 \mathrm{ft}$,; Aug. 7, 1909 (Wallis, I \&); Vancouver (Brit. Mus.,I \&). "British AMERICA", (Scudder, $4 \sigma^{7}$ ). Wyoming : Shell Creek, Bighorn Mts., July I5, I 896 (R. P. Currie, U.S.N.M., I $0^{7}$ ). Also $30^{7} 1$ \& without data.

Nymphs-Nipigon, Ont., Aug. 6-8, I9IO, I $0^{7}$ I $\&$ (St. H), $3 \sigma^{7} 2$ \% (St. F), I (St. E), 3 (St. B) : exuviae $60^{7} 8$ \%. Temagami, Ont., I $0^{7}$ exuvia (P. Hahn). Go Home Bay, Ont., Aug. 1907, I \& (emerging); Aug. I, I908, I \& (St. H). Midland, I or exuvia.

Identity-This species was thought by Hagen ('75) to be the same as the Siberian Ae.crenata Hag., and Calvert ('94), accepting this view, attempted to show the identity of $A e$. eremita Scudd. with Ae. clepsydra Say. This study was based upon forty male specimens, including at least four species, but, although a careful piece of work, it takes nocognizance of the important characters found in the accessory genitalia of the males and the thoracic colour-pattern. A detailed study of all these forms in much larger series leaves no room for doubt as to the specific distinctness of eremiia and the comparison of this form with the types of crenata likewise shows that these two forms are also quite distinct.

Ae crenata differs from Ae. eremita chiefly in the following characters:

Abdomen of male slenderer, sides of 9 slightly divergent caudad (subparallel in eremita); posterior margin of Io more strongly rounded, superior appendages somewhat narrower, the outer margin convexly curved at base, thence straight to the apices, inner margin strongly sinuate, apices slenderer than in eremita, with a small projecting tooth; superior carina percurrent and more gradually elevated apically, with larger 
but fewer denticles (3-5). Profile view of superior appendage straight, scarcely at all elevated apically, the inferior carina less prominent, its deepest part close to the apex. Spines of the anterior lamina somewhat shorter and blunter. Appendages of female much narrower, with a more prominent mid-carina, apices very acute. Lateral thoracic bands broad and straight, shaped like those of juncea, with a distinct dark margin and not at all excavated in front. Blue spots on segment Io in the male smaller and more widely separated than in eremita. Rspl less strongly curved and less widely separated from Rs.

Martin's ('o8) figure of the male appendages of $A e$. hudsonica Selys shows unmistakably that hudsonica and eremita are synonymous, the latter name having priority.

Distribution-Ae. eremita has an extensive distribution throughout the Hudsonian and Canadian Zones, from Atlantic to Pacific, and occurs more locally and in smaller numbers in the Transition Zone. It appears to be the commonest and most generally distributed species of Aeshna in the far north. I f found it more abundant than any other species at Nipigon, north shore of Lake Superior, in the first week of August, I9Io, but at the end of the same month in 1908, it was outnumbered by $A e$. interrupta interrupta and by Ae.canadensis.

Geographical variations-The relative length and depth of the abdominal segments and of the female abdominal appendages is subject to considerable variation. In specimens from Newfoundland, Mount Washington and the far north, seg. 3 is distinctly shorter and deeper than in those from middle and southern Ontario, while in those from Isle Royale, Mich., and northern Ontario, it is about intermediate (vide p. 26).

Habits-I have observed nothing distinctive in the habits of this species. It flies about shallow, reed-grown margins of lakes and bays in company with other species of Aeshna, and may also be met with in bushy pastures and open woods in the neighbourhood of such bodies of water.

Williamson ('o7a) has taken this species together with Ae. interrupta interrupta and canadensis flying about pools in a lumber-yard after sunset. 
Brown ('gI) records a migratory swarm of Ae. eremita in Wisconsin.

Most of the nymphs I found in the Nipigon River were taken in rather deep water ( $15-18$ inches). The two mature nymphs which were taken on Aug. 7 th, I9Io did not transform that season, but lived until the following January. They fed readily until about November but took nothing during the winter.

\section{Aeshna clepsydra Say.}

(Pl. 2, figs. 5, 6; pl. 13, fig. 3 ; pl. I6, figs. $4,4 \mathrm{a} ; \mathrm{pl}$. I 9 , figs. $2,2 \mathrm{a}$; pl. 25 , figs. I, 2.)

N.B.-Undoubted references to the species described here as clepsydra are marked with an asterisk.

Aeshna clepsydra, Say, Journ. Acad. Phil., VIII, p. 12 (1839) ; Calvert, Occ. Pap. Bost. Soc. N.H., VII, 6, p. 23 (1905); Od. B.C.A., p. 183 (1905). Walker, Can. Ent., XI, pp. 383, 388, 45I (I908).* Wilson, Pr. U.S.N.M., XXXVI p. 666 (1909) ; Smith, Ins. N. J., p. 78 (1909) ; Muttkowski, Cat. Od. N.A., p. 109 (1910).*

Aeschna clepsydra, Hagen, Syn. Neur. N.A., p 122, (186I); Pr. Bost. Soc. N.H., XV, p. 271 (1873); l.c., p. 35 (1875); Kirby, Syn. Cat. Od., p. 89 (1890). Beutenmuller, Prel. Cat. Od. N.Y., p. 163 (1890); Harvey, Ent. News, II, p. 73, 75 (189I) ; Calvert, Ent. News, V, p. 243 (1894); Banks, Trans. Am. Ent. Soc, XIX, p. 353 (1892), Calvert, Trans. Am. Ent. Soc., XX, p. 248 (1893); Banks, Can. Ent., XXVI, p. 77 (1894) ; Calvert, Journ. N.Y. Ent. Soc., III, p. 46 ' (1895); Kellicott, Journ. Cinc. Soc. Nat. Hist., XVIII, p. 2 I2 (1895); 1.c., XVIII, p. II 4 (I896); Calvert, Journ. N.Y. Ent. Soc., V, p. 93 (1897) ; Kellicott, Od. Ohio, p. 84 (I 899); Williamson, Drag. Ind., p. 304, pls. 7, figs. 12, I 3 (I900); Calvert, Ins. N.J. Od., p. 7 I (I900); Burnham, Pr. Manch. Inst. Arts Sc., I, p. 32 (I900); Needham, Bull. 47, N.Y. State Mus., pp. 469, 470 (I901); Williamson, Pr. Ind. Ac. Sc., VIII, p. 124 (IgOI)*; Needham and Hart, Bull. Ill. Lab. N.H., VI, pp. 40, 42 (I9OI); Williamson, Ent. News, XIV, p. 7 (I903) ; Osburn, Ent. News, XVI, p. 186, (Ig05); Martin, Cat. Coll. Zool. Selys, XVIII, p. 36 (I908); Muttkowski, Bull. Wis. N.H. Soc, VI, p. 9 I (I908) ; Needham, Rep. Geol. Surv. Mich., App. III, p. 252 (I908); Martin, Gen. Ins., CXV, p. I I (I9II).

A medium-sized species of slender form, remarkable for the variegated pattern of the sides of the thorax.

Male-Occiput lemon-yellow, equilateral, two to threefifths as long as the line of contact of the eyes; frontal vesicle more than twice as broad as long, the yellow area reaching nearly to the lateral ocelli. Eyes bluish grey, pale yellow behind, with a broad dark brownish transverse stripe above; preocular band somewhat wider at the base of the antennæ than one of the ocelli, narrowed to a fine line on the sides where it extends to the lower margin of the nasus. T-spot very heavy, the cross-bar rather strongly convex in front, 2.5-3

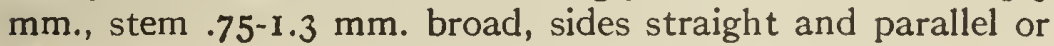
nearly so. Face pale bluish or brownish green; a heavy deep 
brown band on the fronto-nasal suture, which fails to reach the lateral margins by nearly I $\mathrm{mm}$. Rhinarium dark reddish brown, margined above with pale green; labrum pale green, very narrowly bordered above and below with dark brown. Labium pale yellowish or greenish, the middle lobe stained apically with brown, lateral lobes blue or green. Rear of head black.

Thorax of average size, ferruginous, very dark in the humeral region and upper part of lateral surface, distinctly paler on the dorsum between the dorsal bands, covered ventrally and on the lower part of the lateral surface with a greyish bloom, the ventral surface being quite pruinose. Dorsal bands light green, $3.5 \mathrm{~mm}$. long, lower ends pointed and turned outwards and separated by about $4.5 \mathrm{~mm}$., middle breadth about I mm., inner margins strongly convex below, curving mesad above, outer margins concave, upper ends at the antealar sinus about $3 \mathrm{~mm}$. broad, separated at the middle line only by the dorsal carina. Lateral bands broad and irregular in form, pale green below, bluish above; first band rounded at its lower end, about $1.5 \mathrm{~mm}$. broad in its lower half, where it is separated by the humeral suture from a large triangular antehumeral spot. About the middle it is bent abruptly backwards and then inmediately dorsad, the breadth somewhat reduced, terminating in a slender spur which is bent sharply cephalad. Just behind this band and frequently confluent with it are two spots of the same colour, a large subtriangular or rhomboid patch enclosing the metastigma and a smaller one above it. Second lateral band large, triangular, sometimes reaching the.suture in front, lower end acute, upper end $2.5-3 \mathrm{~mm}$. broad, front margin of ten a little excavated near the middle, hind margin straight except where it curves downward at the upper end. Antealar sinus green.

Legs reddish brown; femora somewhat darker; no pale streak on outer surface of fore femora.

Abdomen a little more than four and one-half times as long as the thorax, very slender. Seg. 3 considerably constricted. Seg. I without a ventral tubercle; auricles with 3 (rarely 4) teeth. Spines of anterior lamina short and blunt, directed ventrad and caudad, not projecting below the tergal 
margins. Hamular processes directed mesad and cephalad, short, with bluntly pointed apices and without a distinct apical tubercle, elevated considerably above the adjacent margins of the hamular folds, surface divided by a ridge into anterior and postero-ventral areas, the latter rhomboid and somewhat sulcate. Hamular folds continuous with the processes but distinctly marked off from them, ear-shaped, the outer margins straight, parallel or slightly divergent, inner margins closely approximate. Tergal margins on each side of penis straight. Seg. 3 one-half, seg. 4 very slightly, longer than segs. $\mathrm{I}+2$. Lateral carinae of 8 sinuate at base in ventral view, those of 9 obsolete in the anterior half. Dorsum of ro with an abruptly elevated median tooth and two minute lateral teeth on each side of it.

Superior appendages barely longer than $9+10$, slender in the proximal fifth or sixth, the basal breadth of which is about one-third of the intervening space, thence expanding mesad to about one-third or two-fifths of the length, where the breadth in a vertical dorsal view is one-seventh to one-sixth of the length; sides beyond parallel, converging again in the distal fourth to the rotundo-angulate apices, which are produced in to a rather prominent sharp-pointed backwardly directed spine. In dorsal view the outer margins are nearly straight, the inner margins sinuate in the proximal half, nearly straight beyond. In lateral view the outer margin is also nearly straight, feebly curved downwards at apices, inner (lower) edge beyond the basal fifth forming a well-marked arcuate inferior carina. Superior carina obsolete in the slender basal part, elsewhere moderately sharp, straight, scarcely elevated apically, with 3-5 minute denticles on the apical third. In lateral view it barely rises above the lateral margin before the apex. Inferior appendage elongate-triangular, three-fifths as long as the superior pair, the breadth at base about one-half the length, sides straight, apex acute; in profile view moderately curved, rather narrow, evenly tapering to the apex which is surmounted by a pair of minute spines.

Colour-pattern of abdomen-Ground colour dark brown, distinctly paler in front of the transverse carinae and darken- 
ing posteriorly on each segment; blue spots paler than in most of our species of the genus.

Seg. I brown; dorsal spot blue, lateral spot 3-3.5 mm. long, $1.5 \mathrm{~mm}$. broad, giving off a yellowish offshoot to the front margin of the segment.

Seg. 2 brown; AML pale blue, somewhat V-shaped, the anterior limb at the front margin $2.5-3 \mathrm{~mm}$. long, posterior limb somewhat narrower and not confluent with MD. PL blue, almost or quite crossing the posterior division of the segment, rather narrowly confluent with $\mathrm{PD}$, the latter about two-thirds as wide as the posterior part of the segment, moderately broadly connected with its fellow of the opposite side and giving off cephalad to the front margin a diffuse median band.

Segs. 3-10. Pale spots, except MD, blue; AL on 3-8, well developed on the anterior segments, connected by a narrow basal ring, except on 7 and 8 , and curving mesad along the transverse carinae. Upper margin concave, lower margin not indented. ML on 3-8, generally slightly indented in front, rounded behind, confluent with MD on 3-6 or -7 and of ten with PL on 3. MD on 3-7, yellowish, much elongated transversely, narrowed laterad except on 3 and 4. PD about I $\mathrm{mm}$. long on 3 increasing to $2 \mathrm{~mm}$. on 8 , connate behind on $\mathrm{IO}$, with a $V$-shaped anterior emargination, triangular on 8 and 9 , the inner margins separated by a V-shaped space; elsewhere rounded in front, the inner margins straight and separated only by the dorsal carina. PL on $3-6$ or -7 , an anteriorly directed offshoot from $P D$, broader and nearly straight anteriorly, curved and slender posteriorly. There is also a pair of pale basal ventral spots on segs. 4-7.

Wings hyaline, costal nerves brownish ochraceous, pterostigma dark smoky brown above, paler yellowish brown beneath; membranule of hind wings wholly dark smoky brown not reaching cross-vein of anal triangle, which is 2celled. Two cells between $\mathrm{A}_{3}$ and $\mathrm{A}_{2}$ at their origin. Rs forking at the level of $2-3$ (fore wing) $3-4$ (hind wing) postnodal cells before the stigma; 3 (rarely 4) rows of cells between the forks at the level of the distal end of the stigma and 3-6 cells between the forks at the margin; 4 (rarely 3 or 5 ) rows of cells 
between Rs and Rspl when most widely separated; Mra arising before the middle of the stigma.

$$
\text { Antenodals } \frac{\mathrm{I} 6-20}{\mathrm{II}-14} \text {, postnodals } \frac{9-15}{\mathrm{IO}-\mathrm{I} 6}, \mathrm{CuCr} \frac{5-7}{4-6}, \mathrm{Spt} \frac{2-4}{2-3} \text {. }
$$

Female-Dorsum of 9 about five-sevenths of the length of 8. Genital valves in profile slightly arcuate, the apices not elevated; lateral carinae prominent, percurrent, in profile somewhat irregularly arcuate, in ventral view somewhat sinuate, enclosing a space, which is broadest at about two-fifths the length, the breadth here being about one-third of the length; thence narrowing to the somewhat widely separated apices, each of which bears a minute terminal pencil of hairs. Ventral surface of valves feebly sulcate, inner margins not at all elevated, meeting when the ovipositor is withdrawn, only a very short distance about the middle. Styli scarcely more than $.5 \mathrm{~mm}$. long. Appendages longer than $9+10$, but shorter than $8+9$, more slender in the basal than in the apical half, greatest width at or a little beyond the middle, equal to nearly one-fifth of the length; inner margin more strongly curved than the outer, which is nearly straight; apices rounded, sometimes with a very minute terminal spine.

Colour-pattern-The contrast in the depth of the ground colour of the abdomen before and behind the transverse carinae is somewhat more marked than in the male. The pale markings are very similar, the differences being of the usual kind. PD is shorter, especially on the anterior segments, and is less distinctly or not at all triangular in form on 8 and 9. Lateral spots all somewhat larger, PL confluent with $\mathrm{ML}$ on 2 and generally also 3. Legs somewhat paler reddish brown.

In the two females seen in life one (the specimen figured) resembled the male except that the pale markings were duller and PD green; in the other the colours were not quite mature. It is impossible to determine the range of colour variation from the dried material examined.

Measurements-Thor. $\sigma^{7}$ 10-10.5, +9.5 -10; abd. $\sigma^{7} 45.5$ 49 , क 46-48; seg 3 o 8-9, क 7-8.5; apps. ơ 5.2-5.4, ㅇ 5.335.6; gen. v. 2-2.33; h.w. of 40-47, \& 4.3-44; width h.w. o7 I 2-I 3.33, \& I 3-I 3.5; width seg. 2 o 5-5.7, \& 5.5-5.7. 
Neotype-Harris Collection (Harris Cat. No. 45), Bost. Soc. Nat. Hist.-Massachusetts.

Nymph (pl. 8, fig. 4)-Very similar to that of Ae. canadensis from which it differs as follows: Eyes and posterolateral angles of head very slightly more prominent, the latter similarly or somewhat less broadly rounded. Mentum of labium about three-fifths as broad at base as apex, the apical breadth five-sevenths of the length, somewhat narrower in the proximal three-fifths than in canadensis, the sides not at all arcuate except in the distal two-fifths; middle lobe moderately produced, subarcuate; lateral lobes rather slender terminating in a somewhat strongly curved hook. Supracoxal processes somewhat shorter than in canadensis, bluntly conical, about equal in length, the posterior one a little the stouter, interval less than a right angle. Lateral spines of abdomen somewhat longer than in canadensis, those on seg. 6 extending half way to the posterior margin, on 7 to the margin, on 8 onefourth to one-third beyond the margin, on 9 as far as the proximal two-thirds of ro. Appendages similar to those of canadensis, the superior pair a trifle shorter, being scarcely more than one-half as long as the inferior pair in the male, and about half as long in the female.

The colour-pattern is very much like that of canadensis, but the pale lateral bands in the head and thorax are broader throughout their length; the longitudinal bands of the abdomen are continued to the apical margin of Io (at least in the exuvia) and their margins are almost straight throughout their length. The dark median band is generally paler but more even in depth of shade, not being deepened about the dorsal punctae, which are not marked with darker brown. The dorso-lateral and lateral punctae are also inconspicuously marked.

Measurements-Length of body 36.5-40; mentum of labium 6-6.33; h.w. 8.2-9; h.f. 6-6.2 ; inf. apps. 4.1-4.2; width of head 7.5-8; width of abdomen 7-7.5.

Material determined-38 $0^{7}$ II $\%$. MAINE : Manchester, Aug. 10, 1908. Sept. 7-1 3, 1907. Sept. 18, 1908, Sept. 2-8, 1909, Sept. 12, I910, Oct. 1, I910 (Miss Wadsworth, io $\sigma^{7}$ I $\%$, incl. I $\sigma^{7}$ U.S.N.M.). MAsSachusetTs: (Bost. Soc. N.H., Harris coll. I $\sigma^{7}$ ); (Caudell, U.S.N.M., I $\sigma^{7}$ ); Brookline, (Shurtleff, Bost. Soc. N.H., I $0^{7}$ ); Provincetown, Aug. 6, 1899 (J. E. Benedict, jr., U.S.N.M., \& ९); Wilbrahim, Aug. 3, 1902 (Needham, 1 \%); Bostun. I85S (Uhler, MI.C.Z.' 
I $\sigma^{7}$ ); Salem (Joseph True, M.C.Z., I $\sigma^{7}$ ) ; Natick, 1863 (Sanborn, M.C.Z., I $\sigma^{7}$ ). Onrario: De Grassi Point, Lake Simcoe, Aug. 24, 1908, Aug. 19, 1910 (Walker, I o 1 क) ; Gu Home Bay, Georgian Bay, Aug. 1, 5, I 908 , Aug. 18-26, 1907, July 19, 1910 (Huntsman, Fraser, Cooper, Walker, It $0^{7} 5 \%$ ); Point Pelee, Lake Erie, Aug. 7, 1901 (Walker, I $\sigma^{7}$ ). Michigas: Detroit, (M.C.Z., I $\sigma^{7}$, I \&). INDIANA : Shriner Lake, Aug. 24, 25, 1901 (Williamson, $20^{7}$ ); Crooked Lake, Steuben Co., Sept. 1, 1905 (Waugh, coll. Williamson, I $\sigma^{7}$ ); also $3 \sigma^{7}$ without data.

Nymphs-Go Home Bay, Ont., July, I910, $2 \sigma^{7}$, about to emerge; exuviae 2 o", emerged July 25, 28, 1910 (Cooper); July 31, 1907, I \&; Aug. 13, I908, I $\sigma^{\prime \prime}$; alsu $20^{7}$ I $\$$ without data. Midland, $10^{7}$.

Identity-Say's type which was formerly in the Museum of the Boston Society of Natural History no longer exists and it is impossible to say with certainty which species of the clepsydra group it belonged to. It seems clear, however, that the species described here is the one which has the best right to retain Say's name, for the type locality is Massachusetts, and all the specimens of the clepsydra group that I have seen from that state, with a single exception, belong either to this species or to Ae. verticalis. One of the former is the single specimen labelled clepsydra in the Harris collection. This specimen was probably determined by Say and should be regarded as the neotype.

Distribution-Ae. clepsydra is an eastern species inhabiting the Upper Austral and Transition Zones from New England to Indiana and southern Michigan. It appears to be most common in the eastern part of its range.

Habits-At Go Home Bay this species flies over shallow reed-grown bays and adjacent open marshes, its habitat being apparently similar to that of Ae. canadensis. It begins to appear, however, about a month later, the earliest date of capture recorded being July 19, r910. Two specimens emerged at Go Home on July 25 and 31, 1910. The two Lake Simcoe specimens were taken from tree trunks on the edge of a wood, about half a mile from the nearest possible breeding-place.

\section{Aeshna canadensis Walker.}

(Pl. I, figs. 3,$7 ; \mathrm{pl} .5$, figs. $\mathrm{I}-8 ; \mathrm{pl} . \mathrm{I} 3$, fig. $4 ; \mathrm{pl}$. I6, figs. $5,5 \mathrm{a} ; \mathrm{pl}$. 19, figs. $3,3 \mathrm{a} ; \mathrm{pl} .25$, figs. 3,4 .

A eschna clepsydra, Selys, Ent. M. Mag., II, p. 242 (1875); Calvert, Trans, Am. Ent. Soc., XX, p. 248 (1893) [in part]; Ent. News, V., pp. 9-13, figs. I-4 (1894); Can. Ent., XXVI, p. 318 (I894) : Harvey, Ent. News, XIII, p. 8 (I902); Ruthven, Ec. Surv. N. Mich., p. IOI (1905) [in part]; Fletcher and Gibson, 38th Ann. Rep. 
Ent. Soc. Ont., p. 132 (1908); Muttkowski, Bull. Wis. Nat. Hist. Soc., (2) VI, p. 93 (1908); Martin, Cat. Coll. Zool. Selys., XVIII, p. 36, fig. 36 (1908).

Aeschna juncea, Williamson, Ent. News, XIII, p. I 46 (1902) [in part].

Aeschna verticalis, Walker, 36th Ann. Rep. Ent. Soc. Ont., p. 69 (1906); Can. Ent., XXXVIII, p. 50 (igo6) [in part].

Aeschna " $y$," Williamson, Ohio Nat.,VII, pp. 145, 146, (1907); Walker, Ott. Nat., XXII, p. 54 (1908).

Aeshna canadensis, Walker, Can. Ent., XL, pp. 384, 389, 45I (1908) ; Muttkowski, Bull. Wis. Nat. Hist. Soc., VIII, p. 57 (I910); Cat. Od. N.A., p. Iog (1910); Martin, Gen. Ins., CXV, p. II (IgI I).

Male-A medium-sized species of slender form. Occiput pale yellow, margined laterally with black, equilateral or considerably broader than long, two- to three-fifths as long as the line of contact of the eyes. Frontal vesicle more than twice as broad as long, the yellow area not reaching the lateral ocelli. Eyes grey-green, without blue reflexions, pale greenish or yellowish behind with a dark brownish transverse stripe above. Preocular band somewhat wider at the base of the antennæ than one of the lateral ocelli, becoming very narrow on the sides of the frons but broadening again upon the nasus. T. spot heavy, rather strongly convex in front, $2.5-3 \mathrm{~mm}$., stem .75 to $1.3 \mathrm{~mm}$. broad, sides generally straight and parallel or slightly divergent behind. Face pale bluish or sometimes yellowish green; the frons yellowish to brownish olivaceous just beneath the T-spot, pale yellowish or whitish next the preocular black band; a fine brownish line on the fronto-nasal suture; lateral lobes of nasus rotundo-angulate, scarcely flaring. Rhinarium dark brown, pale reddish above and usually below and along the median line. Labium dull yellow or drab to dull bluish, stained distally with reddish brown; lateral lobes more or less distinctly tinged with greenish blue. Rear of head black.

Thorax of average size, chocolate-brown with a greyish bloom beneath. Dorsal bands rather dull pea-green, sometimes bluish above, nearly straight, $3.5-3.75 \mathrm{~mm}$. long, .75-I $\mathrm{mm}$. broad at the middle, lower ends pointed and separated by about $4.5 \mathrm{~mm}$.; upper ends at the antealar sinus separated by about I mm., expanded, I.25-I.5 mm. broad, of ten separated from the rest of the band as a distinct spot. Agreen orbluish green spot in the antealar sinus; generally an obscure streak just in front of the humeral suture. Lateral bands broad but irregular in form; the first band sometimes wholly blue, but 
generally pea-green in the lower half, often wholly green, rounded at the lower end, $1.33-1.5 \mathrm{~mm}$. broad in the lower half, greatly constricted just above the middle by the deep almost rectangular excavation of the anterior margin, the breadth here being $.33-.75 \mathrm{~mm}$., thence expanding to about $1 \mathrm{~mm}$. near the upper end, from which a rather narrow offshoot passes caudad. Anterior margin above the middle straight, posterior margin slightly sinuate. Second band blue, of ten more or less green below, occasionally wholly green, about I $\mathrm{mm}$. broad at the middle, generally narrowed at the lower end, expanded at the upper end, where the breadth is $1.5-2$ $\mathrm{mm}$.; anterior margin more or less sinuate, posterior margin straight except at the upper end. There is also a pair of grcenish spots at the metastigma and a small yellow spot above them. Interalar spots pale blue.

Legs dark reddish brown, the tarsi and under side of the femora and tibiae darker. Front femora with a pale streak on the proximal half of the posterior surface.

Abdomen 4.5 to nearly 5 times as long as the thorax, slender, strongly constricted before the middle of seg. 3 , without a ventral tubercle. Auricles with 3 or 4 teeth. Spines of the anterior lamina short, not reaching back to the bases of the hamular processes, directed ventrad and caudad and not projecting below the tergal margins when in the usual position. Hamular processes somewhat elongate, proximally parallel and directed cephalad, the apices approximated, bluntly pointed. Hamular folds continuous with the processes, the outer margins divergent, meeting the posterior margins at a rotundo-acute angle, inner margins closely approximated. Tergal margins on each side of the penis straight. Seg. 3 about one-third longer than $I+2$ or 4 ; lateral carinae of 8 in ventral view irregularly bent before the middle; feebly developed or obsolete on 9. Dorsum of Io with an abruptlyelevated sub-basal conical median tooth between two pairs of much smaller teeth.

Superior appendages about as long as 9+1o or barely longer, their basal bread th one-third to two-fifths of that of the intervening space, slender and slightly widening in the basal fourth, then expanding mesad to about two-fifths of the 
length where the breadth viewed dorsad is one-seventh to one-sixth of the length; and narrowing again slightly to the somewhat abruptly decurved apices, which terminate in a short sharp spine; outer margin, in dorsal view, gently convex, inner margin rather strongly sinuate, appearing more or less concave beyond the middle. In lateral view the outer margin is curved gently upwards except towards the apex; inner margin bent downwards beyond the basal fourth, forming an arcuate inferior carina. Superior carina feebly marked in the slender proximal part, somewhat elevated in the apical third, where it bears five or six small denticles. Inferior appendage elongate-triangular, about three-fifths as long as the superior pair, the basal breadth half or barely more than half the length, sides straight or feebly approximated about the middle, a pair of minute recurved spines just before the bluntly pointed apices; in profile view moderately curved, rather narrow, tapering evenly to the apex.

Colour-pattern of abdomen-Spots all blue except MD, which is dull yellowish.

Seg. I fuscous; dorsal spot azure blue; lateral spot a pale bluc streak along the posterior margin, $3 \mathrm{~mm}$. long and generally $3 \mathrm{~mm}$. or less in breadth, though sometimes widening below to I $\mathrm{mm}$.

Seg. 2 fuscous ; AML azure blue, nearly $2 \mathrm{~mm}$. broad in the middle, produced a short distance ventrad along the front margin and continued dorsad along the transverse carina as a broad band which is narrowly confluent with MD. PL and PD confluent, forming an azure blue band, which is nearly as broad below (PL), or from one-half to two-thirds as broad above (PD), as the posterior part of the segment; front margin angularly excavated on each side. A blue streak of variable width runs forward from this band along the median line to the front margin of the segment.

Segs. 3-Io brownish black. AL on 3-8, azure blue, giving off on most of the segments a basal transverse offshoot, which fails to form a complete ring with its fellow of the opposite side; upper margins straight. ML on 3-8, azure blue, enlarging to 6 , rhomboid on $3-4$ or -5 , rounded behind on the remaining segments, anterior margin more or less angularly 
indented. MD on 3-7, of ten represented also on 8 by a pair of dots, of moderate size, on 3 more or less quadrate and confluent with or narrowly separated from ML, on the remaining segments triangular and separate from ML. PD azure blue, on Io sometimes very pale blue or even yellowish ; about I.3I. $5 \mathrm{~mm}$. long on 3 , increasing to $2 \mathrm{~mm}$. on 8 ; narrowly connate behind on Io in about 22 per cent. of cases, rounded in front and mesially and rather narrowly separated on $3-7$, subtriangular on 8 , and triangular on 9, the inner margins straight and more or less divergent and more widely separated on these two segments than on the others, though sometimes narrowly connate behind on 9. PL on 3-6 or -7 , decreasing, separated from 5 or 6 caudad, elsewhere forming a curved offshoot from PD. Ventral surface of abdomen with a pair of pale blue basal spots on $4-6$.

Wings hyaline, costal veins brownish ochraceous, pterostigma dark smoky brown above, pale yellowish brown beneath; membranule of hind wings wholly dark smolky brown, not reaching cross-vein of anal triangle, which is 2-celled. Two cells between $A_{2}$ and $A_{3}$ at their origin. Rs forking at the level of I-3 (fore wing) 2-4 (hind wing) postnodal cells before the stigma; 3 or 4 rows of cells between the forlus at the level of the distal end of the stigma and 3-7 cells between the forks at the margin. Three or 4 (rarely 5 ) rows between Rs and Rspl where most widely separated. MIa arising before the level of the middle of the stigma, usually just beyond the proximal end.

$$
\text { Antenodals } \frac{\mathrm{I} 7-22}{\mathrm{I} 2-\mathrm{I} 5} \text {, postnodals } \frac{9-13}{\mathrm{II}-\mathrm{I} 7}, \mathrm{CuCr} \frac{5-6}{4-6}, \text { Spt } \frac{2-4}{2-3} \text {. }
$$

Female-Abdomen very slightly shorter than the hind wing, its depth, especially at seg. 3 , varying greatly according to locality (vide postea).

Apices of genital valves not elevated, lateral carinae percurrent, feeble in the basal third or fourth, prominent beyond; in profile subangulate or gently arcuate, in ventral view somewhat sinuate, enclosing a space which is broadest in the proximal third or two-fifths, the breadth here being about onefourth the length, thence narrowing very slightly to the some- 
what squarely cut, well-separated apices, which bear each a minute pencil of whitish hairs. Ventral surface of valves slightly sulcate, sloping laterad in the proximal three-fifths, more or less mesad in the distal two-fifths. Inner margins of valves when ovipositor is ensheathed attingent only for a very short distance. Styli about $.66 \mathrm{~mm}$. long, or half the length of the dorsum of 10 . Basal plate of ordinary size, the free margin straight. Appendages not longer than $8+9$, generaly distinctly shorter, the length varying with locality (vide postea), more slender in the basal than in the apical half; greatest breadth a little beyond the middle, equal to onesixth or one-fifth of the length, curve of inner margin stronger than that of outer margin, apices rounded or rotundo-angulate without a terminal tooth.

Colour-pattern-Dorsal thoracic stripes narrower than in the male, of ten obscure in colour, each divided into an anterior more elongatespot, about $.5 \mathrm{~mm}$ broad, and a posterior shorter and broader spot, just in front of the antealar sinus. Lateral thoracic bands similar to those of the male. Lateral abdominal spots somewhat larger than those of the male, especially $\mathrm{PL}$, which is present on 3-7 and is only rarely separated from PD. PD slightly smaller than in the male, separate on 2 , quadrate on 9, the basal rings for the most part complete, though narrow. In colour there is great variation among the females of this species, typical homœochromatic and heterochromatic individuals as well as intermediate forms being met with.

The pure homœochromatic form is rare. At De Grassi Point, Lake Simcoe, I captured a female of this form, differing in colour from the male only in the heavy brownish suffusion of the wings. The dorsal thoracic bands and the lower part of the first lateral thoracic band are green, the upper part of the latter, the second lateral band and the abdominal spots (except MD) blue. Another female taken at Toronto had the lateral thoracic bands wholly blue and the wings entirely clear, and one from the Porcupine Mts., Mich., is also of this type. In the heterochromatic form the occiput is bright yellow, the eyes yellowish green, and bright yellow along the hind margin, face olive-green, labium dull yellowish, 
the lateral lobes plumbeous. Thoracic bands and the interalar spots yellowish to grass-green. Abdominal spots green, the lateral spots, particularly $\mathrm{AL}$ and $\mathrm{ML}$, usually of a more bluish green than PD and PL.

The legs are somewhat paler than those of the male and the wings frequently flavescent, though of ten quite hyaline. The flavescence apparently deepens with age, but it is not entirely dependent upon it, as tenerals may have fairly deeply coloured wings, while those of old battered individuals may be quite hyaline. Flavescent wings are apparently most common in northern individuals, in which they may be of quite a deep shade of brown.

Measurements-Thor. o $\sigma^{7}$ IO-II, क 9.5-10.5; abd. $\sigma^{7} 46$. 51.5 , ㅇ 45-49; seg. 3 o 8-9.4, क 6.75-8.25; depth seg. 2 o 5.25-5.75, क 5.5-6; depth seg. 3 , क 2.5-4.5; apps. o' 5.25-6, o 4-5.6 ; h.w. $0^{7} 43-46.5$, क 42.5-47.33 ; width h.w. of 12.5I4, ㅇ 12.75-I 4.4; pter. of 3.I-3.6, क 3.7-4.3.

Types- $\sigma^{7}$ and $\%$, U.S. National Museum-De Grassi Point, Ont.

Nymph (pl. 6, fig. 4 ; pl. 8, fig. 5 ; pl. 10, fig. 4.)Eyes moderately prominent, shaped as in juncea; lateral margins of head moderately oblique, nearly straight, about one-half longer than the interocular space; postero-lateral angles of head rotundo-obtusangulate, more rounded than in eremita but decidedly less so than in juncea and interrupla; posterior margin straight or very nearly so; mentum of labium about seven-elevenths as broad at base as at apex, the apical breadth a little more than five-sevenths of the length; proximal three-fif ths sligh tly widening distad, the sides barely arcuate, distal two-fif ths expanded, the sides more strongly arcuate, though less so as a rule than in juncea; middle lobe broadly rotundo-angulate or subarcuate, but little produced; lateral lobes rather slender, narrowing somewhat distad, the apices not squarely truncate, outer apical angle well-rounded, inner angle with a distinct tooth. Supracoxal processes well developed, about equal in length, acute, the posterior slightly stouter, interval slightly less than a right angle. Abdomen broadest at seg. 6 or 7; lateral spines present on 6-9, not spreading, extending towards the posterior mar- 
gin of the corresponding segments as follows: on 6 two-fifths to half the distance to the margin, on 7 to the margin or nearly so, on 8 to the margin or slightly beyond, on 9 about as far as the middle of ro. Lateral appendages slender, about threefifths as long as the inferior appendages; basal part of superior appendage of male about one-fifth shorter than the lateral pair, somewhat less broad at base than long, sides straight or nearly so, apex acute. Genitalia of female nearly reaching the posterior margin, genital valves about two-fifths as broad as long, more steeply declivent than in juncea and eremita.

Head behind eyes with a rather narrow pale margin, which is continued over the pronotum and mesothorax, becoming more diffuse on the latter; thorax otherwise nearly uniform brownish, legs concolorous. Abdomen longitudinally striped, a dark median band between two pale ones, these becoming somewhat less distinct caudad and more or less obsolete on Io. These bands are for the most part somewhat conspicuous and well-defined, with the margins nearly straight and subparallel. The median band is solid and dark on the more anterior segments and sometimes on all but the last one or two segments, but is generally broken up posteriorly into a series of subcontinuous dark blotches on the basal part of each segment, obscuring the dorsal punctae. A more or less distinct pale median line runs throughout the band. Pale longitudinal bands as broad or slightly broader anteriorly than the median band, narrower posteriorly, outer edges nearly straight posteriorly, somewhat undulated anteriorly. Sides of abdomen brown, much paler than the median band, the posterior external to the lateral scars, paler than the rest; lateral scars forming a pale undulating line not distinctly outlined laterally, lateral punctae distinct, dorso-lateral punctae almost obsolete.

Measurements - Length of abdomen 35-39.5; mentum of labium 5.5-6 ; h.w. 8.5-9.5; h.f. 6-6.6; inf. apps. 3.8-4.3; gen. \% 1.8; width of head 7.8-8; width of abdomen 7-7.5.

Material Determined-I9o or 67 \%. Nova Scotia : Pictou, July 26, 1889 (W. Sheraton, coll. Calvert, I $\sigma^{7}$ ). NEW BRUNSwICK: St. Andrews, I9Io (Huntsman, I \%). MaINE: Bradley, Aug. 7, 1891 (F. L. Harvey, U.S.N.M., 3 $\left.\sigma^{7}\right)$; Manchester, July 28-Sept. 22, I889, I898, I907-10 (Miss Wadsworth, I 8 
or 6 \% incl. I $\sigma^{7}$ in U.S.N.M.) ; Norway (S. J. Smith, M.C.Z., 2 o' ); Orono, July 28, 29, I 898 (F. L. Harvey, U.S.N.M., 8 ơ I $\%$ ). NEw HampSHIRE: White Mts. (Shurtleff, M.C.Z., I $\left.\sigma^{7}\right)$; White Mountain House, Aug. 22, 1889 (Calvert, I $\sigma^{7}$ ); Franconia (Calvert, M.C.Z., I ठ); Fabyans, Aug. 22, 1889 (Bost. Soc. N.H., I $\sigma^{7}$ ). VERMont: (Ellis Frost, coll. Williamson, I $\sigma^{7}$ ); Newport (Mrs. Slosson, U.S.N.M., I \&). Massachusetrs: (Needham, i $\$$ ). NEw York: Ithaca, Aug. 28, 1889 (Banks, U.S.N.M., I o'); Lake St. Regis, Franklin Co., Sept. 20, 22, 1890 (J. P. Moore, Calvert, 2 o'). Quebec: Quebec (Provancher, M.C.Z., I $\sigma^{7}$ ); Grand Entry, Magdalen Islands, June 30, I90I (D.A. Atkinson, coll. Williamson, 2 $\$-1$ reared). ONTARIo : Ottawa, Meach Lake, July 2 1, 1907 (A. Gibson, I \$); Toronto, Sept. 12, 1907, Sept. 27, 1909 (Walker, Hahn, 7 o 2 \%); Scarboro, Sept. 7, I907 (Huntsman, I o I \%); De Grassi Point, Lake Simcoe, June 25-Sept. 6, 1903-10 (Walker, 20 o 10 \%); Midland, Aug. 8, 1908 (Walker, 4 - ${ }^{7}$ ); Go Home Bay and vicinity, Georgian Bay, June 28-Sept. 8, 1907-10 (Huntsman, Cooper, Walker, 25 o 6 \%); Bala, Sept. I5, 1907 (Huntsman, I ơ); Muskoka (Hahn, I ơ I $\%$ ); Dwight, Northern Muskoka, Aug. 23, 1903 (Walker, I o' I \%); Temagami Forest Reserve, Aug. 14, I906, Sept. I-I I, I 908 (Walker, Hahn, $9 \sigma^{7} 5$ ㅇ); Tobermory, Bruce Co., Aug., I901 (Walker, I $\sigma^{7}$ ); Searchmont, Aug. 1-9, I906 (Williamson, 2 万'); Heyden, July 30. Aug. 3-4, I 906 (Williamson, 6 ने 2 \%) ; Nipigon, Aug. 28-30, 1907, Aug. 6-8, I910 (Walker, 8 o 6 ㅇ) ; Ft. William, Aug. 2, 1910 (Walker, I $\left.\sigma^{7}\right)$. Michigan: Detroit (Hubbard and Schwarz, M.C.Z., I $\sigma^{7}$ ); Oden, Emmet Co., Aug. I I-24, 1906-07 (Williamson, 26 o 3 \%); Porcupine Mts., Ontonagon Co. (A. G. Ruthven, Univ. Mich., 3 o 4 \%); Isle Royale (Gleason, Univ. Mich., I \&); St. Croix River (Muttkowski, I ơ); Douglas Lake, Topinabee, Aug. 19, 20, 1910 (Miss A. O'Brien, 2 구 3 우). Illlnols: "Northern Illinois," 1860 (Uhler, M.C.Z., I ऽ'); Rhode Island, I860 (Walsh, M.C.Z., I ơ); Lake Forest, June, I904 (Needham, I $\left.\sigma^{7}\right)$. INDIANA : Graveyard Lake, Aug. 27 , 1911 (Ray, coll. Williamson, I o7). Missouri, St. Louis, July 10, 1903 (C. L. Merrick, coll. Muttkowski, I \&). Wisconsin : (J. T. Brown, U.S.N.M., I o'); Nagowicka Lake, Waukesha Co., Aug. I7, I90o (C. E. Brown, U.S.N.M., I \&); Fox Lake, Dodge Co., Aug. 9, 1908 (Muttkowski, 2 o ) ; Portage Co., Aug. 20, 1905 (Muttkowski, I $\$$ ); Oostburg, Sheboygan Co., July 8, 1908 (Muttkowski, 1 9); Milwaukee Co., June 14, 1908, July I-Sept. 26, I903 (Muttkowski, 3 o' 3 \%) ; Low Rock, Aug. 15, 1906 (J. D. Hood, I \&). Minnesota: Duluth, Sept. 2 and 3 (O. Sacken, M.C.Z., 2 o" 1 \%). "Dakota" : (Dr. Mark, coll. Calvert, I ㅇ), Manitoba: Westbourne, Aug. 24, I908 (J. B. Wallis, I ō). British Columbia: Vancouver (Brit. Mus., I ơ); Victoria, July (Crotch, M.C.Z., I $\sigma^{7}$ ). Washington: Loon Lake, Colville Valley, July 22, 1882 (S. Henshaw, M.C.Z., $\left.+\sigma^{7}\right)$.

Nymphs-Magdalen Islands, P.Q., 1 \& exuvia with imago, emerged June 3o, 1901 (D. A. Atkinson). Go Home Bay, Ont., and vicinity, June 20, 25, 1907, 2 б about to emerge; Aug.9, 1908, Aug. 10, 14, 1905, 4 क7 6 \% (St. F); Aug. I0, $1905,4 \sigma^{7}$ (St.E), $1 \sigma^{7}$ (St. D), 2 spec. (St. B) ; July 15, Aug. 20, 1909, exuviae $1 \sigma^{7} 1$ f from reared imagoes. Giant's Tomb Island, Georgian Bay, Ont. July 29, 1908, I $\sigma^{7}$ I $\%$ (St. E) $3 \sigma^{7} 4$ ㅇ (St. D). Midland, Ont., Aug. 8, 1908, $\sigma^{7}$ (St. F), 1 ( ( $\mathrm{t}$. E). De Grassi Pt., Ont., Aug. 30, 1910 (St. C and D) ; Sept. 6, $19 c 9$ (St. C); July 27, 1910 (St. B and A); June 22, 1909, and Aug. 5, $191020^{7}$ exuviae from reared imagoes; July 15, 1910, exuviae $2 \sigma^{7} 2 \%$. Toronto, exuviae $2 \sigma^{2}$.

Identity-This is the species to which most of the references to Ae.clepsydra Say belong, and is the one to which Calvert ('94) referred as "presumed clepsydra." Its most distinctive feature is the form of the anterior hamuli, which are more elongate cephalad than in other species of the group. 
It is most likely to be confused with Ae. eremita and Ae. verticalis, both of which it resembles in coloration. The males may be readily separated by the form of the appendages and hamuli but the females are more difficult to distinguish. Eremita may be almost invariably known by the larger size and the black line across the face, but badly preserved females of verticalis and canadensis may give trouble to those who try to separate them, though, in the great majority of cases, the lateral thoracic bands can be seen well enough to render a diagnosis possible.

Distribution-This species inhabits the Transition and Canadian Zones from Atlantic to Pacific, but is apparently much less abundant on the western than on the eastern half of the continent. In the east it occurs throughout the Transition and in the lower part of the Canadian Zones. It is not known how far north it ranges but no specimens have been seen from beyond Lat. 50. N. Occasional examples are taken from within the limits of the upper Austral Zone.

Next to Ae. umbrosa this is the commonest North American species of Aeshna met with in collections.

IIabits - This species breeds among reeds and sedge in shallow sluggish creeks, lakes and bays. With the exception of Ae. californica and the multicolor group it is the earliest species to appear in the adult state. Individuals may sometimes be seen as early as the middle of June but the usual time for their appearance in the Transition Zone in Ontario is during the last week of June and the first week of July. By the middle of July they are numerous and may sometimes occur in very large numbers about the sunny borders of woods, especially coniferous woods. Here they may be seen sunning themselves on the trunks of trees or hanging from the twigs. On hot sultry days they fly restlessly to and fro in small openings among the trees, on the lookout for their prey. In August they are less frequently seen in the woods. They appear to return to their breeding-grounds, where they may be observed in large numbers, gliding over the reeds or skirting the water's edge. Such individuals are all males and may of ten be observed to drop down among the reeds and then emerge with a female, in copula. Apparently copu- 
lation does not take place far from the water as commonly occurs in constricta and other species.

Ae. canadensis is still common at the beginning of September and may sometimes be found until nearly the end of the month.

\section{Aeshna verticalis Hagen.}

(Pl. 13, fig. 5; pl. 16, figs. 6, 6a; pl. I9, figs. 4, 4a; pl.

$$
25 \text {, figs. } 5,6 \text {.) }
$$

Aeschna verticalis, Hagen, Syn. Neur. N.A., p. 122 (I86I) ; Pr. Bost. Soc. N. H., XVIII, p. 34 (I 875); Provancher, Nat. Canad., IX, p. 43 (I 877); Maclaughlin, Trans. Ott. Field Nat. Cl., II, pp. 334, 335 (1887); Wadsworth, Ent. News, I, p. 37 (I 890); Kirby, Syn. Cat. Neur. Od., p. 89 (I890); Beutenmuller, Prel. Cat. Od. N.Y., p. I63 (I 890); Harvey, Ent. News, II, p. 73 (I89I); Banks, Trans. Am. Ent. Soc., XIX, p. 353 (I 892); Kellicott, Journ. Cinc. Soc. N.H., XVII, p. 2 I2 (I 895); I. c. XVIII, p. I I4 (I 896); Kellicott, Od. Ohio, p. 84 (I 899); Williamson, Drag. Ind., p. 304 (I899); Burnham, Manch. Inst. Arts Sc., I, p. 3 I (I900); Needham. Bull. 47, N.Y. State Museum, p. 469 (I90I); Needham and Hart, Bull. Ill. State Lab., VI, p. 46 (I90I); Fyles, 31 st Ann. Rep. Ent. Soc. Ont., p. 54 (I90I); Harvey, Cat. Bibl. Od. Me., p. 8 (I902) ; Williamson, Ent. News, XIV, p. 7 (I903); Needham and Anthony, Pr. N.Y. Ent. Soc., XI, p. I 2 I (I903); Walker, Can. Ent., XXXVIII, pp. I.49, I 50 (1906); Muttkowski, Bull. Wis. N. H. Soc., VI, page 96 (I908); I c. p. I67 (I908).

Aeshna verticalis, Williamson, Ohio Nat., VII, p. I50 (I907); Walker, Can. Ent., XL, pp. 385, 389, 45I (I908) ; Muttkowski, Cat. Od. N.A., p. I I4 (I9Io); Bu!l. Wis. N.H. Soc., VIII, p. I7t (I9I0).

Aeschna juncea verticalis, Calvert, Trans. Am. Ent. Soc., XX, p. 284 (1893); lint. News, V, p. I I (I 894) ; Pr.Cal. Ac. Sc., IV (2), p. 503 (I 895); Jr. N.Y. Ent. Soc., III, p. 45 (I 895); p. 93 (I 897); Davis, Jr. N.Y. Ent. Soc., p. I96 (I 898); Calvert, Ins. N.J., Od., p. 7 I (I g0o) ; Weith, Ent. News, XI, p. 64I (I900); Martin, Cat. Coll. Zoul. Selys, XVIII, p. 35 (I908); Smith, Ins. N.J., p. 78 (1909); Martin, Gen. Ins., CXV, p. I I (I9I I).

Aeshna juncea verticalis, Calvert, Occ. Pap. Bost. Soc. N. H., VII (6), p. 23 (I905): Wilson, Pr. U.S.N.M., XXXVI, pp. 656, 659, 665, 667 (Ig09).

A eschna propinqua, Scudder, Pr. Bost. Soc. N.H., X, pp. 21 t, 215 (1 866) lin part]; Hagen, Pr. Bost. Soc. N.H., XV, p. 376 (I 87 I).

Male-A medium-sized species of slender form. Occiput greenish yellow, equilateral or somewhat broader than long, two- to three-fifths as long as the line of contact of the eyes. Frontal vesicle twice or slightly more than twice as broad as long, the yellow area not quite reaching the lateral ocelli. Eyes green or grey-green, varying considerably in shade, pale yellowish green next the hind margin. Preocular band, at the base of the antennæ, rarely less than twice as broad as one of the lateral ocelli, but reduced to an extremely narrow line on the sides of the frons and nasus. T-spot heavy, 2.5-3 mm., the stem generally short with divergent sides, $.6-.7 \mathrm{~mm}$. broad in front, $\mathrm{I}-\mathrm{I} .33 \mathrm{~mm}$. broad behind. Face yellowish green to olivaceous with a pale yellowish ocular border; a fine brown line on the fronto-nasal 
suture; lateral lobes of nasus not flaring, nearly rectangular, with the apices more or less rounded. Rhinarium reddish brown. Labrum pale dull green, or brownish green, of ten with a plumbeous tinge, margined very narrowly above, more broadly below with black. Labium varying in the living insect from dull greyish obscured with reddish brown to ivory-yellow behind, bluish white more or less obscured by brownish in front, the lateral lobes pale blue or plumbeous, stained apically with reddish brown, Rear of head black.

Thorax of average size, dark reddish brown, with a slight greyish bloom beneath. Dorsal bands conspicuous, pea-green or yellowish green, $4 \mathrm{~mm}$. long, expanding dorsad, .66-1.25 mm. broad at the middle, lower ends pointed and separated by $4-4.5 \mathrm{~mm}$., upper ends at the antealar sinus separated by about I mm., expanded, I.5-1.75 mm. broad. There is also a small green spot upon the antealar sinus sometimes connected with the corresponding dorsal band, as well as a larger green spot just in front of the humeral suture near its middle. Lateral bands fairly broad, yellowish green or pea-green, the second band of ten more or less blue in the upper half, narrowed just above the middle to $.7-.9$ $\mathrm{mm}$. by the obtusangulate excavation of the anterior margin, then widening again very slightly ( $\mathrm{I} \mathrm{mm}$.) and giving off at the upper end a posterior offshoot of nearly the same breadth. The posterior margin of the band is more or less sinuate, but less strongly so than the anterior margin. Second band widening gradually from the pointed lower end to the upper end, which is about $2 \mathrm{~mm}$. broad, middle breadth I $\mathrm{mm}$.; anterior margin curving outwards at the upper end, posterior margin straight. Interalar spots blue-green and green.

Femora dark reddish brown above, black beneath, the posterior surface of the fore trochanters and basal fourth or third of the fore femora pale yellowish, tibiae and tarsi black.

Abdomen nearly 4.5 times as long as the thorax, slender, strongly constricted at 3 . Seg. I without a ventral tubercle. Spinulose area on ventral surface of 2 restricted to the apical third; auricles with $3(2-4)$ teeth. Spines of anterior lamina rather large for the clepsydra group, straight, acute, directed ventrad, caudad and somewhat laterad. Hamular processes 
directed ventrad and mesad, consisting of a short broad proximal and a slender papilliform distal part. Hamular folds continuous with the hamular processes closely approximated above; outer margins divergent, meeting the hind margins in a rather broad curve. Seg. 3 about one-third longer than 4 , which is very slightly longer than $I+2$. Lateral carinae on $\delta$ more or less angulate near the middle. Dorsum of Io with an abruptly elevated median sub-basal tooth, between two pairs of much smaller teeth.

Superior appendages about as long as $9+$ ro or slightly longer, their basal breadth one-fourth or two-sevenths that of the intervening space; slender but slightly widening in the basal fifth, then expanding more rapidly mesad to about twofifths or one-half of the length, the breadth here, viewed dorsad, being one-sixth to one-fifth of the length, and narrowing again to the more or less acute and slightly decurved apices, which terminate in a short sharp spine. Outer margin, viewed dorsad, gently convex; inner margin gently sinuate, usually appearing nearly straight in the distal half before the curve of the apex. In profile the outer margin is curved gently upwards except apically, the inner margin bent downwards forming an arcuate inferior carina. Superior carina feebly marked or obsolete on the slender basal part, distinct beyond and somewhat elevated and gently arcuate in the apical two-fifths ; normally without denticles.

Inferior appendage elongate-triangular, barely more than half as long as the superior pair and about twice as long as the basal breadth, sides straight; a pair of minute recurved spines just before the bluntly pointed apices; in profile view moderately curved, tapering evenly to the apex.

Colour-pattern of abdomen - Seg. I fuscous; dorsal spot blue, $3.5 \mathrm{~mm}$. broad; lateral spot pea-green, rarely bluish, 3.5-4 $\mathrm{mm}$. long and about I $\mathrm{mm}$. broad near the lower end, tapering dorsad.

Seg. 2 fuscous; AML bluish green to blue, 1.5 to nearly $2 \mathrm{~mm}$. broad at the middle, giving off a narrow prolongation ventrad along the anterior margin and another dorsad along the transverse carina, the latter quite widely separated from MD. PL blue, very narrowly connected with, or barely 
separated from, PD, which forms with its fellow of the opposite side a blue band about $\mathrm{I} .3 \mathrm{~mm}$ broad, from which a more or less ill-defined median green streak passes cephalad.

Segs. 3-Io brownish black; all the spots azure blue except $\mathrm{MD}$, which is pale green. $\mathrm{AL}$ on $3-8$, of moderate size, dwindling to a mere dot on 8 , rounded below, giving off, on 3-6 or -7 , a basal transverse offshoot, which on most of the segments forms a complete though narrow ring with its fellow of the opposite side; upper margins straight or slightly concave. ML on 3-8, enlarging to 6 , rhomboid on $3-4$ or -5 , oblong and subangular or rounded behind on the other segments; front margin feebly or not at all indented. MD on 3-7, triangular, the postero-lateral margins concave; often more or less quadrate on 3 and 4 , and occasionally confluent with $\mathrm{ML}$ on 3 . PD I-I.33 mm. long on 3 , increasing to 1.75 or $2 \mathrm{~mm}$. on 8 , rounded mesially and rather narrowly separated on 3-7, more widely separated on 8 and 9, the inner margins straight and more or less divergent cephalad, particularly on 9; well-developed on Io, subquadrate and separated by a variable interval, but never connate. PL usually represented on 3 and 4 only, but often also on 5 and rarely on 6 . On 3 it is a well-marked offshoot from PD, on 4 smaller and more curved, generally an isolated dot when present on 6 or 7 .

Wings hyaline, costal veins brownish ochraceous, pterostigma dark smoky brown above, paler and more yellowish beneath, membranule of hind wing smoky brown, uniform or slightly paler at base, usually not reaching the cross-vein of the anal triangle which is 2 -celled. Two cells between $\mathrm{A}_{2}$ and $\mathrm{A}_{3}$ at their origin. Rs forking at the level of 2-3 (fore wing) $2-4$ (hind wing) postnodal cells before the stigma; 3 rows between the forks at the level of the distal end of the stigma and 3-6 cells between them at the margin. Three or 4 (rarely 5 ) rows of cells between Rs and Rspl, where most widely separated. II 1 a arising before the level of the midldle of the stigma, generally near the proximal end.

Antenodals $\frac{16-20}{12-15}$, postnodals $\frac{10-15}{13-17}, \mathrm{CuCr} \frac{5-7}{5-7}, \mathrm{Spt} \frac{3-5}{2-4}$.

Female-Abdomen about 3.5 times as long as the thorax and barely or no shorter than the hind wing. 
Genital valves as long as the dorsum of 9, lateral carinae very prominent, except at the base, varying considerably in profile view, but more or less gently arcuate with a tendency to be subangularly bent about the distal third; in ventral view nearly straight, bounding a space which is broadest in the proximal two-fifths, the breadth here being about onethird of the length, thence narrowing to the moderately broad squarely cut apices, which bear each a minute pencil of whitish hairs. Ventral surfaces of valves with a more or less well-defined sulcate area occupying about the middle third, distally narrowed and sloping mesad, feebly sulcate; inner margins touching only at a point near the middle, beyond which they are somewhat divergent. Styli .6-.7 mm. long, or half as long as the dorsum of Io. Basal plate of ovipositor with the hind margin straight. Lateral plates distinct. Appendages about as long as $8+9$, slender, expanding to about three-fifths of the length, where the breadth is one-sixth of the length, thence tapering slightly to the rounded apices; curve of inner margin slightly stronger than that of the outer.

The dorsal thoracic bands vary considerably in development but are usually complete, though somewhat narrower than in the male (middle breadth $.5-8 \mathrm{~mm}$.) and more constricted below the expanded upper ends, which are sometimes separated as distinct transverse spots. Lateral bands averaging slightly broader than in the male. Abdominal spots shewing the usual differential characters of the sex, PD being smaller, the lateral spots larger, than in the male. PD is particularly reduced on 3 , and on 2 is but narrowly connected with, or separate from, its fellow of the opposite side. PL on $2-6$ or -7 , relatively large, subtriangular on $3-5$, generally connected throughout with $\mathrm{PD}$ and broadly confluent with AML on 2, and of ten narrowly so with ML on 3.

The extent of colour variation is as yet uncertain. The individual figured on pl. 25, fig. 6, wasstrongly heterochromatic, the spots being all decidedly green or greenish yellow, but in the majority the lateral spots are more or less bluish green, the thoracic bands and dorsal abdominal spots yellowish green. I have never seen a purely homøochromatic female.

The wings vary from hyaline to a moderate degree of 
flavescence. The stigma is, as usual, somewhat paler than in the male.

The following colour notes were made from two specimens taken at De Grassi Point, Lake Simcoe.

\begin{tabular}{|c|c|c|}
\hline $\begin{array}{l}\text { Occiput and frontal } \\
\text { vesicle. }\end{array}$ & $\begin{array}{l}\text { Specimen } \mathbf{I} \text {. } \\
\text { Greenish yellow. }\end{array}$ & $\begin{array}{l}\text { Specimen } 2 . \\
\text { Lemon yellow. }\end{array}$ \\
\hline Eyes & $\begin{array}{l}\text { Greyish brown, pale yellow } \\
\text { hind margin. }\end{array}$ & $\begin{array}{l}\text { Brown, light yellow hind } \\
\text { margin. }\end{array}$ \\
\hline Face & $\begin{array}{l}\text { Olivaceous, pale yellow lat- } \\
\text { erally. }\end{array}$ & Pale yellowish olivaceous. \\
\hline Labium. & $\begin{array}{l}\text { Ivory-yellow, below middle } \\
\text { lobes bluish white, lat. lobes } \\
\text { pale dull blue. }\end{array}$ & $\begin{array}{l}\text { Pale drab with a pinkish } \\
\text { tinge, brownish about mar- } \\
\text { gins. }\end{array}$ \\
\hline Thorax. & $\begin{array}{l}\text { Dark reddish brown; bands } \\
\text { pea-green. Spots between } \\
\text { wings yellowish green. }\end{array}$ & $\begin{array}{l}\text { Chocolate with a grey bloom; } \\
\text { bands and spots between } \\
\text { wings bright yellowish green. }\end{array}$ \\
\hline $\begin{array}{l}\text { Abdomen. } \\
\text { Seg. } 1 .\end{array}$ & $\begin{array}{l}\text { Dark reddish brown. } \\
\text { D pale blue, } L \text { pale yellowish } \\
\text { green. }\end{array}$ & $\begin{array}{l}\text { Dark reddish brown. } \\
D \text { and } L \text { yellowish green. }\end{array}$ \\
\hline Seg. 2. & $\begin{array}{l}\mathrm{AD}, \mathrm{MD} \text { light yellow. } \mathrm{PD} \text {, } \\
\text { pale yellowish green. } \mathrm{AML} \text {, } \\
\mathrm{PL} \text { pale green. }\end{array}$ & $\begin{array}{l}\text { All the spots bright yellow- } \\
\text { ish green. }\end{array}$ \\
\hline Segs. 3-10. & $\begin{array}{l}\text { MD light yellow. PD pale } \\
\text { yellowish green, becoming } \\
\text { more bluish caudad. Lateral } \\
\text { spots all very pale green in- } \\
\text { clined to bluish. }\end{array}$ & $\begin{array}{l}\mathrm{MD}, \mathrm{PD} \text { and } \mathrm{PL} \text { yellowish } \\
\text { green. AL and ML pale } \\
\text { green. Ventral spots pale } \\
\text { greenish. }\end{array}$ \\
\hline
\end{tabular}

Measurements-Thor. o $\sigma^{7}$ 10.5-11.5, क 10-11; abd. $\sigma^{7}$ 46.5-51.3, क 43.25-50; seg. 3 o' 8.6-9.2, क 6.5-8.1; depth seg. 2 o' 5-5.8, क 5-6; depth seg. 3 \% 2.9-3.1; apps. $\sigma^{7}$ 5.335.75, क 5.75-7 ; gen. v. 2-2.6; h.w. ơ 45.5-49.5, क् 43.2-48; width h.w. ơ 13-13.9, क 13.5-15; pter. ơ 3-3.4, क 3.33-4. Type-o , Mus. Comp. Zoology.

Nymph-Unknown.

Material delermined-80 o 33 \%. MaINE : Manchester, July 18, 1890 (1 $\sigma^{\pi}$ ), Aug. 15, 1895, Aug. 22-Sept. 8, 1908, Aug. 23-Sept. 3, 1909, Sept. 2-7, 19 10 (Miss Wadsworth, II $0^{7} 8$ \%) ; West Beach (Hagen, M.C.Z., I $0^{7}$ ). MAssACHUSETts: (Riley, U.S.N.M., Möring, M.C.Z.. $2 \sigma^{7}$ ) ; Beverley, Sept. II, 1870 (M.C.Z., I ơ); Cambridge, (M.C.Z., I \&); Nahant, I 874 (Möring, M.C.Z., I $\sigma^{7} 3$ \%) : Salem (Joseph Lane, M.C.Z., I o $\sigma^{7}$ ); Saugus, (M.C.Z., I $q$ ); Sherbourne, Sept. I7, I864 (M.C.Z., I o'); id. (Babcock, Ac. N.S. Phil., I ơ); Walpole, Aug. 30, 1896 (F. H. Sprague, M.C.Z., I 9); Westborn, Aug. 30, 1894 (Needham, I Q); Wollaston, Sept. 20, I896 (F. H. Sprague, M.C.Z., I O $^{7}$ ). NEW YORK: Long Island, Sept. (O. Sacken, M.C.Z., I \%). Pennsylvania: Akron, Sept. 28, 1897 (J. S. Hine, I $\sigma^{7}$ ); Folsom, Delaware Co., Oct. 4, I890 (Calvert I $\sigma^{7}$ ); Ridley Township, Del. Co., Oct. I1, 1890 (Calvert, I 9 ); Neville Isl., Sept. 27, 1908 (J. L. Graf, $40^{7}$ ); Squaw Run, Alleghany Co., Sept. 6, 1908 (J. L. Graf, coll. Williamson, I $\sigma^{7}$ ). District OF Columbia: Washington (O. Sacken, M. C.Z., I $\left.\sigma^{7}\right)$. ONTARIo: Toronto, Sept. 12, 1907, Sept. 27, 1909 (Walker, Io $0^{7} 3$ 9): Scarboro' Jc., Sept. 7, 1907 (Huntsman, I $\sigma^{7}$ ); De Grassi Point, Lake Simcoe, July 17, 18, 1904 (Walker, $2 \sigma^{7}$ ); id., Aug. 21, 28, 1901, Sept. 5, 1906, 
Aug. I8-25, 1908, Aug. 30-Sept. 6, 1909, Aug. 27, Sept. 7, I910 (Walker, 12 o7 5 8) ; Go Home Bay, Georgian Bay, Aug. 26-30, 1907 (Huntsman, 2 o I \&). MichigaN : Detroit, M.C.Z., 3 \&) ; Petroskey (Mrs. Godfrey Ashbaucher, coll. Williamson, I ơ). Illinors: Chicago, June 13, Ig06 (J.D. Hood, I o7); id. (Bolter, M.C.Z., I \&); Indiana: Fort Wayne, Aug. 23, Sept. 13, 1908 (Williamson, $2 \sigma^{7}$ ) ; id., Sept. 17, I8, 1906, Sept. 15, 1907 (Williamson, 16 o' I \&); Bluffton, Sept. I7, I906 (L.A. Williamson, I ơ); Crooked Lake, Steuben Co.. Sept. I, I905 (Williamson, I \%). Wisconsin: Milwaukee Co., June I4, I908 (Muttkowski, I $\sigma^{7}$, teneral); id., Aug. I0, I908 (Muttkowski, I \$); Magnolia, Sept. 9. I 880 (Hagen, M.C.Z., I $\sigma^{7}$ I $\%$ ). Also 3 or $^{7} \%$ without data.

Identity-This species bears a superficial resemblance to Ae. juncea L.., especially in the coloration and form of the male appendages, and was placed by Calvert ('93) and Martin ('08) as a race of that species. It is not, however, at all close-' ly related to juncea but finds its nearest relative in Ae. canadensis. From this species it differs very obviously in the form of the anterior hamuli, and may be easily distinguished from it in the field by the much brighter thoracic bands. The lateral bands differ but slightly in form from those of canadensis but this difference is very constant. The undenticulated superior carina of the male appendages is an almost constant feature but occasional individuals occur in which a few slight denticles are present. This is the case in the two specimens from Sherbourne, Mass., which were referred by Calvert ('94) to Ae. clepsydra.

Distribution-Alleghanian and Carolinian Zones from the Atlantic States to Wisconsin. In addition to the localities given above it has been recently reported by Muttkowski from Florida ('Io b). Some of the older records, such as the one from California (Calvert, '95), need confirmation, as more than one species have been quoted under the name verticalis.

Habits-All my captures of this insect were made about the borders of woods or in small open spaces surrounded by trees. In its flight and its habit of sunning itself on the trunks of trees or hanging from the branches it resembles Ae. canadensis, with which it is sometimes associated, though it usually makes its first appearance at a time when Ae. canadensis is leaving the woods and returning to its breeding grounds. Although two specimens, one a teneral, are recorded above as having been captured on June 13 and I 5 , the normal time of appearance of this species is during the latter 
half of July, while it is most numerous towards the end of August and in early September. On Sept. 12, 1907, it appeared in very large numbers about the borders of a wood near Toronto.

Two pairs were taken here in copula and I found a third pair in an open wood at De Grassi Pt., Ont., on Aug. 27, 1910. They were resting on the branch of a tree and by approaching very quietly I was able to pick them up with the fingers, but they separated immediately.

I have never discovered the breeding grounds of this species nor do I remember ever to have seen it in the immediate neighbourhood of water. ${ }^{1} \mathrm{Mr}$. Williamson, however, has taken it at Fort Wayne, Indiana, flying over an open marsh, in company with Ae. constricta.

\section{Aeshna tuberculifera Walker.}

(Pl. 13, fig. 6; pl. 17, figs. I, Ia; pl. 20, figs. 2, 2a;

$$
\text { pl. 26, figs. I, 2.) }
$$
[in part].

A eshna juncea verticalis, Calvert, Occ. Pap. Bost. Soc. N.H., VI, p. 23 (1905)

A eshno tuberculifera, Walker, Can. Ent., XL, pp. 385, 387, 451 (1908).

A eschna tuberculifera, Muttkowski, Bull. Wis, N.H. Soc., VI, p. 167 (1908); Martin, Gen. Ins., CXV, p. II (1911).

Male-A slender species of medium or rather large size. Occiput pale bluish green, the antero-lateral margins blackish, usually distinctly broader than long, one-third to two-fifths as long as the line of contact of the eyes. Frontal vesicle reniform, more than twice as broad as long, the yellow area not reaching the lateral ocelli. Eyes in alcoholic specimens deep yellowish olivaceous shading into bright yellow behind, with a small transverse dark spot above. Preocular band not more, generally less, than twice as broad as the first antennal joint, narrowed ventrad on sides of frons, becoming obsolete at the fronto-nasal suture, but broadening again on the nasus. T-spot $2.33-3 \mathrm{~mm}$., stem $.4-.75 \mathrm{~mm}$. broad in front, .8- $\mathrm{Imm}$. behind, sides generally straight, more or less divergent. Face (alcoholic) dull olivaceous with a slight bluish tinge, in dried specimens yellowish olivaceous; paler above and on the

Since the above was written I have seen a few males hovering over small pools on the borders of woods near Toronto. One of these pools is a favourite breeding spot for $A$ e. umbrosa but as a rule it is not frequented by other species of the genus. 
sides next the preocular line. A fine brown line generally present on the fronto-nasal suture. Lateral lobes of nasus rotundo-angulate, scarcely flaring. Rhinarium reddish brown, the upper part green. Labrum light green with very narrow upper and lower marginal black lines. Labium pale obscure yellowish or olivaceous stained with reddish brown toward the fore margins. Rear of head black.

Thorax moderately slender, dark reddish brown, deepening to black around the lateral bands, with a slight greyish bloom beneath. Dorsal bands pea-green, nearly straight, 3.5-4 $\mathrm{mm}$. long, .75-1 $\mathrm{mm}$. broad at the middle, lower ends pointed, separated by about $4 \mathrm{~mm}$., upper ends reaching the antealar sinus, expanded, about $1.5 \mathrm{~mm}$. broad, separated by 1-1.5 mm. Antealar sinus pea-green. Lateral bands blue above, fading into pale green below (pale yellowish in dried teneral specimens), straight, the first band rounded at the lower end, I-I.5 mm. broad in lower third, thence narrowing dorsad to about $\mathbf{I} \mathrm{mm}$. in the upper half and widening again slightly at the upper end, from which a very small offshoot passes caudad; anterior margin sometimes slightly broken above the middle, posterior margin nearly straight. Second band tapering somewhat at the lower end, the margins straight and subparallel; breadth at middle I.3-I.5 mm., slightly broader at upper end. No spots, or at most a minute dot, between the bands. Spots between and at base of wings blue.

Legs dark reddish brown, nearly black on the tibiae, tarsi and underside of the femora; fore femora without a pale streak on the posterior surface.

Abdomen slender, five times as long as the thorax, strongly constricted at 3 . Sternum of I slightly elevated at the hind margin, but without a distinct tubercle. Auricles with 4 or 5 teeth. Tergal margins of 2 opposite sheath of penis subangularly approximated. Spines of the anterior lamina short and blunt, not reaching back to the hamular folds. Hamular processes short and very broad, directed mesad, the ventro-anterior surfaces flat, postero-internal margins arcuate, apices bluntly obtusangulate, with no indication of a tubercle. Hamular folds continuous with ham- 
ular process, not so closely approximated behind as in most species of the clepsydra group, margins thickened, outer margins parallel. Seg. 3 about one-third longer than $I+2$ or 4. Lateral carinae on 8 more or less subangulate or irregularly sinuate, on 9 distinct except for a short distance near the middle, where they are more or less obliterated. Dorsum of 10 with a prominent median and two pairs of small lateral teeth.

Superior appendages usually slightly shorter than $9+10$, sometimes as long, contracted at the extreme base, moderately slender in the proximal fourth, being about half as broad as the intervening space, thence expanding meso-caudad to about two-fifths of the length, the width here being about onefifth of the length, narrowing very little distally, the apices being broadly rounded with a small deflexed terminal tooth near the outer margin. Outer margin viewed dorsad, gently convex proximally, more strongly so distally; inner margin rather markedly sinuate, being convex just beyond the base, just before the middle and before the apex. Superior carina obsolete in the proximal third, gradually and moderately elevated beyond, gently arcuate before the apex, but with no indication of denticles. Profile view: slightly curved upwards; a prominent basal dorsal tubercle and a well-marked sub-basal ventral tubercle, which appears most prominent when viewed obliquely either from above or below. Inner margin in the distal four-fifths bent downwards, forming a fairly prominent arcuate inferior carina, apices slightly decurved. Inferior appendage triangular, with nearlystraight sides, one-half to three-fifths as long as the superior pair, the basal breadth one-half to three-fifths of the length; a pair of minute recurved dorsal spines before the bluntly pointed apices; in profile very gently upcurved, tapering evenly to the apex.

Colour-pattern of abdomen-Segs. I and 2 fuscous, the others brownish black, pale spots all slightly reduced.

Seg. I. Dorsal spot blue, lateral spot wanting.

Seg. 2. AML pale green to azure blue, L-shaped, the horizontal part I-I.5 mm. broad just above the auricle and extending downwards a short distance along the front margin 
to the ventral surface; vertical part somewhat narrower, extending dorsad $2-2.5 \mathrm{~mm}$. above the auricle, ending abruptly and not confluent with MD. PL pale green to azure blue, only about I $\mathrm{mm}$. broad, connected rather narrowly with PD, which is about I.3 long (antero-posterior dimension), connate with its fellow of the opposite side, and in front with a narrow pale median greenish streak.

Segs. 3-Io. AL on 3-8, pale green to blue, smaller than usual, diminishing caudad to a dot, subtriangular, with the upper margins oblique; on 3 about $2.5 \mathrm{~mm}$. broad in front, on the next 2 or 3 segments sometimes giving off dorsad a short narrow basal offshoot. ML on 3-8, pale green to blue, increasing in size caudad to 6 ; more or less rhomboid on 3 , and sometimes 4 , rounded on the succeeding segments, not confluent with MD. MD on $3-7$, pale green, small and subquadrate on 3 and reduced to a pair of dots on 7 , elsewhere triangular, but little elongated transversely. PD on $3-9$, azure blue, increasing in length from I mm. on 3 to $1.3-1.75$ on 8 ; inner margins rounded and separated by about $.5 \mathrm{~mm}$. or somewhat less, except on 8 and 9, where they are straight, somewhat divergent cephalad, and more widely separated. Seg. Io entirely black. PL on 3 only, a small curved offshoot from PD sometimes separated as a minute dot or absent al together.

Wings hyaline or slightly flavescent in tenerals, costal veins rather dark reddish brown, pterostigma dark brown, membranule of hind wing dark smoky brown, fading in to pale greyish at base, not reaching cross-vein of anal triangle, which is 2-celled. Two cells between $\mathrm{A}_{2}$ and $\mathrm{A}_{3}$ at their origin. Rs forking at the level of 2-5 (fore wing) 3-6 (hind wing) postnodal cells before the stigma; 3 (rarely 2 or 4 ) rows of cells between the forks at the level of the distal end of stigma and 3-6 cells between the forks at the wing-margin. Three or 4 rows of cells between Rs and Rspl, the latter not strongly sinuate; Mra arising at a point between the level of the middle and proximal ends of the stigma (almost always near the latter). Three (occasionally 2 or 4 ) cross-veins under stigma.

Antenodals $\frac{\mathrm{I} 8-22}{\mathrm{II}-\mathrm{I} 6}$, postnodals $\frac{\mathrm{II}-\mathrm{I} 8}{\mathrm{I} 3-\mathrm{I} 8}, \mathrm{CuCr} \frac{6-7}{5-6}, \mathrm{Spt} \frac{3-4}{2-3}$. 
Female-Abdomen scarcely five times as long as thorax, slightly widened at apex of 8 and base of 9 , the parts of the genitalia larger than in any other North American species of Aeshna except Ae. constricta. Genital valves as long as dorsum of 9 , or barely longer, in profile arcuate toward the base, the apices slightly elevated; lateral carinae prominent, percurrent, in profile sinuate, in ventral view nearly straight, the enclosed space narrowing slightly caudad; its middle breadth about one-fourth the length; apices rather broad and truncate. Ventral surfaces of valves distinctly declivent, especially at the middle, feebly sulcate. Basal plate of ovipositor of moderate size, hind margin straight; lateral plates distinct. Spines on ventral surface of Io few and scattered, rather coarse. Styli $1.5 \mathrm{~mm}$. long, or about as long as the dorsum of Io. Appendages as long as, or slightly longer than, $8+9$, expanding rapidly from the base to one-fourth or one-third the length, the breadth there being slightly more than one-fifth of the length, tapering in the distal half to the acute or roundly angulate apices, which sometimes terminate in a minute spine. The curve of the margins is generally stronger towards the base than the apex and that of the inner margin stronger and more regular than that of the outer.

The colour-pattern shows the usual marks of distinction from that of the male: the dorsal thoracic bands narrower $(.5 \mathrm{~mm}$.), the lateral abdominal spots somewhat larger and PD slightly smaller and on 9 more widely separated. Ill-defined traces of $\mathrm{PD}$ are sometimes present on IO. $\mathrm{PL}$, as in the male, is represented only on 2 and 3 , though a little larger, and confluent on 2 with AML.

In the single female in which the colours were seen while still fresh they were purely homœochromatic (pl. 26, fig. 2). None of the dried specimens are well enough preserved to determine the natural colours, though in some the PD spots were apparently blue in life, while in one from Hampden, Mass., these spots on the posterior segments are yellow and were probably so in life, so that Ae.tuberculifera is probably more or less dichromatic, like related species.

The wings are sometimes slightly flavescent, especially at the bases and along the costal borders, but I have seen no 
specimens with deeply coloured wings. The pterostigma is, as usual, generally longer than in the male.

Measurements-Thor. $\sigma^{7}$ 9.5-10.5, क IO-I I ; abd. $\sigma^{7} 47.5$ 52.5 , ㅇ 45-54. 5; seg. 3 ơ 8-9.66, क 7.5-9; depth seg. 2 o 5.35.75 , क 5-75-6.25; depth seg. 3 क 2.33-2.9; apps. ơ 4.8-5.75, o 7.33-8.33; gen. v. 3.I-3.5; h.w. of 45.5-49, क 44-50.5; width h.w. $\sigma^{7}$ I 3-I 4.6, o I 2.5-I 5 ; pter. $\sigma^{7} 3-3.6$, o 3.5-4.

Types- $\sigma^{\top}+$, Acad. Nat. Sc. Philadel phia-Isleboro, Me., taken in copula.

Nymph-Unknown.

Material examined-I4 o I I $\%$. MAINE : Isleboro (Dr. S. G. Dixon, Ac. Nat. Sc. Phil., o' o in cop.); Manchester, Aug. 26, 1895, July 20, Aug. 8, I0, I 9 Io (Miss Wadsworth, 7 o 3 o ). MassachusetTs : (A. N. Caudell, U.S.N.M., $1 \sigma^{7}$ ); Walpole, Aug. 30, 1896 (F. H. Sprague, M.C.Z., I o ); Essex Co. (Hagen, M.C.Z., I \&); Provincetown, Aug. 5, 6, I 899 (J. E. Benedict, jr., U.S.N.M, R C. Osburn, $30^{7} 2$ \%) ; Hampden, Aug. 7, I902 (Needham, I \&); Westborn, Aug. 30, 1894 (Needham, I 9 ). Ontario: East Toronto, July 3, I 907 (Huntsman, I $\left.\sigma^{7}\right)$; Etobicoke Creek, near Toronto, Sept. 30, I907 (Walker, I o); Go Home Bay, Georgian Bay, Aug. 26, I 907 (Huntsman I $\sigma^{7}$ ). Wisconsin: Oostburg, July I6, I908 (E. Was, coll. Muttkowski, I \&).

Distribution - Alleghanian; New England, Ontario and Wisconsin.

\section{Aeshna palmata Hagen.}

(Pl. I, fig. 4; pl. I4, fig. I ; pl. 20, figs. 4, 4a; pl. 26, figs. 3, 4.) Aeschna palmata, Hagen, Stett. Ent. Zeit., XVII, p. 369 (1856) ; Selys, Ann.

Soc. Ent. Belg., XV, p. 34 (1872); Martin, Gen. Ins., CXV, p. I 2 (I9I I). Aeshna palmata, Walker, Can. Ent., XL, pp. 379, 388, 450 (1908); Muttkowski, Cat. Od. N.A., p. II3 (I9I0); Bull. Wis., N.H. Soc., VIII, p. I7.4 (I9I0). Aeschna constricta, Hagen, Pr. B.S. N.H., XVIII, P. 34 (1875); Kirby, Syn. Cat. Od., p. 88 (1890) [in part]; Calvert, Trans. Am. Ent. Soc., XX, p. 249 (1893) [in part]; Currie, Pr. Wash. Ac. Sc., III, p. 220 (I90I); Pr. Ent. Soc. Wash., VII, p. I8 (1905); Osburn, Ent. News, XVI, pp. 185, I90 (1905).

A eshna constricta, Calvert, Od. B.C.A., p. I83 (1905) [in part].

Male-A strongly built species of medium or rather large size. Occiput pale yellow or yellowish green, one-half to three-fifths as long as the line of contact of the eyes. Yellow area of frontal vescicle extending laterally to the lateral ocelli. Eyes blue above, with a dark transverse stripe, pale greyish brown below, hind margin whitish. Preocular band varying in width, like the other dark markings of the head, according to locality, but almost always two or three times as broad at base of antennæ as one of the lateral ocelli, narrowed to a heavy black line on the sides of the frons and nasus. T-spot heavy but exhibiting great variability, generally $2.5-3 \mathrm{~mm}$., 
strongly arcuate in front; stem short, .6-.75 mm. broad, with parallel sides. In specimens from Banff this spot is inclined to be a little under the average size, while in examples from Vancouver Island it reaches its greatest development, the cross-bar measuring 3-3.33 mm., and proportionately wider, so that the stem is shortened, and in one example from Departure Bay has virtually disappeared, the cross-bar being directly connected with the preocular band. Frons, nasus and labrum pale green or greenish yellow, a black line on the fronto-nasal suture, varying in width according to locality. In one unusually large and pale example from City Creek Cañon, the line is brown and extremely narrow. Lateral lobes of nasus rotundo-obtusangulate, scarcely or not at all flaring. Labrum bordered above and below by a black line. Rhinarium brownish or plumbeous. Labium pale dull yellow, more or less obscured by reddish brown. Rear of head black.

Thorax robust, dark reddish brown, paler beneath. Dorsal bands yellowish green, .6-.8 $\mathrm{mm}$ broad, tapering below, expanded suddenly at the extreme upper end, this expanded portion being frequently separated as a distinct spot or absent al together, the band in such cases tapering at both ends. No humeral spots or bands. Lateral bands bright greenish yellow, of ten bluish above, nearly straight, more or less distinctly surrounded by a diffuse dark brown margin; first band broadest near the rounded lower end ( $\mathrm{mm}$. or a little more), straight or feebly sinuate about the middle, somewhat narrowed above, not expanded at the upper end and without a posterior offshoot. Second band of about the same width below as the first band, straight, slightly expanded at upper end. There are often two very small greenish spots between the two lateral bands, one at the metastigma, the other above it, but these are not always present.

Legs black, femora more or less reddish brown above in alcoholic specimens. Anterior trochanters and basal fourth or more of posterior surface of anterior femora pale yellowish.

Abdomen about four and one-half times as long as thorax, rather robust, strongly constricted at 3. Seg. I without a distinct ventral tubercle. Auricles with 4-5 teeth. Tergal 
margins of 2 approximated opposite sheath of penis. Spines of anterior lamina strongly developed, projecting caudad about as far as the hamular processes, moderately and evenly curved dorsad. Hamular processes broad and thick, their anterolateral surfaces concave and bounded behind by an arcuate ridge which runs from base to antero-internal angle; apical margin straight and transverse; inner margins approximate in front, divergent behind, where they are in unbroken con tinuity with those of the hamular folds. Hamular folds nearly meeting behind, sinuously bent, but not produced into earlike processes. Seg. 3 one-fifth to one-fourth longer than I +2 or 4 ; lateral carinae of 7 and 8 feebly sinuate in ventral view; dorsum of 10 smooth, without a vestige of a tooth.

Superior appendages about as long as $9+10$, their bases comparatively stout and as broad as the space between them, expanding rapidly by the curving of the inner margin, so that the greatest breadth, at about three-fifths of the length, is equal to about three-tenths of the length. Outer margin curled inwards over the dorsal surface, feebly convex in the proximal half or two-thirds, straight or feebly concave beyond, passing distally into the broad rounded apical margin. Inner margin strongly concave in the basal half, very strongly convex beyond and emarginate before the apex, where it terminates in a slender pointed spine, directed downwards and backwards and surmounted by a stout inwardly directed tubercle, which bears a tuft of brown hairs. Dorsal surface concave, facing rather inwards than upwards in the natural position. Superior carina indicated by a low rounded median ridge.

Inferior appendage about half as long as the superior pair, the basal breadth about half the length; lateral margins feebly convex next the base, straight beyond and meeting in the rather broadly rounded or truncated apex, which is armed above with a pair of minute recurved black spines. Profile view: gently curved upwards, the curve of the lower margin being a little stronger than that of the upper.

Colour-pattern of abdomen-Seg. I fuscous, dorsal spot blue, lateral spot greenish yellow, elongate-triangular, of variable size, $1.5-3 \mathrm{~mm}$. long (transverse), $1 \mathrm{~mm}$., or less, broad. 
Seg. 2 fuscous. AD small, triangular, pale yellowish. AML greenish yellow, about $1.5 \mathrm{~mm}$. broad at middle, giving off ventrad a narrow streak along the front margin and confluent above with MD. PL greenish yellow, partly separated by a deep notch from $P D$, which is a blue band, from the front margin of which a narrow medio-dorsal streak runs forward to connect with AD.

Segs. 3-Io black, the blue spots varying somewhat in size according to locality, but never much reduced. $A D$ on $3-7$ or -8 , small yellowish triangular spots, rudimentary caudad. MD well developed, yellowish, triangular on $3-7$, and generally represented by a pair of dots on 8 . PD well developed, generally rather narrowly separated, increasing in size caudad; on 8 usually nearly half as long as the segment, the inner margins straight and subparallel and separated by less than I $\mathrm{mm}$.; on 9 three-fifths as long as the segment, broadly connate or separated by a narrow line; on Io rather narrowly connate. In specimens from Vancouver Island PD, as well as the other blue abdominal spots, is slightly smaller than usual, and more widely separate from its fellow (except on Io, where they are generally narrowly connate). AL on $3-8$, blue or frequently more or less green on 3 , connected on most of the segments with a narrow basal ring or narrowly separated from it; upper margins straight and horizontal. ML on 3-8, subquadrate becoming larger and more rounded caudad, not confluent with MD. PL on $3-5,-6$ or -7 , variable, decreasing.

Wings hyaline, costal veins brownish yellow, pterostigma dark smoky brown, paler beneath, membranule of hind wing whitish in the proximal fifth, smoky brown distally, reaching nearly to the cross-vein of anal triangle, which is 3-celled. One cell (rarely 2) between $\mathrm{A}_{2}$ and $\mathrm{A}_{3}$ at their margin. Rs in front wing forking opposite the first or second postnodal cell before the stigma, in the hind wing opposite the first to third cell; 3 or 4 rows of cells between the forks at level of distal end of stigma and 3-6 cells between the forks at the wing-margin. Three or 4 rows of cells between Rs and Rspl. M Ia arising beyond the middle of stigma or beyond stigma altogether. 
Antenodals $\frac{\mathrm{I} 3-20}{\mathrm{II}-\mathrm{I} 5}$, postnodals $\frac{9-\mathrm{I} 3}{\mathrm{II}-\mathrm{I} 4}, \mathrm{CuCr} \frac{5-6}{4-5}$, Spt $\frac{2-3}{\mathrm{I}-2}$.

Female-Varying considerably in form according to locality (vide postea); abdomen but little or no longer than the hind wing.

Genital valves rather large, reaching slightly beyond the posterior margin of 9 , in profile considerably arcuate, apices elevated; lateral carinae percurrent, prominent, in lateral view somewhat sinuate, in ventral view almost straight, the space between them broadest at about one-third of its length, the breadth here being equal to about one-fourth of the length, narrowing caudad very slightly to the broad truncated apices. Ventral surface of valves declivent in the proximal third, distally rather shallowly sulcate. Styli about I mm. long, shorter than dorsum of 10 . Appendages about as long as 9 + I0, tapering somewhat more gradually towards the base than the apex; greatest breadth about the middle and equal to one-fifth, or a little more, of the length; curve of inner margin somewhat stronger than that of outer margin; apices rounded, sometimes terminating in a more or less obscure point.

Dorsal thoracic bands much reduced or obsolete, sometimes divided into a superior and inferior spot. Abdominal spots differing from those of the male in the usual way, i.e., PD is smaller, the lateral spots larger, especially $\mathrm{PL}$, which is sometimes confluent with $\mathrm{PD}$ and on 2 with AML. In the specimen from Twin Lakes, Col., which is figured on pl. 26, the spots are decidedly larger than usual and the difference between the two sexes asshown on the plate is greater than it is in specimens from the same locality. In the female from Banff, as in the Twin Lakes specimen, PL is confluent with AML on 2, but elsewhere it is isolated and the basal rings are mere lateral extensions of $A D$ and do not reach $A L$. In individuals from Baker City, Oregon, and Kaslo, B.C., the spots are still smaller and PL is isolated on all the segments on which it is present. In the Kaslo specimens the basal rings have apparently disappeared al together. 
The range of colour variation is as great in this as in any of our species of Aeshna. Mr. C. H Kennedy has sent me a coloured drawing of a purely homœochromatic female, in which the abdomen is blackish brown and all the spots on segs. 3-Io are blue. The upper part of the eyes is also blue. On the other hand the Twin Lakes specimen is reddish brown, somewhat darkened about the margins and elevated parts and the pale markings where well preserved are all yellow with a greenish tinge. Most of the other specimens seen are not well enough preserved to reveal the natural colours. One from Banff was apparently of the intermediate type. The wings are hyaline in all the specimens except the heterochromatic one from Twin Lakes, in which they are flavescent. The stigma is pale brown.

Measurements-Thor. o7 I0.75-II.5, क I0.5-I0.75; abd. $\sigma^{7} 47-52$, क $42-47$; seg. $3 \sigma^{7} 7-9$, ㅇ 4-33-7.5; depth seg. 2 $\sigma^{7} 5 \cdot 25-6$, क 5.5-6 ; apps. $\sigma^{7}+5 \cdot 5-6$; gen. v. 3-3.5; h.w. $\sigma^{7}$ 42-46.5, क 41-42.5; width h.w. ơ 12.66-15, क I3-14; pter. ơ 2.33-3, क 2.6-3.5.

Type- $\sigma^{7}$, Museum Comp. Zoology-Kamtchatka.

Nymph (pl. 7, fig. I; pl. 9, fig. I; pl. I I, fig. I)-Very similar to that of umbrosa, differing chiefly in the stouter form, broader labium and larger genitalia of the female.

Eyes as in umbrosa, postocular part of head also similar, except that the postero-lateral corners are somewhat less broadly rounded. Mentum of labium decidedly broader than in umbrosa, but strongly narrowed at base, the basal breadth being less than half the apical breadth, which is equal to about four-fifths of the length. Proximal four-sevenths expanding gradually but more rapidly than in umbrosa, the sides straight; distal three-sevenths much dilated, the sides strongly arcuate. Lateral lobes not narrowed beyond the base of the movable hook, squarely truncate, angles scarcely rounded, the inner one without a terminal tooth. Supracoxal processes somewhat larger than in umbrosa, equal, slightly outcurved, acute ; intervening space rectangular or nearly so.

Abdomen distinctly stouter than in umbrosa, having about the same form as interrupta and eremita, broadest at 7 or 8 ; lateral spines present on 6 to 9 , a trifle longer than in 
umbrosa, those of 8 extending slightly beyond the posterior margin of the segment, and those of 9 to about three-fifths or two-thirds the length of ro. Abdominal appendages as in umbrosa. Genitalia of female extending over the basal third of 10 , the valves slightly declivent.

In the female specimen the pale markings of the abdomen are obscure, but in the male they are as distinct as in average specimens of umbrosa; and the pattern is nearly the same in the two species. The pale lateral margin of the head is less distinct than in palmata, but the annulations of the legs are quite as in umbrosa. The pale dorsal area of the abdomen in the male specimen is divided anteriorly into two bands by a dark median band, which broadens and becomes diffuse in the more posterior segments. Just external to the pale bands, in line with the dorso-lateral punctae, is a series of narrow longitudinal pale streaks. The lateral scars are outlined in brown and surrounded by diffuse pale areas. The other markings described for umbrosa are less distinct than in that species except the punctae, of which the dorsal as well as the lateral and dorso-lateral are marked with deep brown.

Measurements--Length of body 40.5-4I ; mentum of labium 6.8; h.f. 7-7.2 ; h.w. 8.5-9; inf. apps. $4.25-4.5$; width of head 8 ; of abdomen $7 \cdot 75^{-8}$.

The two exuviae from which the above description was taken were found by Dr. Huntsman at the edge of a pond near Robson, B.C. Aeshna palmata was flying here and was the only species seen except a single female of Ae. californica. These exuviae are very close to those of $A$ e. umbrosa but are distinct and can belong to no other known species than palmata. As in the imagoes of these two species the body is somewhat stouter and the female genitalia a little larger than in umbrosa. The difference in the abdomen is in reality greater than appears on the plate, as the drawing of palmata was made from an exuvia, that of umbrosa from the nymph itself.

Material determined - 50 o $15 \%$. KaмtchatкA : (M. C. Z., I $\sigma^{x}$ ). AlaSka: Kodiak, July 20, 21 , 1899 (T. Kincaid, U.S.N.M., I ơ 2 \&) ; Cook's Inlet, July 20, 1899 (T. Kincaid, U.S.N.M., I ơ), British Columbia: (Crotch, M.C.Z., I ơ I $\sigma^{7}$ ); Departure Bay, Vancouver Is. (Huntsman, $7 \sigma^{7}$ ); Victoria 
(M.C.Z., I 9); Shawnigan Lake, Vanc. Is. (Currie, U.S.N.M., I $\left.\sigma^{7}\right)$; Glacier (Mrs. C. Schaeffer, Ac. N.S. Phil., I \&); Peachland, Aug. I8, 21, I 909 (Wallis, $3 \sigma^{7}$ ); Penticton (Wallis, $2 \sigma^{7}$ ); South Fork Creek, Aug. II, I903 (Currie U.S.N.M., I $\%$ ); Kaslo (Currie, U.S.N.M., I $\%)$. AlBERTA: near Waterton Lake, $4100 \mathrm{ft}$. (E. V. Cowdry, coll. Walker, $3 \sigma^{7}$ ); Banff, July I0-Aug 6, I908 (Sanson, $20^{7} \mathrm{I}$ \%) ; Laggan, July 22 , I90I (Osburn, I $\sigma^{7}$ ). WAsHINGToN: Yakima, Sept. 1894 (Calvert, I $\sigma^{7}$ ) ; Loon Lake, Colville Valley, July 25, 1882 (Henshaw, M.C.Z., I \%). OREGON: Baker City and vicinity, July 31 , I 908 , Aug. 6-Sept. 18, 1909 (C. H. Kennedy, $16 \sigma^{7} 1$ o ); Corvallis (Needham, $1 \sigma^{7}$ ). Colorado: Twin Lakes, Aug. I3-3I, I903 (Calvert, coll. Calvert and Williamson, $3 \sigma^{7}$ I $q$ ) ; Fort Hill, I 873 (M.C.Z., I $\left.\sigma^{7}\right)$; Summit Cañon, Aug. 8, I875 (M.C.Z., I $\sigma^{7}$ ); "South-western part of Colorado," I I000-1 $2000 \mathrm{ft}$. (T.S. Gillin, Ac. Nat. Sc. Phil., I $\sigma^{7}$ ). Yellowstone: Aug. I 872 (Hayden, M.C.Z., $2 \sigma^{7}$ 1\%). UtaH : Mountains east of Ogden, Aug. 22, I897 (Needham, I \&); City Creek Cañon, July 5, I 899 (Calvert, I $\sigma^{7}$ ). NevadA: Reno, Aug. II, I890 (F. 11 Hullman, Ac. N.S. Phil., I \%). Also I $\sigma^{7}$ without data.

Nymphs-Exuviae. I oै 1 9 , Robson, B.C., July 21, 1907 (Huntsman).

Identity-The Alaska specimens, as far as can be judged from their discoloured condition, are identical with the type specimen from Kamtchatka. In the latter the abdominal spots are smaller than in any of the American specimens, but there is much variation in this character, according to locality.

In the great majority of cases the black line across the face will serve to distinguish this species from umbrosa and constricta but occasional individuals occur in Colorado and Utah in which this line is very narrow or practically absent. Such specimens may be known by the other characters given in the key.

Distribution-Boreal ; Kamtchatka and Alaska to Colorado and Utah.

Geographical variations-A considerable range of colour variation is exhibited by this species in the different parts of the territory that it inhabits. The extent of the black markings of the head is greatest in the specimens from Vancouver Island and least in those from Alberta, Colorado and Utah. The reverse is the case with the spots of the abdomen; e.g., the PD spots on seg. 9 of the male are separate in all the Vancouver Island specimens but are broadly connate in nearly all of those from the other localities.

In my key of 1908 I gave Baja California as the southern limit of this species' range. The specimens from this locality which I referred to Ae. palmata were part of the material recorded by Calvert ('95) as Ae. constricta. They differ from 
typical palmata in the broader superior appendages with shorter preapical spines, in the smaller anterior hamuli, the somewhat more complex venation (there being, e. g., two cells between $\mathrm{A}_{2}$ and $\mathrm{A}_{3}$ at their origin) and in the slight reduction of the abdominal spots. $\mathrm{AL}$ is quite insignificant on 7 and 8 ; ML present only to 5 or 6 and very small, while PL is represented only to 4 or 5 , though connected with PD where present. PD is but little reduced.

As I have seen no females from this locality I prefer to leave undecided the question of the status of the Baja California variety.

\section{Aeshna umbrosa Walker.}

A eschna constricta, Scudder, Pr. Bost. Soc. N.H., X, p. 212 (1866) ; Hagen, Pr. Bost. Soc. N.H., XV, p. 376 (I873) ; Provancher, Nat. Canad., IX, p. 42 (1877); Cabot, Mem. M.C.Z..VIII, I, p. 24, pl. 3, fig.I (nymph) (188I); Kirby.Syn. Cat. Od. N.A., p. 88 (1890) [in part] ; Calvert, Trans. Am. Ent. Soc., XX, p. 249 (1893) [in part]; Can. Ent., XXVI, p. 317, 318, (I 894); Ent. News, X, p. 42 (I899) Williamson,Drag. Ind.,pl. 4. fig. Io (nymph); Howard,Ins. Bk.,pl. 4I,fig. 4 (I90I); Needham, Bull. 47,N.Y. St. Mus., p. 470 (nymph),pl. 17, fig. I (I901); Needham and Hart, Bull. Ill. St. Lab., VI, p. 42 (IgoI); Williamson, Ent. News, XIII, p. I 10 (I902); l.c. XIV, p. 227 (1903); Needham, Bull. 68, N.Y. State Mus., pp. 205, 212 , 275, pl. 5 (1903); Walker, Ann. Rep. Ent. Soc., XV, p. 69 (I906); Can. Ent., XXXVIII, p. 149 (1906) [in part]; Martin, Cat. Coll. Zool. Selys; XVIII, p. 48 , fig. 44 (I908).

Aeshna constricta, Calvert, Od. B.C.A., p. I85 (1905) [in part]; Occ. Pap. Bost. Soc. N.H., VII, 6, p. 24 (1905) [in part]; Ent. News, XVII, p. 148, pl. VII (1906).

Aeshna "z”, Williamson, Ohio Nat., VII, p. I45, I46 (I907); Walker, Ott. Nat., XXII, p. 54 (1908).

Aeshna umbrosa, Walker, Can. Ent., XL, pp. 380, 390, 450 (I908); Muttkowski, Bull. Wis. N.H. Soc., VIII, p. 57 (1910); Cat. Od. N.A., p. I I4 (1910).

Aeschna umbrosa, Muttkowski, Bull. Wis. N.H. Soc., VI, p. 167 (1908); Smith, Ins. N. J., p. 78 (1909).

This widespread species varies considerably in the different parts of its geographical range. Two principal varieties may be distinguished, the one occurring in the eastern half of the continent, the other from the Rocky Mountains westward. These may be separated as follows:

PD much reduced, green on segs. 5-10 or on all the segments; seg. 3 variable, but generally rather long and slender; eastern............................Ae. u. umbrosa.

PD of the usual size, blue except on Io; seg. 3 of ordinary length; western..................... u. occidentalis.

Aeshna umbrosa umbrosa Walker.

(Pl. 14, fig. 2; pl.17, figs. 2, 2a; pl. 20, figs. 3, 3a; pl.26, figs. 5, 6.) 
Male-Occiput lemon-yellow, two-fifths to one-half as long as the line of contact of the eyes. Frontal vesicle greenish yellow, this colour extending laterally to the lateral ocelli. Eyes above rather dark olivaceous green with a transversely elongate black spot, partly surrounded by a diffuse violet margin; paler below; edged behind with bright yellow or greenish yellow. Preocular band, at base of antennæ, rarely more than twice as broad as one of the lateral ocelli; reduced on the sides of the frons to a narrow line, which disappears at the nasus. T-spot of moderate size, 2-2.33 $\mathrm{mm}$., stem very variable, frequently a mere line, .25 $\mathrm{mm}$. broad, sometimes as narrow as this in front but expanding to .5 or $.7 \mathrm{~mm}$. at base; more rarely equal throughout. Frons and nasus varying from pale green to comparatively dark olivaceous; pale yellowish laterally and on dorsal surface of frons. Fronto-nasal suture of ten with a very narrow brown line. Rhinarium generally darker than the other pale portions of the face, more or less plumbeous. Labrum pale to moderately dark dull greenish, margined above and below by a very narrow black line. Labium drab or yellowish, more or less obscured peripherally by reddish brown. Rear of head black centrally and above, pale yellowish green (brownish in dried specimens) laterally.

Thorax rather slender, dark rich brown with a reddish or coppery tinge. Dorsal bands yellowish green, 3.5-4 $\mathrm{mm}$. long, separated by about $4 \mathrm{~mm}$. at the pointed lower ends, converging upwards to the antealar sinus, their breadth increasing to about $\mathrm{I} \mathrm{mm}$. at the middle and 1.5 to $2 \mathrm{~mm}$. at upper end, where they are separated by I-I.5 mm.; outer margin more or less strongly curved outwards at the upper ends. A transverse green spot in each antealar sinus, and generally also a darker green humeral streak. Lateral bands bright yellow or greenish yellow, of ten blue at upper end, rather narrow, straight and surrounded by a diffuse black margin. First band rounded at lower end, where it is I.25$1.5 \mathrm{~mm}$. broad, narrowing to .6 or $.8 \mathrm{~mm}$. at the middle and generally giving off caudad at upper end a small triangular offshoot. Second band .75-1.25 mm. broad, equal or slightly constricted by a slight excavation of the hind margin; upper 
end of ten with a narrow cross-bar. There are also frequently one or two small greenish spots at the metastigma and another farther dorsad. Spots at bases of wings above yellowish green, interalar spots pale blue and greenish blue.

Abdomen about five times as long as thorax, strongly constricted at 3 , which is generally longer than in most species, elsewhere fairly broad though not deep. Seg. I without a distinct ventral tubercle. Auricles with 4 (rarely 3) teeth. Tergal areas on each side of penis moderately elevated with numerous spinules, their margins somewhat approximated but less so than in Ae. palmata. Spines of anterior lamina welldeveloped, projecting caudad a little beyond the hamular processes, their apices curved somewhat more abruptly dorsad than in palmata and constricta. Hamular processes smaller than in these two species, their antero-lateral surfaces concave and separated from the rounded inferior surface by an indistinct arcuate ridge; apical margins truncate; inner margins approximate in front, divergent behind, where they are in unbroken continuity with those of the hamular folds. Hamular folds lying directly dorsal to the processes and projecting scarcely any farther caudad, similar to those of Ae. palmata. Seg. 3 nearly or quite one-third longer than $I+2$, or 4 . Lateral carinae of 7 and 8 strongly approximated in the basal third, being separated there by a space about one-half as broad as at apex and appearing strongly sinuate when viewed ventrad. Dorsum of Io smooth, without a tooth.

Superior appendages as long as 9+10, dull brown, shaped as in $A e$. palmata, the only differences being the paler colour and slightly shorter preapical spine. Inferior appendage pale horn colour, darkened at apex and along lateral margins, otherwise as in palmata.

Colour-pattern of abdomen-Seg. I fuscous; dorsal spot blue, narrow; lateral spot absent.

Seg. 2 fuscous, spots reduced. AD obsolete; AML yellow or greenish yellow, rhomboid, about $1.2 \mathrm{~mm}$. in diameter, the upper posterior angle confluent above with MD. PL and PD separate, the former greenish yellow, the latter blue, forming a band half as broad as the posterior part of the segment, with a concave front margin, from which a narrow 
green streak passes forward in the middle line, sometimes 'expanding to form a large diffuse green spot.

Segs. 3-10 dark brown with a greenish tinge, most of the spots green or greenish blue, and so reduced as to give the whole insect as unusually dark appearance. AD a minute elongate greenish spot connected on 4-7 with a narrow pale green basal ring. MD on 3-7, well-developed triangular greenish spots, separate from ML, except sometimes on 3, of ten represented on 8 by a pair of minute dots. PD much reduced but variable, .8-1.25 $\mathrm{mm}$. long on 3 , decreasing and narrowly separated mesially to 7 , where they measure 4 -I $\mathrm{mm}$., somewhat larger and more widely separated on 8 and 9 , diffuse and of variable size on 10. Frequently they are grassgreen or yellowish green throughout, but often the first one or two pairs are pale blue, the remainder green. AL on 3-6 or -7 ; on 3 reduced to a triangular bluish green or blue spot, occupying the antero-ventral angle of the segment; on the others a small rounded pale greenish spot, unconnected with the basal ring and becoming a mere dot on 6 or 7 . ML on 3- or 4-8, palegreen orgreenish blue, small and subquadrate on 3 and 4 , then rapidly enlarging to 7 , those on 7 and 8 being particularly large and more rounded than the others. PL on 3-6 or -7 , small pale greenish elongate spots, becoming minute caudad, widely separate from PD, except sometimes on 3 , where they may be narrowly confluent.

There is also a pair of large pale bluish basal spots on the ventral surface of $4^{-6}$.

Wings with a faint brownish tinge, distinctly shorter than the abdomen, costal veins brownish olivaceous; pterostigma dark smoky brown, paler beneath; membranule whitish in proximal half, dark brown distally; anal triangle with 3 cells; generally 2 cells between $\mathrm{A}_{2}$ and $\mathrm{A}_{3}$ at their origin; Rs in fore wing forking opposite the second to the fourth postnodal cells before the stigma, in hind wing opposite the second to fourth cell; 3 or 4 rows of cells between the forks at the level of the distal end of the stigma and 4 to 7 cells between the forks at the wing-margin. Four to 5 rows of cells between Rs 
and Rspl, where most widely separated. M I a arising before the middle of the stigma (occasionally at the middle).

Antenodals $\frac{15-23}{\text { II }-\mathrm{I} 6}$, postnodals $\frac{\mathrm{I} 2-\mathrm{I} 7}{13-20}, \mathrm{CuCr} \frac{5-7}{4-6}, \operatorname{Spt} \frac{2-4}{2-3(\text { rarely I })}$.

Female-Abdomen a little less than five times as long as thorax; dorsum of 9 distinctly shorter than that of 8 and about half as long as that of 7 .

Genital valves extending slightly beyond the posterior margin of 9, in profile moderately arcuate, the apices very slightly elevated. Lateral carinae percurrent, prominent, in profile nearly straight, in ventral view arcuate, the intervening space lanceolate, broadest at two-fifths of the length, the breadth here being equal to about two-fifths the length, tapering distad to the narrow rounded apices. Ventral surface of valves declivent and flat in the basal fifth, sulcate distally, becoming deeply so at the apices. Styli $.75^{-1} \mathrm{~mm}$. long, distinctly shorter than dorsum of 10 . Free margin of basal plate of ovipositor slightly arcuate. Lateral plates distinct.

Appendages thin and delicate, generally broken off except in tenerals, about as long as $8+9$, tapering much more gradually towards the base than the apex; greatest breadth beyond the middle and equal to about one-fifth the length; curve of inner margin somewhat stronger than that of the outer margin; apices rounded, sometimes terminating in a more or less obscure point.

The colour-pattern corresponds closely to that of the male and there is apparently no tendency to dimorphism. The face tends to be somewhat darker in the male; the dorsal thoracic bands are of a duller green and of ten more or less obscured with brown, being frequently invisible in dried specimens. They are also narrower and generally divided into an upper and lower spot; the former small, the latter more elongate. The lateral bands are often obscured at the extreme upper ends.

Abdomen somewhat paler brown than in the male, the dorsal spot on I and PD on all the segments green, the latter still more reduced than in the male, except on the apical three 
or four segments. AL and ML pale greenish or nearly white, similar in size to those of male. PL larger, of ten confluent with PD on $2-3$ or -4 .

Wings of ten quite deeply flavescent, this colour extending to the apices; pterostigma pale brown.

Measurements (excl. Anticosti specimens) - Thor. $\sigma^{7}$ 9.3II, \& 8.5-9.75; abd. or 48.5-54.5, क 44-50.75; seg. 3 o 8.75ro.33, ㅇ 6.5-8; seg. 9 \% 2.33-2.75; apps. o $5.33-6$, \& 5.4-6.9; gen. v. 2.66-3.25; h. w. o 42-46.5, क 43.5-46.7 ; width h.w. ㄱ1 I2.5-I 4 , क I 3.6-I 4 ; pter. o 2.66-3, ㅇ 3.3-3.66.

Measurements of Anticosti specimens-Thor. or 9-9.25, $\therefore$ 9; abd. $\sigma^{7} 44-48$, क 44 ; seg. 3 o 7.8-8.4, क 6.5; seg. 9 2.5 ; apps. $\sigma^{7} 5-5.2$; gen. v. 2.4 ; h.w. $\sigma^{7} 40-4 \mathrm{I} .5$, क $4 \mathrm{I}$; width h.w. $\sigma^{7}$ I I 5-I 2 , ᄋ I 2 ; pter. $\sigma^{7} 2.7-3$, क 3.2 .

Types- $\sigma^{7} \%$, United States National Museum-De Grassi Point, Ontario.

Nymph (pl.4, figs I-3;pl.7, fig. 2; pl.9, fig. 2 ;pl. I I, fig. 2)Eyes very prominent, the antero-posterior and transverse diameters about equal; lateral margins of head nearly straight, about half longer than the interocular space, or 'equal to twofifths of the length of the hind margin; postero-lateral angles of head prominent but well rounded; hind margin slightly emarginate. Mentum of labium strongly narrowed in the proximal half, but considerably expanded distally, the breadth at base being much less than half that at apex, which is equal to about three-fourths of the length; sidesstraightand slightly divergent from the base to slightly beyond the middle, thence strongly arcuate; middle lobe broadly obtusangulate; lateral lobes broad, equal, squarely truncate; outer apical angle scarcely rounded, inner angle terminating in a small tooth.

Supracoxal processes well developed, conical, the posterior larger and somewhat stouter than the anterior, and usually slightly recurved, the intervening space generally a little greater than a right angle.

Abdomen comparatively slender, broadest about seg. 6 or 7 ; lateral spines present on $6-9$, those on 6 extending onethird to one-half of the distance to the hind margin of the segment; on 7 to the margin or nearly so; on 8 to the margin or slightly beyond; on 9 to the middle of ro. Lateral append- 
ages about three-fifths as long as the inferior pair, very slender in the female but somewhat stouter in the male than in juncea and the clepsydra group, and tapering somewhat suddenly in the distal third or fourth, the apices very slender and finepointed. Basal part of superior appendage of male about onefourth longer than its basal breadth and one-half shorter than the lateral appendages; sides somewhat concave, apex bluntly rounded. Genitalia of female extending barely to the posterior margin of 9; genital valves rather steeply declivent, about three times as long as broad.

Colour dull dark brown, more or less distinctly spotted with pale yellowish, the degree to which the pale markings are obscured varying greatly. Head with a pale lateral marginal band and a submarginal pale spot just behind each eye. The marginal bands are continued caudad across the lateral portions of the pronotum to the meso- and metathorax, where they become much broader, but diffuse and of ten obscure, covering the whole thoracic dorsum, or sometimes broken in to spots; sides of thorax dark brown. Legs dark brown, femora and tibiae each with three pale rings, the former having sub-basal, median and preapical rings. Tarsal joints pale, darkened distally. Abdomen rather dark brown, varied with pale yellowish and brownish, the pale markings often almost entirely obscured. A broad medio-dorsal pale band with slightly undulate margins extends the whole length. Anteriorly it is well defined and about $4-5 \mathrm{~mm}$. broad but posteriorly it becomes gradually narrower and less distinct. This band is more or less darkened mesially by a series of pairs of dark basal blotches, which run together on the more proximal segments and sometimes throughout the whole length of the abdomen to form an irregular median double dark band. Lateral scars pale, distinctly outlined with dark brown; in front of each, on the middle segments, is a basal transverse series of alternate pale and dark spots, about three of each, the outermost of the former occupying the antero-lateral angle of the segment. Spines pale, tipped with black. Lateral and dorso-lateral punctae nearly black; dorsal punctae no darker than the ground colour. 


\section{Walker: North American Species of Aeshna}

Measurements-Length of body 38.5-43.5; mentum of al.um t-7; h.f. 6.3-7.5; h.w. 8-I I inf. apps. 4-4.5; gen. ? $\therefore ;-2 . t$ widih of head 7.4-8.8; width of abdomen 7-7.5.

Materi, determined-295 $\sigma^{7}, 83$ \%. Nova Scotia: (M. C. Z., I $\sigma^{7}$ ); Pictou, Aug. 22, I889 (W. Sheraton, Ac. N.S. Phil., I ơ). Quebec: Anticosti, Sep. 12, I9 10 (E. V. Cowdry, 10 o I $\%$ ); Quebec (Provancher, M. C. Z., 2 \%); Hull Sepr. I4, I9c7 (Letourneaux, Fyles, $2 \sigma^{7}$ ). Ontario: Grimsby, (J. Pettit, M.C.Z., I $0^{7}$ ) ; Toronto, Aug. 2 I, Sept. I I, I907, Oct. I0, I 908 (Walker, $60^{7} 3 \%$, incl. 4 leared) ; East of Scarboro, emerged July 22, I908 (Walker, I $\sigma^{7}$ ); De Grassi Pt., Lake Simcoe, July 2, Sept. 6, I904 (Walker, 8 o 79 ): Go Home Bay, Georgian Bay, Ont., Aug-Sept. 4, I9Io (Huntsman, T. R. Hanley, $3 \sigma^{7} 2$ 7) ; Ottawa, Aug. 71907 (Fletcher, I \&); Rostrevor, Muskoka, Sept. I 5, 1907 (Gibson, I $0^{7}$ ) Port Sidney, Muskoka (Brodie, I $0^{7}$ ); North River and Little Jo Creek, Algonquin Park, Aug. 29, 30, I902 (Walker, I or I \%); Temagami District, Sept. I-I3 Igo8 (Walker, I3 $\sigma^{\gamma} 5$ \%, pair in cop., Sept. 13); Heyden, Algoma, July 30-Aug. 4, 1906 (Williamson, I $70^{7} 2$ \%); Searchmont, Algoma, Aug. 6, I 906 , Aug. 23, I907 (Williamson $30^{7}$ ); Root River Algoma, Aug. 4-7, 1907 (Donaldson, 3 o'? Sault Ste. Marie, Sept. 6-Oct. 5 , 1907 (Donaldson, 27 o 5 우) ; Nipigon, Aug. 28-30, 1907, Sept. 5, I9 I0 (Walker, $3 \sigma^{7}$ I $ᄋ$ ) ; Fort William, Aug. 26, 27, 1907 (Walker, I2 $\sigma^{7}$ ); Rainy River District (H. Cook, I907, 2 o ). MANITOBA : Winnipeg Beach, Sept. 6, I909 (J. B. Wallis, I $\sigma^{7}$ ); Hilton and Treesbank, July 28, I9 Io (J. B. Wallis, $2 \sigma^{7}$ ). MAINe: Manchester, July 6-Oct. 6, I888-I9I0 (Miss Wadsworth, 33 o 8 ㅇ., in cop., July 6 and 7, Sept. 27, 1906); Augusta, Sept. 16, I9I0, (Miss Wadsworth, I o) ; Norway, (S. J. Smith, M.C.Z., 2 ơ, 2 \%); Gorham (M.C.Z., I ơ) ; Millinocket, Aug. 9-Sept. 7, I903 (F. L. Harvey, coll. Williamson, 6 ot 4 \%) ; Russell Stream, N.E. Corry, Aug. 28, I899 (F. L. Harvey, $50^{7}$ ); Bradley, Aug. 2, I899 (Harvey, I $\sigma^{7}$ ) ; Greenfield, Sept. 8, 1897 (Harvey, L.S.N.M., I $\sigma^{7}$ ); Six Ponds, Pisc. Co., Sept. I4, I898,(Harvey, U.S.N.MI., $\left.3 \sigma^{7}\right)$ New Hampshire: Franconia (Mrs. Slosson, U.S.N.M., $3 \sigma^{7}$ ); White Mountains, Aug. 15, I896 (F. H. Sprague, M.C.Z., 2 8) ; id., Aug. 7 (M.C.Z., I $\sigma^{\circ} 2$ \%) : Hermit Lake, White Mountains, Aug. 29, I862 (Scudder, M.C.Z., $\left.1 \sigma^{7}\right)$ Centre Harbour, July (M.C.Z., I $\$$ ). MassachusetTs: (M.C.Z., 2 $\sigma^{\top} 2$ ㅇ) ; Boston, Sept. 6 (B.S.N.H., I ơ); Cambridge, Sept. (M.C.L., 2 \%); Amherst, Aug. 5, 1902 (Needham, I $\sigma^{7}$ ); Wilbrahim (J. O. Martin, coll. Needham, I $\left.\sigma^{7}\right)$; Auburndale, Sept. I I (B.S.N.H., I $\sigma^{7}$ ). Gor Head, Martha's Vineyard, Aug. 25, I904 (B.S.N.H., I o ). NEw YoRK: Ca ro, Aug. I9, I 897 (Calvert, I \%); Catskill Mts., Aug. 28 (E. M. Aaron, Ac. Nat. Sc. Phil., I ơ); Lake St. Regis, Franklin Co., Sept. 22, I 890 (Ac. Nat. Sc., I \&); Clyde, Aug. 30, 1902 (Nelson R. Wood, U.S.N.M., I o ); Oneida, Aug. I, I 902 (Mrs. S. A. Maxon, U.S.N.M., I $\sigma^{2}$ ): Ellenville, Aug. 20, 1907 (Needham, I $\sigma^{7}$ ); West Point, Sept. I874 (Uhler, M.C.Z., I ơ); Dobb's Ferry, Aug. 24, I888 (Calvert, I ơ); New York (Riley, U.S.N.M., I $\sigma^{7}$ I $\%$ ). PEnnsylvania: Delaware Co., Sept. 5, I889, Sept. I0, 24, I 89 I (Calvert, 3 o I $\%$ ) : id., Oct. I, I 893 (Calvert, pair in cop.); Alleghany Co., Oct. 9, I 898, Oct. 6, I901, Aug. 6-Oct. I 3, I903, Sept. 25, I904, Sept. 20, Oct. 6, I908 (J. L. Graf, 3 I ơ I \&); id., June I 8, I 899 (Graf., I \% teneral); Morton, Oct. 3, I889 (Ac. N.S. Phil. I \&); Ohio Pyle, Oct. I, I905 (Williamson, $2 \sigma^{7}$ ); Sunbury (D.C. Heim, coll. Calvert, I ơ); Winthem, (Hagen, M.C.Z. I $8 \sigma^{7}$ ); District of Columbia: Takoma, Sept. I6, I899 (J. A, Williams, U.S.N.M.,I \&). MarYland: (Uhler, I858, M.C.Z., I ơ) ; Baltimore (M.C.Z., I o ). VIRGINIA: Mountain Lake, Aug. 25, I899 (W. R. Maxon and C. C. Pollard, U.S.N.M., $3 \sigma^{7}$ I $\%$ ); Rosslyn (N. Banks, U.S.N.M., I ơ). Tennessee: (L. Thomas, Ac. N.S. Phil., I o ); Roan Station, Sept. 3, I901, (Ac. N.S. Phil., I \&). OHIo: (U.S.N.M., I ơ): Clarkston, Oct. I3, I901 (Williamson, $2 \sigma^{7}$ ) : Medina, Aug. 20, 1897 (J. S. Hine, U.S.N.M., I o'). IndiaNa: Ft. Wayne, Sept. I8, I906, Sept. I 5, I907, Aug. 23, Sept. I3, 1908 (Williamson, 24 or 2 \%): Bluffton, Sept. I8, I904; Aug. 25, Sept. 13, I905, Aug. 26, I906 
Sept. 151907 (Williamson, $40^{7} 2$ \%) ; id., Aug. 30, 1908, (1 9 teneral); Whitby Co., Sept. 2, 1897 (Williamson, I o' I 9 ). Michigan: Oden, Aug. 8- I5, 1906 (Williamson, $20^{7} 2$ \%): Minnehaha Falls, Emmet Co., Aug. 23, 1907 (Williamson, $10^{7}$ ); Wisconsin: Milwaukee Co., Aug. 24, 1902, Aug. 1, 1907 (C. G. Brown, Muttkowski, I of I \&). Nebraska: Loretto, Sept. I, 1906 (coll. W. J. Fraser, I $\$$ ). Also 22 ơ 9 \% without data.

Nymphs-Nipigon, Ont., Aug. 7, 1910, $10^{7}$ exuvia; Go Home Bay, Aug. 8, 1908,1 spec. (St. B); Aug. 7, 1908,19 exuvia from reared imago ; also exuviae $10^{7} 19 . D e$ Grassi Point, Ont., July $15-20,1910$, exuviae $20^{7} 2$. 9 . Toronto, Ont., May, I $908,10^{7} 3$ \% (St. H-St. F also common); July 2 I-Sept. I, 1908, exuviae from reared nymphs $20^{7} 2 \%$; also exuviae $50^{7} 5$ \% I I thaca, N.Y. (cold brook) $1 \sigma^{7}$ (St. F) 2 ( (St. F) (Needham). Also the following without data

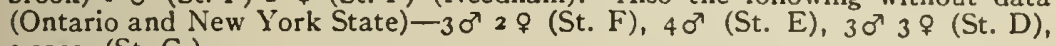
3 spec. (St. C.)

Distribution-Carolinian to Canadian Zones, probably ranging also into the Hudsonian Zone, as the record of $A e$. constricta from Labrador (Hagen '6I) doubtless belongs to this species. The race umbrosa probably grades into occidentalis in the west. This is the commonest species of Aeshna in North American collections.

Geographical variations-This species is subject to the usual variations in form depending upon climatic conditions (vide p. 26). It varies also slightly in size in different parts of its range. The largest average size is exhibited by Ohio and Indiana specimens, the smallest by those from Anticosti. Northern examples are most like the race occidentalis in coloration, the face being generally pale, the lateral thoracic bands of the male bluish at their upper ends, and the PD spots less reduced than in the more southern specimens and blue on the basal three or four segments in the male. In specimens from Lake Simcoe, Ont., and southward there are usually no traces of blue, except on segs. I and 2, and the PD spots are greatly reduced.

Habits-This common dragonfly differs considerably from our other species of Aeshna in its habits. It does not frequent open marshes but flies along woodland streams, ditches, or small pools on the edges of woods. It is also common in more or less shady glades and paths in woods and is most often seen in flight late in the afternoon and at dusk.

Adults begin to appear about the end of June but the period of emergence seems to be irregular; so some individuals do not come out until nearly the end of August. It is the last species to remain on the wing in the autumn, sometimes 


\section{Walker: North American Species of Aeshna}

flying, in the vicinity of Toronto, as late as the second week in October, and probably considerably later farther south.

The nymphs are common in woodland streams, small pools and ditches, and sometimes occur in considerable numbers. They are very like those of the European $A e$. cyanea in both appearance and habits. They appear to be the only Aeshna nymph, that is at all easily obtainable in the full-grown state, in eastern North America.

\section{Aeshna umbrosa occidentalis subsp. nov.}

\section{(Pl. 26, fig. 5.)}

Differs from race umbrosa mainly in the blue colour of nearly all the abdominal spots, and the much larger size of $\mathrm{PD}$, which is somewhat reduced only on 9 and ro, being elsewhere as large as in most other species of Aeshna. The abdomen is somewhat shorter and stouter at seg. 3 than in typical specimens of umbrosa, generally resembling that of Anticosti specimens, though varying considerably with locality.

Occiput lemon-yellow; frontal vesicle greenish yellow; T-spot 2-2.3 mm., stem .25-.33 mm. broad in front, sometimes expanding a little caudad. Face pale green, generally of a bluish shade; a very fine brown line of ten present on the fron tonasal suture; rhinarium plumbeous; labrum pale green; labium dull yellow, brownish or drab, the lateral lobes sometimes slightly plumbeous. Rear of head black above, pale brown in lower half.

Thorax a little stouter as a rule than in race umbrosa, marked as in northern examples of that race, i.e., colour reddish brown, dorsal bands yellowish green, antealar sinus pale green, lateral bands yellow passing into pale blue at the upper ends, surrounded by a nearly black margin.

Abdomen brownish black, the spots all blue except MD (dull greenish), PD on Io (dull greenish) and sometimes AML on 2 , which may be blue or green.

The spots are similar in form to those of race umbrosa, except PL and PD, the former being considerably, the latter much, larger. PD is in fact as large as in consiricta and many specimens of palmata, except on 9 and Io, where it is more or 
less reduced. On I 6 they are separated only by the median carina, on 7 a little more widely, while on 8 and 9 the intervening space is nearly $\mathrm{I} \mathrm{mm}$. broad behind, the inner margins strongly divergent cephalad. On Io they may be connate behind, but are always more or less indistinct and apparently sometimes absent altogether. On the ventral surface of 4 , 5 and 6 there is a pair of large basal spots as in race umbrosa, but they are blue instead of green.

The female differs but very slightly from that of $u m$ brosa, the larger size of PD and PL and the usually paler face and slightly shorter average length of the abdomen being the only characters by which they can be separated. The wings vary from hyaline to distinctly flavescent.

Measurements - Thor. o 9.7-10.5, क 9-10.25; apps. m. 5-5.5, ㅇ 5-6; h.w. \& 4I-46.5, \& 38-45; width h.w. $0^{7}$ I2.3-1 3.5, \% I 2.5 -I 4 .

Types- $\sigma^{T}$ \&, Bluffton Public Museum-New Bridge, Oregon.

Material determined-51 o $^{7}$ II $\%$. BRITISH ColumbIA : Greenwood, Oct. 1, 1906 (W. J. Alexander, coll. Walker, I ơ); Bear Lake, July 21, I903 (Currie, U.S.N.M., I $\%$ teneral); Wellington, Vancouver Is., Sept. 2, 1903 (H. G, Dyar, U.S.N.M., I $\sigma^{7}$ ); Langford Lake, Victoria, July 20, 1902 (coll. Williamson, $\left.1 \sigma^{2}\right)$. Washington: Colfax (L. O. Howard, U.S.N.M., I ơ); Almota, Aug. 1894 (coll. Calvert, I \&); Skokomish River, (T. Kincaid, Ac. N.S. Phil., I \&) Seattle, July 6, 1892 (Ac. N.S. Phil., I o'). Oregon: (Ac. N.S. Phil., I o'); New Bridge, Sept. 8-18, 1909 (C. H. Kennedy, 29 ơ 2 \&) ; Le Grande Valley, Sept. 30, 1909, (Kennedy $\left.20^{3}\right)$; Pine Valley, Sept. 23 (Kennedy, $13 \sigma^{3}$ ); Carson, Sept. 22, 1902 (Kennedy, $4 \% \%$ ). Nevada: Reno, (Morrison, M.C.Z., 1 oे 1 \&). California : (Calvert, 1007 ).

Nymph-Dr. Ris has sent me a full-grown female nymph of Ae. umbrosa from the Yosemite Valley, Cal., dated July 26,1907 . It does not differ in any way from the nymph of the race umbrosa, but on account of the locality it doubtless belongs to occidentalis.

Distribution-British Columbia to California and $\mathrm{Ne}$ vada, probably grading eastward into the race umbrosa.

Habits-Mr. Kennedy has taken this form in Oregon, flying along ditches. Its habits are probably not different from those of the eastern race. 


\section{Aeshna constricta Say.}

(Pl. 2, figs. 1-4; pl. 3, figs. 5, 6; pl. 14, fig. 3; pl. 21, fig. I; pl. 27, figs. 2-4.)

N.B.-Undoubted references to the species described here as constricta are marked with an asterisk.

A eshra constricta, Say, Journ. Acad. Phil., VIII, p. 11 (1839); Calvert, Od. B.C.A., p. 180,285 (1905); Occ. Pap. Bost. Soc. N.H., VII, 6, p. 24 (1905) ; Williamson, Ohio Nat., VII, p. 150 (1907); Walker, Ott. Nat., XXII, p. 54 (1908);* Wilson, Pr. U.S.N.M., XXXVI, p. 659 (1909) ; Muttkowski, Cat. Od. N.A., p. $109(1910) .^{*}$

Aeschna constricta, Hagen, Syn. Neur. N.A., p. 123 (1861);* Pr. Bost. Soc. N.H., XV, p. 271 (1873); Rep. U.S. Geol. Surv. Terr., 1872 , p. 727 (1873); l.c., I873, p. 591 (1874); Pr. Bost. Soc. N.H., XVII, p. $34(1875)$; Rep. U.S. Geog. Geol. Surv., p. 919 (1875); Kirby, Syn. Cat. Neur. Od., p. 88 (1890); Wadsworth, Ent. News, I, p. 37 (1890) ; Beutenmuller, Prel. Cat. Od. N.Y., p. 163 (1890); Harvey, Ent. News, II, p. 73 (189r); Banks, Trans. Am. Ent. Soc., XIX, p. 353 (1892); Calvert, Trans. Am. Ent. Soc., XX, p. 249 (1893); Ent. News, V. p. 243 (1894); Journ. N.Y. Ent. Soc., III, p. 46 (1895); Kellicott, Journ. Cinc. Soc. N.H., XVII, p. 212 (1895); l.c., XVIII, p. 114 (1896); Calvert, Journ. N.Y. Ent. Soc., V, p. 93 (1897); Van Duzee, Ent. News, VIII, p. 89 (1897); Williamson, Rep. State Geol. Ind., pp. 404 (1897); Davis, Journ. N.Y. Ent. Soc., VI, p. 197 (1898); Kellicott, Od. Ohio, p. 83 (1899); ' Calvert, Ins. N. J., Od., p. 71 (1900); Williamson, Drag. Ind., p. 305 (1900); Needham, Bull. 47, N.Y.' State Mus., p. 469 (1901); Elrod, Bull. Univ. Mont., X, P. 150 (1902); Comstock, Ent. News, XIV, P. 200 (1903); Williamson, Fnt. News, XIV, P. 369 (1903); Brimley, Ent. News, XVII, P. $9^{I}$ (1906); Walker, Can. Ent., XXXVIII, p. 149 (1906); Muttkowski, Bull. Wis. N.H. Soc., VI, p. 96 (1908); * l.c., VI, p. 167 (1908); Martin, Cat. Coll. Zool. Selys, XVIII, P. 46 (1908); Cockerell, Ent. News, XIX, p. 457-459 (1908); Martin, Gen. Ins., CXV, p. 11 (1911).

A eschna constrictor, Burnham, Pr. Manch. Inst. Arts Sci., I, p. 32 (1900).

A species of average size and rather broad abdomen, the spots of which are of large size and blue in the male.

Male-Occiput lemon-yellow, usually a little larger than in the two preceding species, but varying in length from twofifths to two-thirds that of the line of contact of the eyes. Frontal vesicle greenish yellow, this colour extending laterad to the lateral ocelli. Eyes green and grey-green with a violet area above, bounded behind by a dark brown transverse stripe; paler below; edged behind with bright yellow. Preocular band little or no broader at base of antennæ than one of the lateral ocelli, reduced on sides of frons to a narrow black line which fails to reach the fronto-nasal suture. T-spot of moderate size, 2-2.6 mm., stem longer than in palmata and umbrosa, $.4-.7 \mathrm{~mm}$. broad in front, expanding to $1 \mathrm{~mm}$., or a little more, behind. Face pale green, the frons of ten more yellowish than the nasus and projecting a little farther in advance of the eyes than in umbrosa and palmata; a fine, 
pale brownish line on the fronto-nasal suture; lateral lobes of nasus obtusangulate, not flaring. Rhinarium plumbeous or brownish. Labrum pale green, very narrowly edged above and below with black. Labium dull greyish to yellowish, more or less obscured peripherally with reddish brown. Rear of head black.

Thor ax moderately robust, reddish brown, paler than in most North American species of the genus. Dorsal bands yellowish green, nearly straight., $4 \mathrm{~mm}$. long, separated by about $4 \mathrm{~mm}$. at their pointed lower ends, from which they converge upwards to the antealar sinus; their breadth increasing to about $\mathrm{I} \mathrm{mm}$. at middle and $1.5 \mathrm{~mm}$. at the upper end, where they are separated by about I-I.5 mm. A transverse spot occupies each antealar sinus, but there is no humeral streak or spot. Lateral bands greenish yellow below, blue above, expanding above the middle, not surrounded by a black margin, though edged behind with black in the lower half. First band about $1.3 \mathrm{~mm}$. broad in the lower half, narrowing a little above the middle to somewhat less than I $\mathrm{mm}$., then expanding again and giving off a small posterior offshoot at the upperend; anterior edge distinctly sinuate about the middle, posterior edge gently curved or slightly sinuate. Second band subequal in the lower half, the breadth at middle about I $\mathrm{mm}$., expanding at upper end by the outward curving of both margins to 3 or $4 \mathrm{~mm}$. In teralar spots greenish blue.

Legs black, upper surfaces of femora dark reddish brown; posterior surface of fore femora pale greyish in their proximal half or four-fif ths.

Abdomen about 4.5 times as long as thorax, strongly constricted at 3; rather broad, the greatest bread th at about the apex of 5; somewhat depressed. Seg. I without a distinct ventral tubercle. Auricles typically with 4 teeth (3-5). Tergal areas on each side of penis moderately elevated, with numerous spinules, the margins moderately approximated. Spines of anterior lamina large and strong, projecting caudad as far as the posterior margins of the hamular processes or a little farther. Hamular processes larger than in palmata and umbrosa, ventral surfaces somewhat convex, separated from the strongiy concave antero-lateral surface by an arcuate ridge which 
runs from the base to the inner angle of the truncated apices; inner margins closely approximated in front, divergent behind, where they are continuous with those of the hamular folds; the latter similar to those of palmata but better developed, closely approximate in the middle line, the margins produced into a rounded lobe just beyond the hamular processes. Seg. 3 one-sixth to one-fifth longer than $\mathrm{I}+2$, and two-fifths to one-half longer than 4. Lateral carinae of 7 nearly straight, or feebly sinuate, those of 8 generally slightly sinuate proximally. Dorsum of 10 smooth, without a tooth.

Superior appendages dark brown, very similar to those of palmata and umbrosa. The slender basal part is slightly longer and more arcuate, the outer margin in the basal half appearing in dorsal view very slightly convex, instead of straight as in the other species; the greatest breadth, which is at about seven-tenths of the length, is equal to three-elevenths of the latter; the ventro-apical spine is distinctly longer than in umbrosa, less sharply pointed than in palmata, the rounded notch between its base and the apical margin generally broader and the preapical tubercle somewhat lower than in the other two species. Inferior appendages as in palmata.

Colour-pattern of abdomen-Seg. I reddish brown; dorsal spot blue; lateral spot represented by a very narrow pale green line along the posterior margin, sometimes also an illdefined pale blotch present.

Seg. 2 reddish brown; AD absent. AML pale yellowish green below and behind, more or less bluish above, $2-2.5 \mathrm{~mm}$. broad in the middle, extending ventrad along the front margin as a narrow streak and confluent above with MD. PL and PD united, forming a broad blue band, of ten greenish below; the front margin indented laterally and on each side of the mid-dorsal line, where it is connected with an ill-defined median blue spot. An additional blue or greenish blue spot occupies the postero-ventral angles of the segment.

Segs. 3-Io black, the blue spots all well developed. AL on $3-8$; on 3 blue or green, the upper margins horizontal and separated by about $1.3 \mathrm{~mm}$.; on the other segments blue, the upper margins straight and somewhat oblique. Basal rings absent. ML on 3-8, enlarging to 7 , front margin not indented, 
hind margin rounded except on 3 , where it is acutangulate or narrowly confluent with PL. MD on $3-8$, small narrow pale green triangles, decreasing in size caudad, smaller and more widely separated than in palmata and umbrosa, separate from ML, except frequently on 3. PD well developed, pale blue to azure blue, enlarging caudad, being about I $\mathrm{mm}$. long on 3 and 1.8 or $2 \mathrm{~mm}$. on 9, connate behind on 10 in about 66 per cent. of cases, well separated on the other segments, the inner margins straight and subparallel from 5 or 6 to 9 . PL on 3-4, -5 or -6 ; on 3 a broad truncated offshoot from PD, on the other segments small isolated spots diminishing caudad. Ventral surface of abdomen wholly black.

Wings a little shorter than abdomen, costal margin dull ochraceous; pterostigma dark brown; membranule of hind wing whitish in the basal half or three-fifths, smoky brown distally, extending beyond the cross-vein of the anal triangle, which is 3-celled. Rs forking at the level of I or 2 postnodal cells before the stigma; with 3 rows of cells between the forks opposite the distal end of the stigma, and 3-5 rows of cells between Rs and Rspl, where most widely separated. Mra arising under distal half of stigma (opposite middle in 5 per cent. of cases).

Antenodals $\frac{\mathrm{I} 4-\mathrm{I} 9}{10-15}$, postnodals $\frac{8-14}{10-16}, \mathrm{CuCr} \frac{5-6}{4-5}, \mathrm{Spt} \frac{2-3 \text { (rarely } 4)}{1-2}$.

Female-Abdomen barely longer than the hind wing, considerably inflated at base and constricted at 3 , widening considerably on 8 and 9 , the latter segment unusually long, being as long as 8 and three-fourths as long as 7 .

Genitalia much larger than usual in the genus; genital valves extending well beyond the apex of 9 , in profile moderately arcuate, the apices strongly elevated; lateral carinae percurrent, very prominent, in lateral view nearly straight and subparallel; the space between them a little broader at the basal third than elsewhere, the breadth here being onefourth of the length, narrowing very slightly caudad to the rather broad, rectangular, and of ten slightly divergent, apices; ventral surface of valves sulcate throughout their entire length. Styli $2 \mathrm{~mm}$. long, and longer than the dorsum of 10. 
Appendages unusually large and strong, rarely broken off in the living insect, a little shorter than $8+9$, greatest width a little before the middle and equal to about two-sevenths of the length; margins curved somewhat more strongly at base than apex and the inner slightly more than the outer; apices acute.

The markings show the usual differences characteristic of the sex. The dorsal thoracic bands are reduced in width to somewhat less than I $\mathrm{mm}$. and are but little, or not at all, expanded at their upper ends. They are usually as conspicuously coloured as in the male but are often obscured by brownish. The lateral bands have the same form as in the male. Of the abdominal markings $\mathrm{AL}$. is connected with narrow basal rings; PD is somewhat smaller than in the male on all the segments except 9, where it is considerably enlarged laterally, extending to the tergal margins; on 8 and 9 it is more widely separated from its fellow, and on Io it is obscure or absent. PL is large on 2, reaching the transverse carina; on 4 , as well as 3 , it is generally confluent with PD.

In colour great variation is met with and a marked tendency to dimorphism is present. In extreme heterochromatic individuals all the pale markings are bright yellow without a trace of green, the eyes are yellowish olivaceous with a bright yellow hind margin, the wings are strongly flavescent and the whole insect has a decidedly yellowish cast. Such individuals are by no means rare but are less frequently met with than the pure homøochromatic type and the intermediate forms, which exhibit every gradation in colour between the two extremes.

A common intermediate type of coloration may be illustrated by the following description taken from a fresh specimen captured at De Grassi Pt., Ontario: Occiput lemon-yellow, eyes above grey-green with a deep blue transverse stripe, paler and more brownish green beneath; hind margin lemon-yellow. Frontal vesicle, frons and nasus ochre-yellow, the latter two with a greenish tinge; rhinarium pale brown; labrum dull clay-yellow; labium pale drab with darker brownish margins. Thorax chocolate-brown with a 
slight greyish bloom; interalar spots pale yellowish green. IVings strongly flavescent, stigma rather dark brown. Femora dark brownish red, the first pair pale yellowish beneath; tibiae dark reddish brown, rarely black beneath. Tibiae, spines and tarsi black. Abdomen reddish brown, D on I and PD on 2 bluish; AML on 2 bright yellowish green; MD bright yellow; AL, ML and PD on 3-10 very pale green with a bluish tinge; PL pale green; basal rings pale yellowish grcen.

Measurements-Thor. or 10.5-11, क 10-10.5; abd. $\sigma^{7}$ $47.5-50.75$, क 44.7-46.5; seg. 3 o 8 8-9.2, क 7-7.25; seg. 9 \% 3.6-4; apps. o7 5.75-6.25, \& 6.25-7.25; gen. v. 4-4.5; h.w. o 43-47, क 43-46; width h. w. o I3.6-I4.9, \& 13.5-15.2; pter. ơ $2.75-3.66$, ㅇ $3 \cdot 5-4$.

Types-Say's types are lost. Neotype (Hagen '6I) $\sigma^{7}$, Museum of Comparative Zoology-Rhode Island, Ill.

Nymph (pl. 6, fig. 5; pl.9, fig. 3; pl.11, fig. 3)-Eyes less prominent than those of Ae. umbrosa and palmata, but slightly larger, appearing somewhat deeper when viewed from the front. Lateral margins of head straight or slightly convex; postero-lateral angles of head not prominent, well rounded off; posterior margin of head feebly emarginate about the middle. Mentum of labium about half as broad at base as at apex, the latter breadth being equal to about sixsevenths of the length; proximal four-sevenths expanding considerably, the sides straight; distal three-sevenths more rapidly widening, the sides moderately arcuate. Middle lobe broadly obtusangulate; lateral lobes, beyond the base of the movable hook, tapering to a slender, slightly incurved point.

Supracoxal processes of moderate size, subequal, bluntly conical; intervening space subrectanguate.

Abdomen considerably stouter than in Ae. umbrosa and somewhat shorter; broadest at 6 . Lateral spines present on $6-9$; on 6 extending one-fourth or less, on 7 one-half to two-thirds, of the distance to the hind margin of the segment; on 8 two-thirds of the distance, or quite to the margin; on 9 as far as the proximal two-fifths of ro. Length of venter of 9 about equal to half of the basal breadth, sides slightly 
arcuate, strongly so at base. Lateral appendages two-thirds as long as the inferior pair; in the male fairly stout and tapering abruptly to the slender, sharp-pointed apices; in the female slender, more gradually tapering. Basal part of superior appendages of male scarcely two-thirds as long as the lateral appendages, about one-fourth longer than broad, sides slightly concave, apex rounded. Genitalia of female remarkably large, the regularly arcuate ovipositor reaching back nearly or quite to the posterior margin of 10 , or even a little beyond it; genital valves steeply declivent.

Colour light brown; head, thorax and legs concolorous. Abdomen with a fine, pale mid-dorsal line between two narrower dark streaks. Punctae all marked with dark brown, the dorsal and lateral rather heavily. The lateral scars are not distinctly outlined and there are no other dark markings, except faint indications of two lateral streaks on each side.

Measurements-Length of body 36-38; mentum of labium 5.7-6.5; h.f. 6-6.25; h.w. 8.75-9; inf. apps. 3.8-4; gen. क 4.3-4.75; width of head 7.8-8; width of abdomen 7-3-7.5.

I refer these nymphs without hesitation to $A e$. constricta on account of the very large genitalia of the female, which correspond in size with those of the imago of this species. The only other species in which the genitalia are comparable in size is Ae. tuberculifera, which does not occur at Whitefish Creek nor any other part of Lake Simcoe, so far as I am aware. Constricta on the other hand is abundant and is the common species at the creek. The only other species I have ever seen there are Ae. umbrosa and occasional individuals of canadensis, both of which have been reared.

Malerial delermined - $108,0^{7} 56$ \%. Nova Scotra: (British Museum $30^{7} 3$ \&). MAINE: Manchester, Aug. 1 - Sept. 10, 1889-1910, Sept. 1909 (Miss Wadsworth, $9 \sigma^{7} 7$ \%). Massachusetis: Hampden, Aug. 7, 1902 Needham, I \&). QUEBEC: Chateauguay (J.G. Jack, M.C.Z., 2 \%); South branch of Nation River, Dundas Co. (A. R. Cooper, $\left.3 \sigma^{7}\right)$. NEw YoRk: Hotel Champlain, Watkin's Glen, Aug. 21, 1890 (Calvert, I $\sigma^{7}$ ); Clyde, I902 (Nelson R. Wood, U.S.N.M., I $\delta^{7}$ ). ONTARIO: Ottawa, July 26,1900 (Fletcher, I $\%$ ); id. (Harrington, 1 \&); Toronto, Aug. 26, 1908, Sept. 12-27, 1906, 1908 (Huntsman, Walker, $\left.8 \sigma^{7} 2^{2}\right)$ ) : De Grassi Pt., Lake Simcoe, Aug. 7-Sept. 8, 1906-1910 (Walker, $160^{7}$ 10 \&). OHro: Medina, Aug. 20, 1897 (J. S. Hine, U.S.N.M., 1 \%). Illinors: Lake Forest. Aug. 2, 1904, Sept. 2, 1902 (Needham, 2 \%); Rhode Island, 1860 (Walsh, M.C.Z., $10^{7}$ I \&). INDIANA : Elkhart (Ac. N.S. Phil., I \&); id., Oct. 12, I899 (R. J. Weith, coll. Williamson, I \&); Bluffton, Sept. 5-Oct. 2, 1904, Aug. 20, Sept. 24, 1905, Aug. I1-Sept. 22, 1907 (Williamson. $36 \sigma^{7}$ 10 8); Fort Wayne, Sept. 7, 1902, Sept. 16-18, 1906, Aug. 25-Sept. 
22, 1907. Aug. 30-Sept. 13, 1908 (IVilliamson, 17 oग 3 \%): Crooked Lake, Steuben Co., Sept. I, I 905 (Williamson, I \&). WisconsIN: Lone Rock, Aug. I8, 1906 (J. D. Hood, coll. Williamson, I o ${ }^{7}$ ); Milwaukee Co., July 17-Aug. 24, Sept. 6, 1902, Sept. 5, 1904. July 10-27, 1905, July 16, 1907. Sept. 9, I908 (Muttkowski, C. E. Brown, Mrs. P. Laur, Milw. Pub. Mus., 6 of 3 \&); Coney Island, Milwaukee River, July 17, 1902 (Val. Fernke, Milw. Pub. Mus., I \&). Soura DAkota: Volga, Aug. 29, 1889 (P.C. Trueman, Ac. N.S. Phil. I $\%$ ). North Dakota, Fargo, July 30, I90I (R. C. Osburn, i ơ I \&). Manitoba: Westbourne, Aug. 26, 29, I 908 (Wallis, 2 ơ I $\%$ ). British Columbia: (Brit. Mus., I $\sigma^{\top}$ ).

Nymphs-Whitefish Creek, Lake Simcoe, Ont., ơ $\%$ (St. D), taken about July 15, 1910, moulted twice; male died after second moult, Aug. 18, 1910; female lived until Dec. 24 , 19ro. Both acquired fully developed wing-pads at second moult and the female full-sized genitalia (vide p. 48). Also or $\sigma^{\circ}$ (St. D), $\sigma^{7} \&$ (St. E) and exuviae of full-grown nymphs, $2 \sigma^{7} 4 \%$, Aug. 10, 1910.

Identity-Say's type came from Indiana and therefore must have belonged either to the species described here or to Ae. umbrosa umbrosa. Hagen's neotype belongs to the present species, and, apart from this, there is one point in Say's description which applies to this species better than to umbrosa. This is the statement that "the posterior interrupted bands (PD) might be called rounded or quadrate spots and are largest and more glaucous on the posterior segments." (The italics are mine.)

$A e$. constricta is more closely related to Ae. palmata than to $A e$. umbrosa, but is very distinct from both, especially in the female genitalia. The taper-pointed lateral lobes of the labium is a remarkable and distinctive feature of the nymph.

Distribution-Upper Austral and Transition Zones from the Atlantic Ocean to Manitoba and the Dakotas, ranging in to the Canadian Zone in Manitoba. The British Columbia record needs corroboration.

Habits-This species first appears in Ontario during the second half of July, becoming numerous about the middle of August and remaining until about the beginning of October, or possibly later.

At Lake Simcoe, where constricta is common and in some seasons very abundant, it flies over open marshes, pastures and fields, especially near woods, though not of ten occurring in the small clearings and glades, which are frequented by its congener Ae. umbrosa. It is most of ten seen on warm, sunny days, and unlike umbrosa it apparently does not fly after sundown, although in hot still weather I have seen it 
late in the afternoon, flying low over grassy spaces (vide p. 34). When at rest it hangs from the branches of trees or settles in bushes, or even weeds close to the ground.

The copulating habits of this species and its mode of oviposition have been described under "General Life History" (pp. 38, 44).

Whitefish Creek where the nymphs were found is a small sluggish stream, which winds through woods and pastures in its upper part, where it is a mere brook, but near its mouth traverses an open swamp supporting a dense growth of reeds, rushes and sedge. The upper, shadier part of the stream is inhabited by nymphs of $A e$. umbrosa, the lower part by those of Ae. constricta. The territories occupied by the two species are not sharply separated but on the whole are quite distinct.

Where constricta is most at home, the stream is quite clear of reedy plants except at its immediate margin where there is a tall dense growth of Acorus calamus, Sparganium sp. and several species of tall sedge. The bottom shelves rapidly from the bank and there is no shallow reed-grown area, such as forms the characteristic habitat of most Aeshna nymphs. Thus the habitat of constricta as represented by Whitefish Creek is somewhat intermediate in character between those of umbrosa and the majority of species of the genus.

The nymphs appear to be difficult to secure and many hours of dredging resulted in but few individuals, and none of these were full-grown. The exuviae, too, are not readily seen. They cling to the reeds, near the base, and are often hidden from view.

\section{Aeshna californica Calvert.}

(Pl. 14, fig. 4; pl 17, figs. 4, 4a; pl. 21, figs. 2, 2a; pl.

$$
\text { 28, figs. I, 2.) }
$$

Aeschna californica, Hagen, Pr. Bost. Soc. N.H., XVIII, p. 33 (1 875 ) [no desc]; Calvert, Pr. Cal. Ac. (2) IV, p. 504, pl. XV, figs, I9, 20, 23 (1895); Needham and Hart, Bull. Ill. State Lab., VI, p. 4 I, 45 (IgOI); Williamson, Ent. News, IV, p. 3,7 (1903): Needham and Anthony, Jr. N.Y. Ent. Soc., XI, p. I2I (I903); Osburn, Ent. News, XVII, pp. 186, I90 (1905); Amer. Nat., XL, p. 396 (1906); Martin, Cat. Coll. Zool. Selys, XVIII, p. 47, 84, fig. 83 (I908); Cockerell, Ent. News, XIX, p. 455.457 (I908).

A eshna californica, Calvert, Od. B.C.A., p. 183 (I905) ; Walker, Can. Ent

XL, p. 378, 386, 450 (I 908 ); Muttkowski, Cat. Od. N.A., p. IO9 (IgIo). 
A species of somewhat less than medium size, with a rather short broad abdomen.

Male-Occiput pale lemon-yellow, rather large, onethird to two-fifths as long as the line of contact of the eyes; frontal vesicle with a large pale yellow reniform spot, or two smaller spots; eyes pure blue, fading below to bluish grey; preocular band two to three times as broad at bases of antennæ as one of the lateral ocelli, narrowing on the sides of the frons to about half that breadth, and widening again at the fronto-nasal suture; T-spot $2.3-3 \mathrm{~mm}$., stem two or three times as broad behind as in front, the former breadth varying from 1.25-2, the latter .4-I.4. Face pale dull blue or greenish, yellowish on each side of the stem of the T-spot. A black line on the fronto-nasal suture and another at base of labrum. Lateral lobes of nasus rotundo-angulate, distinctly flaring. Labium pale blue to pale yellowish or dull olivaceous. Rear of head black.

Thorax moderately dark brown, appearing somewhat pale in dried specimens on account of the thinness of the cuticle and the rather long and dense growth of pale brownish hairs; sutures very dark brown. Dorsal bandsreduced to a pair of small elongate pale spots on the anterior half of the thoracic dorsum, often obscure or indistinguishable in dried specimens. Lateral bands bluish white (often yellowish white in dried specimens) more or less distinctly edged behind with blackish; first band nearly straight, about I mm. broad near the rounded lower end, tapering rapidly dorsad to one-half or less of this breadth; second band nearly equal, scarcely I mm. broad, curved slightly caudad.

Legs black, posterior surface of fore trochanters and femora in their basal half pale yellowish.

Abdomen about four times as long as the thorax, rather stout, strongly constricted at 3 but rapidly expanding again, so that the posterior margin of 3 is but little narrower than that of 4. Seg. I with a prominent spinulose ventral tubercle. Auricles with 2 or 3 teeth. Spines of anterior lamina welldeveloped, strongly curved, extending back to the hind margin of the hamular processes or a little beyond; the latter with the inner margins straight and attingent, the apices sharp- 
pointed and directed cephalad; hamular folds large, mouseear-shaped, continuous with the hamular processes, closely approximated mesially. Segs. 5-8 with rudimentary accessory lateral carinae, best marked on 6 and 7 . Median tooth-like elevation in dorsum of 10 low and rounded as seen in profile.

Superior appendages about twice as long as 10 , slender and distinctly divergent in the proximal fifth, thence convergent, the breadth increasing to or slightly beyond the middle, thence decreasing very slightly to the bluntly angulate and closely approximated apices; inner margin viewed dorsad rather strongly sinuate, being strongly concave before the middle, gently convex beyond; outer margin viewed dorsad distinctly convex at base, gently so or nearly straight beyond; in lateral view curved regularly upwards. Superior carina percurrent, rather strongly elevated and arcuate in the apical third, not denticulate; infero-internal margin gently curved forming a low inferior carina: a low sub-basal ventral tubercle at about two-sevenths of the length of the appendage. Inferior appendage slightly less than one-half as long as the superior pair, and about three-fourths as broad at base as long, triangular with slightly convex lateral margins and bluntly rounded apex, which bears a pair of minute dorsal teeth; in lateral view moderately curved upwards.

Colour-pattern of abdomen-Abdomen brownish black, varied with castaneous; all the spots caerulean blue, mostly well developed.

Seg. I. Dorsal spot absent, lateral spot indicated by a pale marginal line less than $2 \mathrm{~mm}$. long.

Seg. 2. Blue spotsvery large; AML bounded below by the auricle, upper margin very oblique, confluent with MD; posterior part of the segment above the level of the auricles entirely blue except for a pair of oblique black dorsal spots just behind the transverse carina.

Segs. 3-10. Black ground colour on the dorsum of 3-5 in front of the transverse carina and behind MD varied with castaneous. AL on 3-7 or -8 , very large on 3 , covering whole of lateral surface; of moderate size on $4-6$, the upper margin oblique; minute on 7 and a mere dot when present on 8. ML on $3-8$, very large on 6 and 7 . MD on $3-8$, greenish blue, 
subcrescentic on $3-6$, a pair of dots on $7-8$. PD on $3-10$, well developed, semi-elliptical, each separated from its fellow by about $5 \mathrm{~mm}$., except on 8 and 9 , where they are somewhat smaller, more elongate and separated by $\mathrm{I} \mathrm{mm}$. or more; on Io as large as on 9, not connate.

Wings hyaline; costal veins pale horn-yellow; pterostigma dark brown; membranule of hind wings extending nearly to apex of anal triangle, whitish in proximal half, smoky brown distally, the two areas generally sharply separated; anal triangle 3-celled; one cell between $\mathrm{A}_{2}$ and $\mathrm{A}_{3}$ at their origin, in the hind wings; outer side of triangle of hind wing fully I.5 times as long as inner side; Rs forking at the level of I-2 postnodal cells before the pterostigma, base of the fork but siightly asymmetrical, the two branches equally well developed, not or but little convergent at the wing-margin; 2-3 rows of cells between the forks except at the margin, where there are usually 4 or 5 cells; 3 (2-4) cells between Rs and Rspl where most widely separated; Mia arising beyond the level of the distal end of the stigma (sometimes opposite the distal end).

Antenodals $\frac{\mathrm{I} 2-\mathrm{I} 5}{8-\mathrm{IO}}$, postnodals $\frac{7-\mathrm{IO}}{9-\mathrm{I} 2}, \mathrm{CuCr} \frac{5-6}{4-5}, \mathrm{Spt} \frac{\mathrm{O}-\mathrm{I}}{\mathrm{O}-\mathrm{I}}$.

Female-The usual differences from the male, in form, are present. Abdomen not quite four times as long as the thorax and about equal in length to the hind wings.

Genital valves as long as seg. 9, in profile arcuate in the proximal three-fifths or three-fourths, the apices straight, approximated; no distinct lateral carinae nor ventral surface; styli about one-third the length of the ovipositor $(.66 \mathrm{~mm}$.); basal plate small, more or less furrowed on each side, posterior margin straight.

The most marked difference in the pattern of the abdominal spots is the smaller size and wider separation of the PD spots, except on seg. Io. On seg. 2 these spots are frequently separate at the mid-dorsal line as on the succeeding segments and are partly or wholly marked off from PL. The lateral spots are larger and are more or less confluent on 2 and 3 and sometimes on 4.

Both blue and yellow females occur, according to Mr. 
Kennedy, who has observed this species in life. He has sent me a coloured drawing of a specimen in which all the pale markings are a pure chrome-yellow on a ground colour which is of a more yellowish brown than in the male. In the specimen figured, the only alcoholic one I have seen, the colours were apparently perfectly preserved at the time the drawing was made, and the ground colour was noticeably more yellowish than in the alcoholic male. The face was greenish yellow, labium pale greenish, eyes grass-green with a yellow outer margin; thoracic bands very pale yellowish green; abdominal spots pale green, PD more yellowish than the others. Many of the dried specimens that I have examined appear to have been coloured like the males.

Measurements - Thor. ơ \& IO-II ; abd. कृ 39.5-43.5, ㅇ 37-40; seg. 3 o 6.3-7.5, क 5.5-5.8; width seg. 2 o $5-5 \cdot 33$; width seg. 3 क $3 \cdot 3-3 \cdot 5$; apps. $\sigma^{7} 4 \cdot 25-5$, क 4.5-4.9; gen. v. o I.75-2; h.w. o 38-49, क 37-40; width h.w. ơ I2-I2.6, \& I I.66-I 2.25; pter. ơ 3-3.8, क 3.5-3.8.

Types-o o $^{7}$, Coll. Calvert-Mt. Tamalpais, Cal.

Nymph (pl. 7, figs. 3, 3a; pl. 9, fig. 4; pl. I I, fig. 4)-Eyes larger but less prominent than in the other species here treated, except multicolor; postocular part of the head short, the lateral margins slightly arcuate next the eyes, thence passing by a stronger curve in to the almost straight posterior margin; mentum of labium rather short, about half as broad at base as at apex, the apical breadth a little shorter than the length, expanding distally throughout the length, especially in the distal three-sevenths; lateral margin slightly sinuate, the curve proximally very feebly convex, more strongly so towards the distal end; median lobe slightly produced, obtusangulate; lateral lobes slightly narrower distad of movable hook than in multicolor, the outer apical angles somewhat rounded off, inner angles with a minute tooth.

Supracoxal processes rectangularly divergent, acute, the anterior of moderate size, the posterior considerably larger, recurved.

Abdomen moderately stout, broadest at 6 or 7 ; in the exuvia, which is deeply convex, at 5. Lateral spines present on $6-9$, those on 6 distant from the hind margin by $1-2$ times 
their own length, on 7 reaching back as far as the margin or but little short of it, on 8 slightly beyond the margin, on 9 to about the middle of ro. Venter of 9 nearly two-fifths as long as broad. Lateral appendages about three-fifths as long as the inferior pair, slender, tapering gradually to the finepointed apices. Basal part of superior appendage of male triangular, one-half shorter than the lateral appendages and about as long as the basal breadth; sides nearly straight, apex acute. Genitalia of female distant from the posterior margin of 9 by one-sixth or one-fifth of their length, genital valves not steeply declivent.

General colour (exuvia) dull brown, pale markings more or less obscure or inconspicuous. Head with a group of pale spots between the eyes, including a median and three or four spots on each side of it; a roundish spot just behind each eye and a pale marginal band which is continued across the outer ends of the pronotum. Sides of thorax with a few small pale spots. Femora dark with three narrow, ill-defined pale annuli; tibiae generally also with traces of two or three such annuli. Abdomen, with two dorsal pale bands, which are broad and distinct on the first four segments but become gradually narrower and more obscure caudad, usually being almost or quite indistinguishable on the last four or five segments. Lateral scars inconspicuously ringed with brown, punctae marked with brown, but all inconspicuous. Lateral appendages pale, with basal and median annuli and the apices dark.

Measurements-Length of body $33-36.5$; mentum of labium $4.5-5$; h.w. 6.8-8; inf. apps. $3.75-4.2$; width of head, 7-7.3; of abdomen 7 (exuvia 6-7).

Material determined-41 o $^{7}$ I9 $\%$. Britrsa Columbia: (Crotch, Ḿ. C. Z., I $\sigma^{7}$ ) Victoria, July I4, 17 , I90I (Currie, U.S.N.M., 3 o I 9 ); Departure Bay, Vancouver Id., June 20, July 4, 5, 1908 (Huntsman, 5 of I \%); Diver Lake, Vanc. Id., July 23, I908 (Huntsman, I $\sigma^{7}$ ); Peachland (Wallis, I $\%$ ). WAssINGTON: Sunnyside, April 23-28, 1910 (Kennedy, 2 o I $\$$ ) id, May 8, I910 (Kennedy, $14 \sigma^{7} 4 \%$ ); id. June 12, I910 (Kennedy, I $\sigma^{7}$ ); Ellenburgh, April 8, 1897 (Needham, I \%); Seattle, July 6, 1892 (Ac. N.S. Phil., I \%); Kent, June, 9, I905 (H. E. Burke, U.S.N.M., I ơ). OREGON: Portland, July 8, 1905 (Currie, U.S.N.M., I \&); Corvallis, May, 7, 1878, June 30, I896 (Needham, I $\sigma^{2}$ I \%). CAllFornia: (M.C.Z., 2 \%) ; Fresno, April 7-23, I900 (E. A. Schwarz, U.S.N.M., I o' 2 \%); Utah Lake, June, 19, I891 (E. A. Schwarz, U.S.N.M., I $\left.\sigma^{7}\right)$; Gulf of Georgia (A. Agassiz, M.C.Z., 4 ( 
M.C.Z., I $\sigma^{7}$ ); San Mateo (A. Agassiz, M.C.Z., 1 ( $\left.\sigma^{7}\right)$; Sonoma Co., Apr. 27-May 9 (R. Osten Sacken, M. C.Z., I $\sigma^{7}$ ). NEvadA: Reno, 1878 (Morrison, M.C.Z., $3 \mathrm{o}^{7}$ ). UTAH: Ogen (Cyrus Thomas, M.C.Z., I $\$$ ).

Nymphs-Nigger Pond, Sunnyside, Wash., May 10, 1910; 1 \% (about to transform); 1 (St. F); 1 \% (St. E); exuviae $100^{7} 14$ \% (Kennedy).

Distribution-Upper and Lower Sonoran. California and Arizona to southern British Columbia.

Habits-This species is the earliest North American Aeshna to appear in the adult state. As the dates of capture given above show, it may appear as early as the second week in April (California, Washington). Mr. Kennedy found it at Sunnyside, Washington, on May 8, I910, flying about Niggër Pond in considerable numbers. He observed several pairs in copula and states that, while thus engaged, they are more retiring than $A e$. multicolor and do not indulge in wild nuptial flights. A few weeks later they had left the pond and were ranging freely over the countryside. The nymph was first described from a specimen taken from an irrigation ditch at Tombstone, Arizona (Needham and Hart 'or). It has also been found by Osburn ('06) to inhabit brackish water.

\section{Aeshna multicolor Hagen.}

(Pl. I4, fig. 5; pl. I7, figs. 5, 5a; pl. 21, figs. 3, 3a.)

Aeschna multicolor, Syn. Neur. N.A., p. 121 (186I) ; Rep. U.S. Geol. Surv. Terr., 1872, p. 727 (1873); 1. c., 1873, p. 591 (1874); Pr. B.S.N.H., XVIII, p. 33 (1875); Kirby, Syn. Cat. Od., p. 88, I890; Banks, Trans. Am. Ent. Soc., XIX, p. 353 (1892) ; Calvert, Ent. News, III, p. 26 (1892); Pr. Cal. Ac Sc., (2) IV, p. 508, pl. 15, figs. 25, 26 (1895); Tr. Am. Ent. Soc., XXIX, p. 43 (1902); Williamson, Ent. News, XIV, p. 7 (1903); Currie, Pr. Ent. Soc. Wash., V, p. 303 (1903); l.c. VII, p. I8 (I905); Osburn, Ent. News, XVI, pp. 186, I90 (I905); Baker, Invert. Pac., I, p. 87 (I905); Martin, Cat. Coll. Zool. Selys, XVIII, p. 48, fig. 45 (1908); Gen. Ins., CXV, p. 12 (1911).

Aeshna mullicolor, Calvert, B.C.A, p. 183 (1905); Williamson, Ent. News IX, p. 265, 301, text fig. (1908); Walker, Can. Ent., XL., p. 279, 386, 450 (1908); Muttkowski, Cat. Od. N.A., p. 113 (1910.)

Aeschna furcifera, Karsch, Ent. Nachr., XVII, p. 310 (1891).

Of average to rather large size, the thorax robust and the abdomen somewhat short.

Male-Occiput pale bluish, two-fifths to one-half as long as the line of contact of the eyes; frontal vesicle pale blue, the blue area separated from the lateral ocelli by a space narrower than one of the latter. Eyes pure blue, of the same shade as the abdominal spots, sometimes pale greenish along the hind margin. The blue colour usually disappears in dried specimens but may be retained to some extent in well 
preserved examples. Preocular band scarcely broader, at base of antennæ, than the lateral ocelli, continued ventrad on each side as a narrow line on the lower half of the frons and nasus. T-spot 2.8-3.2 mm., stem I.45-1.66 mm. broad behind, $.55-.75 \mathrm{~mm}$. in front, sides straight or slightly concave. Face slightly broader than in Ae. mutata. Frons and nasus pale blue or grey-blue with a narrow yellowish white submarginal area; fronto-nasal suture ochraceous; lateral lobes of nasus rounded, their margins but little flaring. Rhinarium and labrum greenish, the latter narrowly margined above and below with dark brown. Labium blue, plumbeous or olivaceous in dried specimens. Rear of head black.

Thorax robust, moderately dark brown with a coppery tinge. Dorsal bands light blue, $4 \mathrm{~mm}$. long, .65-.75 $\mathrm{mm}$. broad, sometimes slightly broader at the upper ends, where they are approximated, and of ten giving off mesad an offshoot from the lower ends. Lateral bands light blue, sometimes greenish below, straight, very oblique; first band nearly equal, about I mm. broad, rounded below; second band generally a little narrower, tapering to the lower end and sometimes expanding slightly towards the upper end. Interalar spots blue.

Legs black, anterior femora with a pale streak on the proximal half of the posterior surface.

Abdomen somewhat less than four times as long as the thorax, moderately stout, considerably constricted before the middle of 3 , then rapidly expanding again to the apex of 4 .

Seg. I with a prominent ventral tubercle, bearing a few inconspicuous spines and a tuft of long brownish hairs. Auricles with 2-3 teeth. Tergal margins of seg. 2, bounding the genital fossa, strongly sinuate, considerably elevated in the posterior third. Spines of the anterior lamina welldeveloped, reaching caudad to the posterior margins of the hamular processes, moderately curved dorsad, sharply pointed. Hamular processes rather broad and thick, mesially attingent, antero-lateral surfaces concave, bounded behind by an arcuate ridge running from the base to the antero-internal angle, which is somewhat acute. Hamular folds continuous with the hamular processes, rather long and contracted, 
mouse-ear-shaped, closely approximated mesially, the apices strongly acutangulate, outer margins slightly divergent. Seg. 3 as long as $\mathrm{I}+2$, one-third to two-fifths longer than 4 , and one-seventh to one-sixth longer than 6 . Dorsum of 10 with a median and two pairs of sub-median tooth-like elevations, the former relatively small and rounded in profile view.

Superior appendages about as long as $8+9$, or a trifle longer, slender at base, expanding on the inner margin to about five-twelfths of the length, where the breadth is about twice that at base and equal to about one-seventh of the total length; thence remaining equal as far as the distal fourth or fifth, whence curving strongly downwards and slightly outwards they taper to the long slender pointed apices. In dorsal view they appear very slender, the outer margin gently arcuate, the inner very slightly sinuate. Superior carina subobsolete in the basal half, suddenly elevated in the distal half into a very prominent angular crest, the apex of which is a little more than one-third of the length of the appendage from the apex of the latter. In profile view a low sub-basal ventral tubercle appears at one-fifth to one-fourth of the length; the outer margin is curved slightly upwards except apically, and above it the superior carina is elevated to a height about equal to the depth of the inner portion of the appenciage directly beneath it, this part being bent downwards to form an inferior carina, which, a little beyond the apex of the superior carina, is produced in to a strong spine, dirceted rentrad and caudad, its apex recurved. The distance between the apex of this spine and that of the appendage is equal to about one-fifth of the length of the latter. Inferior appendage elongate-triangular, feebly acuminate, slightly more than one-half as long as the superior pair, the breadth at base three-eighths of the length, upper surface with a distinct median carina, apex rounded with a pair of small recurved dorsad teeth; in profile view moderately curved, subequal and tapering but little apically.

Colour-pattern of abdomen-Seg. I fuscous ; dorsal and lateral spots blue, or the latter sometimes narrowed to a mere marginal line.

Seg. 2 fuscous; AML blue, extending I-2 mm. above the 
auricle and a variable distance below it, its upper margin very oblique and confluent with $\mathrm{MD}$. PL + PD covering the posterior division of the segment except part of the ventral surface and a narrow brown space on each side behind the transverse carina, which is continued mesad into adark brown oblique streak.

Segs. 3-IO. MD on all the segments and sometimes PD on 10 greenish, the other spots pale pure blue. AL on 3-7 or -8 , the first three or four pairs connected by a narrow basal ring; large on 3 , the upper margins straight and separated by a brown band of about I mm. breadth; of moderate size, decreasing caudad on 4-7, the upper margins more or less oblique. ML on $3-8$, of moderate to large size, irregularly quadrate or roundish, separated from $\mathrm{MD}$, anterior edges not indented. MD on $3-8$, rudimentary on 8 , elsewhere relatively large, triangular. PD on 3-10, irregularly semi-elliptical, varying in length from about I.3 to nearly $2 \mathrm{~mm}$., separated mesially by spaces of varying width but always much wider on 8-10 than elsewhere, especially on 9; on Io they are paler than on the other segments and are larger and better defined than in mutata. PL on $3-5$ or -6 ; short, broad, curved offshoots of $\mathrm{PD}$, with which they are broadly confluent.

Wings hyaline; costal veins pale horn-yellow; pterostigma dark brown above, ochraceous beneath ; membranule of hind wing extending nearly to the anal angle, whitish in the basal third or fourth, dark smoky brown distally. Anal triangle 3celled; A2 in hind wing arising opposite or distal to the last cubito-anal cross-vein before the sub-triangle; outer side of anal loop longer than inner side of triangle. Rs forking opposite I-2 (fore wings) 2-3 (hind wings) postnodal cells before the stigma, the fork almost symmetrical at base, and both branches equally well developed, generally not converging towards the wing-margin. Three rows of cells between the forks opposite the distal end of the stigma. Supplements strongly curved; 3 or 4 rows of cells between Rspl and Rs between the points of widest divergence. M I a arising beyond the stigma. Usually a single row of cells between $\mathrm{M}_{3}$ and $\mathrm{M}_{4}$ in the hind wing, for a short distance just before the marginal cells. 
Antenodals $\frac{14-18}{9-12}$, postnodals $\frac{7-10}{8-13}, \mathrm{CuCr} \frac{5-6}{3-6}$, Spt $\frac{2-3}{1-2}$.

Female - The abdomen is about the same in length as in the male and is not usually very stout. Abdominal seg. 3 is shorter, seg. 4 longer, than in the male, there being but little difference in length between these segments.

Genital valves as long as seg. 9, in profile slightly arcuate with the apices a little elevated, lateral carinae distinct only apically, elsewhere broadly rounded; ventral surfaces somewhat declivent, not distinctly sulcate. Basal plate with the hind margin straight; lateral plates distinct. Styli scarcely half as long as the dorsum of $10(.75 \mathrm{~mm}$.). Appendages nearly as long to a little longer than $8+9$, tapering nearly equally at apex and base, curve of the inner margin a little stronger than that of the outer; greatest breadth about the middle, equal to about one-fif th of the length; apices acute or narrowly rounded.

The dorsal thoracic bands are narrower than in the male and are either divided into a superior and an inferior spot or represented by the latter alone. They are frequently indistinguishable in dried specimens. Lateral spots of seg. 2 forming a continuous broad band; brown area behind the median suture broader than in the male, owing to the smaller size of the PD spots which are also somewhat reduced on the other segments. They are not confluent on any of the segments. PL on 3-5 or -6 , larger than in the male, of ten separated from PD posteriorly, connected with ML on 3. I have seen no purely homœchromatic specimens though they probably occur. Intermediate and markedly heterochromatic examples are present in the material studied. A fairly well preserved specimen from Portland, Ore., and two from Sunnyside, Wash., belong to the latter type of coloration, while two from Departure Bay, Vancouver Is., are of the intermediate type. Mr. Kennedy makes the following notes on one of the Sunnyside specimens: "Eyes brown, edged behind with grey-blue, markings of thorax and abdomen yellowish with greenish hue." In these specimens the wings are also somewhat flavescent at base and along the costal edge. In the British Columbia females the head is coloured as in the male, 
dorsal thoracic bands greenish, lateral bands yellowish green below, blue above. Spots of abdomen pale green, except those on segs. 2 and 3 , which are largely blue. The ground colour of the abdomen is brown shading into black around the light areas.

Measurements-Thor. o7 II-I2, \& II.3-II.5; abd. or 43-45, \& 43-46; depth seg. 2 o7 5.4-6, क 5.8-6; seg. 3 व 6.5-7.2, क 6-6.25; seg. 4 o 5-5.25, क 5.4-5.7; apps. ơ 6-6.5, क 5.5-6.2; gen. v. 2.25 ; h.w. $\sigma^{7} 42.5-45$, \& 44-45; width h.w. के I3-14, के I3.5-14.5; pter. के 2.8-3.6, क 3.5-3.8.

Types-ơ $\%$, Mus. Comp. Zoology.

Nymph (pl. 7, figs. 4, ta; pl.9, fig. 5; pl. I I, fig. 5)-General surface smoother than usual, more than ordinarily transparent. Eyes large but less prominent than in species of the juncea, clepsydra and cyanea groups; lateral margins of head short, curving evenly from the eye to the straight posterior margin. Mentum of labium about twice as broad at apex as at base, the apical breadth equal to about eight-ninths of the length, expanding distad throughout its length, especially in the distal three-sevenths, though this part is less dilated than in most of our species of the genus; lateral margins sinuate, the curve being feebly convex or almost straight in the proximal part, more strongly so towards the distal end. Middle lobe very little produced, subangulate; lateral lobes, distad of movable hook, broad, parallel, squarely truncate; outer angles but little rounded off, inner angles with a small tooth.

Supracoxal processes short conical, subequal; interval rather greater than a right angle.

Abdomen rather short and broad, strongly convex above in the exuvia, in which the greatest breadth is reached at seg. 5; segs. 6 and 7 being of about the same breadth. Lateral spines present on 6-9; those on 6 mere rudiments, on 7 extending two-thirds to four-fifths of the distance to the posterior margin of the segment, on 8 to the margin or slightly beyond, on 9 to the middle of ro or just beyond. Venter of 9 nearly three times as broad at base as long. Lateral appendages three-fifths as long as the inferior pair, rather slender in both sexes, tapering gradually to the slender fine- 
pointed apices; distal third in the male somewhat excavated below. Breadth of basal part of superior appendage of male equal to about three-fourths of the length of one of the sides, which are somewhat concave; apex small, rounded. Genitalia of female small, about onethird of their length shorter than segment 9; genital valves not steeply declivent.

Colour somewhat dark brown, more or less spotted and mottled with pale yellowish. Head above with a group of pale spots between the eyes, including a larger central spot and three or four smaller ones on each side; a pair of crescentic spots bounding the scars externally, a spot immediately behind each eye and a lateral marginal band which is continued across the outer ends of the pronotum. Thorax with a number of small scattered pale spots; wings with the veins heavily marked with dark brown, the interspaces pale. Legs dark brown, the femora and tibiae each with three pale annuli. Abdomen variable as to distinctness of the pale markings. In well-marked specimens the following can be made out: (I) A series of pairs of subtriangular spots, each pair at the base of one of the segments. Anteriorly the spots are largest and coalesce to form two irregular bands; posteriorly they generally decrease in size and of ten become subobsolete on the last two or three segments. (2) A series of subcrescentic spots immediately laterad of the former series between the dorso-lateral and lateral punctae. (3) A series of pale blotches surrounding the lateral scars which are outlined in dark brown. (4) A mid-dorsal series of sublanceolate spots on some of the segments, each spot surrounded by the corresponding dorsal punctae. All the punctae are distinctly marked with dark brown.

Measurements-Length of body 35-40 ; mentum of labium 5-5.75; h.f. 6-6.9; h.w. 8-9; inf. apps. 4-4.5; width of head 7.7-8.5; width of abdomen 8.3-9 (exuvia 7-8.5).

The nymphs and exuviae upon which the above description is based were all taken by Mr. Kennedy at Nigger Pond, Sunnyside, Wash., where they were associated with those of Ae. californica, but occurred in largernumbers. None were reared, but there can be no doubt that they belong to 
multicolor, for many of the exuviae were found on May 8 , a date that is much too early for any other species of Aeshna in this locality. Moreover the resemblance to the nymph of californica is so close that it could scarcely belong to any species except multicolor, the only near relative of californica in this region; and, indeed, some of the differential characters of the two nymphs closely correspond to those of the adults of these species. Thus (I) the triangular basal part of the superior appendage of the male is more elongate in the multicolor nymph, this structure being the rudiment of the inferior appendage of the adult male, which is likewise more elongate than in californica (pl. 7, figs. $3 \mathrm{a}, 4 \mathrm{a}$; pl. I 7, figs. 4, 5); (2) the number of antenodal veins is greater in both nymph and adult of multicolor in the great majority of cases ; (3) the size of the multicolor nymph is distinctly larger.

Only californica was seen about the pond on May 8, when the first lot of exuviae was collected, but on July I7, when the second lot was taken, only multicolor was present. The first lot of exuviae consisted of both species, the second of multicolor only.

Material determined - 45 or 17 o . British Columbia : Loon Lake, Ainsworth (Kootenay), July I I, 1903 (Currie, U.S.N.M., 2 o ) ; Victoria, July (Crotch, M.C.Z., I $\sigma^{7}$ ); Departure Bay, Vancouver Is., June 20, July 4-23, I 908 (Huntsman, I 2 o' 3 \%) ; Diver Lake, Vanc. Is., July 23, I908 (Huntsman, I $\sigma^{7}$ ). Washington: Sunnyside, June I3, July 9, 1910 (Kennedy, $70^{7} 39$ ). OREgon: Portland, July I2, 1905 (Currie, U.S.N.M., I \&). IDAHO: Moscow Mt. July 27 (H.E. Burke, U.S.N.M., I \&). Colorado: Fort Lupton, July 22, 1900 (Osburn, coll. Williainson, I ơ, fragments); Denver (E. V. Beales, coll. Calvert, I ㅇ). Uтан: Red Butte Cañon, Salt Lake Co., June I8, I899 (Browning, coll. Calvert, I o). CAl.ifornia: (M.C.Z., B. Gerhard, coll. Williamson, $4 \mathrm{C}^{\prime}$ I $\%$ ); San Francisco (R. Osten Sacken, M.C.Z., I \&); Savoclito, June I (M.C.Z., I ơ); Claremont (Baker, coll. Calvert, I o ); Keeler, July 6 (Wickham, coll. Calvert, I \&); Ontario, July I3, 1907 (Williamson, 3 o ) ; Los Angeles (U.S.N.M., A. Davidson, coll. Calvert, I ơ I 9 ); Pasadena, Sept. 5-13, I900 (Fordyce Grinnell, jr., coll. IVilliamson and Calvert, $3 \sigma^{\top}$ ); San Diego, April (Crotch, M.C.Z., I o $\sigma^{\top}$ ). ARIzONA: Winslow, July 3I, Igor (Barber and Schwarz, U.S.N.M., I ơ ); Williams, July (Barber and Schwarz, U.S.N.M., I $\left.\sigma^{7}\right)$. NEw MExico: Beulah, Aug. I9oi (Skinner, Ac. N.S. Phil., I $\sigma^{7}$ ); La Cruces (U.S.I.M., I 우). TExas: Pecos River (M.C.Z., I ơ 2 \%). MExico : San José del Cabo, Baja California, Oct. I 893 (G. Eisen, coll. Calvert, I $\sigma^{7}$ ); Tacubaya, D.F., April, I 899 (O. W. Barrett, coll. Calvert, I $\left.\sigma^{\top}\right)$; Santa Maria, Puebla, June (O.W. Barrett, coll. Calvert, I $\left.\sigma^{7}\right)$. Nymphs-Nigger Pond, Sunnyside, Wash., May 8, 1910, $8 \sigma^{7} 3$ 우 (St. H) ; $15 \sigma^{7}$ ro o (St. F); exuviae $13 \sigma^{7} 11$ O. Id., July 17, 1910 , exuviae $12 \sigma^{7} 21$ ㅇ․

Distribution-Upper and Lower Sonoran, Mexico (Distrito Federal and Puebla) to Texas, Colorado and southern British Columbia. Of the material recorded by Professor 
Calvert as Ae. multicolor from Costa Rica and Panama, I have seen I $\&$ from Irazu (Costa Rica) and I $\sigma^{x}$ from the Volcan de Chiriqui (Panama). These belong to Ae. jalapensis Williamson, as does also a $\sigma^{7}$ from Amula, Guerrero.

\section{Aeshna mutata Hagen.}

(Pl. 14, fig. 6; pl. 17, figs. 6, 6a; pl. 21, figs. 4, 4a; pl. 22, fig. 5 ; pl. 28 , fig. 3 .)

Aeschna mutata, Hagen, Syn. Neur. N.A., p. 124 (1861); Kirby, Syn. Cat. Od. N.A., p. 89 (1890); Banks, Trans. Am. Ent. Soc., XIX, p. 353 (1892).

Aeshna mutata, Williamson, Ent. News, XIX, pp. 264, 30I, text fig. (1908); Walker, Can. Ent., XL, pp. 379, 386, 450 (I908); Muttkowski, Cat. Od. N.A., p. II 3 (1910); Skinner, Ent. News, XXII, p. 336 (1911).

Aeschna multicolor, Weith, Ent. News, XI, p. 64I (1900); Williamson, Pr. Ind. Ac. Sci., p. 173, 176 (1900).

Aeschna verticalis, Osburn and Hine, Ohio Nat., I, p. 14 (1900).

A species of average size and build, with a rather short abdomen, and somewhat long and narrow wings.

Male-Occiput dull yellowish (bluish in life?), edged laterally with black, one-third to two-fif ths as long as the line of contact of the eyes. Frontal vesicle pale blue above, the blue area separated from the lateral ocelli by a space fully as broad as one of the latter. Eyes in life pale blue, in dried specimens dark olivaceous with a bluish cast. Preocular band about twice as broad at base of antennæ as one of the lateral ocelli; narrowed to a hair-line on the lower half of the frons and nasus. T-spot $2.3-2.8 \mathrm{~mm}$., stem about $1.75 \mathrm{~mm}$. broad behind, $.75 \mathrm{~mm}$. broad in front, the sides distinctly sinuate, being straight or concave in front, convex behind. Frons and nasus pale blue or grey-blue, pale yellowish next to the ocular margin; lateral lobes of nasus rounded obtusangulate, slightly flaring. Labrum in dried specimens brownish with a very narrow basal and a broader apical dark brown margin. Labium plumbeous.

Thorax slenderer than in Ae. multicolor, moderately dark brown with a coppery tinge in dried specimens. Dorsal thoracic bands light blue, nearly $4 \mathrm{~mm}$. long and about $\mathrm{I} \mathrm{mm}$. broad, except at the upper ends, where they nearly meet in the middle line just in front of the antealar sinus, and where the breadth is increased to $2 \mathrm{~mm}$. Sometimes the lower ends are also expanded. Lateral bands pale blue, nearly straight, surrounded by a diffuse dark brown margin; the first band slightly sinuate just below the middle, about I mm. broad at 
the lower end, expanding and becoming diffuse at the upper end, where the breadth is 2.5 to $3 \mathrm{~mm}$.; second band straight and equal except at the expanded upper end, breadth below $.5-.75 \mathrm{~mm}$., above $\mathrm{I} .5$ to $2 \mathrm{~mm}$.

Legs black, proximal half of anterior femora with a pale streak on the posterior surface.

Abdomen four to four-and-a-half times as long as the thorax, moderately slender, somewhat less inflated than usual at base, moderately constricted at 3 , then rapidly expanding to the apex of 4. Seg. I with a very low ventral tubercle, bearing a few inconspicuous spinules and a tuft of long pale brown hairs. Auricles with 2-3 teeth; ventral surface of 2 with a few minute spinules, especially nearly the posterior margin. Tergal margins bounding the genital fossa strongly sinuate, considerably elevated in the posterior third. Spine of the anterior lamina well-developed, moderately curved dorsad, sharply pointed, extending caudad to the posterior margins of the hamular processes; the latter rather broad and thick, meeting along the middle line, antero-inferior surfaces concave, bounded behind by an arcuate ridge, which runs from the base to the antero-internal angle, posterior margins arcuate. Hamular folds continuous with the processes, elongate, acutangulate behind, deeply concave and closely approximated mesially, their outer margins subparallel.' Seg. 3 one-seventh longer than $I+2$, one-third longer than 4 . Segs 5-7 with traces of accessory lateral carinae about the middle. Median dorsal tooth on seg. Io appearing very low and elongate in profile view.

Superior appendages slightly longer than $9+10$, slender in the basal fifth, then expanding on the inner margin to about five-twelfths of the length,where the breadth is a little more than twice that at base and equal to about one-fifth of the length; thence remaining equal as far as the distal seventh, whence, curving strongly downwards and slightly outwards, they taper to the sharply pointed apices. In dorsal view they appear slender, the outer margin gently and somewhat irregularly arcuate, the inner margin slightly sinuate.

Superior carina percurrent, low in the proximal two- 
thirds then suddenly elevated with an angulate crest, the apex of which is about one-third of the length of the appendages from the apex of the latter. In profile a low subbasal tubercle at one-seventh to one-sixth of thelength appears; the outer margin is nearly straight except towards the apex, the superior carina raised above it to a height usually much less than the depth of the inner part of the appendages directly beneath it, this part being bent downwards to form an inferior carina, which is produced into a strong spine, directed ventrad and caudad, its apex recurved. The distance between its apex and that of the appendage is equal to about one-sixth of the length of the latter. Inferior appendage elongate-triangular, slightly acuninate, seven-twelfths as long as the superior pair, the basal breadth three-eighths of the length, upper surface without a median carina, apex bluntly rounded; in profile view rather strongly curved proximally, more gently distally, tapering more rapidly caudad than in multicolor.

Seg. I fuscous, dorsal and lateral spots blue, the latter 3-3.5 $\mathrm{mm}$. long, somewhat less than I mm. broad.

Seg. 2 fuscous, spots all blue. AML with the anterior margin extending $\mathrm{I}-2 \mathrm{~mm}$. above the auricle and a variable distance below it; upper margin very oblique, continuous with MD; posterior part of the segment above the ventral surface wholly blue, except a narrow brown band on each side, passing obliquely mesad from the transverse carina, and a dark brown spot behind the auricles. A few irregular blue blotches on the ventral surface also.

Segs. 3-Io dark brown. MD on all the segments and PD on Io pale yellowish (green in life?), the other spots blue. AL on 3-7 or -8 , each pair except the last connected by a narrow basal ring; large on 3 , the upper margins straight and separated by about $1.5 \mathrm{~mm}$.; of fairly large size also on $4-7$, the upper margins nearly straight. $\mathrm{ML}$ on $3-8$, of moderate size, irregularly quadrate, the anterior edge of all but the last pair angularly indented, those on 3-5 or -6 narrowly confluent with MD. MD on $3-8$, the last pair rudimentary, the others well-developed, triangular with the hind edges concave. PD on 3-IO, pairs of semi-elliptical spots about $1.5 \mathrm{~mm}$. long on most of the segments, narrowly separated mesially except 
on 8-10, where the intervals are much wider, especially on 10 , on which the spots are small and ill-defined. PL on 3-5, generally rudimentary on 5 , elsewhere a narrow curved offshoot from PD.

Wings rather narrow, more or less flavescent, the hind pair about as long as the abdomen; costal veins dull brownish yellow; pterostigma dark brown, ochraceous beneath, membranule of hind wings smoky brown, with the base more or less whitish or grey, reaching nearly to the apex of the anal triangle, which is 3 -celled. A2 in hind wing arising basal to the last cubito-anal cross-vein before the subtriangle; outer side of anal loop about as long as inner side of triangle. Rs forking opposite the third (fore wing) or the third to fifth (hind wing) postnodal cell before the stigma, the fork nearly symmetrical at base ; 3 or 4 rows of cells between Rspl and Rs between the points of widest divergence. Mra generally arising opposite the distal end of the stigma but often a little beyond or before the end. Two rows of cells between $\mathrm{M}_{3}$ and $\mathrm{M}_{4}$ in the hind wing, from the point where $\mathrm{M}_{4}$ appears forked to the margin of the wing.

Antenodals $\frac{17-2}{\mathrm{II}-14}$, postnodals $\frac{9-12}{10-13}, \mathrm{CuCr} \frac{5-6}{5-6}, \mathrm{Spt} \frac{2-4}{2-3}$.

Female-Abdomen as long or a little longer than in the male, rather slender.

Genital valves barely as long as seg. 9, in profile very slightly arcuate, the apices a little elevated; lateral carinae rounded; the ventral surfaces not distinctly sulcate; posterior margin of basal plate straight; styli not quite I mm. long. Appendages a little longer than $8+9$, slender at base, outer margin straight, inner margin strongly arcuate, the curve at apex a little more marked than at base; greatest breadth about the middle, equal to about one-fifth of the length; apices rotundo-angulate.

Colour-pattern-[Colours mainly as described by Williamson, ('08) from a single specimen]. Occiput greenish yellow; eyes dark greenish brown with a narrow green posterior border, paler below. Face yellowish green, obscured with brown, margined with yellowish; frons above dull bluish, a 
pale brown line on the fronto-nasal suture; rhinarium plumbeous; labrum pale olivaceous; labium olive-green. Thorax olivaceous brown; dorsal bands divided each into a superior and an inferior greenish spot; lateral bands green, yellowish above. Abdomen castaneous, shading into black around the pale areas, which are green; on the first three or four segments margined with yellowish, in the posterior segments obscured with drabbish. On seg. 2 the lateral spots are connected to form a single broad band, and on 3 and $4 \mathrm{ML}$ is confluent with PL. PD somewhat smaller, PL larger, than in the male. Wings strongly flavescent, the stigma pale brown.

In the females from Angola, Ind., and Wilbrahim, Mass., both of which are teneral, the lateral thoracic bands are yellowish white, in part bluish, a possible indication of the homœochromatic type of coloration.

Measurements-Thor. के \& I0-I I ; abd. के 45-47.75, \$ 48-5I ; depth seg. 2 o' 4.9-5.2, \& 5.33-5.5; seg. 3 o'7.3-8, क 7-7.5; seg. 4 वा 3.6-5.9, क 6.5-6.75; apps. वा 5.8-6.3, क 6.5-7.5; gen. v. 2-2.2; h.w. $\sigma^{7} 44-47$; $\$ 47.75-5$ I ; width h.W. O' I3-I4, \& I4-I4.33; pter. o 3.3-3.75, \& 3.8-4.2.

Type-\&, Mus. Vienna-" North America."

Nymph-Unknown.

Material determined-I4 ơ 4 \%. Massachuserts: Wilbrahim, June 5, 1902 (Needham, 2 o 1 \%, teneral). Onlo: Stewart's Lake, Kent, June 22, 1900 (J. S. Hine, coll. Osburn, ). Indiana: Bluftion, June 30, July 2-13, I907 (Williamson, 12 of 1 \&); Angola, June, I908 (Mary Shafer, coll. Williamson, I 9 , teneral). "Norta America" (M.C.Z., I \&).

Identity-This species is closely related to Ae. multicolor, but I have seen no individuals that are in any way intermediate between the two forms. In fact multicolor shows no tendency anywhere to vary towards mutata, exhibiting indeed a marked uniformity of type throughout its entire area of distribution, as far as is indicated by the material I have studied.

The Mexican species Ae. jalapensis Williamson is still more closely related to $A e$. mutata.

Distribution-Carolinian; Indiana, Ohio, Massachusetts, Pennsylvania.

Habits-All that is known of the habits of this species has been given by Williamson (loc. cit.). 


\section{LITERATURE CITED.}

BAKER, C. F.

I 905. Notes on the Neuropteroid Insects of the Pacific Coast of North America, with Descriptions of New Species by Nathan Banks. Invertebrata Pacifica, I, pp. 85-92.

BALFOUR-Browne, Frank.

1909. The Life-history of the Agrionid Dragonfly. Proc. Zool. Soc. London, pp. 253-258, pls. 33-34.

BANKS, NATHAN.

I892. A Synopsis, Catalogue, and Bibliography of the Neuropteroid Insects of Temperate North America. Trans Am. Ent. Soc., XIX, pp. 327-374.

I894. The Odonata of Ithaca, N.Y., Can. Ent., XXVI, pp. 76-78.

BERGROTH, E.

I88I. Zur geographischen Verbreitung einiger Odonaten. Entom. Nachr., VII, pp. 85-88.

Beutenmuller, William.

1890. Preliminary Catalogue of the Odonata found in the State of New York. Dragonflies vs. Mosquitoes, pp. I63-I64.

Brimley, C. S.

1906. North Carolina Records of Odonata in 1904 and I905, with Corrections of somẹ Previous Records. Ent. News, XVII, pp. 9I-92.

Brown, J. J.

I89I. Flights of Dragonflies. Insect Life, III, pp. 4I34I4.

BURMEISTER, $\mathrm{H}$.

I839. Handbuch der Entomologie, Vol. II. Odonata, pp. $805-862$.

BURNHAM, EDWARD J.

I900. Preliminary Catalogue of the Anisoptera of Manchester. Proc. Manch. Inst. Arts and Sciences, I, pp. 27-38. 
BUTLER, HoRTENSE.

1904. The Labium of the Odonata. Trans. Am. Ent. Cabot, Louis. Soc., XXX, pp. II I-I34, pls. II-VII.

I88I. The Immature State of the Odonata. Part II, Subfamily Æschnina. Mem. Mus. Comp. Zool., VIII, No. I, pp. I-40, pls. I-V.

Calvert, Philip P.

1893. Catalogue of the Odonata (Dragonflies) of the Vicinity of Philadelphia with an Introduction to the Study of this Group of Insects. Trans. Am. Ent. Soc., XX, pp. 152a-272, pls. II-III.

I 894a. On the Specific Identity of Aeschna clepsydra Say and Ae. crenata Hagen (eremita Scudder.) Ent. News, V, pp. 9-13, figs. I-5.

1894b. Data on the Distribution of Dragonflies. Ent. News, V, pp. 242-244.

1894c. Notes on Nova Scotian Dragonflies. Can. Ent., XXVI, pp. 317-320.

I 895a. Odonata of New York State. Journ. N.Y. Ent. Soc., III, pp. 39-48.

I 895b. The Odonata of Baja California, Mexico. Proc. Cal. Acad. Science, Second Series, IV, pp. 463558 , pls. XV-XVII.

I 897. Additons to the Odonata of the State of New York. Journ. N.Y. Ent. Soc., V, pp. 9 I-95.

1898. On Burmeister's Types of Odonata. Trans. Am. Ent. Soc., XXV, pp. 27-104.

1899. Foot-note on "A Note on Copulation among Odonata" (Williamson). Ent. News, X, p. 42.

1900a. Insects of New Jersey-Odonata. 27th Ann. Rep. N. J. State Board Agric., pp. 66-75.

I90ob. Note on "Kingbirds eating Dragonflies" (J. P. Moore)! Ent.

1903. A List of the Insects of Beulah, New Mexico - Neuroptera Odonata. Trans. Am. Ent. Soc., XXIX, pp. 42-45. 
1905a. Fauna of New England, 6. List of the Odonata. Occasional Papers Bost. Soc. Nat. Hist., VII, pp. I -43 .

I 905b. Biologia Centrali-Americana-Neuroptera Odonata. Pp. I7-420, pls. I-X. London (I90I-I908).

1906. Copulation of Odonata, II. Ent. News, XVII, pp. I 48-I 50, pl. VII.

1909. The Composition and Ecological Relations of the Odonata Fauna of Mexico and Central America. Proc. Ac. Nat. Sci. Phil., I 908, pp. 460-49I, with Map, pl. XXVI.

I909. The Insects of New Jersey-Odonata.

CAMPBELl, F. M.,

1885. Dragonfly Migration. Ent. Month. Mag., XXI, p. 192.

Charpentier, Toussaint DE.

I840. Libellulinae Europaeae, pp. I-I80, pls. I-XLVIII. Leipzig.

Cockerell, T. D. A.

1908. A Dragon-fly Puzzle and its Solution. Ent. News, XIX, pp. 455-459.

Сомsтоск, G. F.

1903. A List of Lepidoptera found in the Adirondack Mountains. Ent. News, XIV, pp. 197-200. Odonata p. 200.

Currie, Rolla P.

1901. Papers from the Harriman Alaska Expedition, XXII. Entomological Results (14): The Odonata. Proc. Wash. Acad. Sci., III, pp. 2I7-223.

1903. The Odonata collected by Messrs. Schwarz and Barber in Arizona and New Mexico. Proc. Ent. Soc. Wash., V, No. 4, pp. 298-303.

1905. Dragonflies from the Kootenay District of British Columbia. Proc. Ent. Soc. Wash., VII, No. I, pp. 16-20.

DAvis, WM. T.

I 898. Preliminary List of the Dragonflies of Staten Island, with Notes and Dates of Capture. Journ. N. Y. Ent. Soc., VI, pp. 195-198. 
ElRod, MORTON J.

1902. A Biological Reconnaissance in the Vicinity of Flathead Lake. Bull. Univ. Montana, No. Io, Biological Series No. 3, pp. 9I-I 82.

Evans, W. F.

I 845. British Libellulinae, pp. I-28. 2 I coloured figs. London.

FLeTCher, JAMES.

I 906. Entomological Record, 1905. 36th Ann. Rep. Ent. Soc. Ont., p. IO4.

Fletcher James, and Gibson, Arthur.

1908. Entomological Record, 1907. 38th Ann. Rep. Ent. Soc. Ont., pp. II3-I4I.

1909. Entomological Record, 1908: 39th Ann. Rep. Ent. Soc. Ont., pp. 99-I 20.

Fyles, Thomas W.

I90I. The Dragonflies of the Province of Quebec. 3Ist Ann. Rep. Ent. Soc. Ont., pp. 52-55.

Gibson, ArThur.

1910. The Entomological Record, 1909. 40th Ann. Rep. Ent. Soc. Ont., p. I I O-I 28.

1911. The Entomological Record, I9Io. 4Ist Ann. Rep. Ent. Soc. Ont., pp. IOI-I 20.

Hagen, Hermann August.

I 840. Synonymia Libellularum Europaearum, pp. I-84. Koenigsberg, Prussia.

1856. Die Odonaten-Fauna des russischen Reichs. Entom. Zeitung Stettin, XVII, pp. 363-38I.

186I. Synopsis of the Neuroptera of North America, with a List of the South American Species. Smithson. Misc. Coll., IV. Odonata, pp. 55-187.

1873a. Report on the Pseudoneuroptera and Neuroptera of North America in the Collection of the late Th. W. Harris. Proc. Bost. Soc. Nat. Hist., $X V$, pp. 263-30I.

I 873b. Report on Mr. S. H. Scudder's Odonata from the White Mountains, after an Examination of the Types. L.c., XV, pp. 376-377. 
I873c. Odonata from the Yellowstone. Sixth Ann. Rep. U. S. Geol. Surv. Terr., I 872 (Hayden), pp. 727-729.

1874. Report on the Pseudo-neuroptera and Neuroptera collected by Lieut. W. L. Carpenter in I 873 in Colorado. Ann. Rep. U.S. Geol. and Geog. Surv. Terr., I 873 (Hayden), pp. 57 I-606.

1875a. Report upon the Collections of Neuroptera and Pseudo-neuroptera made in portions of Colorado, New Mexico and Arizona, during the years 1872 , 1873 and I874. Rep. Geog. Geol. Expl. Surv. West rooth Merid. Engineer Dept. U.S. Army, pp. $911-922$.

1875b. Synopsis of the Odonata of North America. Proc. Bost. Soc. Nat. Hist., XVIII, pp. 20-96.

1890. Two Species of Aeschna. Psyche, V, pp. 353-355. HARVEY, Frances Leroy.

1891. A Contribution to the Odonata of Maine. Ent. News, II, pp. 73-75.

1902. A Catalogue and Bibliography of the Odonata of Maine with an Annotated List of their Collectors. University of Maine Studies, No. 4.

HeBard, MORgan.

1910. A few Records from Northern Michigan in the Order Odonata. Ent. News, XXI, pp. I34-I 35 .

HowaRd, L. O.

1901. The Insect Book. Odonata, pp. 363-376, pls. XL-XLVIII. New York.

Kammerer, Paul.

1907. Symbiose zwischen Libellenlarve und Fadenalge. Arch. für Entw. der Org., XXV, pp. 53-8r.

Karsch, Ferdinand.

I89 a. Kritik des Systems der Aeschniden. Ent. Nachr., XVII, pp. 273-290.

I89I b. Acht neue Aeschniden, l.c., XVII, pp. 305-3I3. Kellicott, David S.

I895. Catalogue of the Odonata of Ohio, Part I. Journ. Cinc. Soc. Nat. Hist., XVII, pp. I95-2I6. 
I 896. Catalogue of the Odonata of Ohio, Part II. L.c., XVIII, pp. I05-I I4.

I899. The Odonata of Ohio. Special Papers, Ohio Acad. Sci., No. 2. viii + I I6 pp., pls. I-4.

KIRBY, W. F.

I890. A Synonymic Catalogue of Neuroptera Odonata or Dragonflies, with an Appendix of Fossil Species. $x+202$ pp. London.

Kolenati, Frederico A.

I846. Meletemata entomologica, V-Neuroptera, pp. I 13-I20. St. Petersburg.

LINNÉ, CARL VON.

I 758. Systema Naturae, I-Neuroptera, pp. 543-552. LUCAS, W. J.

I900. British Dragonflies (Odonata). xiv +356 pp., 27 pls., 57 text figs. London.

Maclaughlin, T. J.

1887. Ottawa Dragonflies. Trans. Ottawa Field Nat. Club., II, pp. 329-342.

MARTIN, RENÉ.

I908. Collections Zoologiques du Baron Edm. de SelysLongchamps. Catalogue systematique et descriptif. Fasc. XVIII, Aeschnines, pp. I-84, pls. I-II.

1909. Ibid. Fasc. XIX, Aeschnines, pp. 85-156, pls. III-IV.

I910. Ibid Fasc. XX, Aeschnines, pp. I57-223, V-VI.

1911. Genera Insectorum, Fasc. II5. Odonata, Fam. Aeschnidae, Subfam. Aeschninae, pp. I-34, pls. I-VI.

MOORE, J. PERCY.

1900. Kingbirds eating Dragonflies. Ent. News, XI, p. 340 .

Mueller, F. O.

1867. Enumeratio ac Descriptio Libellularum agri Friedrichsdalensis. Nova Acta Acad. Caes. Leop. Car., III, pp. I22-I3I. 
Walker: North American Species of Aeshna 209

MutTKOWSKI, RICHARD A.

1908a. Review of the Dragonflies of Wisconsin. Bull. Wis. Nat. Hist. Soc., VI, pp. 57-I27.

rgo8b. A Summer's Insect Collecting-Odonata. L.c., VI, pp. I66-168.

19roa. New Records of Wisconsin Dragonflies. L.c., VIII, pp. 53-59.

I9rob. Catalogue of the Odonata of North America. Bull. Publ. Mus. Milw., I, art. I, pp. I-207.

rgroc. Miscellaneous Notes and Records of Dragonflies (Odonata). Bull. Wis. Nat. Hist. Soc., VIII, pp. I 70-I 79 .

I9II. New Records of Wisconsin Dragonflies, II. L.c., IX, pp. 28-4I, pl. IV.

NEEDHAM, JaMES G.

1900. The Fruiting of the Blue Flag. Amer. Nat., XXXIV, No. 40r, pp. 36r-386.

1901. Aquatic Insects in the Adirondacks. Bull. 47, N.Y. State Mus., pp. 383-6r2, pls. I-XXXVI, 42 text figs.

1903a. Aquatic Insects in New York State. Bull. 68, N.Y. State Mus., Ent. I8, parts 2 and 3, pp. 204279, pl. V.

1903b. A Genealogic Study of Dragonfly Venation. Proc. U.S. Nat. Mus., XXVI, pp. 703-764, pls. I-XXIV, 44 text figs.

1904. New Dragonfly Nymphs in the United States National Museum. L. c., XXVII, pp. 685-720.

1908. Notes on the Aquatic Insects of Walnut Lake. Rep. Board Geol. Surv. Mich. 1907 on the Biology of Walnut Lake. App. III, pp. 252-27I.

1910. Report of the Entomologic Field Station conducted at Old Forge, N.Y., in the Summer of 1905. Bull. 124, N.Y. State Mus., App. C., pp. I56-284.

OsBurn, Raymond C.

1905. The Odonata of British Columbia. Ent. News, XVI, pp. 184-196. 
1906. Some Experiments with Dragonflies in Brackish Water. Amer. Nat., XL, pp. 395-399.

Osburn, R. C., ANd Hine, J. S.

1900. Dragonflies taken in a Week. Ohio Nat., I, p. I4. Provancher, L'AbBé.

1897. Petite Faune entomologique du Canada. Névroptères. Le Naturaliste Canadien, IX (continued from vol. VIII), pp. 38-43.

Ris, F.

1885. Neuroptera Helvetiae, analytisch bearbeitet als Grundlage einer Neuropteren-fauna der Schweiz (Gustav Schoch). Odonata (Die schweizerischen Libellen), pp. 35-85.

Ruthven, Alexander G.

1906. Spiders and Insects from the Porcupine Mountains and Isle Royale, Michigan. From "An Ecological Survey of Northern Michigan" (C. C. Adams). Ann. Rep. State Board Geol. Surv., 1905, pp. 100-106.

SAY, Thomas.

1839. Descriptions of New North American Neuropterous Insects, and Observations on some already described by (the late) Th. Say. Journ. Acad. Nat. Sc. Phil., VIII, Pt. I, pp. 9-46.

Scudder, Samuel H.

1866. Notes on Some Odonata from the White Mountains of New Hampshire. Proc. Bost. Soc. Nat. Hist., X, pp. 21 I-222.

Selys-Longchamps, EDmond DE.

I840. Monographie des Libellulidées d'Europe, pp. I-220, pls. I-4. Paris and Brussels.

1850. Revues des Odonates ou Libellules d'Europe, pp. I-408, pl. I-II. Brussels and Leipzig.

1875. Notes on Odonata from Newfoundland, collected in 1874 by Mr. John Milne. Ent. Month. Mag., II, pp. 24 I-243.

Selys-Longchamps, Edmond De, and Maclachlan, Rober T.

1872. Matériaux pour une faune névroptérologique de l'Asie septentrionale. Ann. Soc. Ent. Belg., 
XV, pp. 25-77 (Odonata by Selys-Longchamps, pp. $25-45)$.

SKINNER, HENRY M.

I902. "Doings of Societies." Ent. News, XIII, p. 26.

1903. Ibid., 1.c., XV, p. 288.

I9I I. Ibid., l.c., XXII, p. 336.

SMITH, JOHN B.

I909. Insects of New Jersey. Rep. N. J. State Museum. Odonata, pp. 73-82.

Stefanelli, P.

I882. Osservazioni sui costumi e sullo svilluppo dell' Aeschna cyanea Müll. Bull. Soc. Ent. Ital., I 882, pp. 236-238.

Stephens, James Francis.

I835. Illustrations of British Entomology, or a Synopsis of Indigenous Insects, etc., VI-Mandibulata. Odonata, pp. 70-96. London.

TILLYARD, R. J.

1909. Studies in the Life-histories of Australian Odonata. I. The Life History of Petalura gigantea Leach. Proc. Linn. Soc. N. S. W., XXXIV, part 2, pp. 256-267, pl. XXIV.

VAN Duzee, E. P.

I897. List of the Dragonflies taken near Buffalo, N.Y. Journ. N. Y. Ent. Soc., V, pp. 87-9I.

IVAdsworth, Miss Mattie.

I 890. List of the Dragonflies (Odonata) taken at Manchester, Kennebec Co., Me., in I888 and 1889. Ent. News, I, pp. 36-37, 55-57.

WALKER, EDMUND M.

1905. Orthoptera and Odonata from Algonquin Park, Ontario. 36th. Ann. Rep. Ent. Soc. Ont., pp. 64-70.

1906. A First List of Ontario Odonata. Can. Ent., XXXVIII, pp. I49-I54.

I908a. The Dragonflies of the Ottawa District. Ott. Nat., XXII, pp. 49-63.

I 908b. A Key to the North American Species of Aeshna. Can: Ent., XL, pp. 377-39I, 450-45I. 
WALLENGREN, H. D. J.

1894. Öfversikt af Skandinaviens' Pseudoneuroptera. Ent. Tidskrift, IV, pp. 235-270.

WEITh, R. J.

1900. Indiana Odonata. Ent. News, XI, p. 641.

IVILliaMson, Edward B.

I 897. September Dragonflies of Round and Shriner Lakes, Whitley Co., Indiana. Rep. State Geol. Ind., pp. 403-405.

I 899. A note on Copulation Among Odonata. Ent. News, X, pp. 42-43.

I900a. The Dragonflies of Indiana. 24th Ann. Rep: Dept. Geol. Nat. Res. Ind., pp. 229-233.

1900b. Additions to the Indiana List of Dragonflies, with a Few Notes, No. I. Proc. Ind. Ac. Sci., pp. 173-178.

1901. Additions to the Indiana List of Dragonflies, with a Few Notes, No. II. L.c., pp. I 19-127.

1902a. A list of the Dragonflies observed in Western Pennsylvania. Ent. News, XIII, pp. 65-71, 108-113.

1902b. Dragonflies (Odonata) from the Magdalen Islands. Ent. News, XIII, pp. 144-146.

1903a. A proposed new genus of Odonata (Dragonflies) of the Subfamily Aeschninae, Group Aeschna. Ent. News, XIV, pp. 2-9, pl. II.

1903b. The Dragonflies (Odonata) of Tennessee, with a Few Records for Virginia and Alabama. Ent. News, XIV, pp. 22 I-229.

1906a. Dragonflies (Odonata) collected by Dr. D. A. Atkinson in Newfoundland, with Notes on some Species of Somatochlora. Ent. News, XVII, pp. I33-I 39, pls. V and VI.

1907a. A Collecting Trip North of Sault Ste. Marie, Ontario. Ohio Nat., VII, pp. I29-148. 
Walker: North American Species of Aeshna 213

1907b. List of Dragonflies of Canada. L.c., VII, pp. I 48 - I 50.

1908. Three related Species of Aeshna. Ent. News, XIX, pp. 264-27I, 30I-308.

Wilson, Charles Branch.

1909. Dragonflies of the Mississippi Valley collected during the Pearl Mussel Investigations on the Mississippi River, July and August, 1907. Proc. U.S. Nat. Mus., XXXVI, pp. 653-67I.

Zetterstedt, Johanne Wilhelmo.

I 840. Insecta Lapponica. Neuroptera, pp. IOI5-1080. Leipzig. 




\section{PLATE 1. \\ Clunatic Variatrons.}

Figs. 1-4. Abdominal Segments I-4 of females of four species of Aeshna, illustrating variations in length and. depth of the segments. (Lateral view, $\times 2$.)

1. Ae. interrupta interrupta; $a$, from the Bay of Islands, Newfoundland; $b$, Heyden, Ont.; $c$, Ottawa, Ont.

2. Ae eremita; $a$, from the Bay of Islands, Newfoundland; $b$, Searchmont, Ont.; $c$, Toronto, Ont.

3. Ae. canadensis; a from Grand Entry, Magdalen Islands; $b$, Porcupine Mountains, Mich.: $c$, De Grassi Point, Ont.

4. Ae. palmata; $a$, from Kodiak, Alaska; $b$. Twin Lakes, Col.; c, Ogden, Utah.

5-7. Abdominal segments 8-10 and appendages of females of three species of Aeshna, illustrating: variations in length of appendages. (Lateral view, $\times$ 2.)

5. Ae. interrupta; $a$, Bay of Islands, Newfoundland; $b$, Heyden, Ont.; $c$, Ottawa, Ont.

6. Ae. eremita; $a$, Bay of Islands, Newfoundland; $b$, Heyden, Ont.; $c$, Toronto, Ont.

7. Ae. canadensis; a, Grand Entry, Magdalen Islands; b, Porcupine Mountains, Mich.; c, De Grassi Pt., Ont. 


\section{HAM

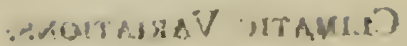

क)

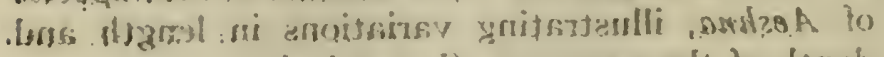

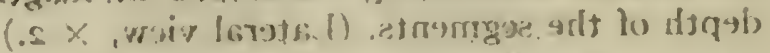

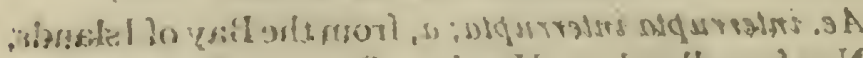

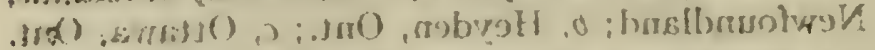

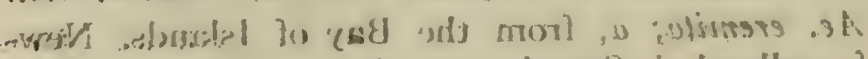

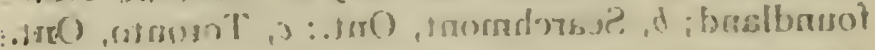

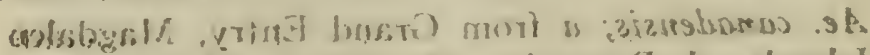

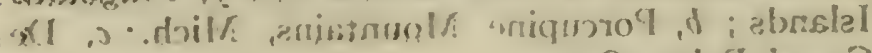

$$
\text { .tan, mio' ieesta) }
$$

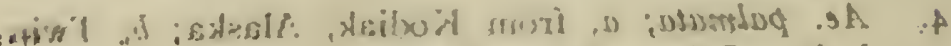

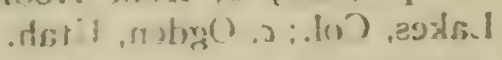

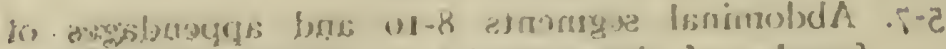

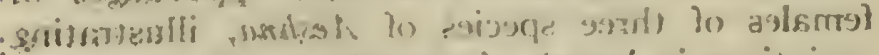

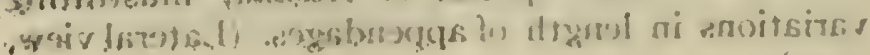

(.5 $\times$

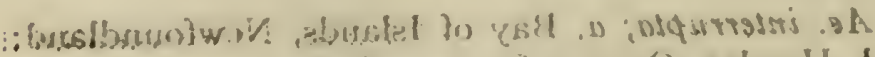

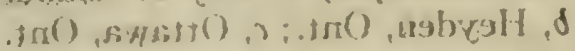

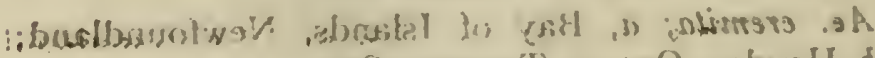

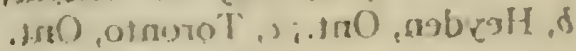

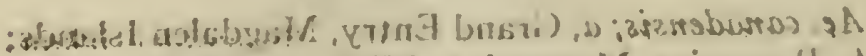

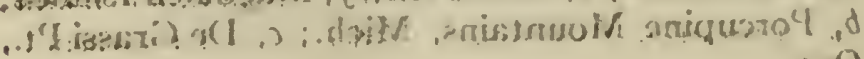



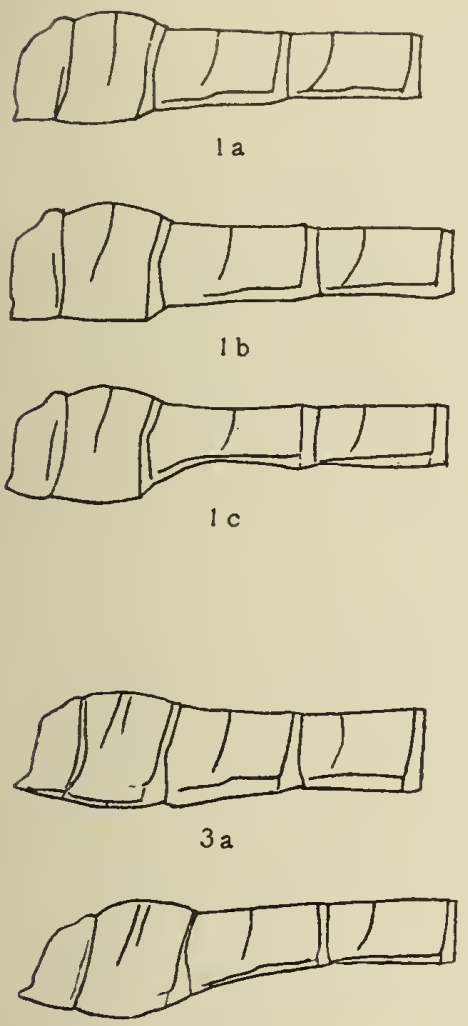

$3 \mathrm{~b}$

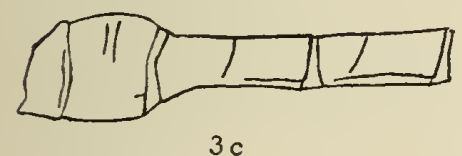

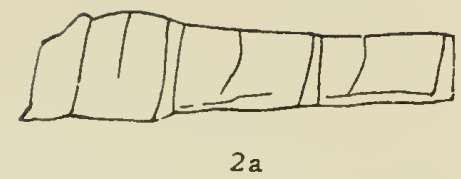
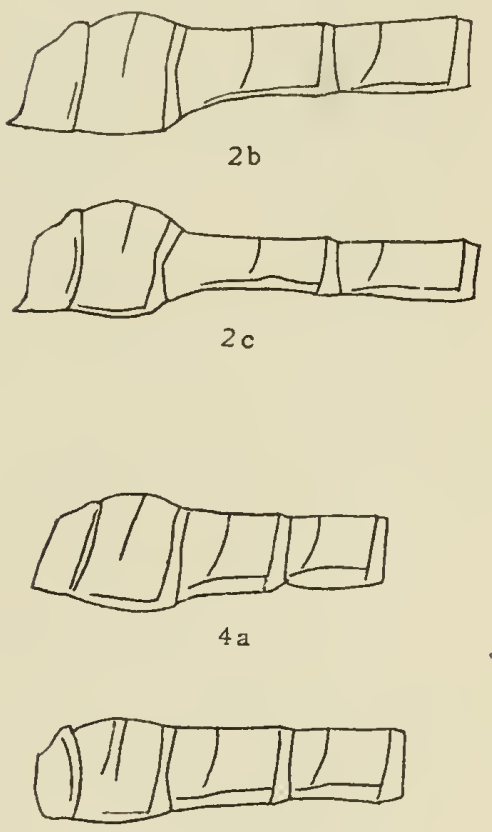

$4 \mathrm{~b}$

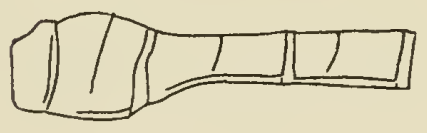

$4 c$
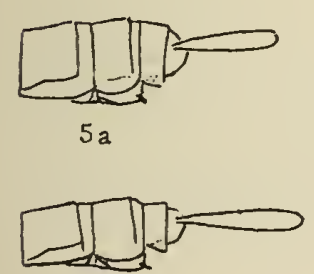

5 b

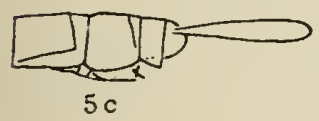

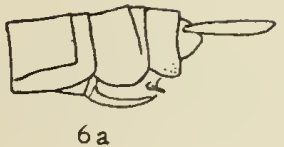

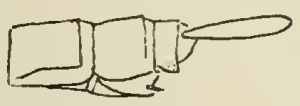

$6 \mathrm{~b}$

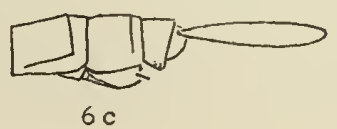

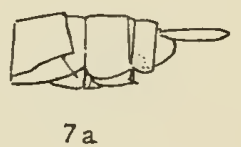
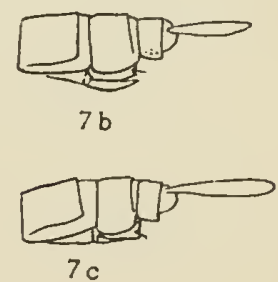

HELIOTYPE CO. BOSTON 



\section{PLATE 2.}

\section{COpulatory Position.}

Fig. I. Ae. constricta, pair in copula, De Grassi Point, Ont. From dried specimens, killed with benzine. (From photograph, by A. J. Reading.)

“2. Ae. constricta, connection between male and female genitalia, from the same specimens. AH, anterior hamulus; $\mathrm{PH}$, posterior hamulus; $\mathrm{Sp}$, spine of the anterior lamina; Ov, ovipositor; GV, genital valve.

“ 3. Ae. constricta, appendages of male, grasping head of female during copulation. Oblique view from behind, from another pair taken at De Grassi Point, Ont.

“ 4. The same, viewed from above.

" 5. The corresponding position in Ae. clepsydra. Lateral view, from specimens taken at Go Home Bay, Ont.

" 6. The same viewed obliquely from behind and beneath.

" 7. The corresponding position in Gomphus spicatus Hagen, viewed obliquely from behind. 


\section{$\therefore 011-3$

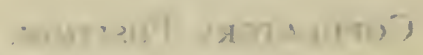

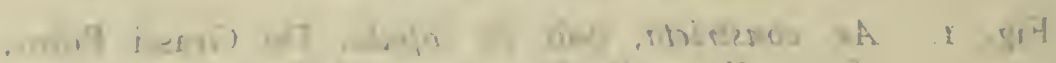

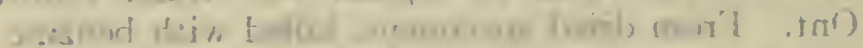

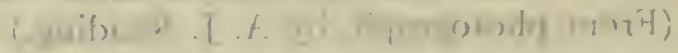

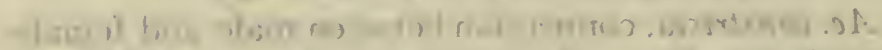

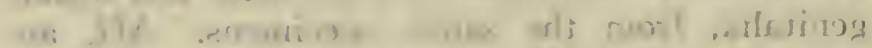

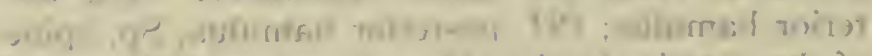

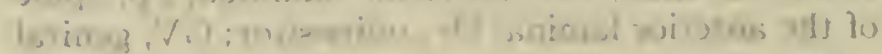
avles

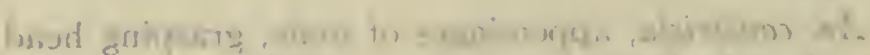

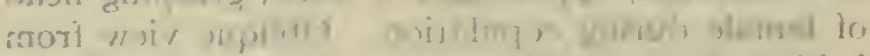

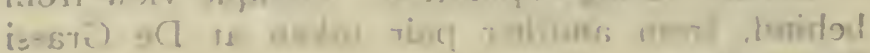
. गार I .176 4

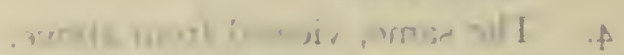

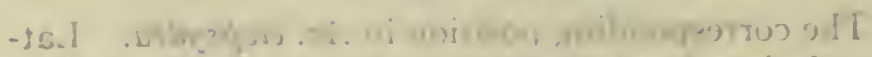
?.?

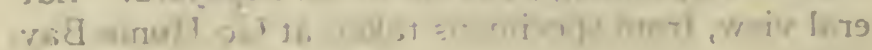

$\sin 0$

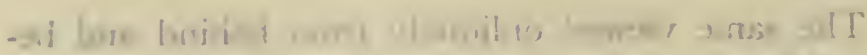
d $.076 \pi$

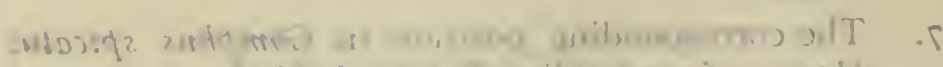

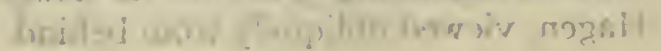




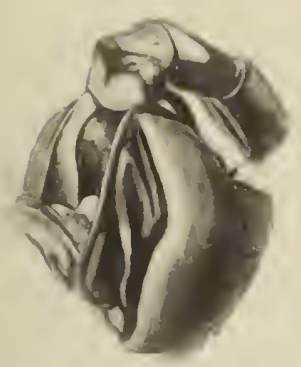

3

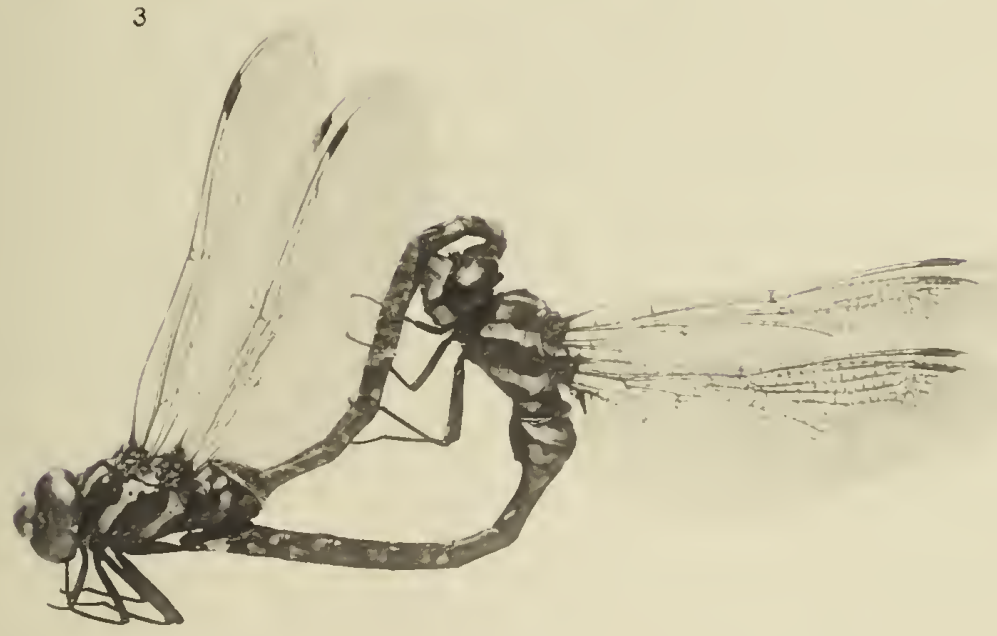

1

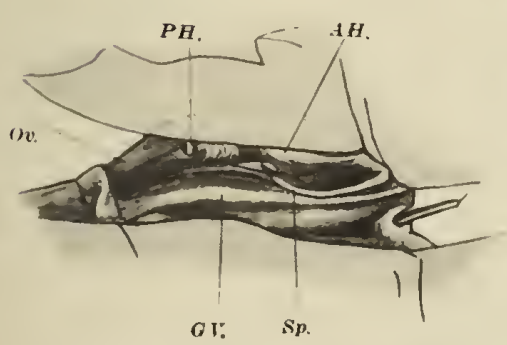

2
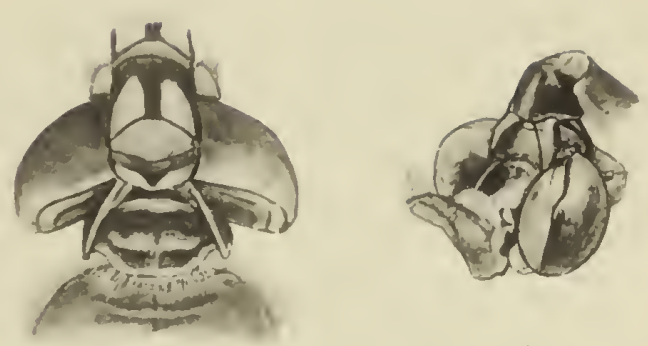

7
4 



\section{PLATE 3. \\ Oviposition.}

Figs. I. Ae eremita, female ovipositing in the stem of Sparganium. (X I.5.)

" 2. Stem of Sparganium, showing punctures made by the ovipositor of Ae. eremita. (X I.5.)

" 3. Eggs of Ae. eremita in natural position in Sparganium. $(\times 3$.

“ 4. Egg of Ae. eremita. (X 20.)

" 5. Stem of Acorus calamus, showing slits made by the ovipositor of Ae. constricta. ( $\times$ I.5.)

6. Egg of Ae. constricta. $(\times 20$. 


\section{. . $91 / \mathrm{l} 1$ \\ vosth ivo}

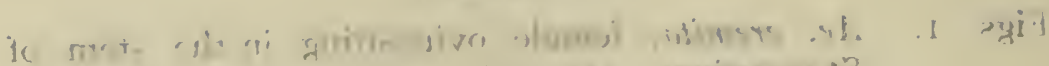

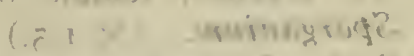

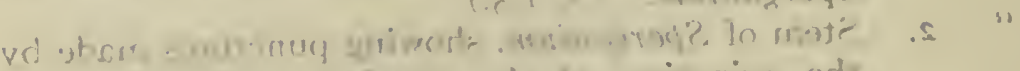

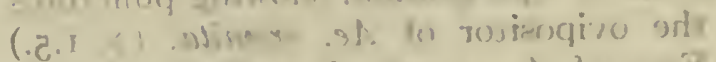
.ઈ, (. $₹ \times 1$. 0 s. ( i. $x$ : . 1)

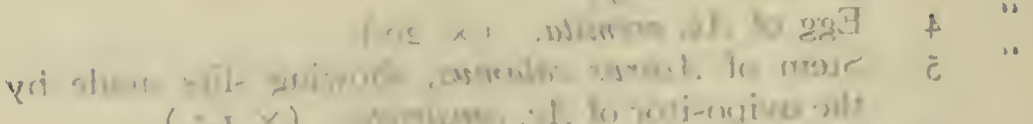

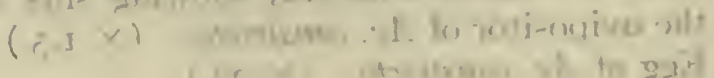

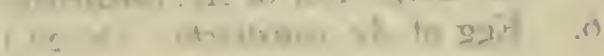



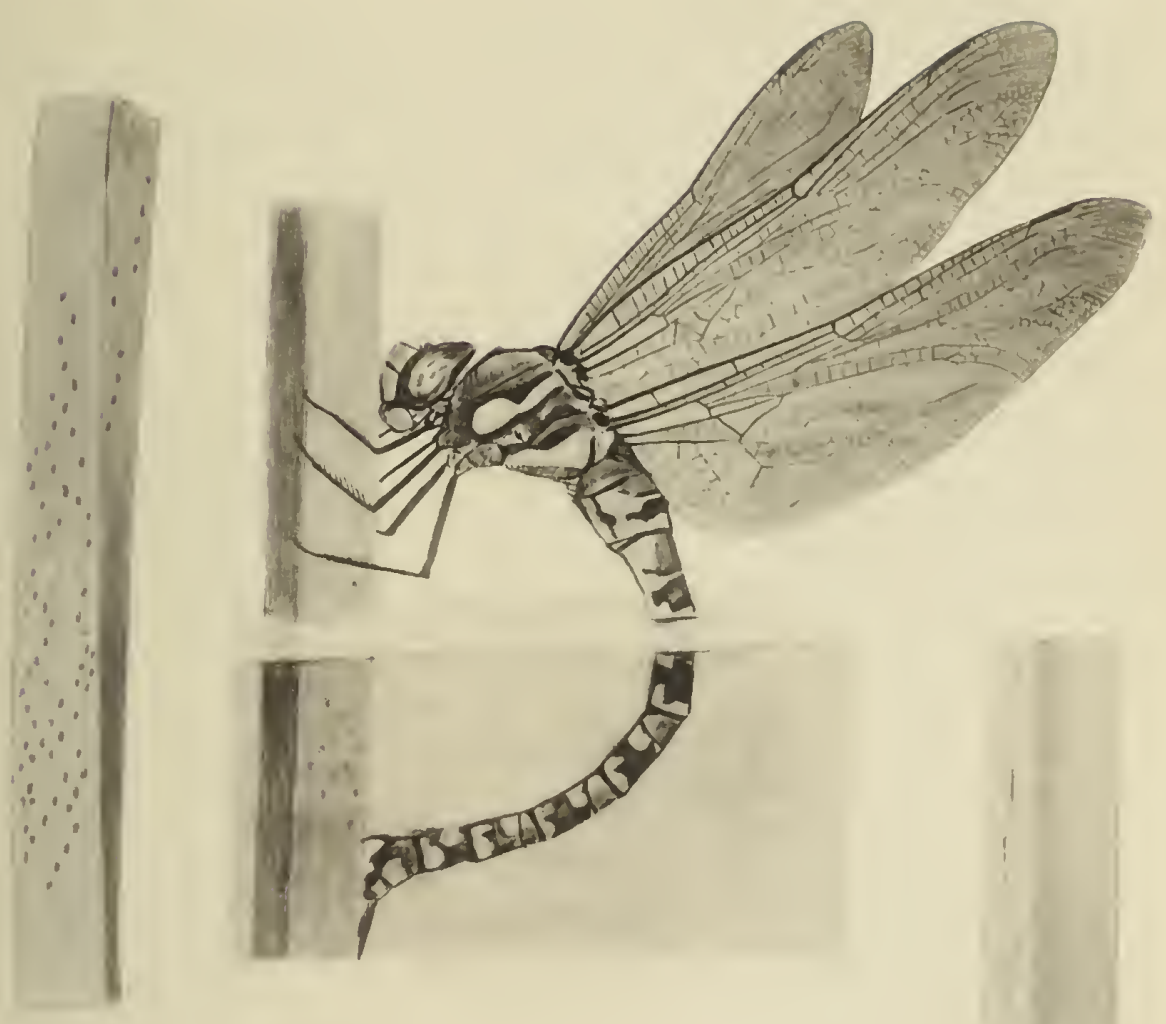

2

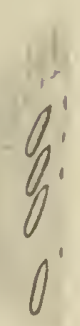

3
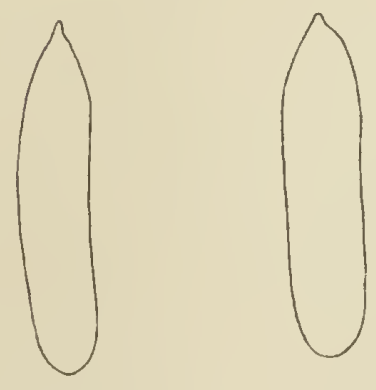

4

6 

PLATE 4.

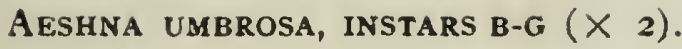

Fig. I. Instar B.

"2. "C.

"3. " D.

Fig. 4. Instar E.

"5. " F.

"6. “ G. 
. $35 / .19$

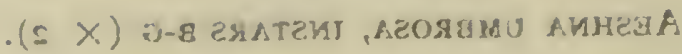

3 Istanl + gir

.

. "

.g mojenl. . gind

.300

(1) 2 . 2 


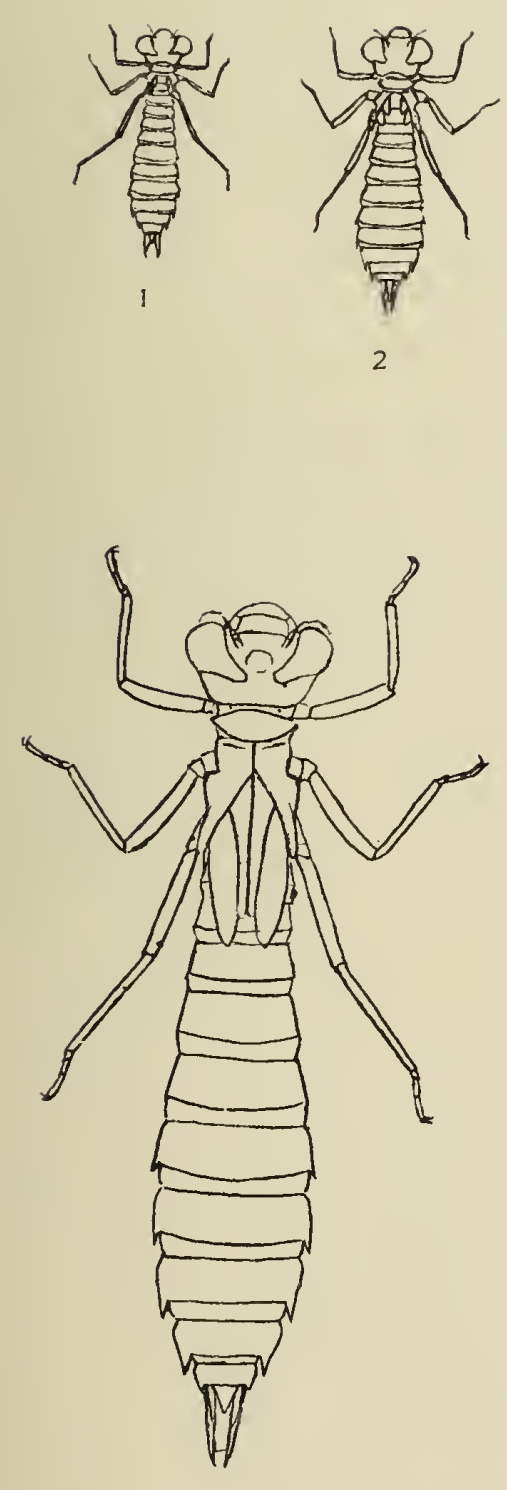

6
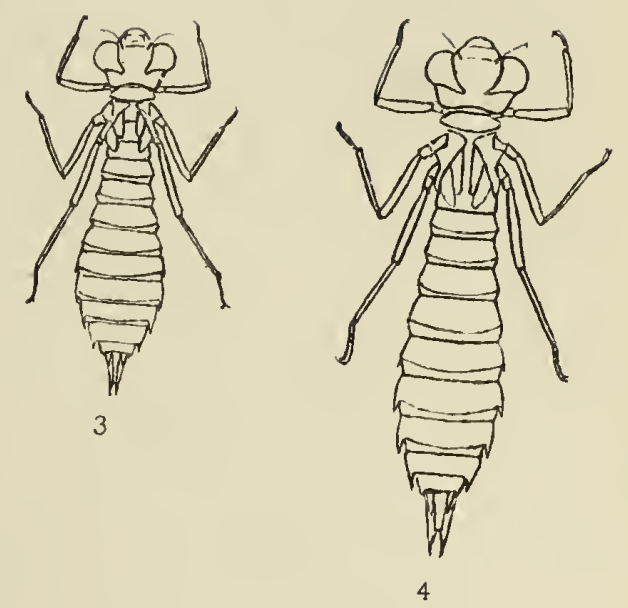

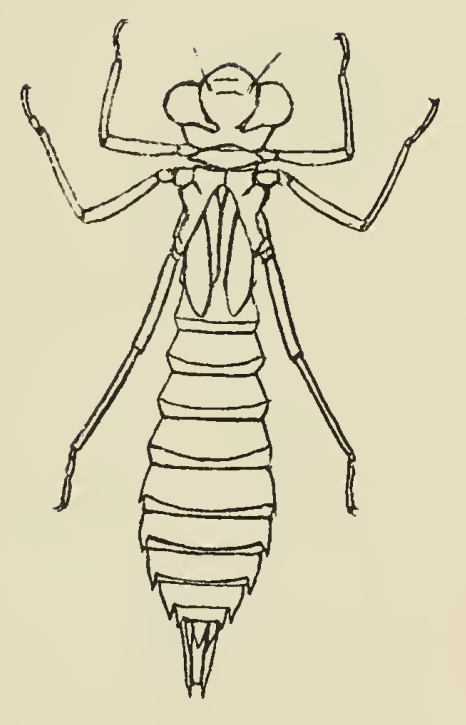

5 



\section{PLATE 5.}

AEshna Canadensis, EMERGENCE of IMAGo.

Fig. I. Nymph suspended, prior to emergence of imago.

2. Emergence of head and thorax.

3. Emergence of wings.

4. Extraction of hind pair of legs.

5. Resting position.

6. Extraction of end of abdomen.

7. Imago immediately after emerging.

8. Imago immediately after full expansion of wings. 


\section{$-3 r d i$

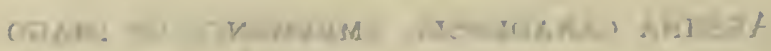

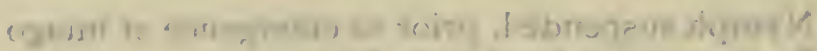

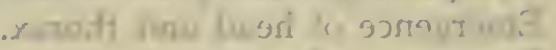

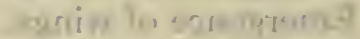

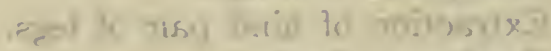
scirence zaldeal

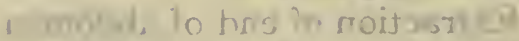

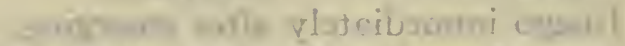
$1 \cdot 2 i^{3}$ 

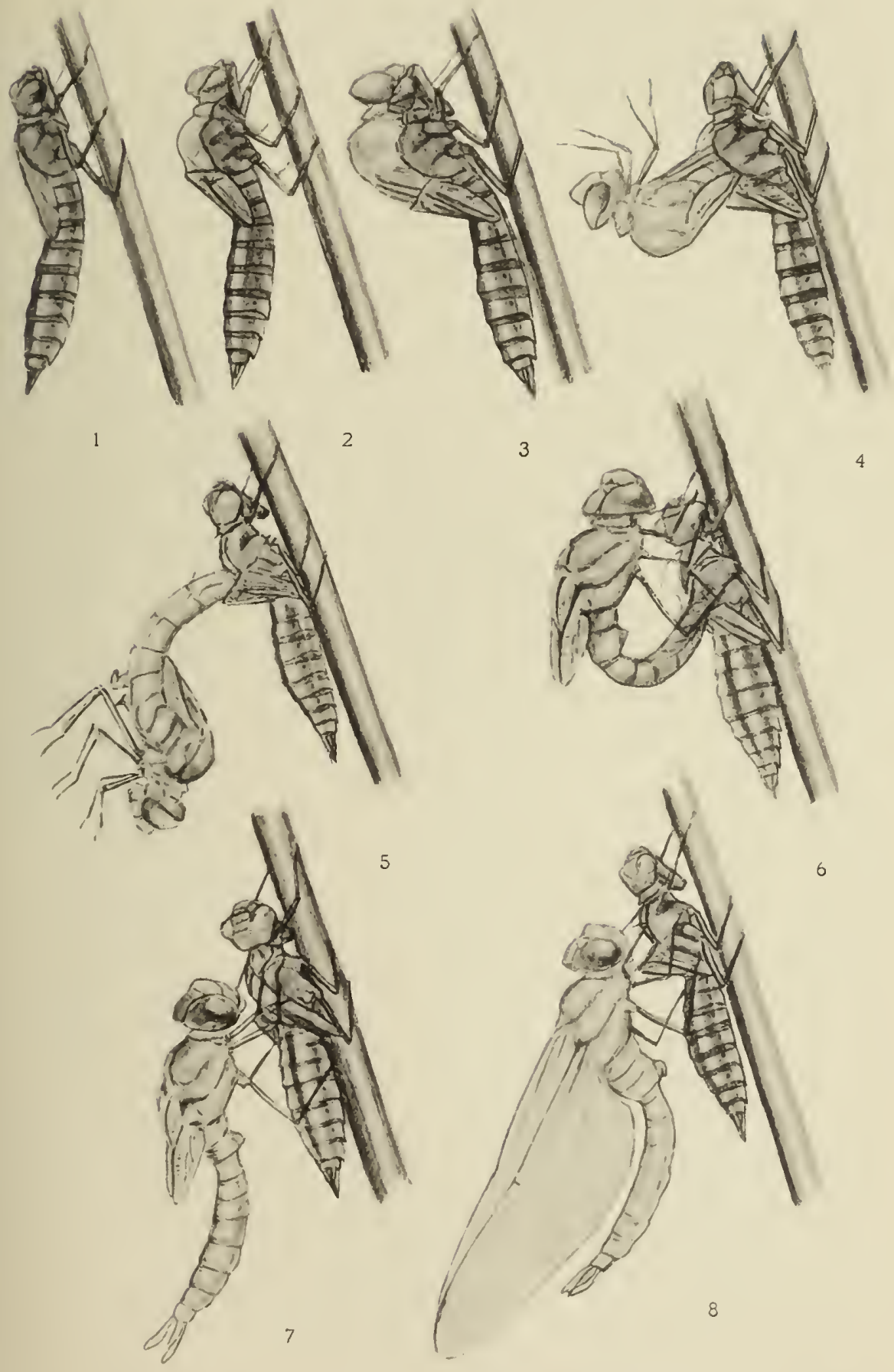

4 



\section{PLATE 6.}

\section{NyMPHs. ${ }^{2}$}

Iiig. I. Aeshna juncea 9 , Cierfs, Switzerland.
2. " interrupta interrupta $0^{7}$, Nipigon, Ont.
3. " eremita o", Go Home Bay, Georgian Bay, Ont.
4.
"canadensis $0^{7}$, Go Home Bay, Ont.
5. " constricta \&, Lake Simcoe, Ont.

'All the figures enlarged one-half. 


$$
\begin{aligned}
& 3 \quad 11419 \\
& \text { yon }
\end{aligned}
$$

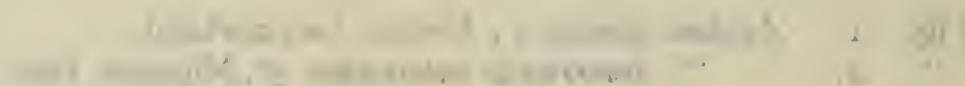

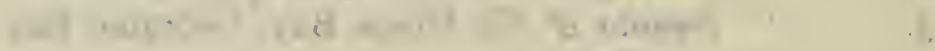

(mi)

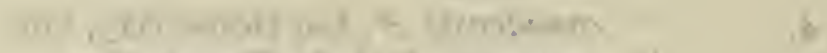

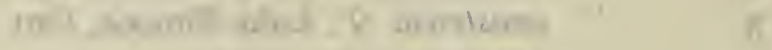

$$
, \ldots, \ldots+\ldots
$$



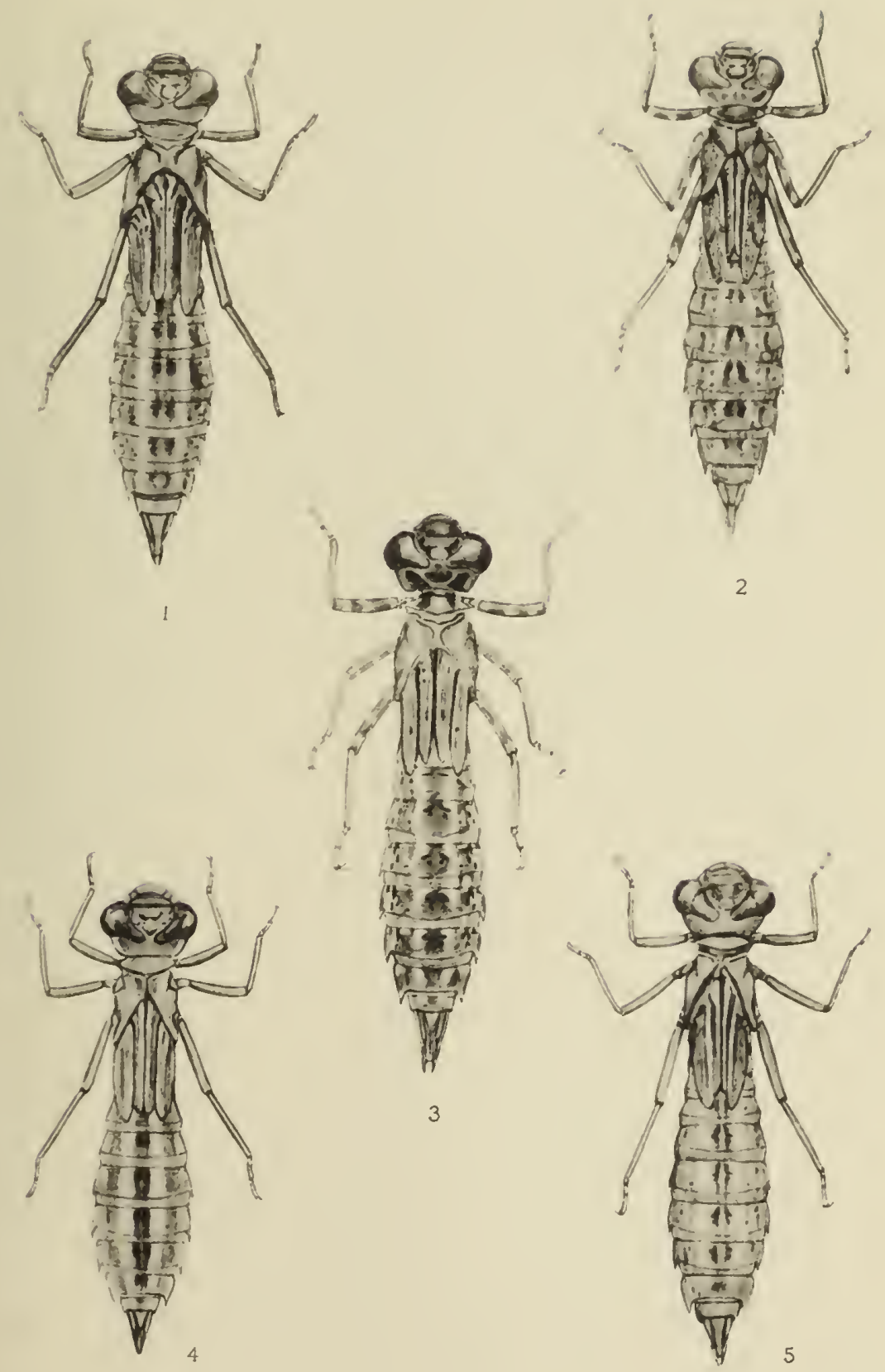

E. Y. W. DEL.

HEIITTYFE CC BOSTON 



\section{PLATE 7.}

\section{NYMPHS. ${ }^{1}$}

Fig. I. Aeshna palmata $\&$, Robson, B. C.

"2. " umbrosa umbrosa or, Toronto, Ont.

"3. " "californica $q$, Sunnyside, Wash.

" 3a. " " $\sigma^{7}$, abdominal appendages, dorsal view.

"4. " multicolor \&, Sunnyside, Wash.

"4a. " " $\sigma^{7}$, abdominal appendages, clorsal view.

All the figures, except za and мa, enlarged one-half. 


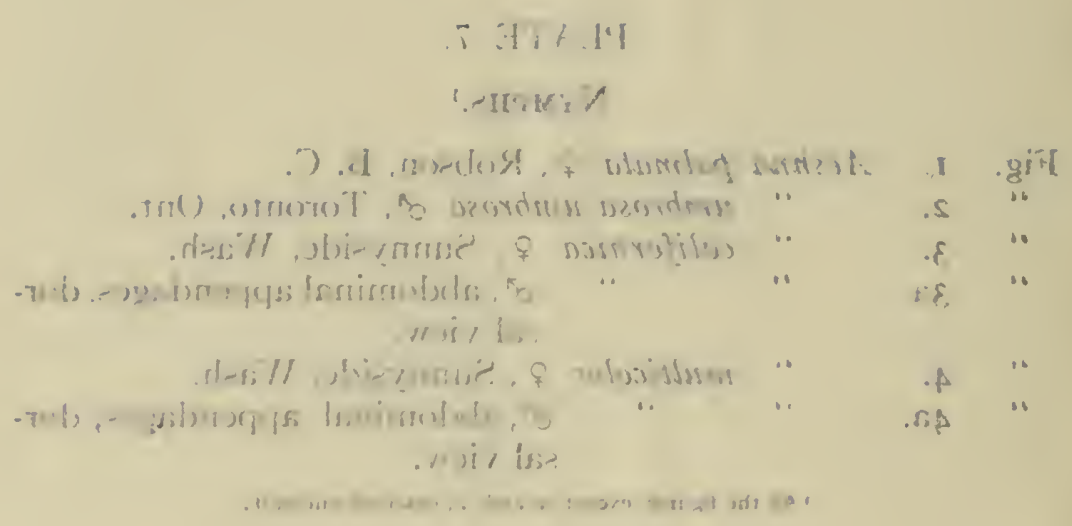



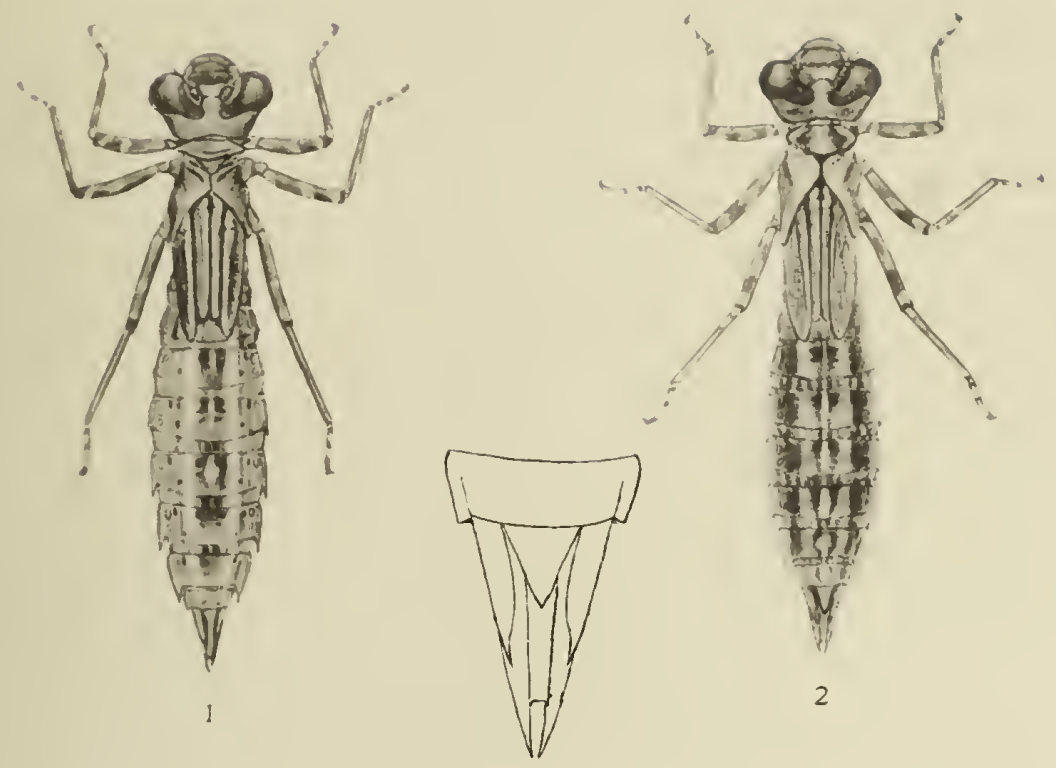

$3 a$
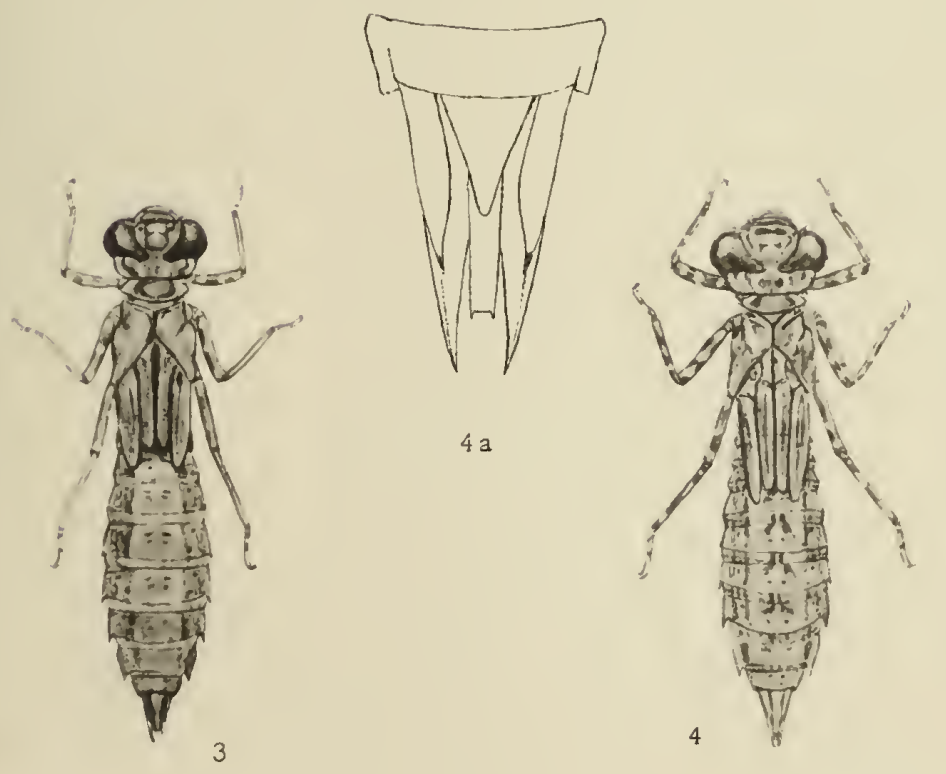

PLATE 8.

LABIA OF NyMphS.

Figs. I. Aeshna juncea, Cierfs, Switzerland.

2. " interrupta interrupia, Nipigon, Cms.

3. " "eremita, Nipigon, Ont.

4. "clepsydra, Go Home Bay, Ont.

5. " canadensis, Go Home Bay, Ont. 


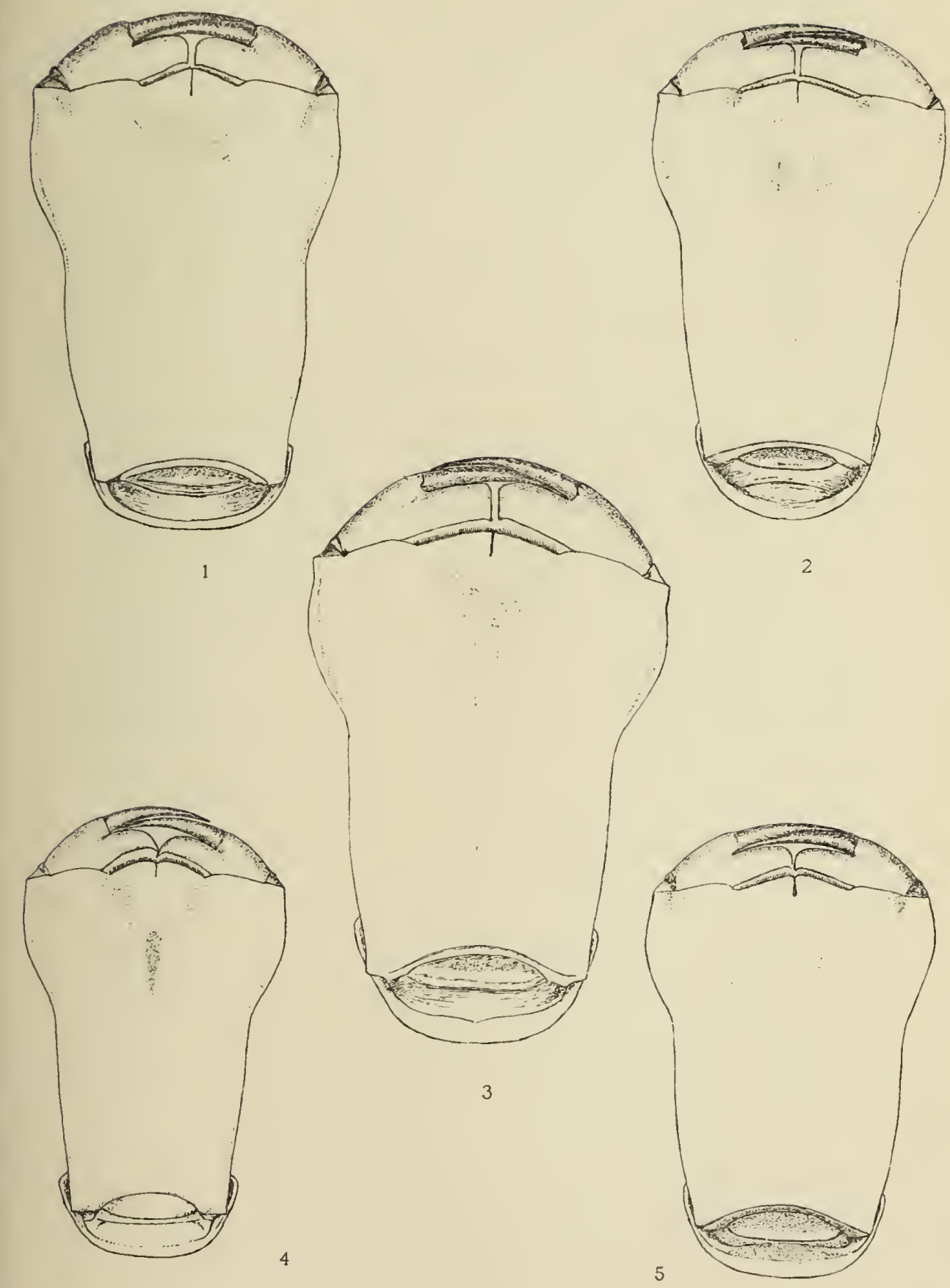

E. M. K.., C $F$ M. LUC. ET DEL. 

PLATE 9.

LABIA OF NyMPHS.

Fig. I. A eshna palmata, Robson, B. C.

2. " umbrosa umbrosa, Lake Simcoe, On.

3. " "constricta, Lake Simcoe, Ont.

4. " californica, Sunnyside, Wash.

¿. “multicolor, Sunnyside, Wash. 
e zilkil

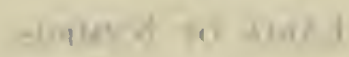

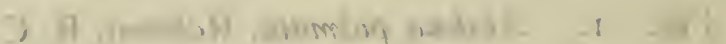

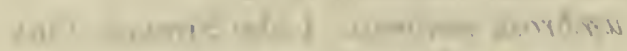

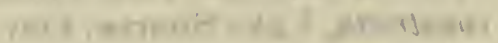

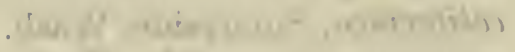

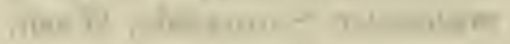




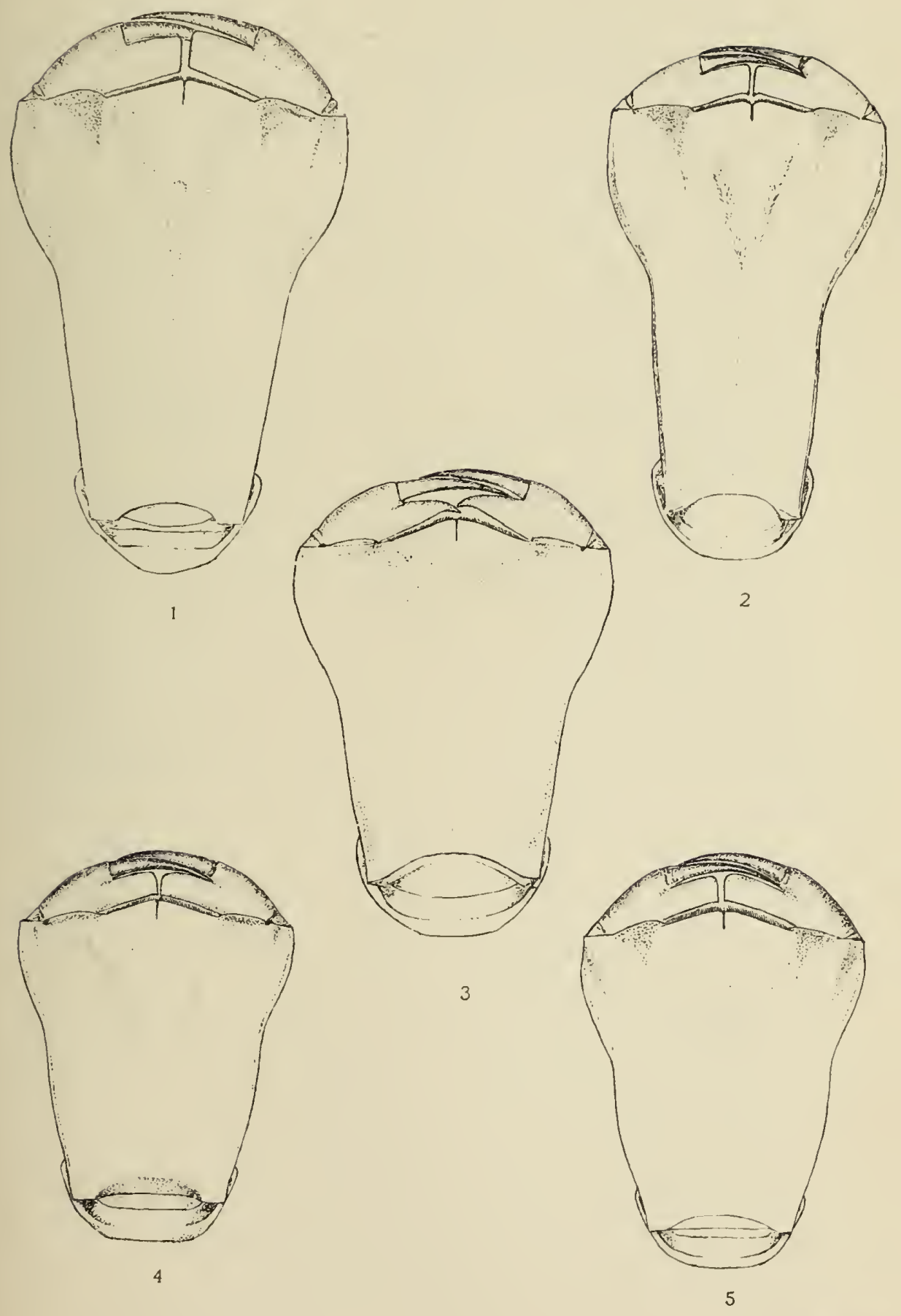



PLATE 10.

TERMINAL SEgMENTS AND GHNTAHA UF FEMALE NYMPHS.

Fig. 1. Aeshna juncea, Cierfs, Switzerland.

"2. " interrupta interntota, Nipigon, Ont.

"3. " " eremita, Nipigon, Ont.

"4. " "canadensis, Cro Home Bay, Ont. 


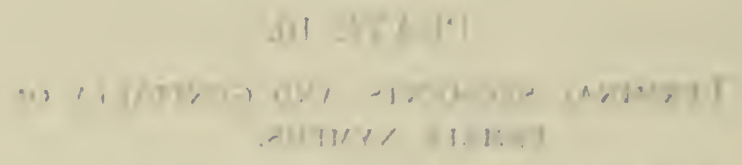

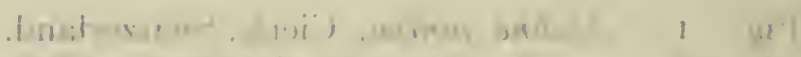

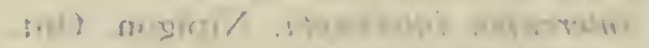

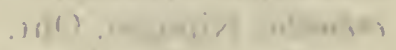

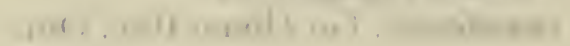



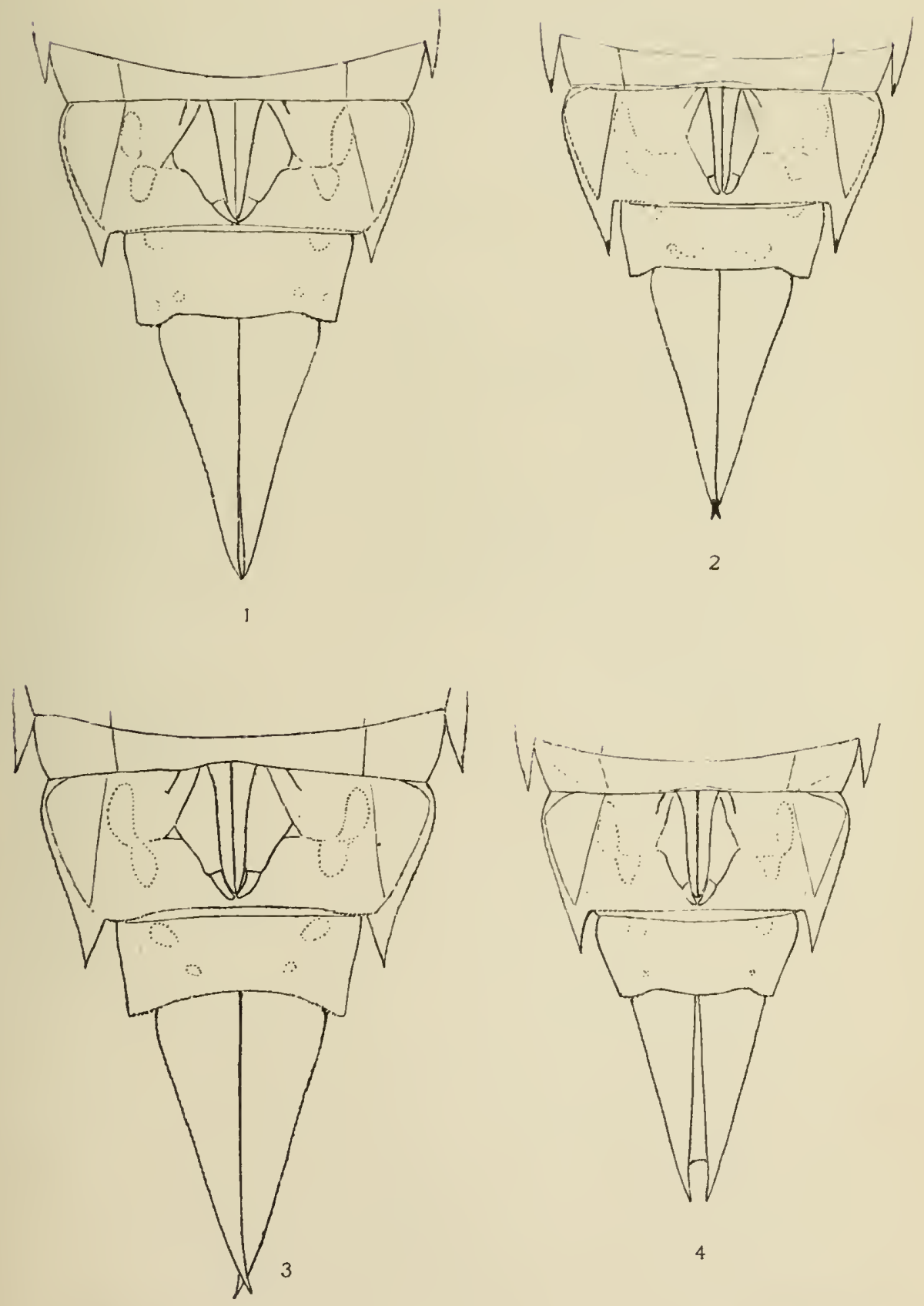



\section{PLATE 11.}

TERMinal SEgments AND genitalia of FEMALE NYMPHS.

Fig. I. Aeshna palmata, Robson, B. C.

2. " umbrosa umbrosa, Toronto, Ont.

3. " "constricta, Lake Simcoe, Ont.

4. " californica, Sunnyside, Wash.

5. " multicolor, Sunnyside, Wash. 
11391.11

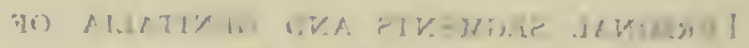

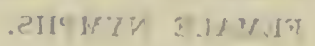

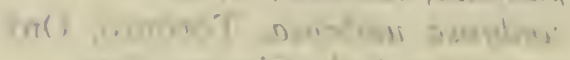

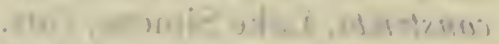

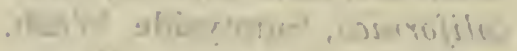

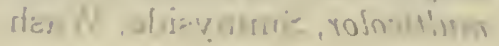

\begin{tabular}{|c|c|}
\hline$n k, g 1$ & \\
\hline & $=$ \\
\hline & $\varepsilon$ \\
\hline ' & $t$ \\
\hline & . ते, \\
\hline
\end{tabular}



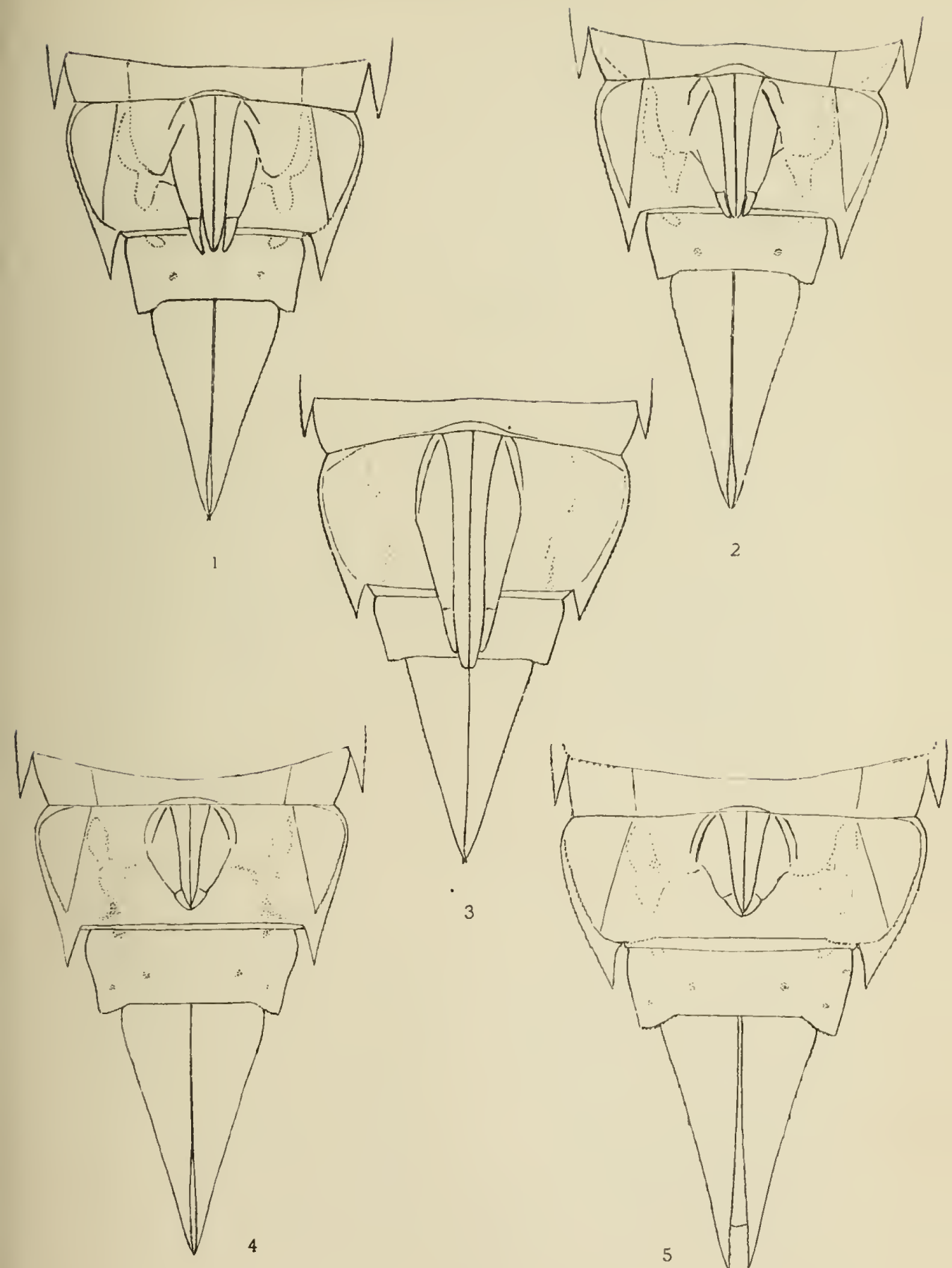



\section{PLATE 12.}

ANTERIOR HAMULI IND ANTERIOR LAMINA.

Fig. I. Cordulegaster dorsalis, anterior hamulus, Departure Bay, Vancouver Is., B.C.

“ 2. Basiaeschna janata, Go Home Bay, Ont.

“ 3. Boyeria vinosa, Algonquin Park, Ont.

" 4. Aeshna caerulea septentrionalis, Labrador.

“5. " " sitchensis, Isle d'Orleans, Quebec.

"6. " " 6 juncea, Bighorn Mountains, Wyo.

"7. " " subarctica, Nipigon, Ont. 


\section{3 ) $1: 11$

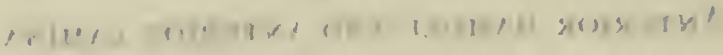

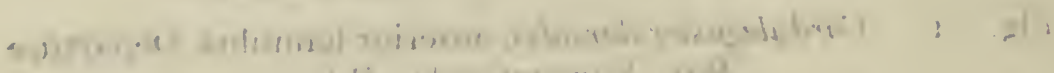

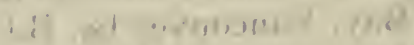

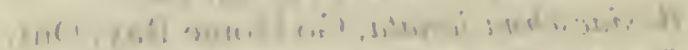

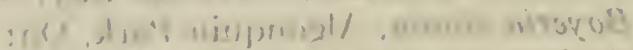

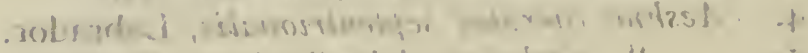

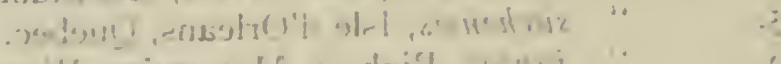

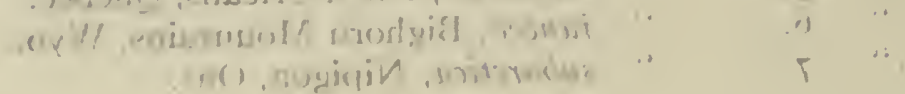




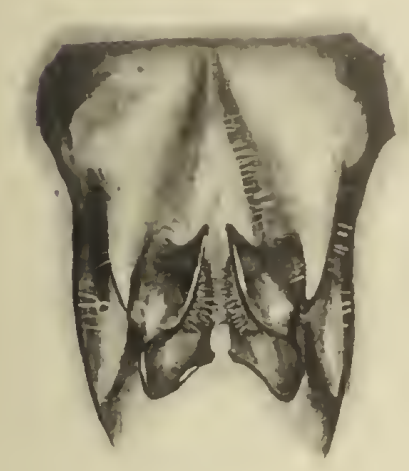

2

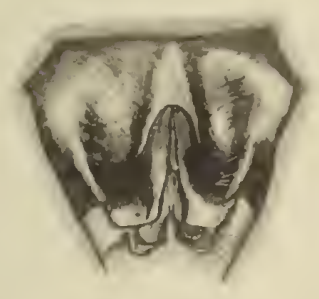

4
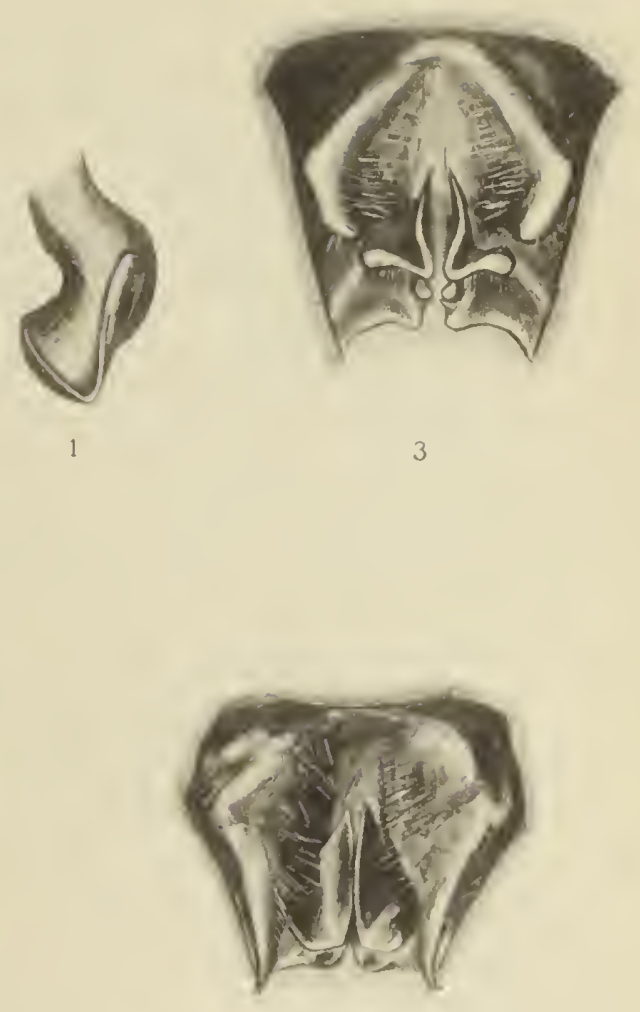

5
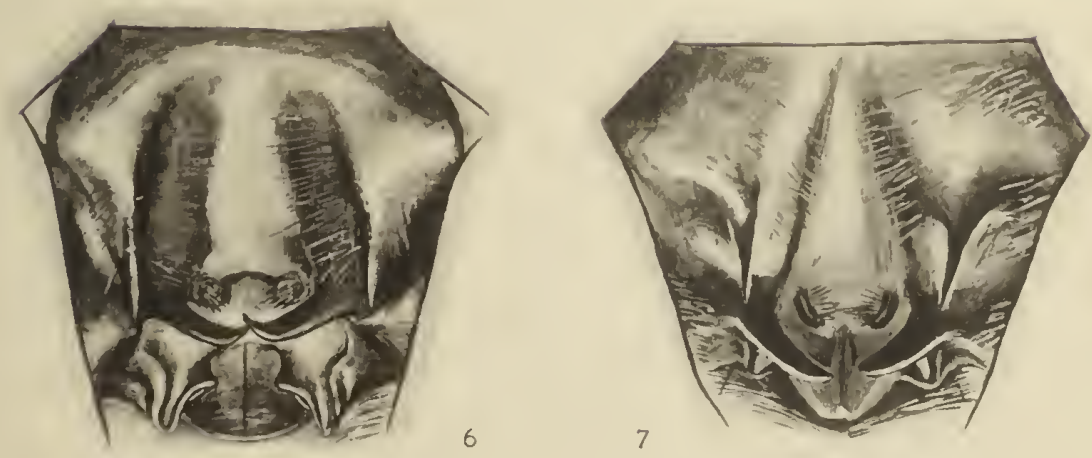

E. M. W., CAM. LUC. ET DEL

HELIOTYPE CO., BOSTUN 

PLATE 13.

ANTYRIOR HAMULI AND ANTERIOR IAMINA.

Fig. I. Aeshnu interrupta interrupta, Heyden, Ont.

“2. " "eremita, Algonquin Park, Ont.

"3. " "clepsydra, Go Home Bay, Ont.

"4. " "canadensis, Lake Simcoe, Ont.

" $5 . \quad$ "verticalis, fort Wayne, Ind.

"6. " " tuberculifera, Provincetown, Mass. 


\section{(ii) $591 / \mathrm{II}$}

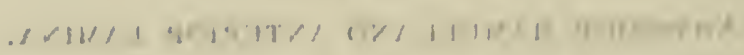

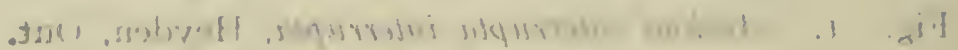

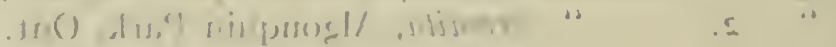

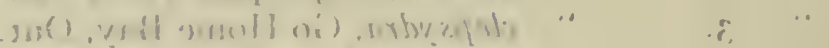

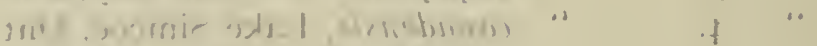

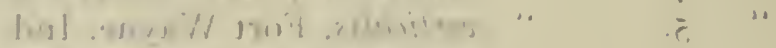

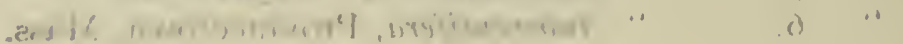



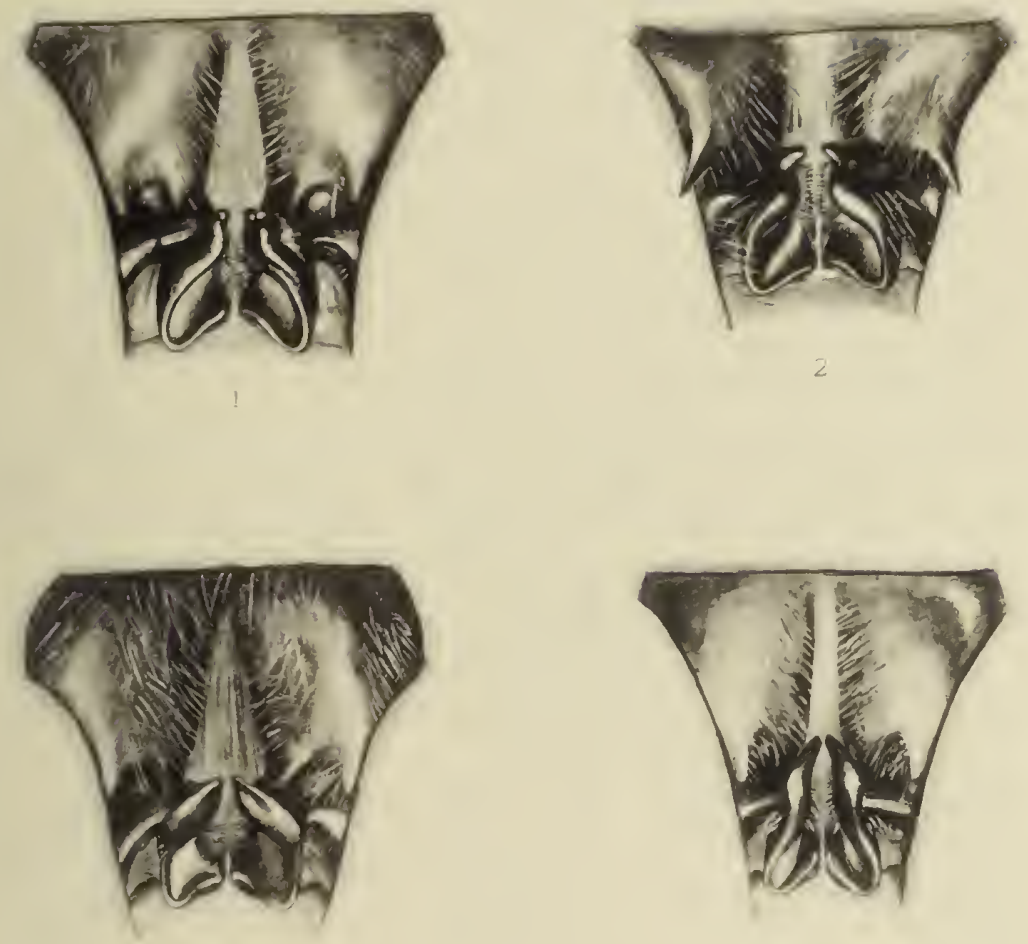

4
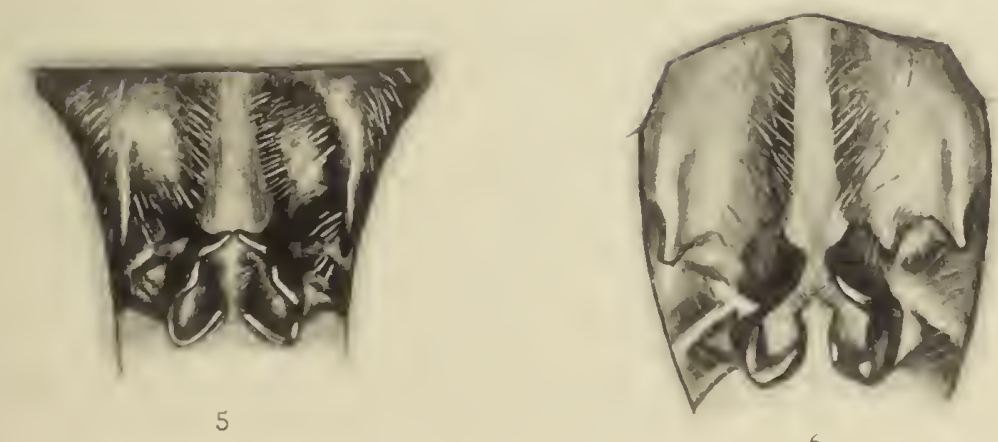

6 



\section{PLATE 14.}

ANTERIOR HAMULI AND ANTERIOR LAMINA.

Fig. I. Aeshna palmata, Kodiak, Alasika.

" 2. " umbrosa umbrosa, Lake Simcoe, Ont.

" 3. " constricta, Lake Simcoe, Ont.

"4. " "californica, Fresno, Cal.

" $5 . \quad$ "multicolor, Sunnyside, Wash.

" $6 . \quad$ " mutata, Fort Wayne, Ind. 


\section{$-1+1+1+1$}

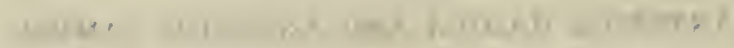

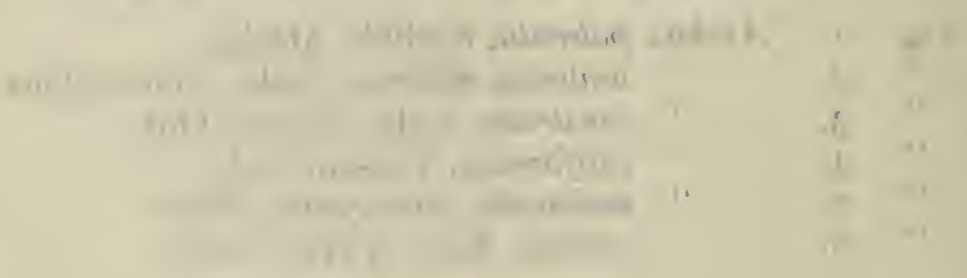




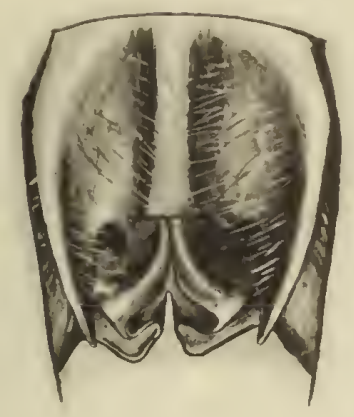

1

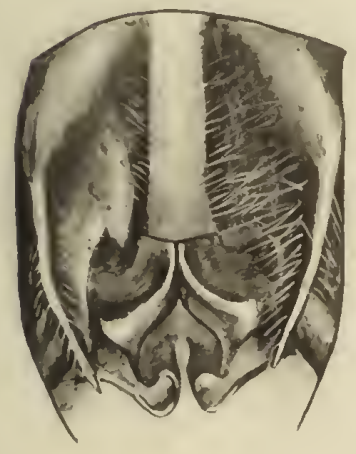

3

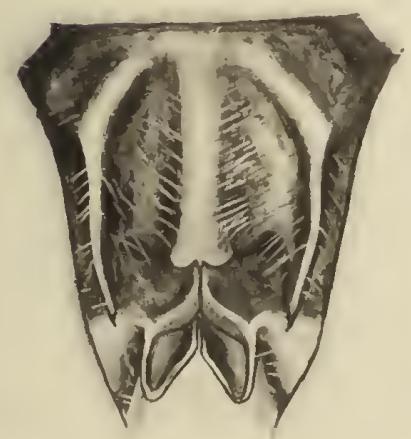

5

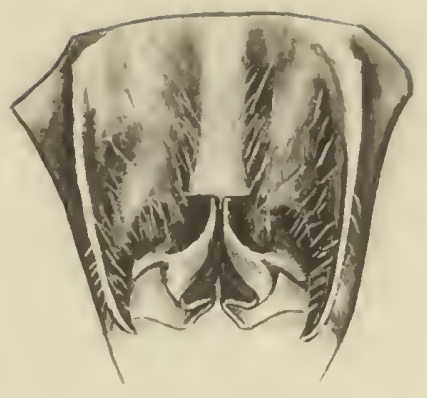

2

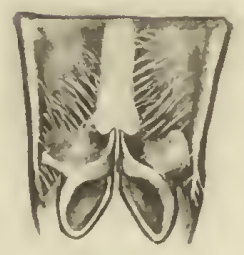

4

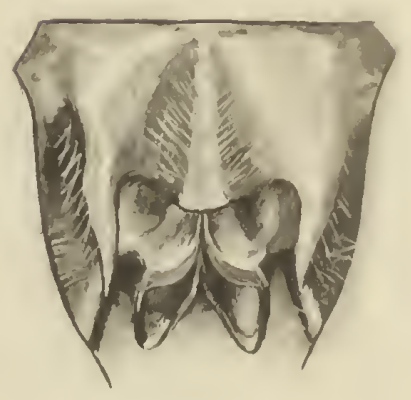

6 

PLATE 15.

Male afadominal appENDages, nORSal and LATERAL VIEWS.

Fig. I. Aeshna caerulea septentrionalis, Labrador.

iIa.

." 2.

"

"

"

"1

" sitchensis, Isle d"(irleans, Que.

2a. " " Westbourne, Man.

“ 3.

" juncea, Kodiak, Alaska.

“ 3a.

“4 4 .

“4a.

“ 5 .

“ 5 a.

“ 6.

"6a.

“ subarctica, Isle Royale, Michigan.

" interripta interrupta, Searchmont, ODt.

" " " Tenagami, Ont.

" " " nevadensis, Reno, Nevada. 


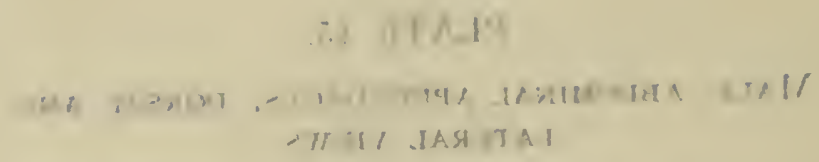




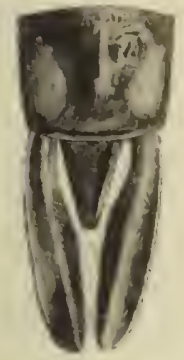

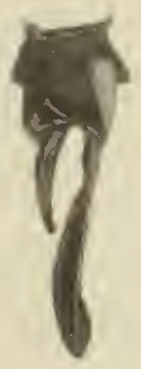

la

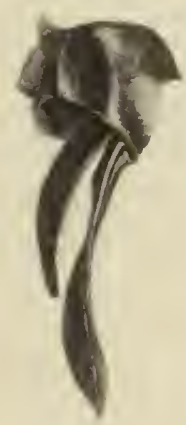

$3 a$

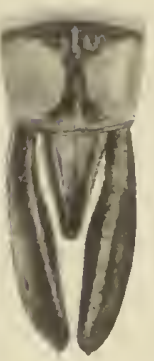

2
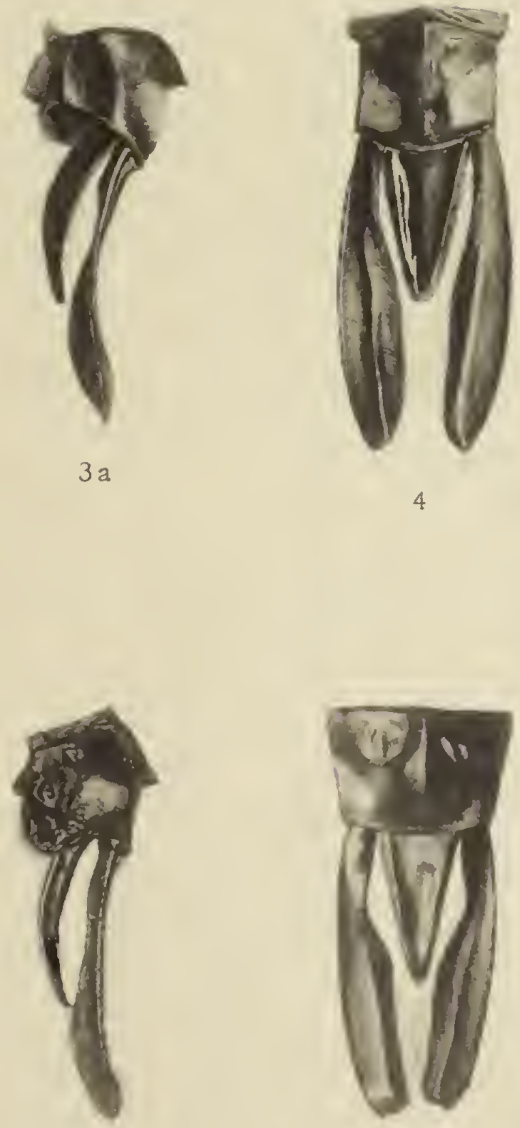

$5 a$

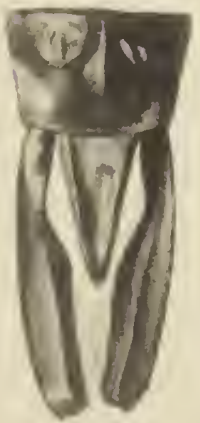

6

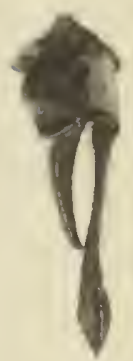

$2 \mathrm{a}$

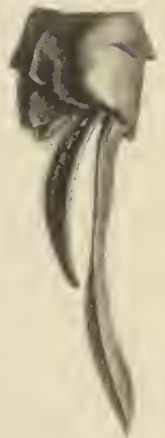

$4 a$

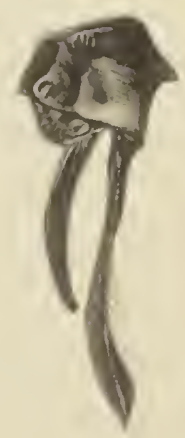

$6 a$

E. M. W. CAM, LUC. ET DEL. 

PLATE 16.

Male abdominal appendages, dorsal and LATERAL VIEWS.

Fig. I. Aeshna interrupta lineata, Regina, Sask.

Ia. " "

2. " " " interna, Beulah, New Mexico.

2a. " " " " " "

"3. " " eremita, Algonquin Park, Ont.

" 3a. " " " Heyden, Ont.

" 4. " "clepsydra, Shriner Lake, Ind.

"4a. " " " Go Home Bay, Ont.

"5. " "canadensis, De Grassi Point, Ont.

" 5 a. " " " Oden, Mich.

"6. " " verticalis, De Grassi Point, Ont.

"6a. " " " Fort Wayne, Ind. 


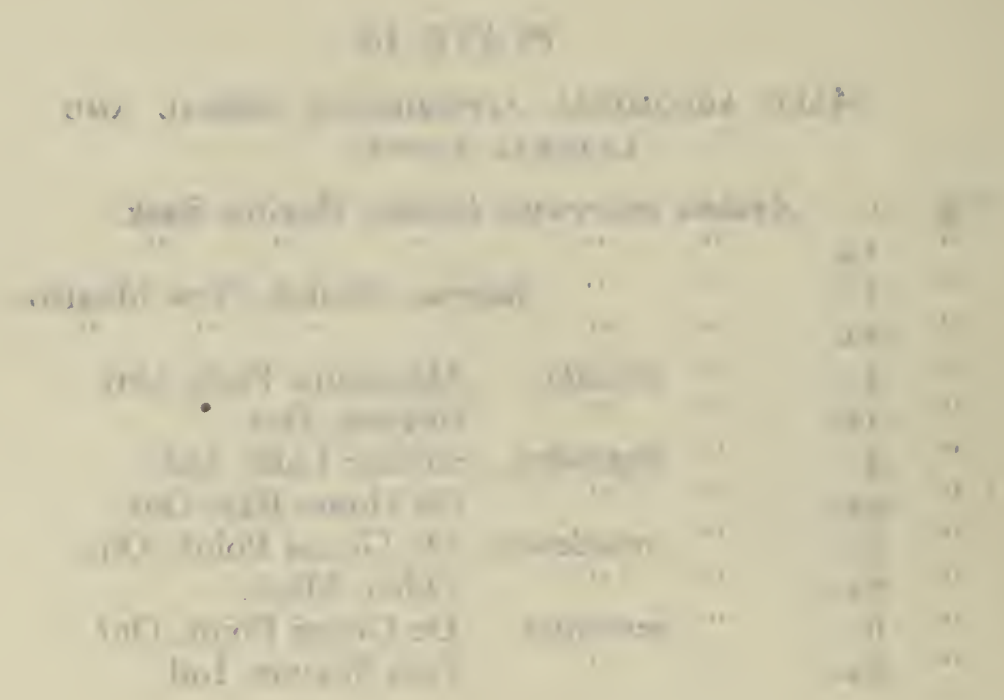




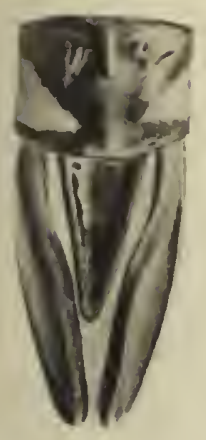

1

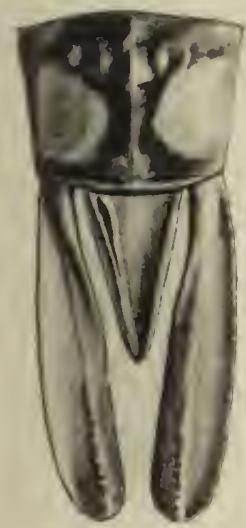

3

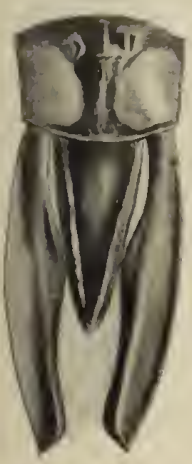

5

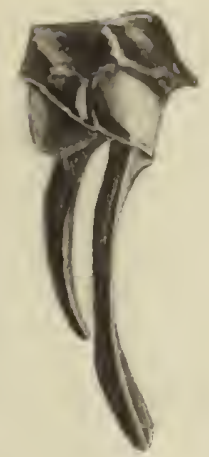

1 a

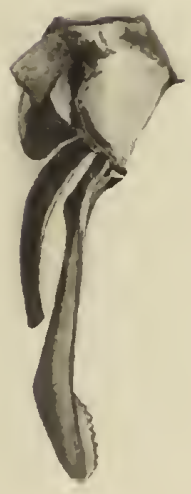

$3 a$

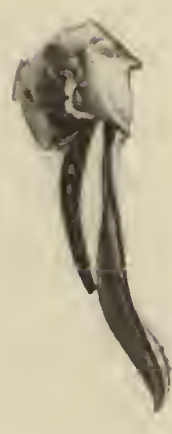

5 a

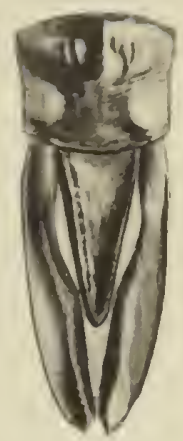

2

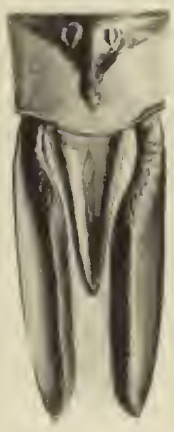

4

$4 a$
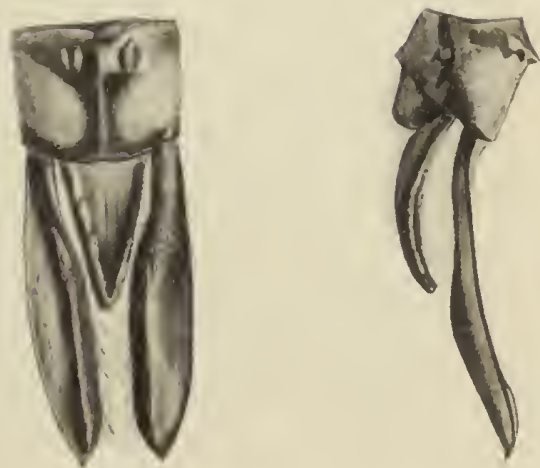

$6 a$ 



\section{PLATE 17.}

Male ABDOMINAL APPENDAgES.

Fig. I. Aeshna tuberculifera, Isleboro, Maine, dorsal view. "ra. " " " " lateral view.

"2. " umbrosa umbrosa Algonquin Park, Ont.,

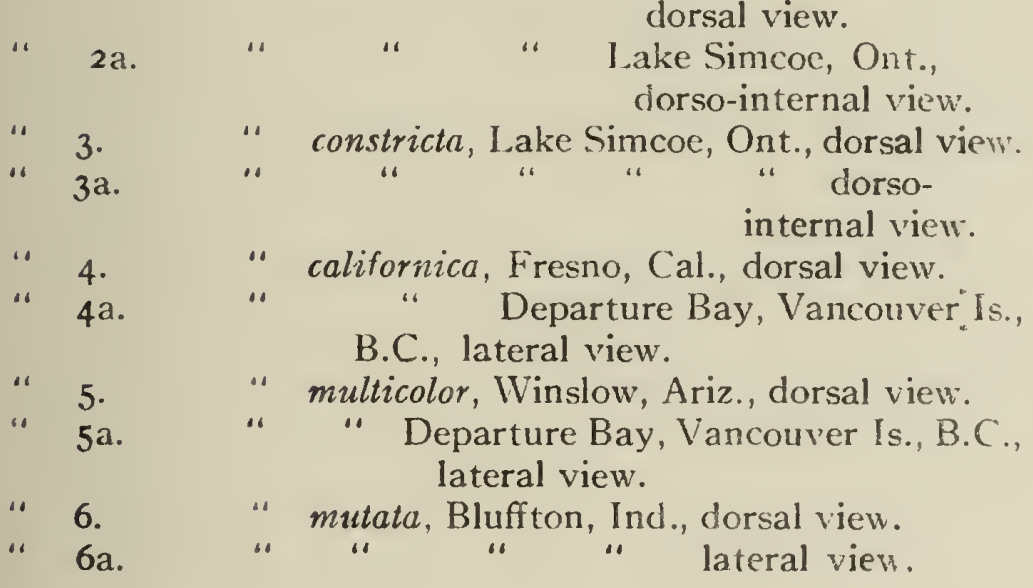




\section{הr IN/ 17}

\section{- - I0)}

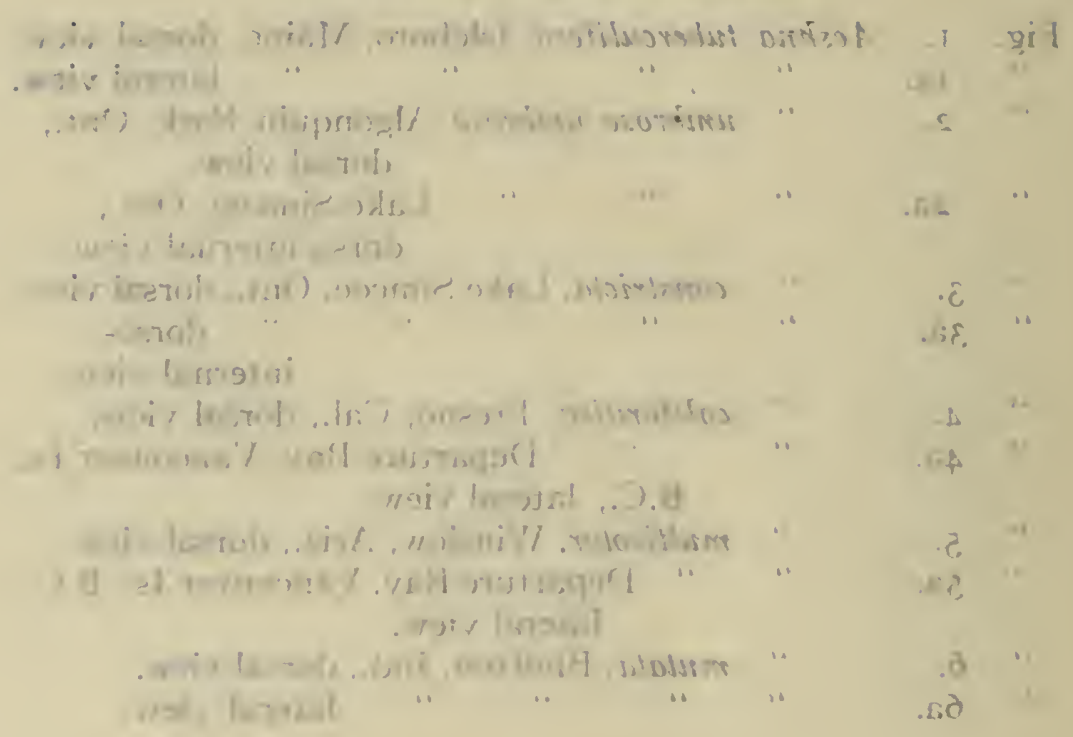




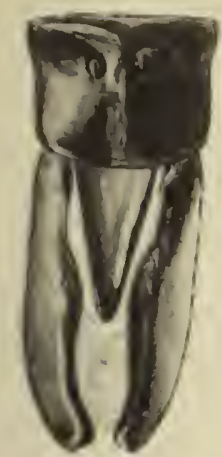

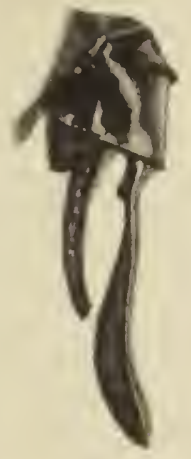

I a
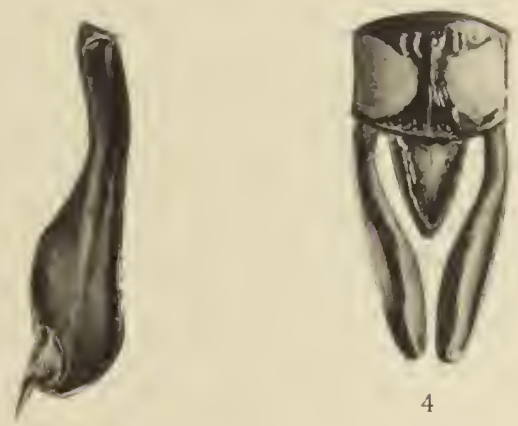

4

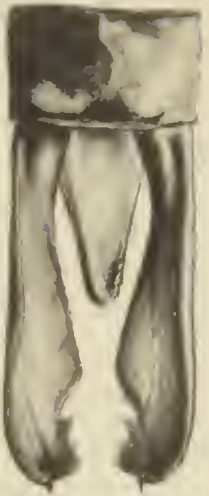

2

3 a

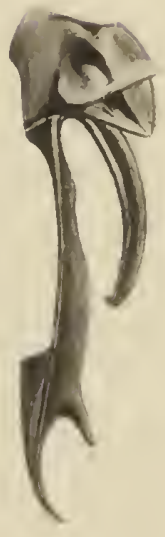

5 a

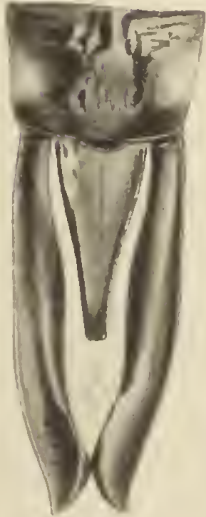

6
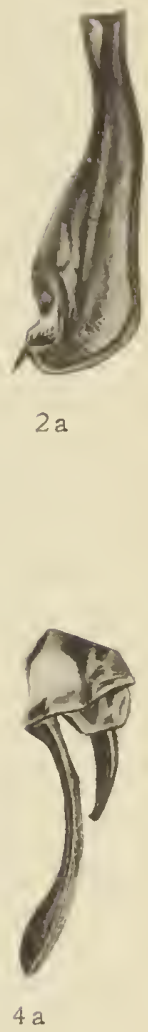

$2 a$

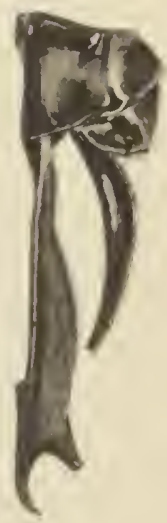

$6 a$

E. M. W., CAM. LUC. ET DEL 

PLATE 18.

Female genitalia AND APPENidages, ventral: AND LATERAL VIEWS.

Fig. I. Aeshna caerulea septentrionalis, Bay of Islands, Nid.

Ia.

“ 2.

“ $2 \mathrm{a}$.

“ 3 .

" 3 a.

“ 4 .

"4a.

" sitchensis, Bay of Islands, Nfd.

“ juncea, Banff, Alberta.

“ subarctica, Nipigon, Ont. 


$$
\text { 1) II/ II }
$$

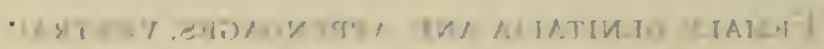

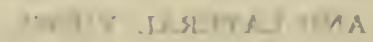

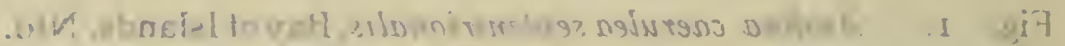

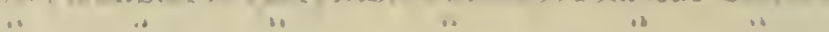

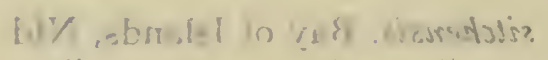
: 1

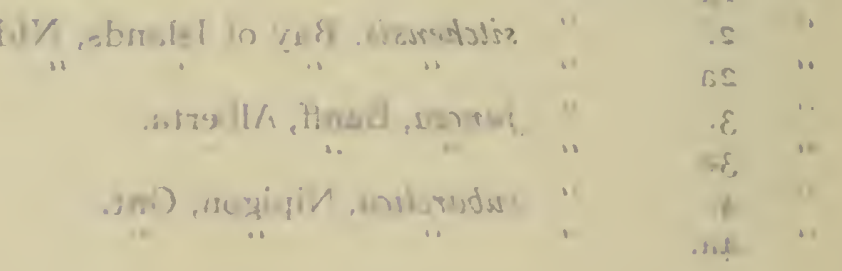



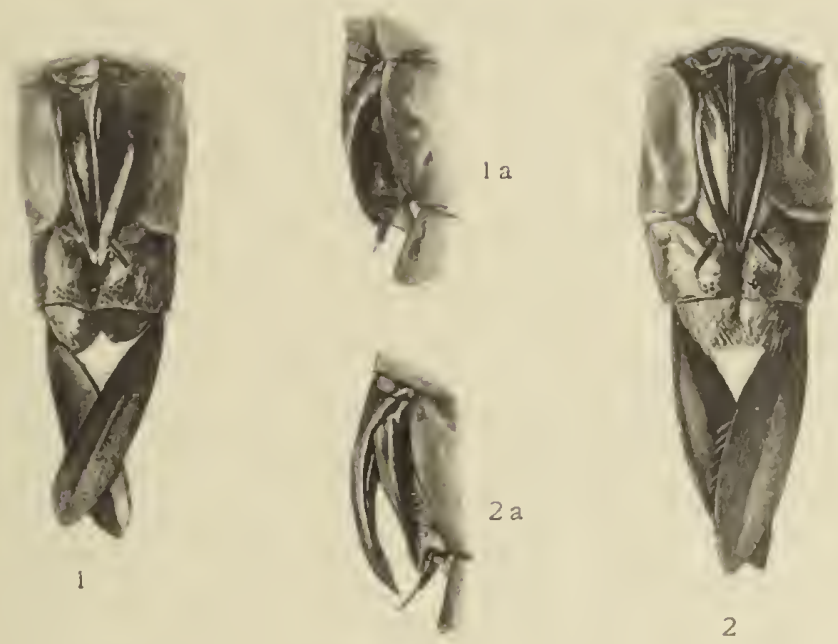

2

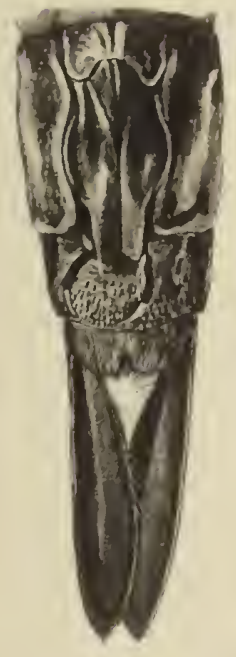

3

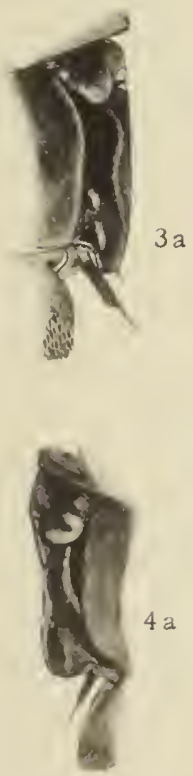

E. M. W., CAM. LUC. ET OEL.

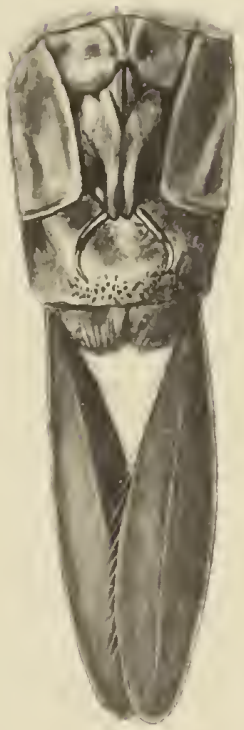





\section{PLATE 19.}

Female Genitalia and appendages, ventral AND LATERAL VIEWS.

Fig. x. Aeshna eremita, Heyden, Ont.
" 2 .
“ clepsydra, Lake Simcoe, Ont.
“2a.
" "
" canadensis, Temagami, Ont.
(1) 3 . 3 .

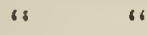
"verticalis, Toronto, Ont.
“ 4 . $4 a$.
"
" 6 


\section{(:) 1!! 141}

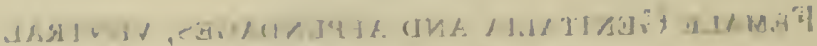

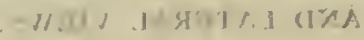

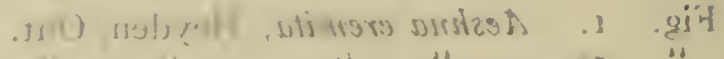

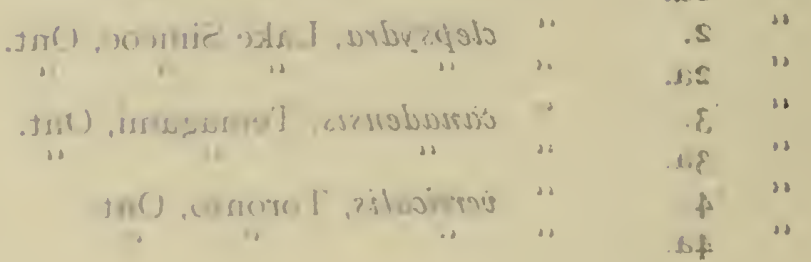



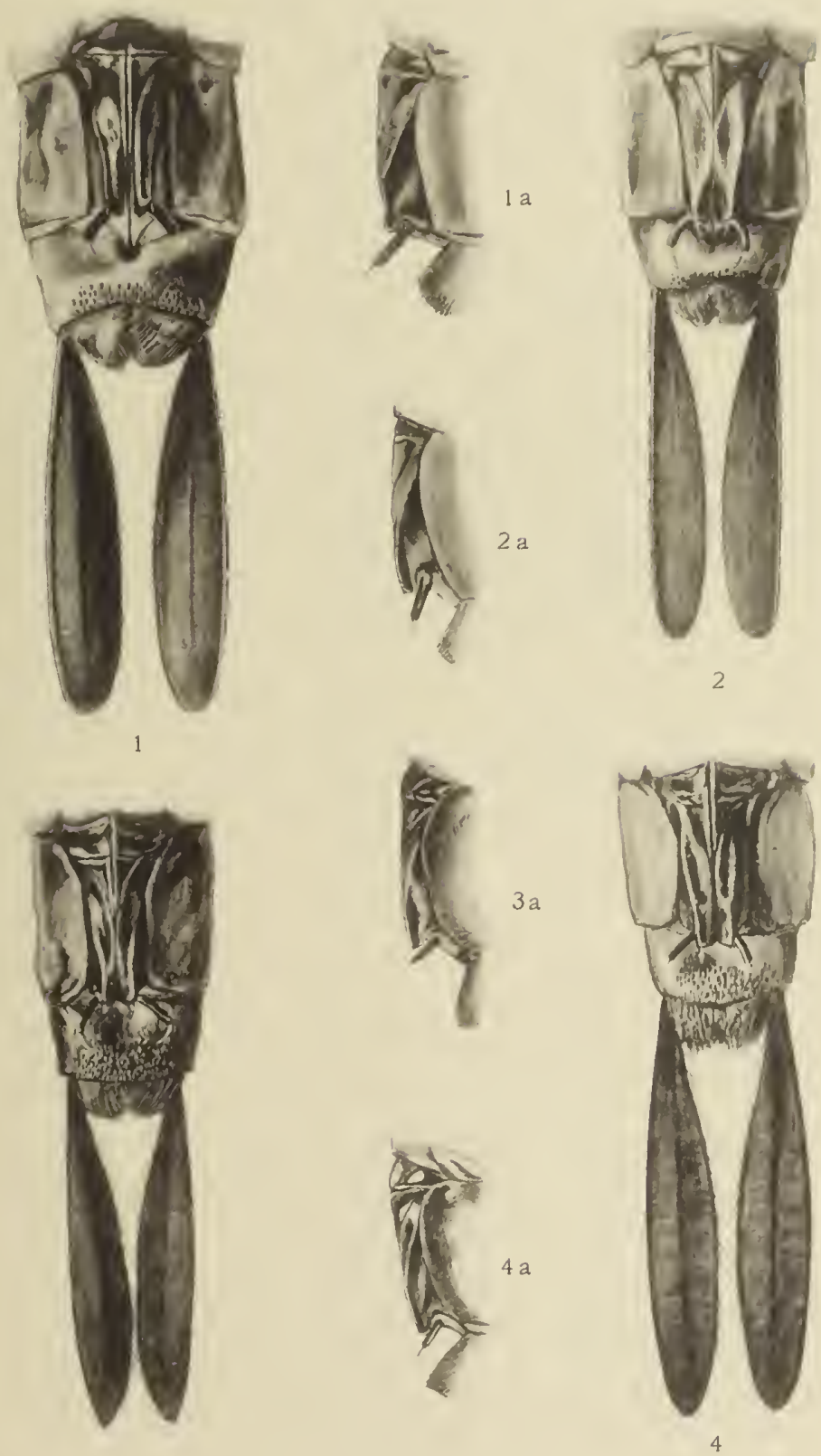

3

E. M. W. CAM, LUC, ET DEL. 

PLATE 20.

Female (ienttalia and appendages, ventralo AND LATERAL VIEWS.

Fig. I. A eshna interrupta interrupta, Algonquin Park, Ont’
"Ia

" 2.

2.

$2 a$.

“" tuberculifera, Manchester, Me.

“ 3.

“ $3 \mathrm{a}$.

" 4 .

“ ta.

" umbrosa, Lake Simcoe, Ont.

" " " "

"palmata, Kodiak, Alaska.

Twin Lakes, Col. 


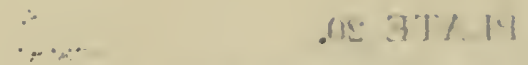

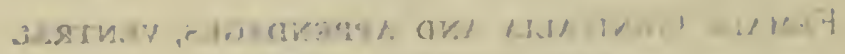

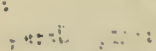

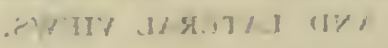

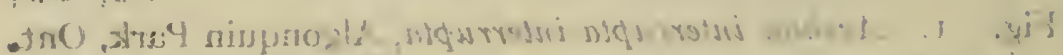

tano, imbxems l

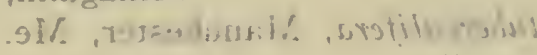

,

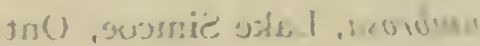

$\therefore$ a A

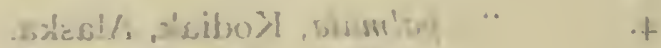

(a), es: 

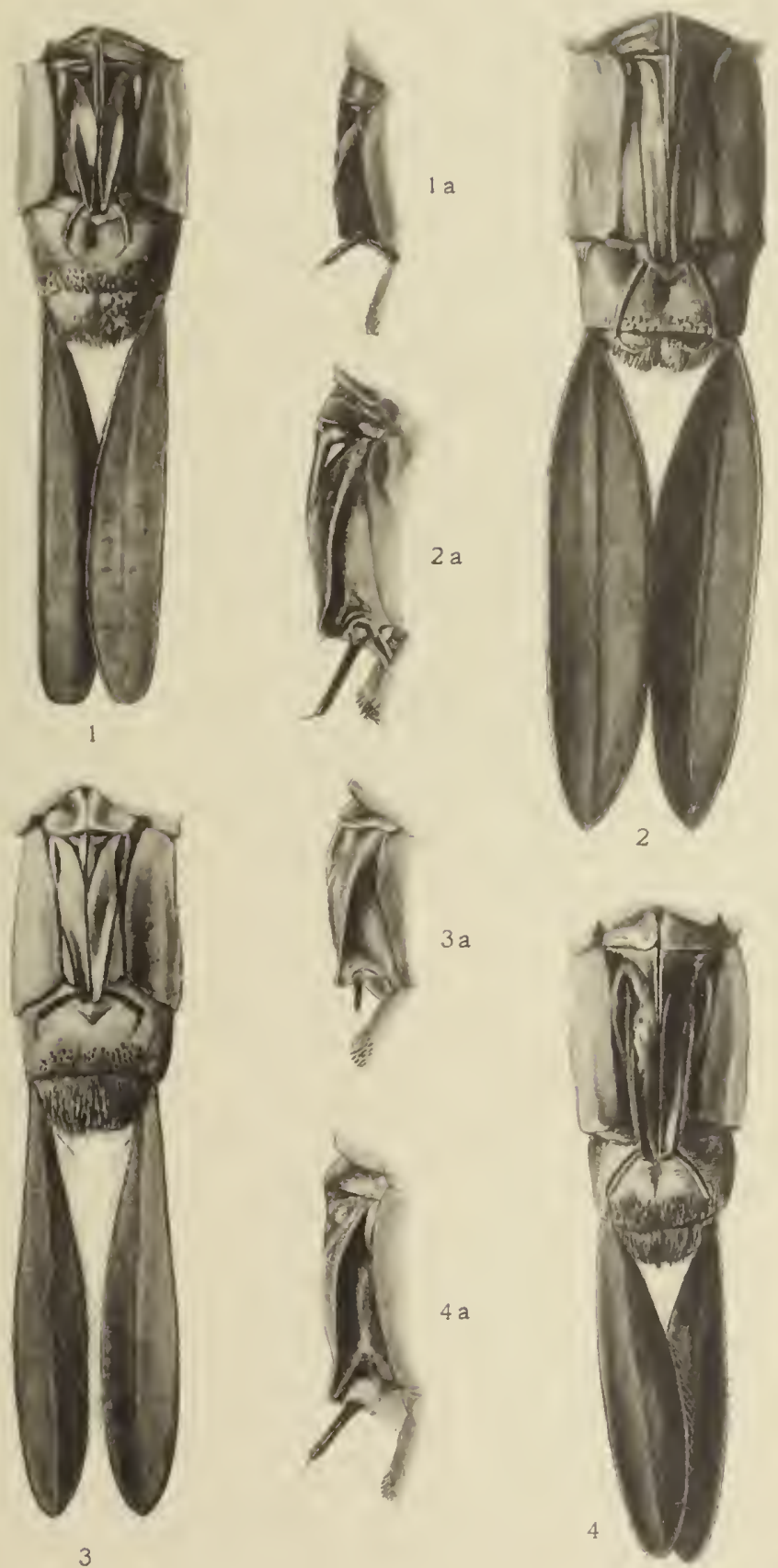

E. M. W., CAM, LUC. ET DEL.

HELIOTYPE CO BOSTON 



\section{PLATE 21.}

Female Genitalia AND APPENDAGes, Ventral

AND LATERAL VIEWS.

Fig. I. Aeshna constricta, Lake Simcoe, Ontario.

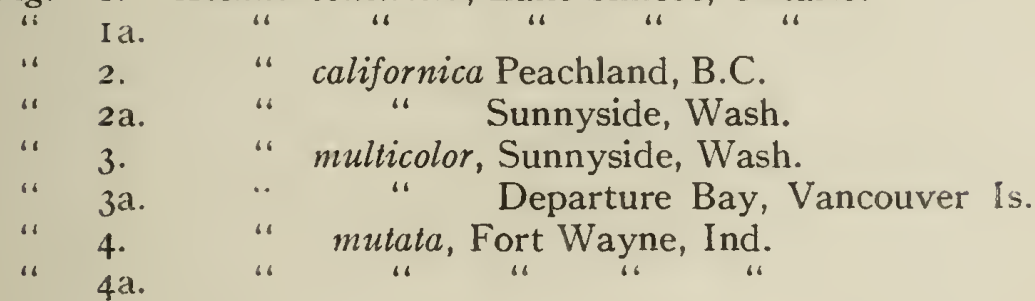




\section{IL ITt.J'}

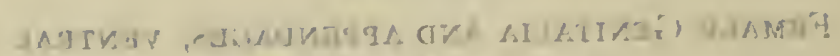

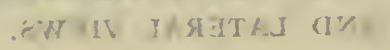

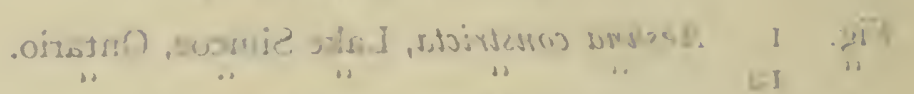

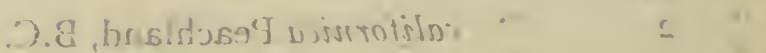

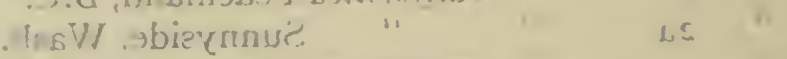

.

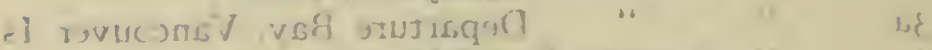

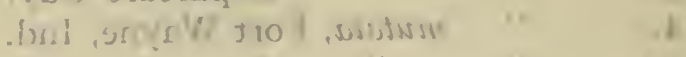



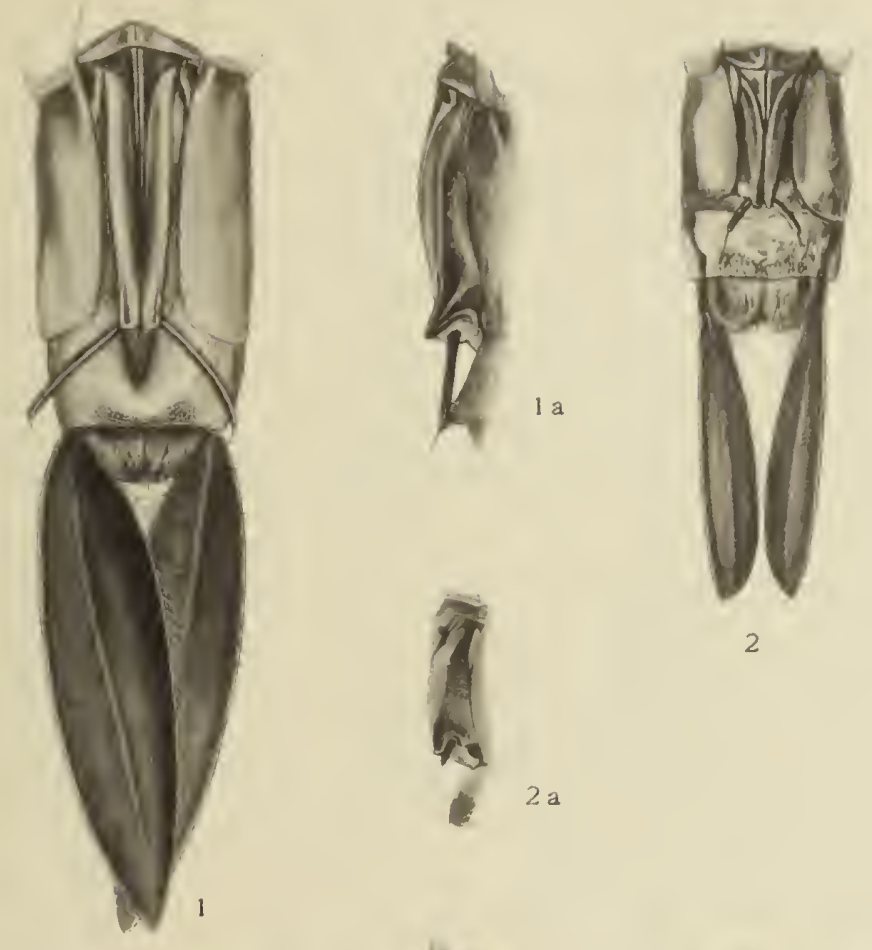

2
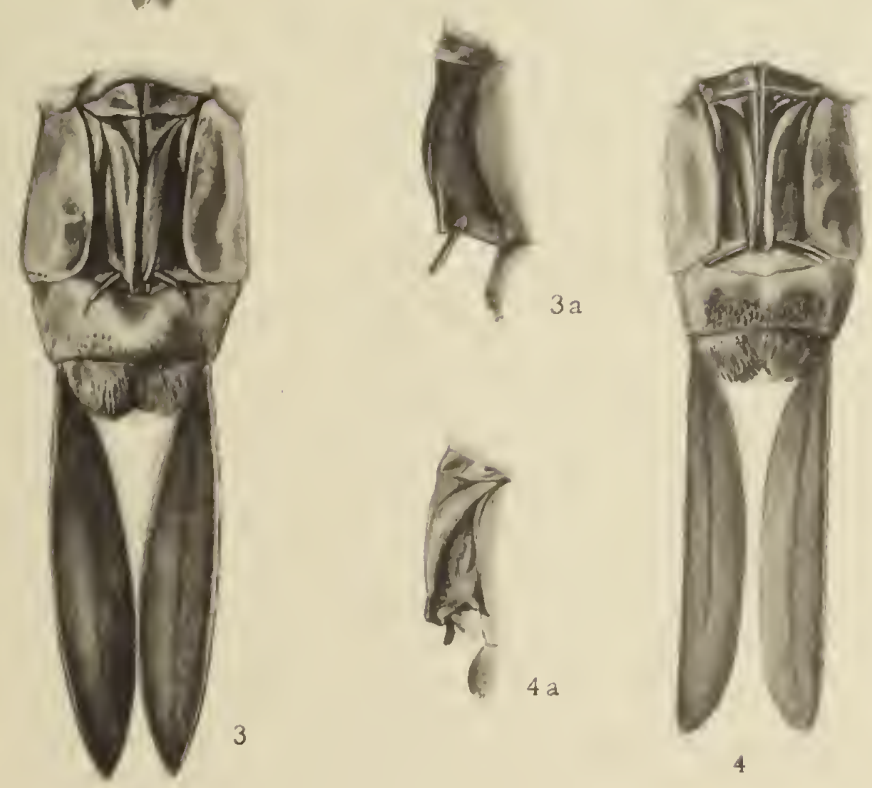

E. M. W., CAM. LUC, ET DEL.

HEIIOTYPE CO. BOSTON 

PLATE 22.

Fig. 1. Aeshna caerulea septentrionalis $\sigma^{7}$, Labrador. ?, Bay of Islands, Nfd. ( $\times$ I.5.) $\sigma^{7}$, dorsal view of head.

4. " sitchensis $\sigma^{\circ}$, dorsal view of head.

5. " " mutata . , Fort Wayne, Indiana. ( $\times$ 1.5.)

$6,7 . \quad$ " interrupta interrupta $\%$, Bay of Islands, Nfd.
8.
“ 1
" $\&$ Magdalen Islands, Que.
9.
" "nevadensis o", Reno, Nevada.
10.
“ interna o", City Creek Cañon, Utah.
I1.
ㅇ, Lambs' Cañon, Wasatch Mountains, Utah. 


\section{A. IYA.14}

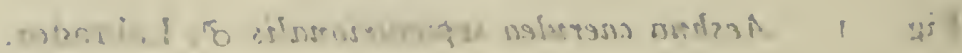
$(. ? 8 \div)$

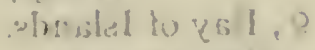

$(3 i, 1,1,191$

1. vortu Leatris , "s

he dit

biall las saje line, is cisostalse

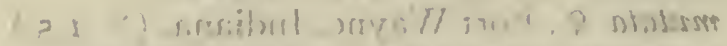

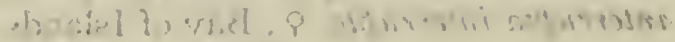
$.11 \%$

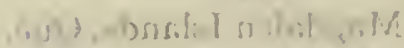

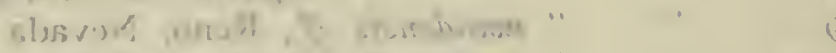

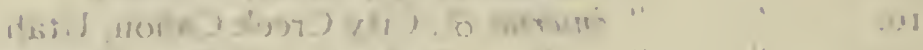

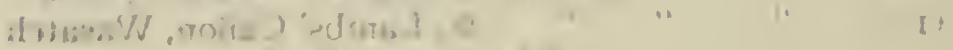

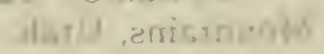



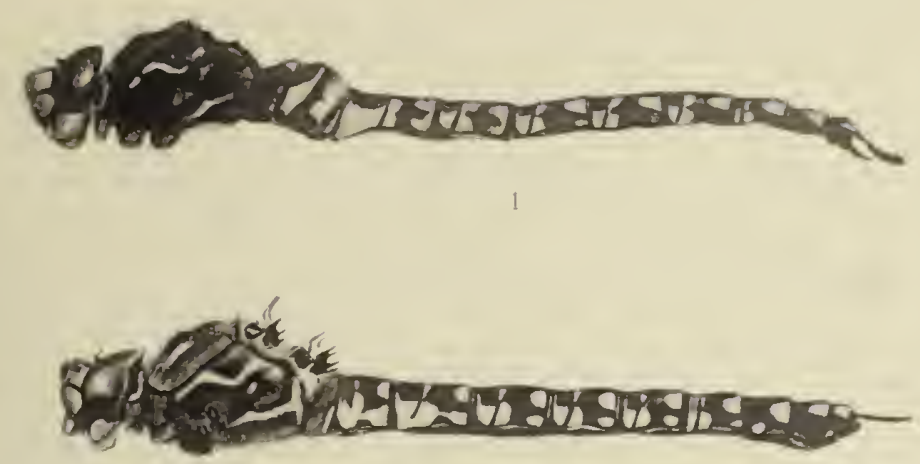

2

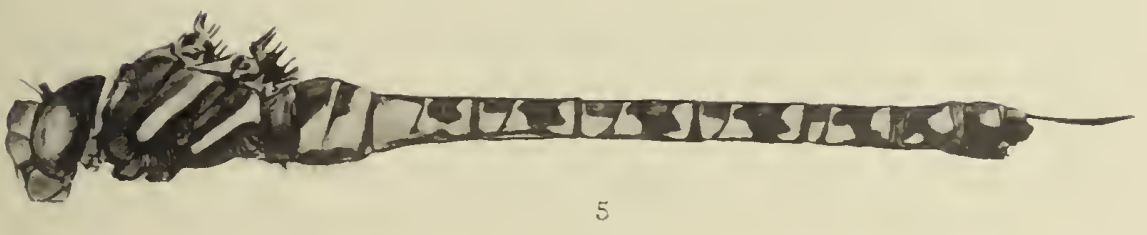

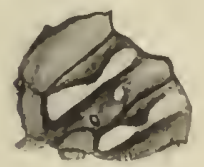

6

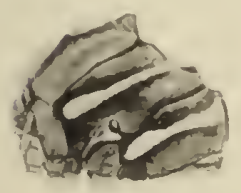

9

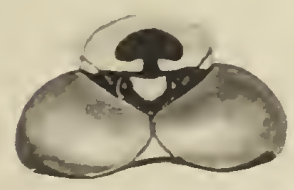

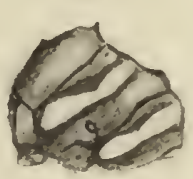

7

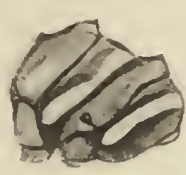

10

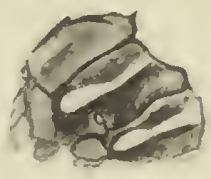

8

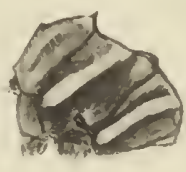

11

3

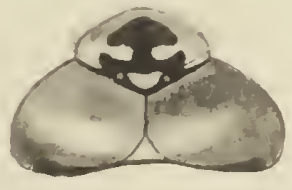

E. พ. w. 2 ! 



\section{PLATE $23 .{ }^{1}$}

Fig. 1. Aeshna sitchensis o", Westbourne, Man. (Dried.)
2.
ㅇ , Isle Royale, Mich. (Dried.)
3. "juncea $\sigma^{\pi}$, Nipigon, Ont. (Fresh.)
" 9 ,
, " "Alcoholic.)
4.
5.
" subarctica
6.
" $\%$,
(Fresh.)

1 The figures on this and the following plates are all enlarged one-half. 


\section{$12.1 / 01$}

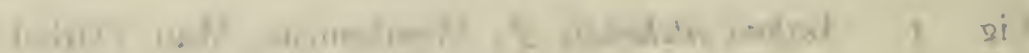

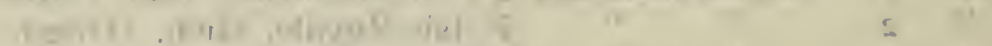

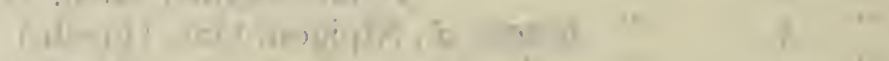

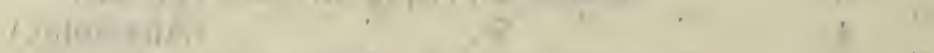

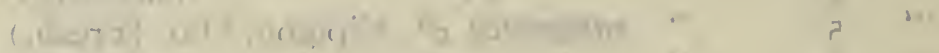

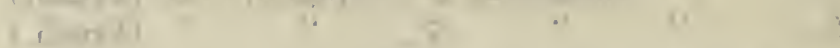

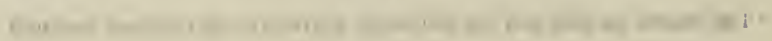



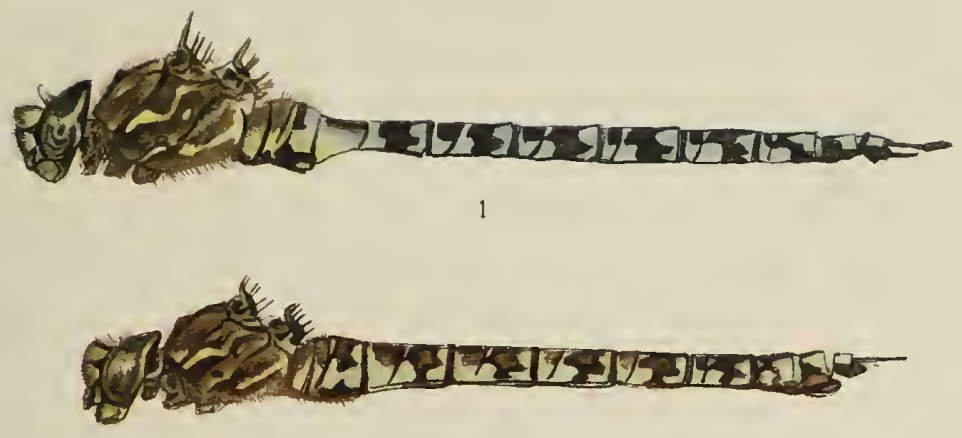

2

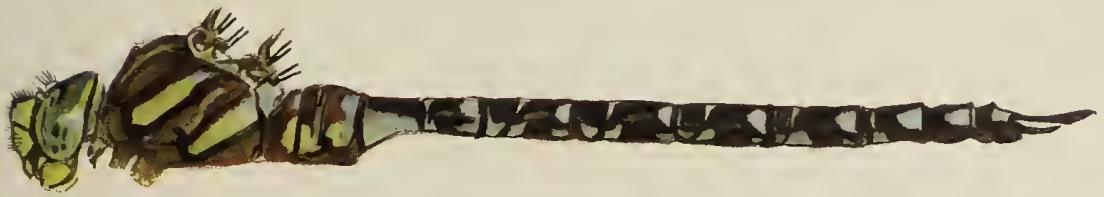

3

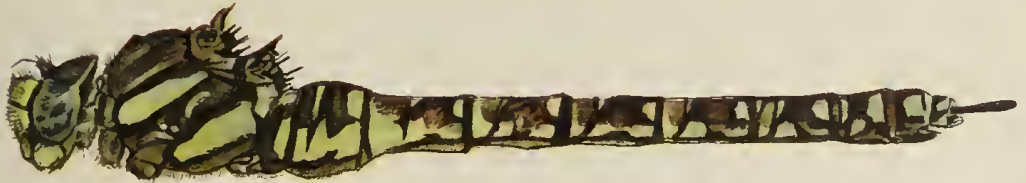

4

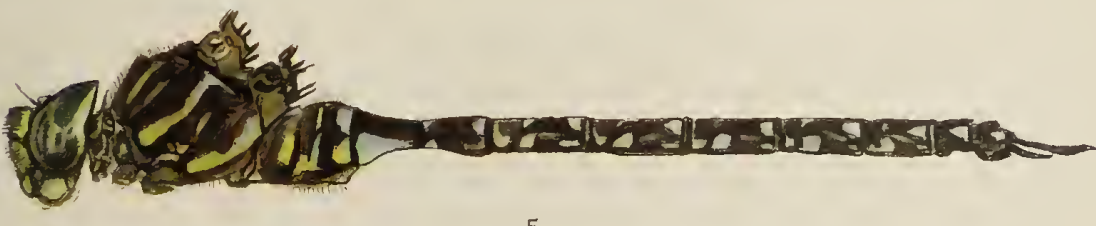

5

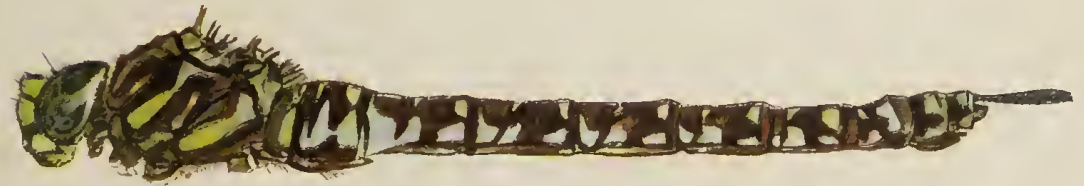

6 

PIATE 24.

Fig. 1. Aeshna eremita o", Go Home Bay, Ont. (Fresh.)

"2. “ " " " Nipigon, Ont. (Fresh.)

"3. " interrupta interrupta $\sigma^{\star}$, Nipigon, Ont.

(Fresh.)

"4 4 .

" $\quad$, Nipigon, Ont.

(Fresh.)

" 5 . " "

lineata $\sigma^{7}$, Waterton Lake, Alta.

(Dried.)

" 6

6. " "

“ क , Regina, Sask. (Alcoholic.) 


$$
\text { is ati.14 }
$$

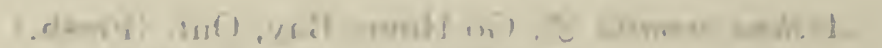

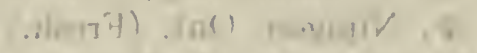

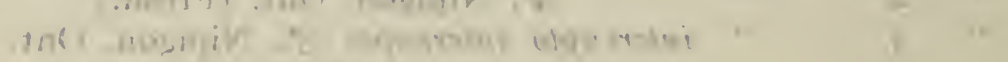
thenting

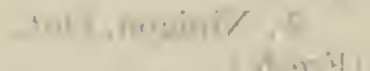

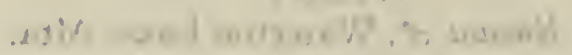

$$
\text { limitil }
$$

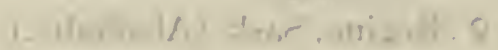

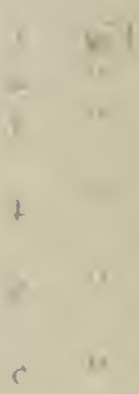




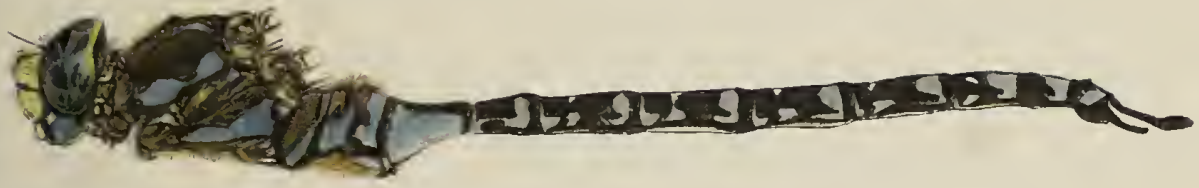

1

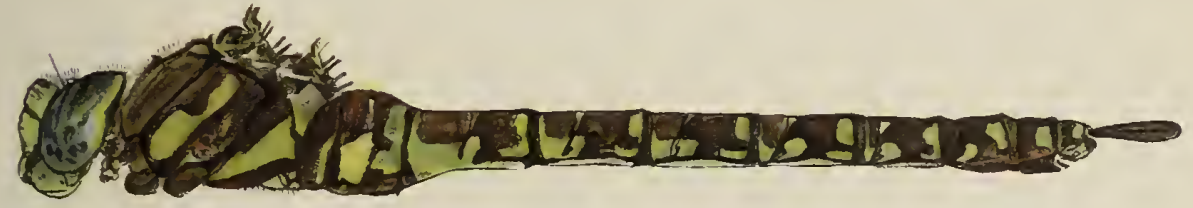

2

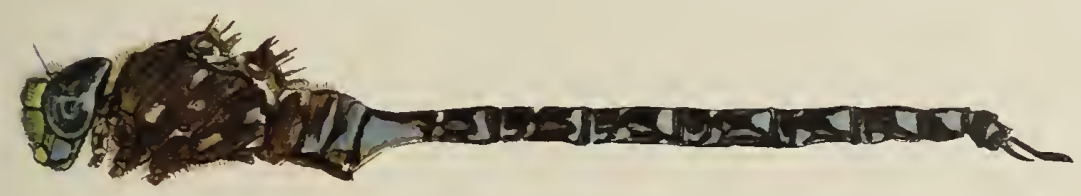

3

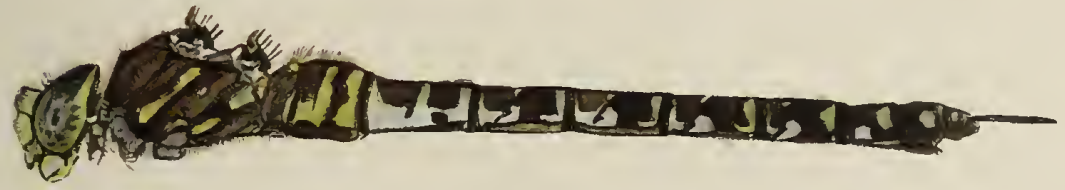

4

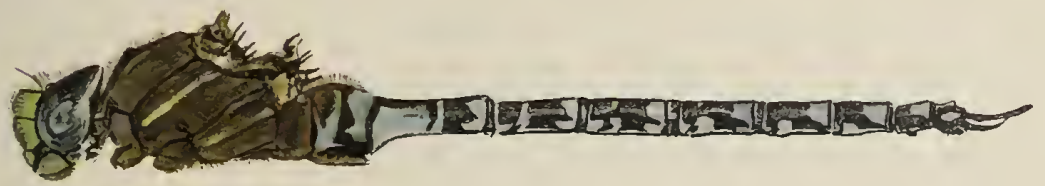

5

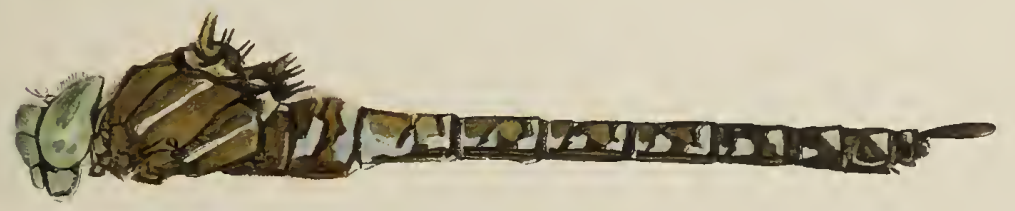

6

E. M. W. DEL. 



\section{PLATE 25.}

Figs. 1. Aeshna clepsydra $\sigma^{\prime}$, Go Home Bay, Ont. (Fresh.) 2. " " 3. "canadensis o", Go Home Bay, Ont. (Fresh.)

4. " "

5 .

“verticalis $0^{7}$, Toronto, Ont. (Fresh.)

6.

" $\quad$. De Grassi Point, Ont. (Fresh.) 


\section{$\therefore \rightarrow 17$ in}

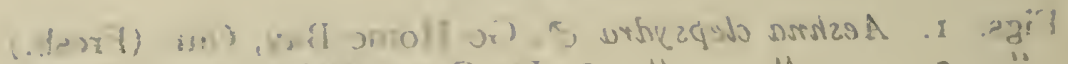

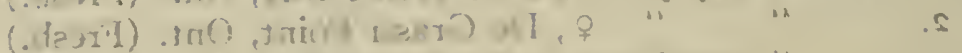

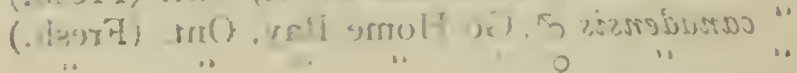

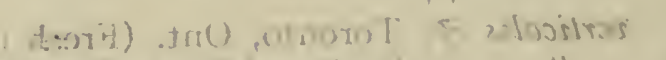

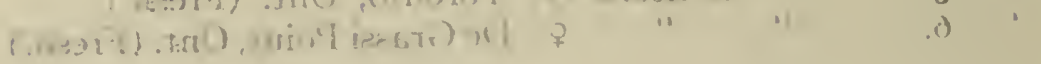




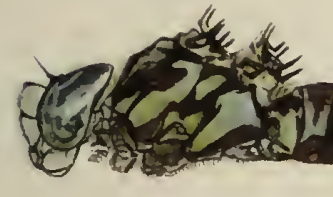

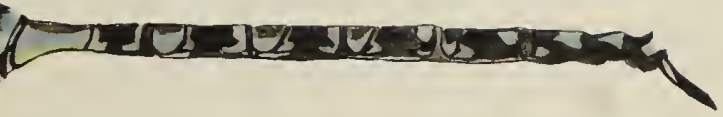

1

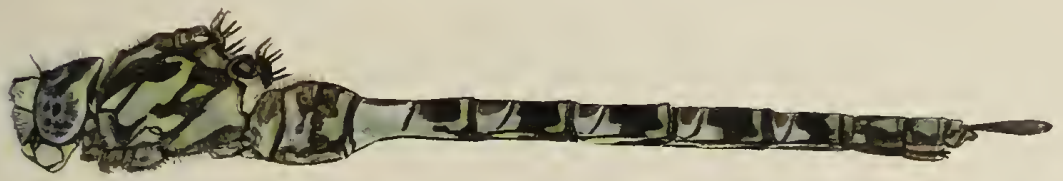

2

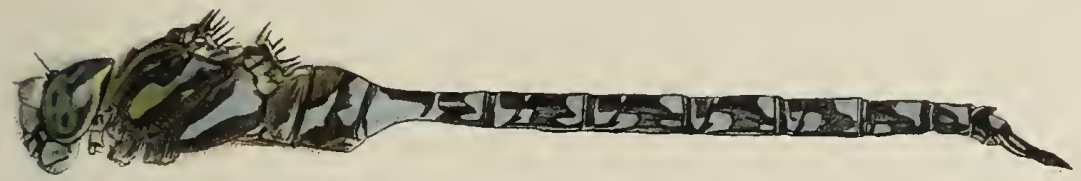

3

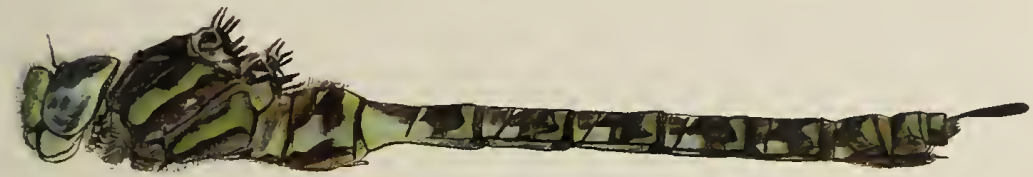

4
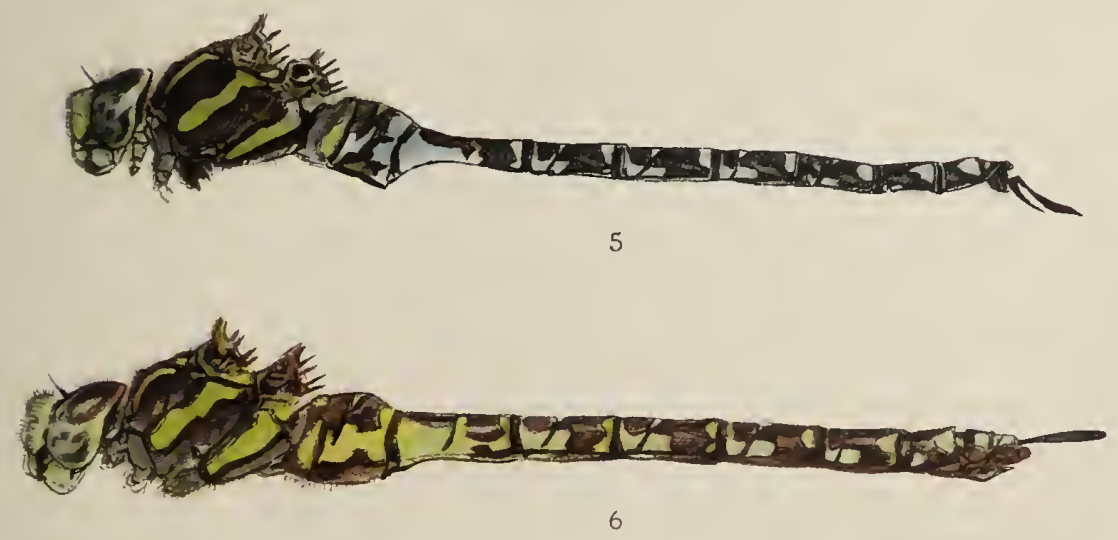

PLATE 26.

Figs. 1. Aeshno tuberculifera $\sigma^{7}$, Cro Home Bay, Ont. (Alcoholic.)
" 2.
“ $\quad$, Etobicoke Creek, Ont.
(Alcoholic.)
"3. "palmata $\sigma^{7}$, Departure Bay, Vancouver ls.
B.C. (Alcoholic.)
․ Twin Lakes, Col. (Dricd.)
"6. 6 .
" umbrosa umbrosa o".




\section{$+1\}, \cdots$}

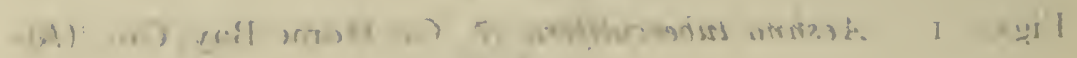
iil ns.

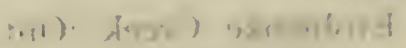

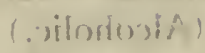

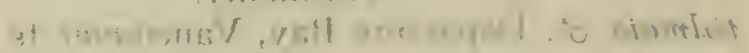

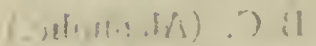

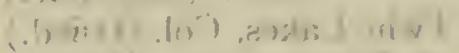

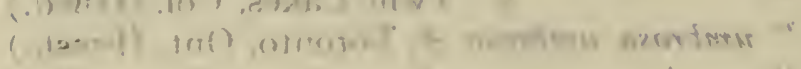




PLATE 27.

Fig. 1. Aeshna umbrosa occidentalis $\sigma^{7}$, New Bridge, Or. (Dried.)
" 2.
" constricta $\sigma^{x}$, De Grassi Point, Ont. (Fresh.)
3 .
“
ㅇ (homœochromatic), De Grassi
Point, Ont. (Fresh.)
4 .
“ $\quad$ (heterochromatic), De Grassi
Point, Ont. (Fresh.) 


$$
\text { .- } 9010
$$

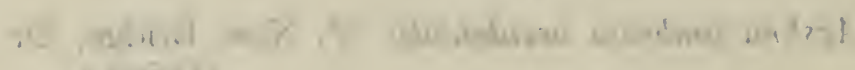

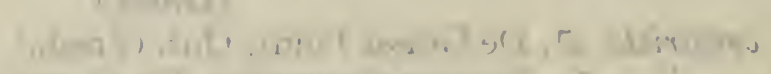
com

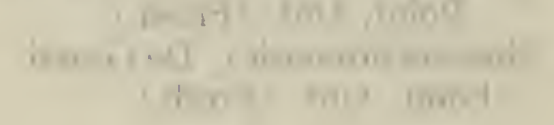



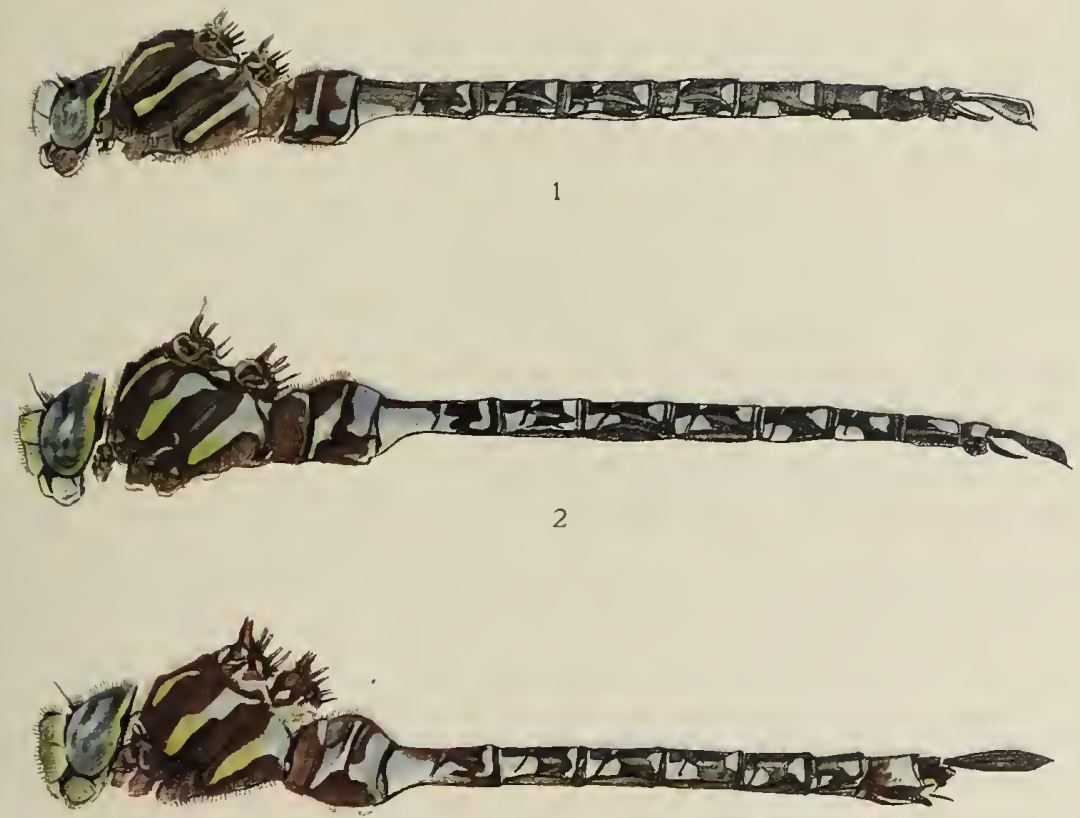

3

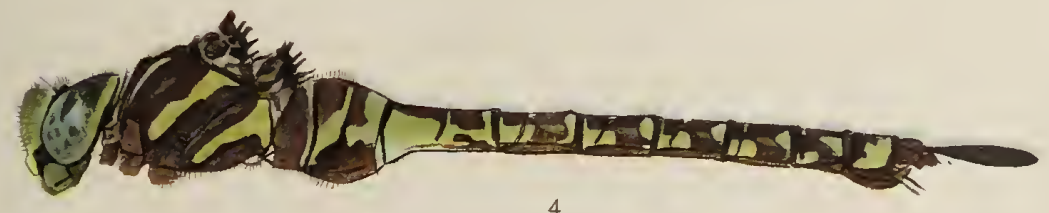

4 



\section{PLATE 28.}

Figs. 1. Aeshna californica ơ , Departure Bay, Vancouver Is. (Alcoholic.)

" 2. $\quad$ " $\quad$ \%, Departure Bay, Vancouver Is. (Alcoholic.)

" 3. " mutata ơ, Bluffton, Ind. (Dried.)

" 4. "multicolor o", Departure Bay, Vancouver Is. (Alcoholic.)

5. ․ Departure Bay, Vancouver Is. (Alcoholic.) 


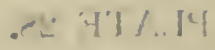

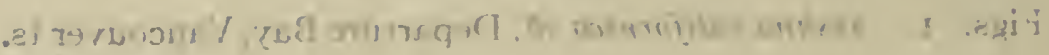
(.rilolos)

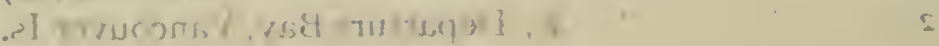
( ilatos!l

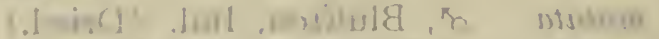

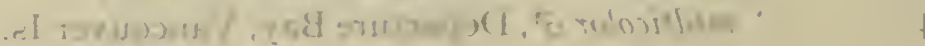

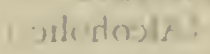

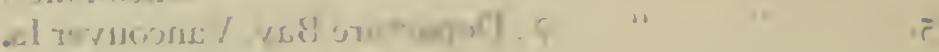
(. Dilontonl/ ) 

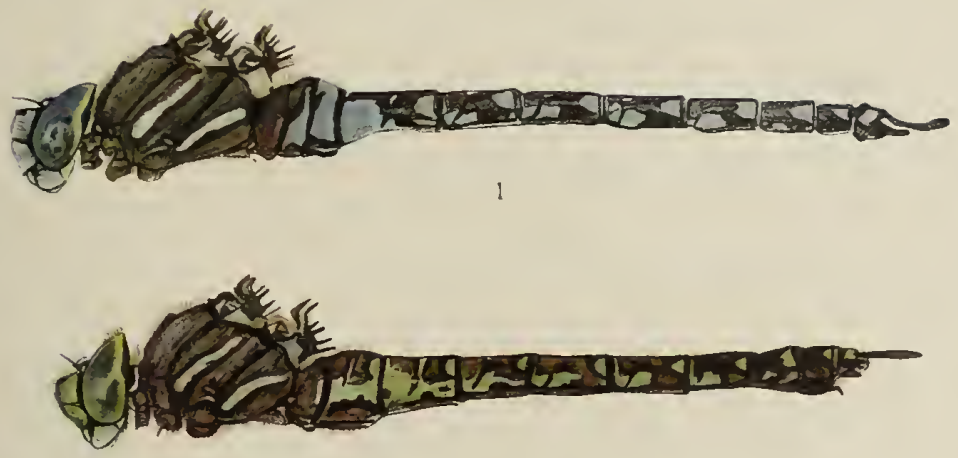

2
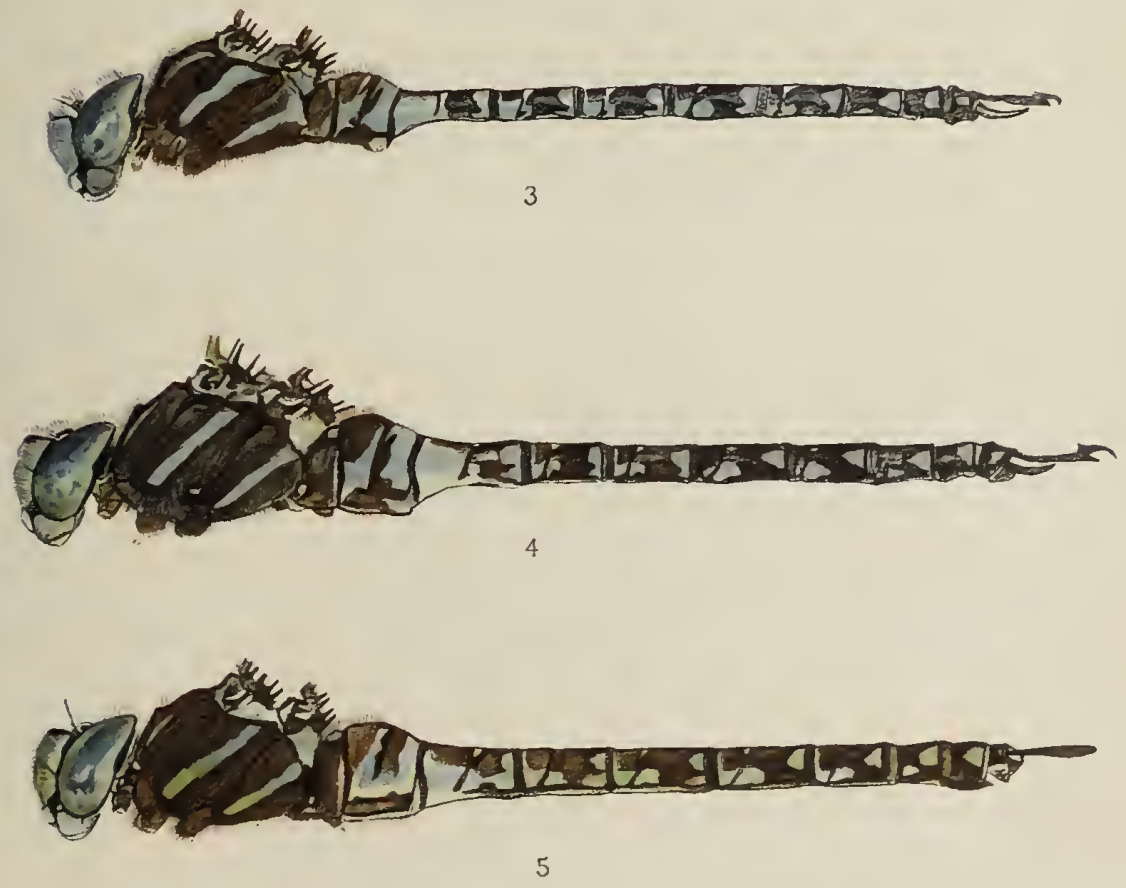

E. M. W. DEL. 





\section{DATE DUE}

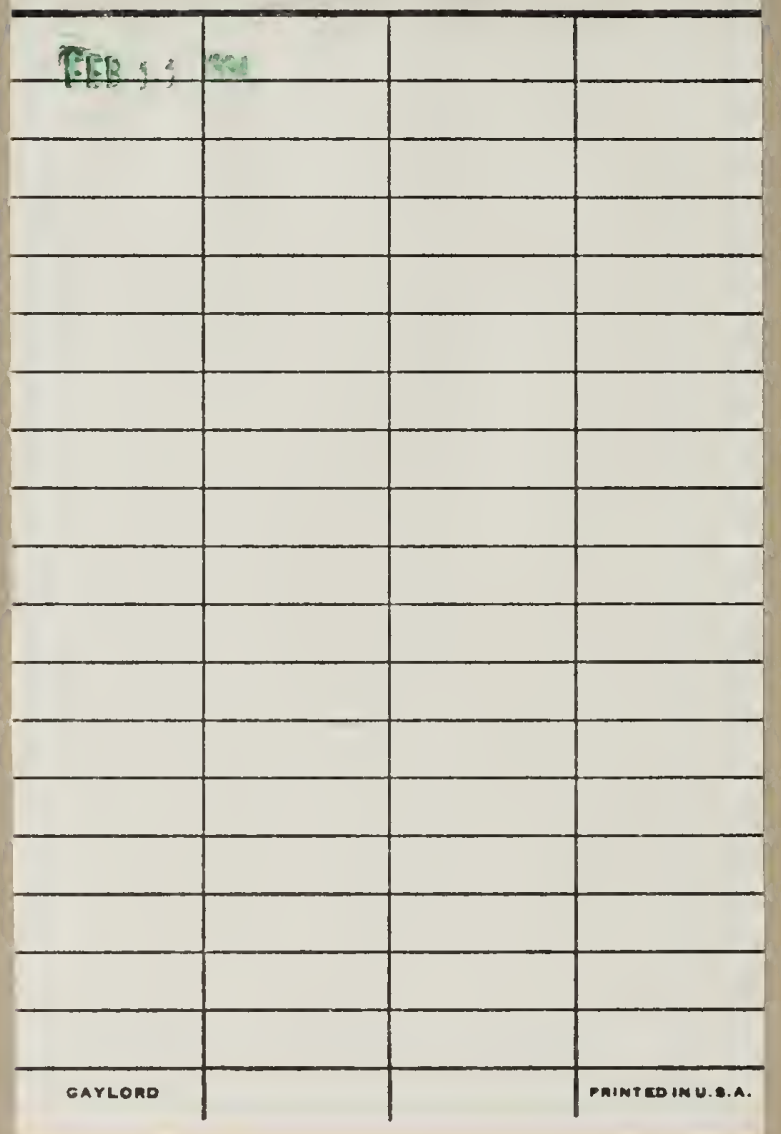

J th. is

Aith $183^{\circ}$

I $D E 0_{0}$ ) 
9Q:5203.A4 W3

35002

Walker, Edward Murton 001978217

The North American dragonflies of the ge

q Q $L$

520.3

A4: 3

141076 
